\title{
A Comprehensive Inventory of Radiological and Nonradiological Contaminants in Waste Buried or Projected to be Buried in the Subsurface Disposal Area of the INEL RWMC During the Years 1984-2003
}

\section{Volume 1}

Published May 1995

Idaho National Engineering Laboratory Lockheed Idaho Technologies Company Idaho Falls, Idaho 83415 


\section{DISCLAIMER}

Portions of this document may be illegible in electronic image products. Images are produced from the best available original document. 


\section{PREFACE}

This report, $A$ Comprehensive Inventory of Radiological and Nonradiological Contaminants in Waste Buried or Projected to be Buried in the Subsurface Disposal Area of the INEL RWMC During the Years 1984-2003, is composed of three volumes. Volume 1 consists of the main body of the report and Appendices A, C, D, E, F, and G. Appendix B, the complete printout of the inventory database, is provided in Volumes 2 and 3. Because of its size, distribution of Appendix B has been limited. A copy of the volumes containing Appendix B can be provided on request.

\section{DISCLAIMER}

This report was prepared as an account of work sponsored by an agency of the United States Government. Neither the United States Government nor any agency thereof, nor any of their employees, makes any warranty, express or implied, or assumes any legal liability or responsibility for the accuracy, completeness, or usefulness of any information, apparatus, product, or process disclosed, or represents that its use would not infringe privately owned rights. Reference herein to any specific commercial product, process, or service by trade name, trademark, manufacturer, or otherwise does not necessarily constitute or imply its endorsement, recommendation, or favoring by the United States Government or any agency thereof. The views and opinions of authors expressed herein do not necessarily state or reflect those of the United States Government or any agency thereof. 


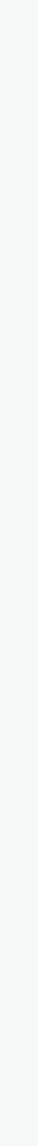




\begin{abstract}
This report presents a comprehensive inventory of the radiological and nonradiological contaminants in waste buried or projected to be buried from 1984 through 2003 in the Subsurface Disposal Area (SDA) at the Radioactive Waste Management Complex (RWMC) of the Idaho National Engineering Laboratory. The project to compile the inventory is referred to as the recent and projected data task. The inventory was compiled primarily for use in a baseline risk assessment under the Comprehensive Environmental Response, Compensation, and Liability Act. The compiled information may also be useful for environmental remediation activities that might be necessary at the RWMC. The information that was compiled has been entered into a database termed CIDRA-the Contaminant Inventory Database for Risk Assessment.
\end{abstract}

The inventory information was organized according to waste generator and divided into waste streams for each generator. The inventory is based on waste information that was available in facility operating records, technical and programmatic reports, shipping records, and waste generator forecasts. Additional information was obtained by reviewing the plant operations that originally generated the waste, by interviewing personnel formerly employed as operators, and by performing nuclear physics and engineering calculations. In addition to contaminant inventories, information was compiled on the physical and chemical characteristics and the packaging of the 99 waste streams.

The inventory information for waste projected to be buried at the SDA in the future was obtained from waste generator forecasts. Additional information was obtained by interviewing waste generator personnel and by performing nuclear physics and engineering calculations.

The contaminant inventories were developed in the form of best estimates. Upper and lower bounds were also formulated by evaluating the methods by which contaminant quantities were estimated.

The completeness of the contaminant inventories was confirmed by comparing them against inventories in previous reports and in other databases, and against the list of contaminants detected in environmental monitoring performed at the RWMC.

This report is a follow-on to a previous report ${ }^{\mathrm{a}}$ that covered waste buried during the years 1952 through 1983 . The methodologies used in the two reports are essentially identical. Taken together, the two reports encompass the waste buried or projected to be buried in the SDA from 1952 through 2003.

a. A Comprehensive Inventory of Radiological and Nonradiological Contaminants in Waste Buried in the Subsurface Disposal Area of the INEL RWMC During the Years 1952-1983, EGG-WM-10903, EG\&G Idaho, Inc., June 1994. 


\section{ACKNOWLEDGEMENTS}

The efforts of many people were required to compile the contaminant inventory presented in this report and to develop the CIDRA database. The contributions of these people are gratefully acknowledged. The principal contributors were as follows:

Program Management

Technical Lead

Data Gatherers

Uncertainty Analysis

Database and Application

Development

Environmental Monitoring

Comparisons

Comparisons Against Other Documents and Databases

Technical Editors
Douglas K. Jorgensen

Rozanne M. Huntley

Thomas A. Matzen

Thomas H. Smith

Cynthia E. Klassy

TAN

Henry K. Peterson

TRA

Yale D. Harker

Cecilia R. Amaro

ICPP Donald W. Rhodes

NRF Patrick R. Leonard

ANL-W Roy P. Grant, ANL-W

Other Donald W. Rhodes

Jeffrey J. Einerson

Cathy J. Barnard

Melinda J. Schlafman

Michael R. Groh

Connee D. White

Tiffany A. Bensen

Cynthia E. Klassy

Donald E. Kudera

Thomas H. Smith

DeAnne Casperson

Gayle C. Black 
viii 


\section{CONTENTS}

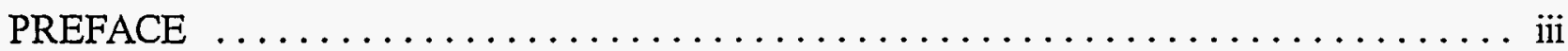

ABSTRACT $\ldots \ldots \ldots \ldots \ldots \ldots \ldots \ldots \ldots \ldots \ldots \ldots \ldots \ldots \ldots \ldots \ldots \ldots \ldots \ldots \ldots \ldots \ldots$

ACKNOWLEDGEMENTS $\ldots \ldots \ldots \ldots \ldots \ldots \ldots \ldots \ldots \ldots \ldots \ldots \ldots \ldots \ldots \ldots \ldots \ldots$ vii

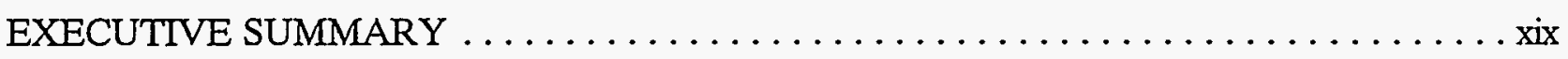

ACRONYMS AND ABBREVIATIONS $\ldots \ldots \ldots \ldots \ldots \ldots \ldots \ldots \ldots \ldots \ldots \ldots \ldots \ldots \ldots \ldots$ xxvii

REGULATORY SOURCES CITED $\ldots \ldots \ldots \ldots \ldots \ldots \ldots \ldots \ldots \ldots \ldots \ldots \ldots \ldots \ldots \ldots \ldots \ldots$ xlii

1. INTRODUCTION AND BACKGROUND $\ldots \ldots \ldots \ldots \ldots \ldots \ldots \ldots \ldots \ldots \ldots \ldots \ldots \ldots \ldots$

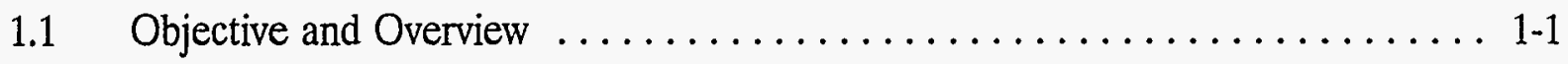

1.2 Brief History and Description of the SDA $\ldots \ldots \ldots \ldots \ldots \ldots \ldots \ldots \ldots \ldots \ldots$

1.3 Pertinent Regulations and Agreements $\ldots \ldots \ldots \ldots \ldots \ldots \ldots \ldots \ldots \ldots \ldots \ldots$

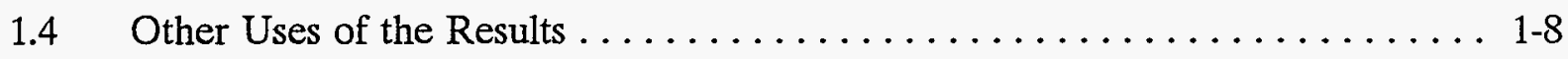

References for Section $1 \ldots \ldots \ldots \ldots \ldots \ldots \ldots \ldots \ldots \ldots \ldots \ldots \ldots \ldots \ldots \ldots \ldots \ldots \ldots \ldots .1-10$

2. METHODOLOGY FOR DATA COLLECTION AND COMPILATION ....... 2-1

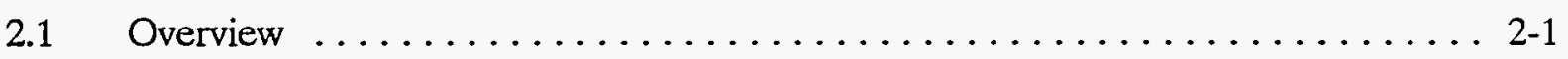

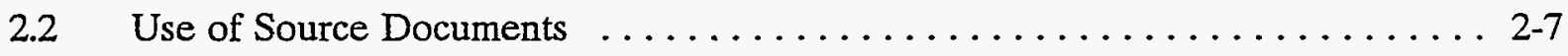

2.3 Use of the Radioactive Waste Management Information System ......... 2-8

2.3.1 Description of RWMIS . . . . . . . . . . . . . . . . .

2.3.2 RWMIS Download for the Current Task $\ldots \ldots \ldots \ldots \ldots \ldots . . .6$

2.3.3 RWMIS Limitations $\ldots \ldots \ldots \ldots \ldots \ldots \ldots \ldots \ldots \ldots \ldots \ldots \ldots \ldots \ldots$

2.4 Method for Estimating Contaminant Quantities in Future Waste $\ldots \ldots \ldots$ 2-11

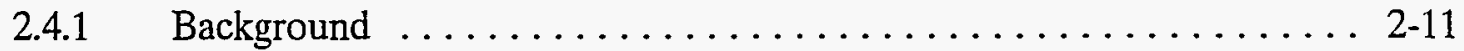

2.4.2 Available Projections of Future Waste ............... 2-11

2.4.3 Accuracy of Past Projections ................... 2-12

2.4.4 Waste-Projection Approach Selected for the Present Study . . . . . . 2-13

2.4.5 Volumetric Disposal Capacity of the SDA ............... 2-14 


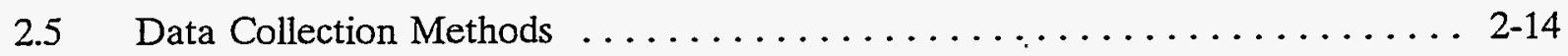

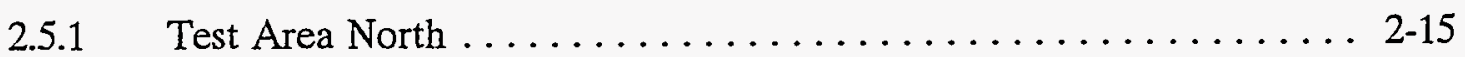

2.5 .2 Test Reactor Area ......................... 2-19

2.5.3 Idaho Chemical Processing Plant $\ldots \ldots \ldots \ldots \ldots \ldots \ldots \ldots .2-33$

$2.5 .4 \quad$ Naval Reactors Facility ...................... 2-37

2.5.5 Argonne National Laboratory - West . . . . . . . . . . . . . 2-40

2.5.6 Other Generators . . . . . . . . . . . $2.44 \ldots \ldots \ldots \ldots \ldots$

2.6 Data Qualification Process $\ldots \ldots \ldots \ldots \ldots \ldots \ldots \ldots \ldots \ldots \ldots \ldots \ldots \ldots \ldots . . .49$

2.7 Contaminant Inventory Database for Risk Assessment $\ldots \ldots \ldots \ldots \ldots \ldots 2-52$

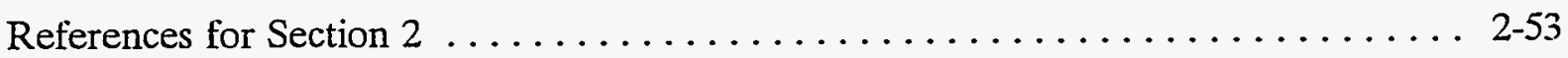

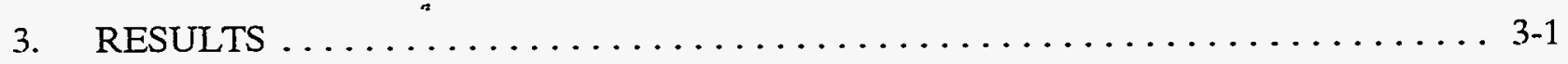

$3.1 \quad$ Introduction and Totals $\ldots \ldots \ldots \ldots \ldots \ldots \ldots \ldots \ldots \ldots \ldots \ldots \ldots \ldots \ldots \ldots \ldots$

3.1.1 Introduction and Conventions Followed ............... 3-1

3.1.2 Rollup of Nonradiological Contaminants Over All Generators . . . . . 3-3

3.1.3 Rollup of Radiological Contaminants Over All Generators ........ 3-4

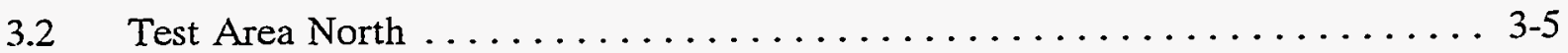

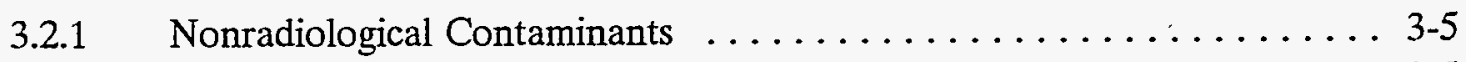

3.2.2 Radiological Contaminants . . . . . . . . . . . . . . . .

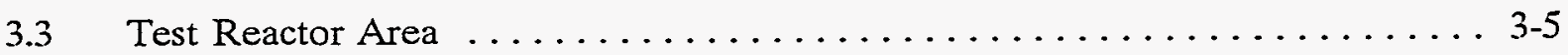

3.3.1 Nonradiological Contaminants $\ldots \ldots \ldots \ldots \ldots \ldots \ldots \ldots . . \ldots \ldots$

3.3.2 Radiological Contaminants . ....................

3.4 Idaho Chemical Processing Plant $\ldots \ldots \ldots \ldots \ldots \ldots \ldots \ldots \ldots \ldots \ldots \ldots \ldots \ldots \ldots .6 \ldots$

3.4.1 Nonradiological Contaminants $\ldots \ldots \ldots \ldots \ldots \ldots \ldots \ldots \ldots . .6$

3.4.2 Radiological Contaminants . . . . . . . . . . . . . . .

$3.5 \quad$ Naval Reactors Facility $\ldots \ldots \ldots \ldots \ldots \ldots \ldots \ldots \ldots \ldots \ldots \ldots \ldots \ldots \ldots \ldots$

3.5.1 Nonradiological Contaminants . . . . . . . . . . . . . . 3-7

3.5.2 Radiological Contaminants ..................... $3-7$

3.6 Argonne National Laboratory-West $\ldots \ldots \ldots \ldots \ldots \ldots \ldots \ldots \ldots \ldots \ldots . .6$

3.6.1 Nonradiological Contaminants $\ldots \ldots \ldots \ldots \ldots \ldots \ldots \ldots \ldots . . .6$

3.6.2 Radiological Contaminants . . . . . . . . . . . . . . . . 


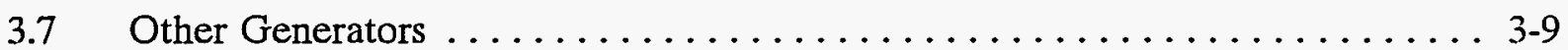

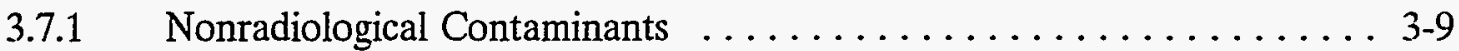

3.7.2 Radiological Contaminants .................... 3-10

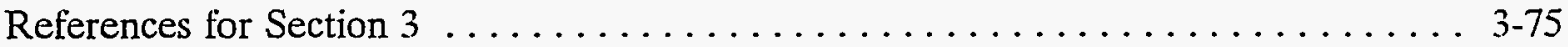

4. EVALUATION OF INVENTORY ENTRIES FOR CONTAMINANTS WITH "UNKNOWN" QUANTITIES ........................... 4-1

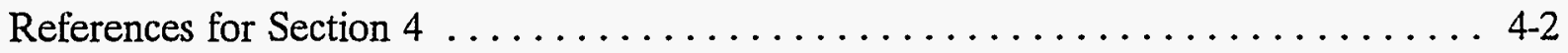

5. DATA UNCERTAINTY: SOURCES AND METHODS FOR ESTIMATING ..... 5-1

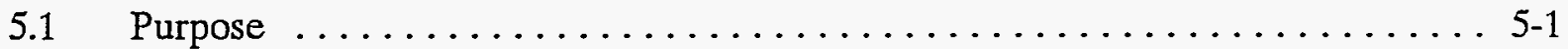

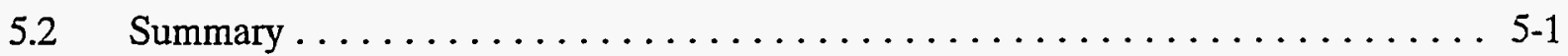

5.3 Requirements Concerning Uncertainty Estimates $\ldots \ldots \ldots \ldots \ldots \ldots . . \ldots \ldots$

5.4 How Uncertainties and Biases Were Addressed for the Recent Waste ..... 5-2

5.4.1 Background ............................. 5-2

5.4.2 Biases and Corrections for Radiological Data Originally Obtained by the G-M Counter Survey Method $\ldots \ldots \ldots \ldots \ldots \ldots \ldots \ldots$ 5-4

5.4.3 Scaling Factor Uncertainties for Radiological Data $\ldots \ldots \ldots \ldots . . . .6$

5.4.4 Uncertainties for Nonradiological Contaminants ........... 5-11

5.4.5 Best Estimates and Bounds for the Recent Waste .......... 5-12

5.5 How Uncertainties and Biases Were Addressed for the Projected Waste . . . . 5-15

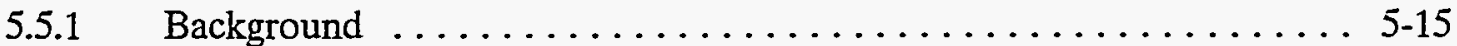

5.5.2 Bias and Uncertainty of Waste Generator Forecasts $\ldots \ldots \ldots \ldots$. $5-16$

5.5.3 Best Estimates and Bounds for the Projected Waste-General ..... 5-18

5.5.4 Best Estimates and Uncertainty for Projected Waste when Bias Corrections are Not Applicable . . . . . . . . . . . . . . . . 5-19

5.5.5 Best Estimates and Uncertainty for Projected Waste when G-M Method Bias Correction is Applicable but Generator Forecast Bias Correction is Not ................. 5-21

5.5.6 Best Estimates and Uncertainty for Projected Waste when G-M Method Bias Correction is Not Applicable but Generator Forecast Bias Correction is ................... 5-22

5.5.7 Best Estimates and Uncertainty for Projected Waste when G-M Method Bias Correction and Generator Forecast Bias Correction are Applicable . .................. 5-23

5.5.8 Uncertainties for Nonradiological Contaminants ........... 5-24 
5.6 Summary of Equations for Standard Deviations ............... $5-24$

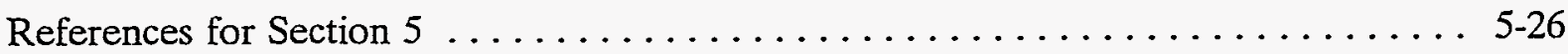

6. CONFIRMING THE COMPLETENESS OF THE RESULTS $\ldots \ldots \ldots \ldots \ldots \ldots 6-1$

6.1 Comparison of Inventory with Estimates Given in Earlier Reports . . . . . . . 6-1

6.1.1 Nonradiological Contaminants $\ldots \ldots \ldots \ldots \ldots \ldots \ldots \ldots \ldots .6 .1$

6.1.2 Radiological Contaminants ..................... $6-3$

6.2 Comparison of Inventory with Inventories in Existing Databases $\ldots \ldots \ldots \ldots 6-7$

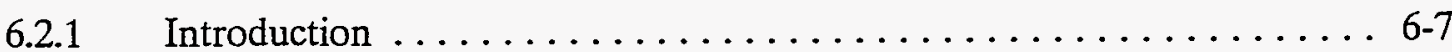

6.2.2 Comparisons at the Level of Individual Radionuclides, Summed Over All Generators . . . . . . . . . . . . .

6.2.3 Comparisons at the Level of Individual Generators, Summed Over All Radionuclides . . . . . . . . . . . . . . . . . 6-19

6.3 Comparison of the Inventory with Contaminants Detected in Environmental Monitoring $\ldots \ldots \ldots \ldots \ldots \ldots \ldots \ldots \ldots \ldots \ldots \ldots \ldots \ldots \ldots, 6.20$

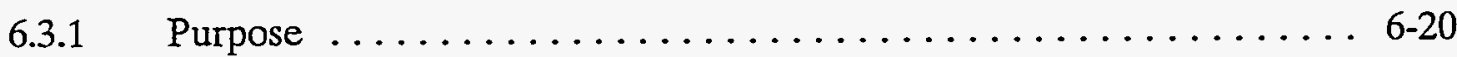

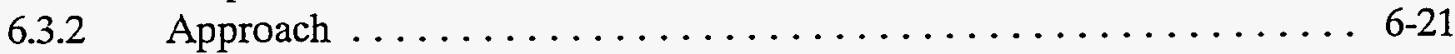

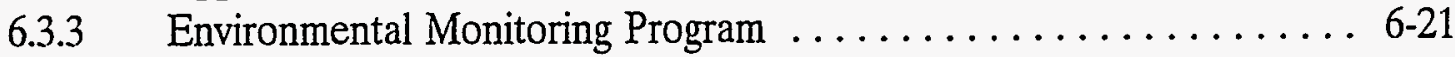

6.3 .4 Special Studies ........................... 6-21

6.3.5 Summary of Monitoring Results ................. 6-23

6.3.6 Comparison of Contaminants Detected in Monitoring Activities Against Contaminants Identified in the Waste Inventory . . . . . . 6-23

6.4 Contaminant Profile Data Sheets $\ldots \ldots \ldots \ldots \ldots \ldots \ldots \ldots \ldots \ldots \ldots .6 \ldots \ldots$

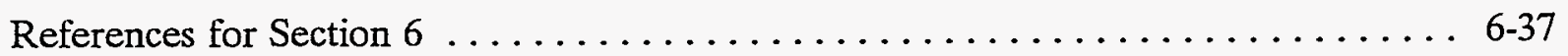

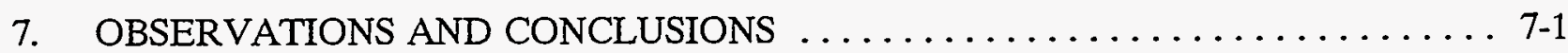

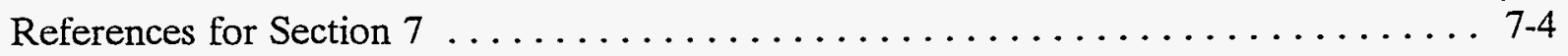

Appendix A-Data Collection Forms $\ldots \ldots \ldots \ldots \ldots \ldots \ldots \ldots \ldots \ldots \ldots \ldots \ldots \ldots \ldots \ldots \ldots \ldots$

Appendix B-Complete Printout of the Contaminant Inventory and Other Information

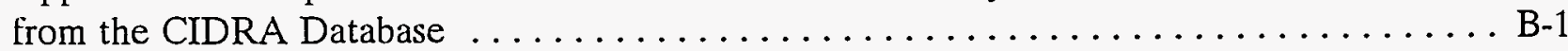

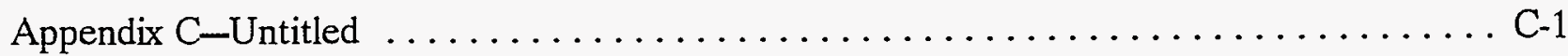

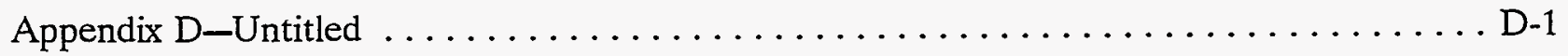


Appendix E-Assumed Distributions of Generic Terms and Dual Entries for Radioactivity in the RWMIS Shipping Record Rollups, for Use in the CIDRA

Versus RWMIS Comparisons $\ldots \ldots \ldots \ldots \ldots \ldots \ldots \ldots \ldots \ldots \ldots \ldots \ldots \ldots \ldots \ldots \ldots \ldots$

Appendix F-Summary of Results of Environmental Monitoring at the Subsurface

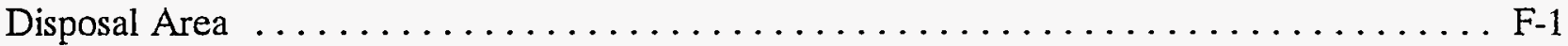

Appendix $G-C o n t a m i n a n t$ Profile Data Sheets $\ldots \ldots \ldots \ldots \ldots \ldots \ldots \ldots \ldots$. . . . . . . . .

\section{FIGURES}

1-1. Overview logic flowchart for the task $\ldots \ldots \ldots \ldots \ldots \ldots \ldots \ldots \ldots \ldots \ldots \ldots$

1-2. Overview layout of the Radioactive Waste Management Complex, including the Subsurface Disposal Area, Transuranic Storage Area, and

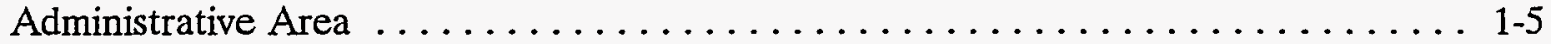

2-1. Locations of the Idaho National Engineering Laboratory waste generators in 1984-2003 and the location of the Radioactive Waste Management Complex . . . . . 2-3

2-2. Approach for information flow in developing the inventory $\ldots \ldots \ldots \ldots \ldots . \ldots$.

5-1. The process from waste generation to disposal $\ldots \ldots \ldots \ldots \ldots \ldots \ldots \ldots \ldots$

6-1. Approach for comparing the radionuclide inventory in CIDRA with that in the shipping record rollups of the RWMIS $\ldots \ldots \ldots \ldots \ldots \ldots \ldots \ldots \ldots$

\section{TABLES}

2-1. Primary information fields in the Radioactive Waste Management Information System database . . . . . . . . . . . . . .

2-2. Waste streams generated at Test Area North during $1984-1993 \ldots \ldots \ldots$. . . . .

2-3. Waste streams expected to be generated at Test Area North during 1994-2003 . . . 2 2-18

2-4. Master list of radionuclides evaluated for waste from the Test Reactor Area ..... . 2-24

2-5. Nuclides and activity scaling factors for dry radioactive waste from the Test Reactor Area . . . . . . . . . . . . . . . . . . . . . . . . . . . . . 2 2-27

2-6. Nuclides and activity scaling factors for sludge waste from the Test Reactor Area . . 2-29

2-7. Nuclides and activity scaling factors for reactor coolant resin from the Test Reactor Area ............................... 2-31 
2-8. Waste streams generated at the Test Reactor Area during 1984-1993

2-9. Waste streams expected to be generated at the Test Reactor Area during 1994-2003

2-10. Waste streams generated at the Idaho Chemical Processing Plant during 1984-1993

2-11. Waste streams expected to be generated at the Idaho Chemical Processing

2-12. Waste streams generated at the Naval Reactors Facility during 1984-1993

2-13. Waste streams expected to be generated at the Naval Reactors Facility during 1994-2003

2-14. Waste streams generated at Argonne National Laboratory-West during 1984-1993

2-15. Waste steams expected to be generated at Argonne National Laboratory-West during 1994-2003 . . . . . . . . . . . . . . . . . 2-46

2-16. Waste streams generated by other generators during $1984-1993 \ldots \ldots \ldots \ldots$. . . . 20

2-17. Waste streams expected to be generated by other generators during 1994-2003

3-1a. Inventory of nonradiological contaminants (listed by quantity) from all generators for the years $1984-1993$

3-1b. Inventory of nonradiological contaminants (listed alphabetically) from all generators for the years 1984-1993.

3-2a. Inventory of nonradiological contaminants (listed alphabetically) from all

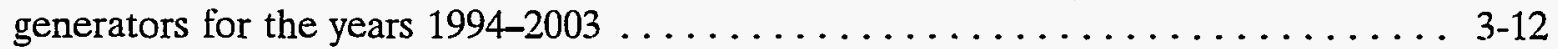

3-2b. Inventory of nonradiological contaminants (listed alphabetically) from all generators for the years 1994-2003

3-3a. Inventory of radiological contaminants (listed by quantity) from all generators for the years 1984-1993 (activity at time of disposal)

3-3b. Inventory of radiological contaminants (listed alphabetically) from all generators for the years 1984-1993 (activity at time of disposal)

3-4a. Inventory of radiological contaminants (listed by quantity) from all generators for the years 1994-2003 (activity at time of disposal) 
3-4b. Inventory of radiological contaminants (listed alphabetically) from all generators for the years 1994-2003 (activity at time of disposal) . . . . . . . . . 3-24

3-5a. Inventory of nonradiological contaminants (listed by quantity) from Test Area North for the years $1984-1993 \ldots \ldots \ldots \ldots \ldots \ldots \ldots \ldots \ldots \ldots \ldots \ldots \ldots \ldots .27$

3-5b. Inventory of nonradiological contaminants (listed alphabetically) from Test Area North for the years $1984-1993 \ldots \ldots \ldots \ldots \ldots \ldots \ldots \ldots \ldots \ldots .27$

3-6a. Inventory of radiological contaminants (listed by quantity) from Test Area North for the years 1984-1993 (activity at time of disposal) . . . . . . . . . . 3-28

3-6b. Inventory of radiological contaminants (listed alphabetically) from Test Area North for the years 1984-1993 (activity at time of disposal) . . . . . . . 3-30

3-7a. Inventory of radiological contaminants (listed by quantity) from the Test Area North for the years 1994-2003 (activity at time of disposal) . . . . . . . . 3-32

3-7b. Inventory of radiological contaminants (listed alphabetically) from the Test Area North for the years 1994-2003 (activity at time of disposal) . . . . . . . 3-32

3-8a. Inventory of nonradiological contaminants (listed by quantity) from the Test Reactor Area for the years $1984-1993$. . . . . . . . . . . . . . . . . . 3-33

3-8b. Inventory of nonradiological contaminants (listed alphabetically) from the Test Reactor Area for the years $1984-1993$. . . . . . . . . . . . . . . . . 3 3-33

3-9a. Inventory of nonradiological contaminants (listed by quantity) from the Test Reactor Area for the years 1994-2003

3-9b. Inventory of nonradiological contaminants (listed alphabetically) from the Test Reactor Area for the years $1994-2003 \ldots \ldots \ldots \ldots \ldots \ldots \ldots \ldots \ldots .34$

3-10a. Inventory of radiological contaminants (listed by quantity) from the Test Reactor Area for the years 1984-1993 (activity at time of disposal) . . . . . . . . 3-35

3-10b. Inventory of radiological contaminants (listed alphabetically) from the Test Reactor Area for the years 1984-1993 (activity at time of disposal) . . . . . . . . 3-38

3-11a. Inventory of radiological contaminants (listed by quantity) from the Test Reactor Area for the years 1994-2003 (activity at time of disposal) . . . . . . . . 3-41

3-11b. Inventory of radiological contaminants (listed alphabetically) from the Test Reactor Area for the years 1994-2003 (activity at time of disposal) . . . . . . . 3 3-43

3-12a. Inventory of nonradiological contaminants (listed by quantity) from the Idaho Chemical Processing Plant for the years 1984-1993 : 
3-12b. Inventory of nonradiological contaminants (listed alphabetically) from the Idaho Chemical Processing Plant for the years $1984-1993 \ldots \ldots \ldots \ldots \ldots \ldots$. . . 45

3-13a. Inventory of radiological contaminants (listed by quantity) from the Idaho Chemical Processing Plant for the years 1984-1993 (activity at time of disposal) . . . 3-46

3-13b. Inventory of radiological contaminants (listed alphabetically) from the Idaho Chemical Processing Plant for the years 1984-1993 (activity at time of disposal) . . . 3-47

3-14a. Inventory of radiological contaminants (listed by quantity) from the Idaho Chemical Processing Plant for the years 1994-2003 (activity at time of disposal) . . . . . . . . . . . . . . . . . . . . . . . . . . . . . . 3-48

3-14b. Inventory of radiological contaminants (listed alphabetically) from the Idaho Chemical Processing Plant for the years 1994-2003 (activity at time of

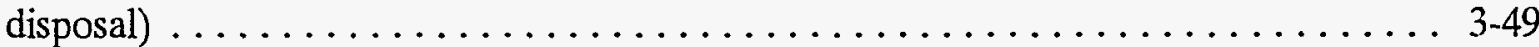

3-15a. Inventory of nonradiological contaminants (listed by quantity) from the Naval Reactors Facility for the years 1984-1993

3-15b. Inventory of nonradiological contaminants (listed alphabetically) from the Naval Reactors Facility for the years 1984-1993

3-16a. Inventory of radiological contaminants (listed by quantity) from the Naval Reactors Facility for the years 1984-1993 (activity at time of disposal)

3-16b. Inventory of radiological contaminants (listed alphabetically) from the Naval Reactors Facility for the years 1984-1993 (activity at time of disposal) . . . . . . 3-52

3-17a. Inventory of radiological contaminants (listed by quantity) from the Naval Reactors Facility for the years 1994-2003 (activity at time of disposal) . . . . . . 3-53

3-17b. Inventory of radiological contaminants (listed alphabetically) from the Naval Reactors Facility for the years 1994-2003 (activity at time of disposal) . . . . . . 3-54

3-18a. Inventory of nonradiological contaminants (listed by quantity) from Argonne National Laboratory-West for the years 1984-1993

3-18b. Inventory of nonradiological contaminants (listed alphabetically) from Argonne National Laboratory-West for the years $1984-1993$. . . . . . . . . . . 3-55

3-19a. Inventory of nonradiological contaminants (listed by quantity) from Argonne National Laboratory-West for the years $1994-2003$. . . . . . . . . . 3-56

3-19b. Inventory of nonradiological contaminants (listed alphabetically) from Argonne National Laboratory-West for the years 1994-2003 
3-20a. Inventory of radiological contaminants (listed by quantity) from Argonne National Laboratory-West for the years 1984-1993 (activity at time of

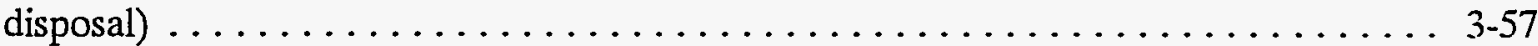

3-20b. Inventory of radiological contaminants (listed alphabetically) from Argonne National Laboratory-West for the years 1984-1993 (activity at time of disposal)

3-21a. Inventory of radiological contaminants (listed by quantity) from Argonne National Laboratory-West for the years 1994-2003 (activity at time of disposal) .

3-21b. Inventory of radiological contaminants (listed alphabetically) from Argonne National Laboratory-West for the years 1994-2003 (activity at time of

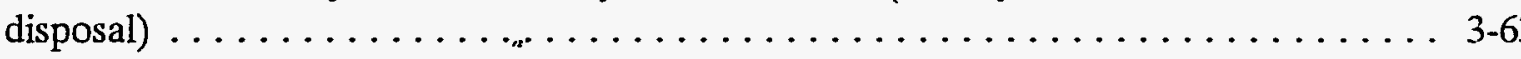

3-22a. Inventory of nonradiological contaminants (listed by quantity) from other

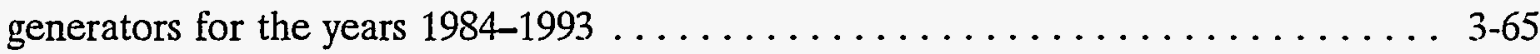

3-22b. Inventory of nonradiological contaminants (listed alphabetically) from other

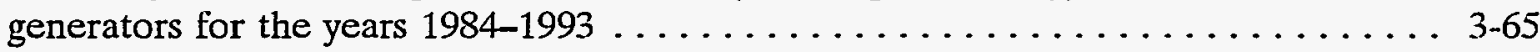

. 3-23a. Inventory of nonradiological contaminants (listed by quantity) from other

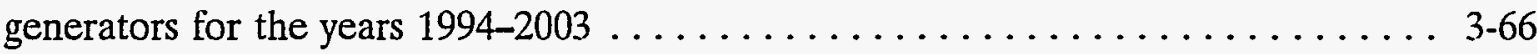

3-23b. Inventory of nonradiological contaminants (listed alphabetically) from other

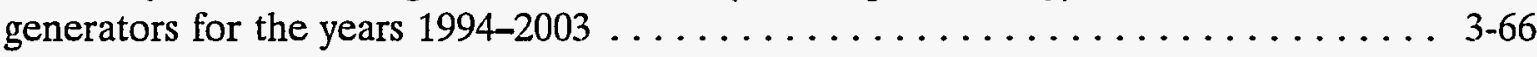

3-24a. Inventory of radiological contaminants (listed by quantity) from other generators for the years 1984-1993 (activity at time of disposal) . . . . . . . . . 3-67

3-24b. Inventory of radiological contaminants (listed alphabetically) from other generators for the years 1984-1993 (activity at time of disposal) . . . . . . . . 3-69

3-25a. Inventory of radiological contaminants (listed by quantity) from other generators for the years 1994-2003 (activity at time of disposal) . . . . . . . . 3-71

3-25b. Inventory of radiological contaminants (listed alphabetically) from other generators for the years $1994-2003$ (activity at time of disposal) . . . . . . . . 3-73

5-1. Scaling factor relative standard deviations for EPRI (1987) data $\ldots \ldots \ldots \ldots \ldots$ 5-10

5-2. Scaling factor relative standard deviations for use in the Recent and Projected Data Task uncertainty estimation 
5-3. Comparisons of forecasted and reported actual radioactivity (Ci) in waste disposed of in the Subsurface Disposal Area, for recent years and facilities

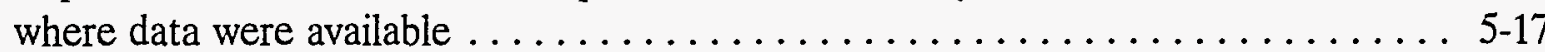

5-4. Formulae for calculating standard deviation $\mathrm{s}_{\mathrm{ij}}$ for radiological contaminants when laboratory analysis data and informed professional judgement are not available .................................... 5-25

6-1. Lead disposal in the Subsurface Disposal Area from 1984 through January 15,1986 , taken from Wells $(1986) \ldots \ldots \ldots \ldots \ldots \ldots \ldots \ldots \ldots \ldots$ 6-3

6-2. Comparison of CIDRA radionuclide inventory for the projected period (1994-2003) against direct compilation of waste generator forecasts for the same years (Randall 1994) . . . . . . . . . . . . . . . . . . $6-5$

6-3. Radionuclide inventories as given by RWMIS shipping record rollups and by CIDRA (with and without Geiger-Müller counter corrections): 1984-1993 . . . 6 6-10

6-4. Radioactivity totals by generator as given by RWMIS shipping record rollups, and by CIDRA (with and without Geiger-Müller counter corrections) . . . 6-20

6-5. Routine environmental monitoring activities performed at the Subsurface Disposal Area (compiled from Wilhelmsen et al. 1994).

6-6. Comparison of results of environmental monitoring against results of the inventory compilation 


\section{EXECUTIVE SUMMARY}

\section{Introduction and Background}

This report documents the compilation of a comprehensive inventory of radiological and nonradiological contaminants in waste buried in the Subsurface Disposal Area (SDA) at the Radioactive Waste Management Complex (RWMC) of the Idaho National Engineering Laboratory (INEL). The inventory was compiled primarily for use in a baseline risk assessment (BRA) under the Comprehensive Environmental Response, Compensation, and Liability Act (CERCLA). The project to compile the inventory is referred to as the recent and projected data task (RPDT).

The RWMC, located in the southwest portion of the INEL, is a solid radioactive waste disposal site. It consists of the 38.85-ha SDA, the 22.7-ha Transuranic Storage Area, and the Administrative Area.

The inventory covers the waste buried and projected to be buried in the SDA from 1984 through 2003. The SDA disposal units covered in this report include the nontransuraniccontaminated waste pits and soil vault rows open during the period of interest.

Waste in the Transuranic Storage Area is not included in this inventory because it is stored aboveground. Waste disposed of in the SDA before 1984 is excluded because it is covered in the previous report covering the years 1952-1983. ${ }^{b}$

The inventory addresses radioactive waste, hazardous substances per CERCLA [which encompass hazardous waste per the Resource Conservation and Recovery Act (RCRA)], and mixed waste.

This task built upon the inventories in previous reports and databases by adding several types of additional information that are needed for the BRA:

- A more comprehensive inventory of nonradiological contaminants

- Identification of specific radionuclides previously listed under generic names [e.g., mixed fission products (MFP) or mixed activation products (MAP)]

- $\quad$ Physical and chemical forms of the contaminants and of the host waste streams

- Uncertainties in the contaminant quantities.

b. A Comprehensive Inventory of Radiological and Nonradiological Contaminants in Waste Buried in the Subsurface Disposal Area of the INEL RWMC During the Years 1952-1983, EGG-WM-10903, EG\&G Idaho, Inc., June 1994. 
This inventory was compiled pursuant to regulations and agreements related to CERCLA. A Federal Facility Agreement and Consent Order (FFA/CO) for the INEL was signed by the U.S. Department of Energy, U.S. Environmental Protection Agency, and State of Idaho Department of Health and Welfare to protect human health and the environment. One of the INEL waste area groups (WAGs) defined under the FFA/CO is WAG-7, the RWMC.

Under the CERCLA implementing regulations of 40 CFR 300.430 (d)(2), the lead agency is required to "characterize the nature of and threat posed by the hazardous substances and hazardous materials and gather data necessary to assess the extent to which the release poses a threat to human health or the environment ...." The information collected is to cover "... the general characteristics of the waste, including quantities, state, concentration, toxicity, propensity to bioaccumulate, persistence, and mobility" and "the extent to which the source can be adequately identified and characterized."

Per guidance in the National Contingency Plan under CERCLA, a human health BRA will be performed for the SDA. The inventory developed here and in the previous report will be used to help determine the source term for the BRA. As currently planned, the inventory will also be used in the WAG-7 BRA for the comprehensive remedial investigation/feasibility study.

In addition to helping determine the BRA source term, the inventory information compiled here and in the previous report has other potential uses. Examples are evaluating remedial alternatives (should remediation be required), assessing health and safety hazards to workers, and identifying potential operational problems.

\section{Methodology for Data Collection and Compilation}

\section{The Challenge}

The approach for compiling the inventory information had to reflect the complex nature of the waste disposal situation at the SDA. When disposal at the SDA began 42 years ago, requirements and practices did not include the current requirements for waste characterization, so complete information about the waste was not obtained when it was generated and disposed of. Although the collection of information for newly generated waste improved gradually, there were still some information gaps during the 1984-1993 time period.

The disposal area is large and the waste is varied, so drilling and sampling to determine the contaminant inventory is not feasible. Even a massive drilling and sampling campaign would not result in an inventory in which high confidence could be placed, because of the heterogeneity of the waste.

Information about and inventory compilations of the waste buried in the SDA have been produced in previous efforts for various uses. Some of the compilations have been entered into databases, such as the Radioactive Waste Management Information System (RWMIS). The previous compilations contain useful information, but they have limitations. For example, RWMIS problems include the following. Some textual descriptions are generic (e.g., "plant waste") and do not provide insight into the actual contents of the waste. RWMIS contains very little information concerning nonradiological contaminants in the waste. The radionuclide listings 
in RWMIS have problems, such as (a) entries with only one radionuclide identified, e.g., Pu-239, whereas knowledge of the waste-generating process indicates that other radionuclides must also be present; (b) entries with only the element specified, e.g., uranium, with no designation of a particular radionuclide; (c) entries with only generic radioactivity terms MAP or MFP identified, with no designation of particular radionuclides; and (d) entries with only one fission product identified, e.g., Cs-137, whereas others must also be present.

Most previous compilations were derived solely from shipping records. Many addressed only the radiological contaminants in the waste. It was concluded that the existing compilations, though very useful, were not adequate to support the BRA.

\section{The Approach}

A different approach to compile the inventory information was devised. The approach emphasized the use of information about the processes that generated the waste, supplemented by information from reports, shipping records, and databases. First, the facilities that generated the SDA waste were divided into six groups, as follows: Test Area North (TAN), Test Reactor Area (TRA), Idaho Chemical Processing Plant (ICPP), Naval Reactors Facility (NRF), Argonne National Laboratory-West (ANL-W), and "other" generators (this designation includes all other onsite facilities, all other offsite facilities, and decontamination and decommissioning programs). Six lead data gatherers were then appointed to direct the compilation of information on the waste from the six generators. In nearly every case, each lead data gatherer had worked previously at the waste generator location whose information he was assigned to collect, and each was familiar with the operational activities that generated the waste.

Figure S-1 depicts the flow of information in this approach. The rectangles represent items of information, and the ovals represent technical activities performed on the information. Several sources of information were used by the data gatherers: process knowledge and plant operating records, inventory and other technical reports, engineering and nuclear physics calculations, shipping records and databases thereof, interviews with current and past plant operating personnel, and waste generator forecasts. For each of the waste generators, varying uses were made of these sources, depending on the availability of each and the nature of the waste.

The waste from a given facility of a given generator was subdivided into several waste streams. Basically, a waste stream was defined so as to reduce the nonhomogeneity within the stream. For example, one stream consisted of all of the beryllium reflectors from TRA.

A standardized, five-page data form was used to record the information for each of the 99 identified waste streams. The form requested the following information: the waste generator, the building, and the assigned number of the waste stream from that building; the physical and chemical form of the waste stream itself; the quantities (including uncertainties) and the physical and chemical forms of any nonradiological contaminants and radiological contaminants in the stream; and the source(s) and reliability of the information.

After the information was entered onto data forms, it was subjected to qualification as shown in Figure S-1 and entered into the new Contaminant Inventory Database for Risk Assessment (CIDRA). 
Process knowledge and plant operating records

Inventory and olher

lechnical reports
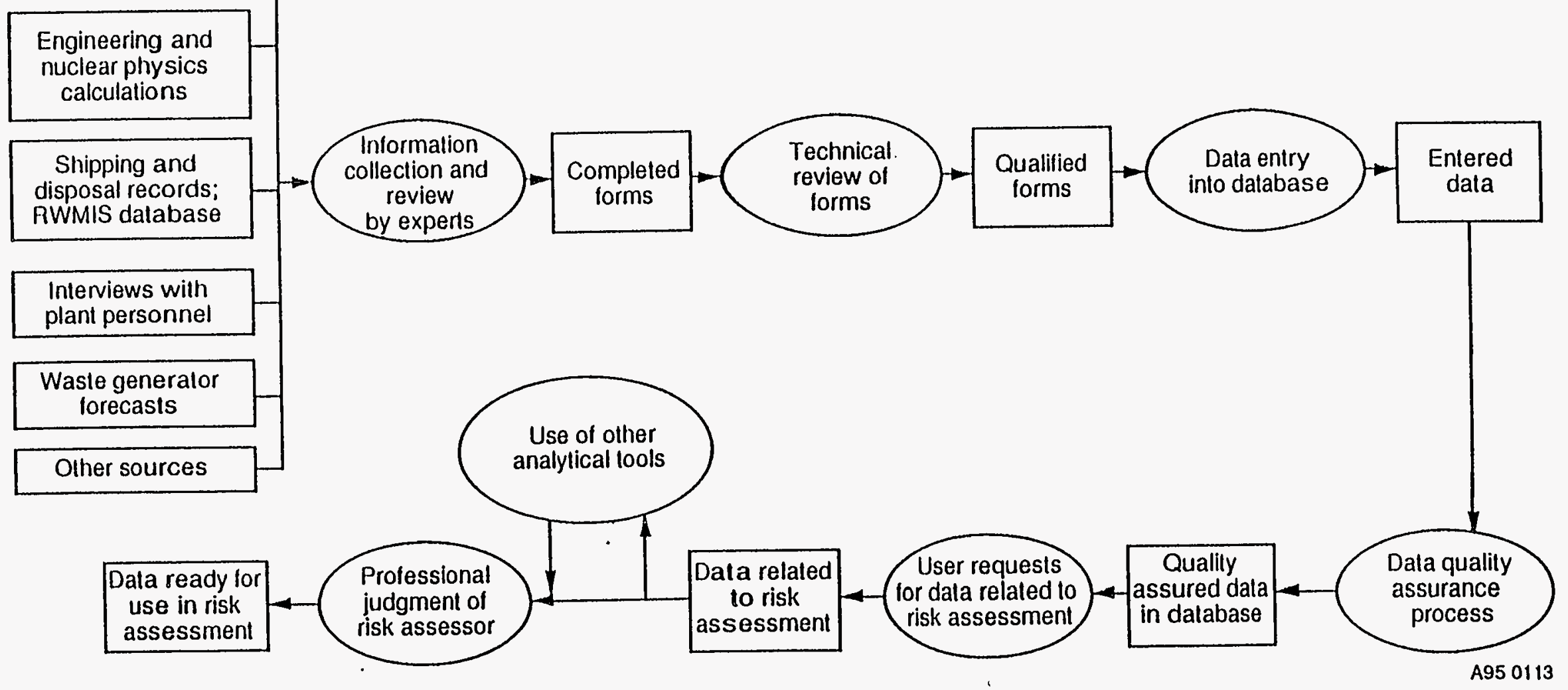

Figure S-1. Approach for information flow in developing the inventory. 


\section{Results}

An appendix to this report, in several volumes, contains a complete printout of the information in the CIDRA database.

Tables S-1 and S-2 list the total best-estimate quantities of each contaminant, covering all waste streams from all generators for the recent (1984-1993) period. Similarly, Tables S-3 and S-4 list the total best-estimate quantities for all waste streams from all generators for the projected (1994-2003) period. Upper and lower bounds are also given. Tables S-1 and S-3 list the nonradiological contaminants, in terms of grams (g). Tables S-2 and S-4 list the radiological contaminants, in terms of curies $(\mathrm{Ci})$ at the time of disposal. Similar tables are presented in this report for each waste generator.

All inventories in this report are given to only two significant digits. Specification of more significant digits would give an erroneous impression of the accuracy inherent in the inventories.

The uncertainties in the contaminant inventory were evaluated as follows. Best estimates of the annual or total quantities of each contaminant for each waste stream were made by the data gatherers. Upper and lower bounds, analogous to $95 \%$ confidence limits, accompany the best estimates. When possible, the bounds are based on actual measurements and on the experience and knowledge of the data gatherers. When not possible, generic error bounds were constructed by propagation of known biases and expected uncertainties. Using standard statistical techniques, the errors in annual quantities for individual waste streams were propagated to obtain upper and lower bounds on the total quantity for each contaminant. This error-propagation procedure is programmed into CIDRA. For the projected waste, this effort included estimating the uncertainty in the waste generator forecasts.

A bias in many of the waste records is due to the use of the Geiger-Müller (G-M) counter survey method to estimate the quantities of radiological contaminants in the waste containers. Radioactivity data believed to have been obtained by this method were corrected in the CIDRA inventory. The correction was based on extensive study of the results of previous evaluations on the accuracy of that method, using laboratory mock-ups and actual waste containers. The overall correction, which is a product of three multiplicative factors, is a downward revision by a factor of 2 for the affected contaminants and waste streams.

The accuracy of the waste generator forecasts, by which the radioactivity in future waste was projected, was evaluated. Comparison of past forecasts against later disposals showed that the forecasts have been biased upward by, on the average, a factor of 4 . A correction was applied in CIDRA to projections that were based on the waste generator forecasts. 
Table S-1. Inventory of nonradiological contaminants (listed alphabetically) from all generators for the years 1984-1993.

\begin{tabular}{cllll}
\hline $\begin{array}{c}\text { CAS } \\
\text { number }\end{array}$ & \multicolumn{1}{c}{ Chemical } & $\begin{array}{c}\text { Best } \\
\text { estimate } \\
(\mathrm{g})\end{array}$ & $\begin{array}{c}\text { Lower } \\
\text { bound }\end{array}$ & $\begin{array}{r}\text { Upper } \\
\text { bound }\end{array}$ \\
\hline $7440-38-2$ & Arsenic & $5.0 \mathrm{E}-01$ & $2.5 \mathrm{E}-01$ & $7.5 \mathrm{E}-01$ \\
$1332-21-4$ & Asbestos & $2.3 \mathrm{E}+06$ & $1.5 \mathrm{E}+06$ & $3.1 \mathrm{E}+06$ \\
$7440-41-7$ & Beryllium & $6.3 \mathrm{E}+06$ & $6.3 \mathrm{E}+06$ & $6.4 \mathrm{E}+06$ \\
$7440-43-9$ & Cadmium & $1.8 \mathrm{E}+00$ & $1.5 \mathrm{E}+00$ & $2.0 \mathrm{E}+00$ \\
$7440-47-3$ & Chromium & $2.9 \mathrm{E}+01$ & $1.4 \mathrm{E}+01$ & $4.4 \mathrm{E}+01$ \\
$7440-50-8$ & Copper & $2.3 \mathrm{E}+04$ & $1.1 \mathrm{E}+04$ & $4.5 \mathrm{E}+04$ \\
$7439-92-1$ & Lead & $9.8 \mathrm{E}+07$ & $8.1 \mathrm{E}+07$ & $1.1 \mathrm{E}+08$ \\
$7439-97-6$ & Mercury & $2.0 \mathrm{E}+00$ & $1.0 \mathrm{E}+00$ & $3.0 \mathrm{E}+00$ \\
$1314-23-4$ & Zirconium oxide & $4.5 \mathrm{E}+03$ & $3.8 \mathrm{E}+03$ & $5.2 \mathrm{E}+03$ \\
\hline
\end{tabular}


Table S-2. Inventory of radiological contaminants (listed alphabetically) from all generators for the years 1984-1993 (activity at time of disposal).

\begin{tabular}{|c|c|c|c|c|}
\hline Radionuclide & $\begin{array}{c}\text { Best } \\
\text { estimate } \\
\text { (Ci) }\end{array}$ & $\begin{array}{c}\text { Percent } \\
\text { of total } \\
(\%)\end{array}$ & $\begin{array}{l}\text { Lower } \\
\text { bound }\end{array}$ & $\begin{array}{l}\text { Upper } \\
\text { bound }\end{array}$ \\
\hline $\mathrm{Ag}-108 \mathrm{~m}$ & $1.1 E-07$ & $<0.05$ & $5.5 \mathrm{E}-10$ & 7.7E-07 \\
\hline $\mathrm{Ag}-110$ & $1.9 \mathrm{E}+00$ & $<0.05$ & $1.0 \mathrm{E}-02$ & $1.4 \mathrm{E}+01$ \\
\hline $\mathrm{Ag}-110 \mathrm{~m}$ & 1.8E-02 & $<0.05$ & $1.3 \mathrm{E}-04$ & $1.2 \mathrm{E}-01$ \\
\hline Am-241 & $3.7 \mathrm{E}+00$ & $<0.05$ & 2.7E-02 & $2.6 \mathrm{E}+01$ \\
\hline Au-198 & $2.4 \mathrm{E}-02$ & $<0.05$ & $1.3 \mathrm{E}-03$ & $1.2 \mathrm{E}-01$ \\
\hline $\mathrm{Ba}-137 \mathrm{~m}$ & $4.6 \mathrm{E}+00$ & $<0.05$ & $3.0 \mathrm{E}+00$ & $6.8 \mathrm{E}+00$ \\
\hline $\mathrm{Ba}-140$ & $2.4 \mathrm{E}+00$ & $<0.05$ & 4.1E-02 & $1.6 \mathrm{E}+01$ \\
\hline $\mathrm{Br}-82$ & $1.0 \mathrm{E}-03$ & $<0.05$ & 5.1E-06 & 7.3E-03 \\
\hline C-14 & $4.0 \mathrm{E}+01$ & $<0.05$ & 4.1E-01 & $2.8 \mathrm{E}+02$ \\
\hline Cd-109 & $1.1 \mathrm{E}-02$ & $<0.05$ & $5.6 E-05$ & $7.9 \mathrm{E}-02$ \\
\hline Ce-139 & $3.0 \mathrm{E}-04$ & $<0.05$ & $1.5 \mathrm{E}-06$ & $2.2 \mathrm{E}-03$ \\
\hline Ce-141 & $2.9 E+00$ & $<0.05$ & $5.4 \mathrm{E}-02$ & $1.8 \mathrm{E}+01$ \\
\hline Ce-144 & $2.1 \mathrm{E}+02$ & $<0.05$ & $3.9 \mathrm{E}+01$ & $6.8 E+02$ \\
\hline $\mathrm{Cm}-242$ & 8.8E-02 & $<0.05$ & 6.8E-04 & $6.2 E-01$ \\
\hline $\mathrm{Cm}-244$ & 7.6E-02 & $<0.05$ & $5.2 \mathrm{E}-04$ & $5.4 \mathrm{E}-01$ \\
\hline Co-57 & $1.5 E+00$ & $<0.05$ & 8.6E-02 & $7.8 E+00$ \\
\hline Co-58 & $2.0 \mathrm{E}+05$ & 7.1 & $2.5 E+04$ & $7.5 E+05$ \\
\hline Co-60 & $1.4 \mathrm{E}+06$ & 50.8 & $9.3 E+05$ & $2.0 \mathrm{E}+06$ \\
\hline $\mathrm{Cr}-51$ & $4.7 E+04$ & 1.7 & $5.4 \mathrm{E}+03$ & $1.9 E+05$ \\
\hline Cs-134 & $1.4 E+02$ & $<0.05$ & $6.1 E+00$ & $7.7 E+02$ \\
\hline Cs-137 & $3.1 E+03$ & 0.1 & $1.1 E+03$ & $7.0 \mathrm{E}+03$ \\
\hline Eu-152 & $4.1 E+00$ & $<0.05$ & $2.0 \mathrm{E}-01$ & $2.2 E+01$ \\
\hline Eu-154 & $3.3 E+00$ & $<0.05$ & $3.5 \mathrm{E}-01$ & $1.4 \mathrm{E}+01$ \\
\hline Eu-155 & $3.9 \mathrm{E}+01$ & $<0.05$ & 5.1E-01 & $2.6 \mathrm{E}+02$ \\
\hline $\mathrm{Fe}-55$ & $1.6 E+05$ & 5.7 & $1.4 E+05$ & $1.8 E+05$ \\
\hline $\mathrm{Fe}-59$ & $1.5 \mathrm{E}+04$ & 0.5 & $1.5 \mathrm{E}+03$ & $6.0 \mathrm{E}+04$ \\
\hline Gd-153 & $1.3 E+00$ & $<0.05$ & $1.1 \mathrm{E}-02$ & $9.2 \mathrm{E}+00$ \\
\hline
\end{tabular}


Table S-2. (continued).

\begin{tabular}{|c|c|c|c|c|}
\hline Radionuclide & $\begin{array}{c}\text { Best } \\
\text { estimate } \\
(\mathrm{Ci})\end{array}$ & $\begin{array}{c}\text { Percent } \\
\text { of total } \\
(\%)\end{array}$ & $\begin{array}{l}\text { Lower } \\
\text { bound }\end{array}$ & $\begin{array}{l}\text { Upper } \\
\text { bound }\end{array}$ \\
\hline $\mathrm{H}-3$ & $3.0 \mathrm{E}+05$ & 10.7 & $1.0 \mathrm{E}+05$ & $6.8 \mathrm{E}+05$ \\
\hline Hf-181 & $3.4 \mathrm{E}+03$ & 0.1 & $3.0 \mathrm{E}+03$ & $3.9 E+03$ \\
\hline Hf- 175 & $2.8 E+03$ & 0.1 & $2.5 \mathrm{E}+03$ & $3.2 E+03$ \\
\hline $\mathrm{I}-129$ & $2.1 \mathrm{E}-03$ & $<0.05$ & 3.1E-05 & $1.4 \mathrm{E}-02$ \\
\hline $\mathrm{I}-131$ & $1.1 \mathrm{E}-01$ & $<0.05$ & $2.2 \mathrm{E}-03$ & 7.2E-01 \\
\hline $\mathrm{I}-132$ & $1.0 \mathrm{E}+00$ & $<0.05$ & $5.6 \mathrm{E}-03$ & $7.3 \mathrm{E}+00$ \\
\hline I-133 & $1.5 \mathrm{E}-03$ & $<0.05$ & $7.6 \mathrm{E}-06$ & $1.1 \mathrm{E}-02$ \\
\hline In-113m & $8.2 \mathrm{E}-02$ & $<0.05$ & $4.4 \mathrm{E}-03$ & 4.2E-01 \\
\hline Ir-192 & $6.6 \mathrm{E}-01$ & $<0.05$ & $5.4 \mathrm{E}-03$ & $4.6 \mathrm{E}+00$ \\
\hline La-140 & $2.8 \mathrm{E}+00$ & $<0.05$ & $4.9 \mathrm{E}-02$ & $1.8 \mathrm{E}+01$ \\
\hline $\mathrm{Mn}-54$ & $1.2 \mathrm{E}+05$ & 4.2 & $1.2 E+04$ & $4.8 \mathrm{E}+05$ \\
\hline Mn-56 & $1.3 \mathrm{E}+00$ & $<0.05$ & $6.6 \mathrm{E}-03$ & $9.5 \mathrm{E}+00$ \\
\hline Mo-99 & $2.3 \mathrm{E}-02$ & $<0.05$ & $1.6 \mathrm{E}-04$ & $1.6 \mathrm{E}-01$ \\
\hline $\mathrm{Na}-22$ & $5.4 \mathrm{E}-01$ & $<0.05$ & $3.6 \mathrm{E}-02$ & $2.6 \mathrm{E}+00$ \\
\hline $\mathrm{Na}-24$ & $2.7 \mathrm{E}+00$ & $<0.05$ & $2.0 \mathrm{E}-02$ & $1.9 \mathrm{E}+01$ \\
\hline $\mathrm{Nb}-94$ & $2.0 \mathrm{E}-01$ & $<0.05$ & $8.9 \mathrm{E}-04$ & $1.5 \mathrm{E}+00$ \\
\hline $\mathrm{Nb}-95$ & $3.8 \mathrm{E}+03$ & 0.1 & $2.6 \mathrm{E}+03$ & $5.4 \mathrm{E}+03$ \\
\hline $\mathrm{Ni}-59$ & $1.4 \mathrm{E}+03$ & $<0.05$ & $1.1 E+03$ & $1.8 \mathrm{E}+03$ \\
\hline $\mathrm{Ni}-63$ & $4.8 \mathrm{E}+05$ & 17.2 & $4.3 E+05$ & $5.2 \mathrm{E}+05$ \\
\hline Np-237 & $3.7 \mathrm{E}-03$ & $<0.05$ & $2.2 \mathrm{E}-05$ & $2.7 \mathrm{E}-02$ \\
\hline Pm-147 & $2.4 \mathrm{E}+00$ & $<0.05$ & $1.2 \mathrm{E}-02$ & $1.7 \mathrm{E}+01$ \\
\hline $\operatorname{Pr}-144$ & $1.1 \mathrm{E}+02$ & $<0.05$ & $1.9 \mathrm{E}+01$ & $3.7 E+02$ \\
\hline Pu-238 & 3.6E-01 & $<0.05$ & $8.5 \mathrm{E}-03$ & $2.2 \mathrm{E}+00$ \\
\hline $\mathrm{Pu}-239$ & $2.4 \mathrm{E}+00$ & $<0.05$ & $2.4 \mathrm{E}-01$ & $1.0 \mathrm{E}+01$ \\
\hline $\mathrm{Pu}-240$ & $5.7 \mathrm{E}-02$ & $<0.05$ & $2.4 \mathrm{E}-03$ & $3.1 \mathrm{E}-01$ \\
\hline Pu-241 & $1.7 \mathrm{E}+01$ & $<0.05$ & $1.0 \mathrm{E}-01$ & $1.2 \mathrm{E}+02$ \\
\hline $\mathrm{Pu}-242$ & $1.2 \mathrm{E}-08$ & $<0.05$ & $6.0 \mathrm{E}-11$ & $8.9 \mathrm{E}-08$ \\
\hline
\end{tabular}


Table S-2. (continued).

\begin{tabular}{|c|c|c|c|c|}
\hline Radionuclide & $\begin{array}{c}\text { Best } \\
\text { estimate } \\
(\mathrm{Ci})\end{array}$ & $\begin{array}{l}\text { Percent } \\
\text { of total } \\
(\%)\end{array}$ & $\begin{array}{l}\text { Lower } \\
\text { bound }\end{array}$ & $\begin{array}{l}\text { Upper } \\
\text { bound }\end{array}$ \\
\hline $\mathrm{Ra}-226$ & $1.1 \mathrm{E}+00$ & $<0.05$ & 8.7E-01 & $1.4 \mathrm{E}+00$ \\
\hline Re-188 & $9.3 \mathrm{E}-03$ & $<0.05$ & $4.7 \mathrm{E}-05$ & $6.8 \mathrm{E}-02$ \\
\hline Rh-106 & $6.1 \mathrm{E}+01$ & $<0.05$ & $1.1 \mathrm{E}+01$ & $2.0 \mathrm{E}+02$ \\
\hline Ru-103 & $1.9 \mathrm{E}-01$ & $<0.05$ & $2.5 \mathrm{E}-03$ & $1.3 \mathrm{E}+00$ \\
\hline Ru-106 & $6.4 \mathrm{E}+01$ & $<0.05$ & $1.3 E+01$ & $2.0 \mathrm{E}+02$ \\
\hline Sb-124 & $1.1 \mathrm{E}-02$ & $<0.05$ & $2.4 \mathrm{E}-04$ & $7.1 \mathrm{E}-02$ \\
\hline Sb-125 & $2.9 E+03$ & 0.1 & $2.4 \mathrm{E}+03$ & $3.4 \mathrm{E}+03$ \\
\hline Sc-46 & $5.0 \mathrm{E}+01$ & $<0.05$ & $2.6 \mathrm{E}-01$ & $3.6 \mathrm{E}+02$ \\
\hline Se-75 & $4.5 \mathrm{E}-02$ & $<0.05$ & $8.0 \mathrm{E}-04$ & $2.9 \mathrm{E}-01$ \\
\hline Sn-113 & $2.4 \mathrm{E}+01$ & $<0.05$ & 2.1E-01 & $1.7 \mathrm{E}+02$ \\
\hline $\mathrm{Sn}-117 \mathrm{~m}$ & $1.2 \mathrm{E}+02$ & $<0.05$ & $6.1 \mathrm{E}-01$ & $8.7 \mathrm{E}+02$ \\
\hline Sn-119m & $8.8 \mathrm{E}+03$ & 0.3 & $7.6 \mathrm{E}+03$ & $1.0 \mathrm{E}+04$ \\
\hline Sr-89 & $3.0 \mathrm{E}+00$ & $<0.05$ & 3.7E-02 & $2.0 \mathrm{E}+01$ \\
\hline Sr-90 & $5.8 \mathrm{E}+02$ & $<0.05$ & 4.4E+01 & $2.6 \mathrm{E}+03$ \\
\hline Sr-91 & $4.4 \mathrm{E}-03$ & $<0.05$ & $2.2 \mathrm{E}-05$ & $3.2 \mathrm{E}-02$ \\
\hline Sr-92 & $1.6 \mathrm{E}-03$ & $<0.05$ & $8.2 \mathrm{E}-06$ & $1.2 \mathrm{E}-02$ \\
\hline Тa-182 & $1.8 \mathrm{E}+04$ & 0.6 & $1.6 \mathrm{E}+04$ & $2.0 \mathrm{E}+04$ \\
\hline Tc-99 & $5.0 \mathrm{E}-01$ & $<0.05$ & $2.8 \mathrm{E}-03$ & $3.6 \mathrm{E}+00$ \\
\hline $\mathrm{Te}-125 \mathrm{~m}$ & $4.2 E+01$ & $<0.05$ & $2.2 \mathrm{E}-01$ & $3.0 \mathrm{E}+02$ \\
\hline $\mathrm{Te}-132$ & $5.6 \mathrm{E}-03$ & $<0.05$ & $3.3 \mathrm{E}-04$ & $2.8 \mathrm{E}-02$ \\
\hline Th-228 & $1.0 \mathrm{E}+01$ & $<0.05$ & $8.4 \mathrm{E}+00$ & $1.2 \mathrm{E}+01$ \\
\hline U-232 & $2.2 E+00$ & $<0.05$ & $1.8 \mathrm{E}+00$ & $2.7 \mathrm{E}+00$ \\
\hline U-234 & $3.5 \mathrm{E}+00$ & $<0.05$ & $3.3 \mathrm{E}+00$ & $3.7 \mathrm{E}+00$ \\
\hline U-235 & $1.6 \mathrm{E}-01$ & $<0.05$ & $1.5 \mathrm{E}-01$ & $1.6 \mathrm{E}-01$ \\
\hline U-236 & $2.3 \mathrm{E}-03$ & $<0.05$ & $1.1 \mathrm{E}-03$ & $4.1 \mathrm{E}-03$ \\
\hline U-238 & $1.6 \mathrm{E}+00$ & $<0.05$ & $1.6 \mathrm{E}+00$ & $1.7 \mathrm{E}+00$ \\
\hline V-48 & $2.0 \mathrm{E}-01$ & $<0.05$ & $4.4 \mathrm{E} \cdot 03$ & $1.2 \mathrm{E}+00$ \\
\hline
\end{tabular}


Table S-2. (continued).

\begin{tabular}{|c|c|c|c|c|}
\hline Radionuclide & $\begin{array}{c}\text { Best } \\
\text { estimate } \\
\text { (Ci) }\end{array}$ & $\begin{array}{c}\text { Percent } \\
\text { of total } \\
(\%)\end{array}$ & $\begin{array}{l}\text { Lower } \\
\text { bound }\end{array}$ & $\begin{array}{l}\text { Upper } \\
\text { bound }\end{array}$ \\
\hline W-185 & $6.4 \mathrm{E}+03$ & 0.2 & $5.6 \mathrm{E}+03$ & $7.3 E+03$ \\
\hline Y-88 & $3.0 \mathrm{E}-03$ & $<0.05$ & $1.5 \mathrm{E}-05$ & $2.2 \mathrm{E}-02$ \\
\hline Y-90 & $2.0 \mathrm{E}+02$ & $<0.05$ & $3.5 \mathrm{E}+01$ & $6.7 \mathrm{E}+02$ \\
\hline$Y-93$ & $1.1 \mathrm{E}-01$ & $<0.05$ & $5.6 \mathrm{E}-04$ & $8.0 \mathrm{E}-01$ \\
\hline $\mathrm{Zn}-65$ & $1.0 \mathrm{E}+03$ & $<0.05$ & $8.5 \mathrm{E}+00$ & $7.2 \mathrm{E}+03$ \\
\hline Zr-95 & $2.1 \mathrm{E}+03$ & 0.1 & $1.4 \mathrm{E}+03$ & $3.0 \mathrm{E}+03$ \\
\hline Total & $2.8 E+06$ & 99.6 & & \\
\hline
\end{tabular}


Table S-3. Inventory of nonradiological contaminants (listed alphabetically) from all generators for the years 1994-2003.

\begin{tabular}{cllll}
\hline $\begin{array}{c}\text { CAS } \\
\text { number }\end{array}$ & \multicolumn{1}{c}{ Chemical } & $\begin{array}{c}\text { Best } \\
\text { estimate } \\
(\mathrm{g})\end{array}$ & $\begin{array}{c}\text { Lower } \\
\text { bound }\end{array}$ & $\begin{array}{c}\text { Upper } \\
\text { bound }\end{array}$ \\
\hline $7440-38-2$ & Arsenic & $2.1 \mathrm{E}-01$ & $1.0 \mathrm{E}-01$ & $3.2 \mathrm{E}-01$ \\
$1332-21-4$ & Asbestos & $1.1 \mathrm{E}+06$ & $1.0 \mathrm{E}+05$ & $2.1 \mathrm{E}+06$ \\
$7440-39-3$ & Barium & $7.3 \mathrm{E}+00$ & $3.7 \mathrm{E}+00$ & $1.1 \mathrm{E}+01$ \\
$7440-41-7$ & Beryllium & $5.0 \mathrm{E}+07$ & $5.0 \mathrm{E}+07$ & $5.1 \mathrm{E}+07$ \\
$7440-43-9$ & Cadmium & $5.8 \mathrm{E}+00$ & $3.4 \mathrm{E}+00$ & $8.3 \mathrm{E}+00$ \\
$7440-47-3$ & Chromium & $1.9 \mathrm{E}+01$ & $9.5 \mathrm{E}+00$ & $2.8 \mathrm{E}+01$ \\
$7439-92-1$ & Lead & $1.6 \mathrm{E}+00$ & $1.2 \mathrm{E}+00$ & $1.9 \mathrm{E}+00$ \\
$7439-97-6$ & Mercury & $1.3 \mathrm{E}-02$ & $1.1 \mathrm{E}-02$ & $1.5 \mathrm{E}-02$ \\
\hline
\end{tabular}

xxix 
Table S-4. Inventory of radiological contaminants (listed alphabetically) from all generators for the years 1994-2003 (activity at time of disposal).

\begin{tabular}{|c|c|c|c|c|}
\hline Radionuclide & $\begin{array}{c}\text { Best } \\
\text { estimate } \\
\text { (Ci) }\end{array}$ & $\begin{array}{c}\text { Percent } \\
\text { of total } \\
(\%)\end{array}$ & $\begin{array}{l}\text { Lower } \\
\text { bound }\end{array}$ & $\begin{array}{l}\text { Upper } \\
\text { bound }\end{array}$ \\
\hline $\mathrm{Ag}-108$ & $1.6 \mathrm{E}-01$ & $<0.05$ & $5.2 \mathrm{E}-03$ & $9.4 \mathrm{E}-01$ \\
\hline $\mathrm{Ag}-110 \mathrm{~m}$ & $9.7 \mathrm{E}-04$ & $<0.05$ & $5.2 \mathrm{E}-05$ & $4.9 \mathrm{E}-03$ \\
\hline Am-241 & $2.1 \mathrm{E}-01$ & $<0.05$ & $1.3 \mathrm{E}-02$ & $1.0 \mathrm{E}+00$ \\
\hline $\mathrm{Au}-198$ & $1.6 \mathrm{E}-02$ & $<0.05$ & $9.0 \mathrm{E}-04$ & $8.0 \mathrm{E}-02$ \\
\hline Ba-137m & $1.1 E+00$ & $<0.05$ & $6.1 \mathrm{E}-03$ & $8.0 \mathrm{E}+00$ \\
\hline Ba-140 & $4.2 \mathrm{E}-02$ & $<0.05$ & $1.5 \mathrm{E}-03$ & 2.4E-01 \\
\hline C-14 & $9.5 \mathrm{E}+01$ & $<0.05$ & $7.4 \mathrm{E}+00$ & $4.3 \mathrm{E}+02$ \\
\hline Ce-141 & $1.4 \mathrm{E}-01$ & $<0.05$ & $8.1 \mathrm{E}-03$ & $6.7 \mathrm{E}-01$ \\
\hline Ce-144 & $5.8 \mathrm{E}+01$ & $<0.05$ & $7.2 \mathrm{E}+00$ & $2.3 \mathrm{E}+02$ \\
\hline $\mathrm{Cm}-242$ & $2.2 \mathrm{E}-01$ & $<0.05$ & $1.6 \mathrm{E}-02$ & $1.0 \mathrm{E}+00$ \\
\hline $\mathrm{Cm}-244$ & $1.9 \mathrm{E}-01$ & $<0.05$ & $1.2 \mathrm{E}-02$ & $9.3 \mathrm{E}-01$ \\
\hline Co-57 & $1.2 \mathrm{E}-01$ & $<0.05$ & $4.5 \mathrm{E}-03$ & $6.8 \mathrm{E}-01$ \\
\hline Co-58 & $1.0 \mathrm{E}+05$ & 2.7 & $5.9 \mathrm{E}+03$ & $5.0 \mathrm{E}+05$ \\
\hline $\mathrm{Co}-60$ & $7.9 \mathrm{E}+05$ & 21.0 & $3.1 E+05$ & $1.7 \mathrm{E}+06$ \\
\hline $\mathrm{Cr}-51$ & $2.6 E+04$ & 0.7 & $1.6 \mathrm{E}+03$ & $1.3 E+05$ \\
\hline Cs-134 & $5.0 \mathrm{E}+00$ & $<0.05$ & $8.5 \mathrm{E}-01$ & $1.7 \mathrm{E}+01$ \\
\hline Cs-137 & $1.6 \mathrm{E}+03$ & $<0.05$ & $6.3 E+02$ & $3.3 \mathrm{E}+03$ \\
\hline $\mathrm{Eu}-152$ & $6.9 \mathrm{E}-01$ & $<0.05$ & $3.8 \mathrm{E}-02$ & $3.5 \mathrm{E}+00$ \\
\hline Eu-154 & $1.4 \mathrm{E}+00$ & $<0.05$ & $1.6 \mathrm{E}-01$ & $5.5 \mathrm{E}+00$ \\
\hline Eu-155 & $7.2 E+01$ & $<0.05$ & $4.4 \mathrm{E}+00$ & $3.5 \mathrm{E}+02$ \\
\hline $\mathrm{Fe}-55$ & $3.8 \mathrm{E}+04$ & 1.0 & $1.7 \mathrm{E}+04$ & $7.6 \mathrm{E}+04$ \\
\hline $\mathrm{Fe}-59$ & $8.1 E+03$ & 0.2 & $4.4 E+02$ & $4.1 \mathrm{E}+04$ \\
\hline $\mathrm{H}-3$ & $2.6 \mathrm{E}+06$ & 70.4 & $1.3 \mathrm{E}+06$ & $5.0 \mathrm{E}+06$ \\
\hline Hf-181 & $1.6 \mathrm{E}-01$ & $<0.05$ & $8.8 \mathrm{E}-03$ & $8.3 \mathrm{E}-01$ \\
\hline I-129 & $5.1 \mathrm{E}-02$ & $<0.05$ & $6.2 \mathrm{E}-03$ & $2.0 \mathrm{E}-01$ \\
\hline $\mathrm{I}-131$ & $2.5 \mathrm{E}-02$ & $<0.05$ & $1.5 \mathrm{E}-03$ & $1.2 \mathrm{E}-01$ \\
\hline In-113m & $5.4 \mathrm{E}-02$ & $<0.05$ & $3.1 \mathrm{E}-03$ & $2.7 \mathrm{E}-01$ \\
\hline
\end{tabular}


Table S-4. (continued).

\begin{tabular}{|c|c|c|c|c|}
\hline Radionuclide & $\begin{array}{l}\text { Best } \\
\text { estimate } \\
\text { (Ci) }\end{array}$ & $\begin{array}{l}\text { Percent } \\
\text { of total } \\
(\%)\end{array}$ & $\begin{array}{l}\text { Lower } \\
\text { bound }\end{array}$ & $\begin{array}{l}\text { Upper } \\
\text { bound }\end{array}$ \\
\hline Ir-192 & $1.4 \mathrm{E}+00$ & $<0.05$ & $1.4 \mathrm{E}-01$ & $5.7 E+00$ \\
\hline La-140 & $1.1 \mathrm{E}-01$ & $<0.05$ & $6.5 \mathrm{E}-03$ & $5.4 \mathrm{E}-01$ \\
\hline $\mathrm{Mn}-54$ & $6.5 E+04$ & 1.7 & $3.5 \mathrm{E}+03$ & $3.3 E+05$ \\
\hline Mo-99 & 2.4E-02 & $<0.05$ & $1.3 \mathrm{E}-03$ & $1.2 \mathrm{E}-01$ \\
\hline $\mathrm{Na}-22$ & $1.1 \mathrm{E}-01$ & $<0.05$ & $6.1 \mathrm{E}-03$ & $5.5 \mathrm{E}-01$ \\
\hline $\mathrm{Nb}-94$ & $1.9 \mathrm{E}+00$ & $<0.05$ & $1.9 \mathrm{E}-02$ & $1.3 \mathrm{E}+01$ \\
\hline $\mathrm{Nb}-95$ & $6.8 \mathrm{E}+03$ & 0.2 & $2.2 E+03$ & $1.6 \mathrm{E}+04$ \\
\hline Ni-59 & $1.9 \mathrm{E}+02$ & $<0.05$ & $1.9 \mathrm{E}+00$ & $1.3 E+03$ \\
\hline $\mathrm{Ni}-63$ & $6.9 \mathrm{E}+04$ & 1.8 & $2.5 \mathrm{E}+04$ & $1.5 \mathrm{E}+05$ \\
\hline $\mathrm{Np}-237$ & $1.7 \mathrm{E}-02$ & $<0.05$ & $4.3 \mathrm{E}-04$ & $1.0 \mathrm{E}-01$ \\
\hline $\operatorname{Pr}-144$ & $2.6 \mathrm{E}+00$ & $<0.05$ & $2.5 \mathrm{E}-01$ & $1.1 \mathrm{E}+01$ \\
\hline $\mathrm{Pu}-238$ & $4.1 \mathrm{E}-01$ & $<0.05$ & $2.6 \mathrm{E}-02$ & $2.0 \mathrm{E}+00$ \\
\hline Pu-239 & $4.2 \mathrm{E}-01$ & $<0.05$ & $2.7 \mathrm{E}-02$ & $2.0 \mathrm{E}+00$ \\
\hline Pu-240 & $4.5 \mathrm{E}-02$ & $<0.05$ & 3.0E-03 & $2.2 \mathrm{E}-01$ \\
\hline $\mathrm{Pu}-241$ & $4.6 \mathrm{E}+01$ & $<0.05$ & $3.0 \mathrm{E}+00$ & $2.2 \mathrm{E}+02$ \\
\hline Rh-106 & $3.9 \mathrm{E}-01$ & $<0.05$ & $3.2 \mathrm{E}-02$ & $1.7 \mathrm{E}+00$ \\
\hline $\mathrm{Ru}-103$ & $1.6 \mathrm{E}-02$ & $<0.05$ & $8.8 \mathrm{E}-04$ & $8.2 \mathrm{E}-02$ \\
\hline Ru-106 & $4.0 \mathrm{E}-01$ & $<0.05$ & $3.4 \mathrm{E}-02$ & $1.8 \mathrm{E}+00$ \\
\hline $\mathrm{Sb}-124$ & $2.4 \mathrm{E}-03$ & $<0.05$ & $1.3 \mathrm{E}-04$ & $1.2 \mathrm{E}-02$ \\
\hline Sb-125 & $4.1 \mathrm{E}+00$ & $<0.05$ & 3.7E-01 & $1.8 \mathrm{E}+01$ \\
\hline Sc-46 & 3.7E-02 & $<0.05$ & $2.0 \mathrm{E}-03$ & $1.9 \mathrm{E}-01$ \\
\hline Se-75 & $9.4 \mathrm{E}-03$ & $<0.05$ & $5.1 \mathrm{E}-04$ & 4.8E-02 \\
\hline Sn-113 & $6.3 \mathrm{E}-02$ & $<0.05$ & $3.7 \mathrm{E}-03$ & $3.1 \mathrm{E}-01$ \\
\hline Sn-117m & 3.4E-02 & $<0.05$ & $2.0 \mathrm{E}-03$ & $1.7 \mathrm{E}-01$ \\
\hline Sr-89 & $5.4 \mathrm{E}-04$ & $<0.05$ & $2.9 \mathrm{E}-05$ & 2.7E-03 \\
\hline Sr-90 & $8.2 \mathrm{E}+01$ & $<0.05$ & $1.1 \mathrm{E}+01$ & $3.1 E+02$ \\
\hline Ta-182 & $7.6 \mathrm{E}+03$ & 0.2 & $2.4 \mathrm{E}+03$ & $1.8 \mathrm{E}+04$ \\
\hline
\end{tabular}


Table S-4. (continued).

\begin{tabular}{lllll}
\hline Radionuclide & $\begin{array}{c}\text { Best } \\
\text { estimate } \\
(\mathrm{Ci})\end{array}$ & $\begin{array}{c}\text { Percent } \\
\text { of total } \\
(\%)\end{array}$ & $\begin{array}{c}\text { Lower } \\
\text { bound }\end{array}$ & $\begin{array}{c}\text { Upper } \\
\text { bound }\end{array}$ \\
\hline Tc-99 & $1.4 \mathrm{E}+00$ & $<0.05$ & $8.6 \mathrm{E}-02$ & $6.7 \mathrm{E}+00$ \\
Te-132 & $2.9 \mathrm{E}-03$ & $<0.05$ & $1.6 \mathrm{E}-04$ & $1.5 \mathrm{E}-02$ \\
$\mathrm{U}-234$ & $5.0 \mathrm{E}-02$ & $<0.05$ & $3.1 \mathrm{E}-02$ & $7.6 \mathrm{E}-02$ \\
$\mathrm{U}-235$ & $1.7 \mathrm{E}-03$ & $<0.05$ & $1.3 \mathrm{E}-03$ & $2.3 \mathrm{E}-03$ \\
$\mathrm{U}-236$ & $6.0 \mathrm{E}-03$ & $<0.05$ & $2.9 \mathrm{E}-03$ & $1.1 \mathrm{E}-02$ \\
$\mathrm{U}-238$ & $5.2 \mathrm{E}-02$ & $<0.05$ & $3.2 \mathrm{E}-02$ & $7.8 \mathrm{E}-02$ \\
$\mathrm{Xe}-133$ & $5.0 \mathrm{E}-04$ & $<0.05$ & $2.7 \mathrm{E}-05$ & $2.5 \mathrm{E}-03$ \\
$\mathrm{Y}-90$ & $6.9 \mathrm{E}+01$ & $<0.05$ & $7.0 \mathrm{E}+00$ & $2.9 \mathrm{E}+02$ \\
Zn-65 & $1.2 \mathrm{E}+00$ & $<0.05$ & $6.5 \mathrm{E}-02$ & $6.1 \mathrm{E}+00$ \\
Zr-95 & $3.2 \mathrm{E}+03$ & 0.1 & $1.0 \mathrm{E}+03$ & $7.7 \mathrm{E}+03$ \\
\hline Total & $3.8 \mathrm{E}+06$ & 100.0 & & \\
\hline
\end{tabular}




\section{Observations and Conclusions}

The observations and conclusions for the contaminants in the recent (1984-1993) and projected (1994-2003) waste are as follows:

- The combined use of many types of information sources-process knowledge, operating records, nuclear physics calculations, reports, interviews, shipping records, the RWMIS database, waste generator forecasts, and others-was essential to achieve the present degree of completeness of the recent and projected inventories.

- For nonradiological contaminants, the inventory information that could be located or deduced for the 1984-1993 and 1994-2003 periods from information sources and that is compiled in CIDRA is believed to be substantially complete.

- The number and quantities of nonradiological contaminants identified in or projected to be in the waste being disposed of in the SDA decreased dramatically after 1984. For most (but not all) of those nonradiological contaminants, the presence of the contaminant could cause the waste to be designated as hazardous per RCRA. Beginning in 1984, DOE was required to come into compliance with RCRA, so acceptance of mixed waste for disposal at the SDA was discontinued in April 1984. An exception was made for contaminated lead used as radiation shielding, which was allowed for disposal as late as December 31, 1987.

- For the radiological contaminants, the inventory information that could be located or deduced for the 1984-1993 and 1994-2003 periods from information sources and that is compiled in the new CIDRA database is believed to be substantially complete.

- A considerable effort was devoted to estimating the uncertainty in the quantities of nonradiological and radiological contaminants. For the projected waste, this effort included estimating the uncertainty in waste generator forecasts.

- A considerable effort was devoted to breaking down the generic radioactivity terms MAP, MFP, and unidentified beta/gamma-emitters for each generator so that a specific distribution of radionuclides would be available for the risk assessment.

- The predominant (by mass) nonradiological contaminants identified in the waste were as follows: for the 1984-1993 period-lead, beryllium, asbestos, copper, zirconium oxide, and chromium; for the 1994-2003 period-beryllium, asbestos, and chromium.

- The predominant (by radioactivity at the time of disposal) radiological contaminants identified in the waste were as follows: for the 1984-1993 period-Co-60, Ni-63, H-3, $\mathrm{Co}-58$, Fe-55, Mn-54, Cr-51, Ta-182, and Fe-59; for the 1994-2003 period-H-3, Co-60, Co-58, Ni-63, Mn-54, Fe-55, and Cr-51.

- To confirm its substantial completeness, the compiled recent (1984-1993) inventory of radiological contaminants was compared against the corresponding inventory in the 
RWMIS database. The results of these comparisons confirm that the current task has not overlooked any substantial radioactivity in the waste. The total activity in CIDRA (without the G-M correction) agrees with the total inventory in RWMIS to within the accuracy allowed by the use of two significant figures. For all of the principal, longerlived radionuclides, the activity in CIDRA is similar to or larger than that in RWMIS.

- The total activities of the fission products differ between CIDRA and RWMIS by about $20 \%$. This difference is less than the total random error for estimating the radioactivity in an individual waste shipment.

- The CIDRA value agrees with the RWMIS entry for tritium (H-3) to within the study precision of two significant figures. The H-3 is almost entirely in the beryllium reflectors from the TRA waste.

- The total activities of the activation products differ $<1 \%$ between CIDRA and RWMIS.

- The activities of C-14, Tc-99, and I-129 in CIDRA are considerably larger than those in RWMIS. These radionuclides are important because of their very long half-lives and their relatively high mobility if released from the waste form. These radionuclides are very difficult to measure in waste shipments. The values in CIDRA were developed by means of nuclear physics calculations.

- As an additional confirmation of its completeness, the compiled nonradiological inventory for the 1984-1993 period was compared against the information found in previous reports. Very few studies have been performed on the nonradiological contaminants buried in the SDA in the recent period. Therefore, the comparisons were of limited value but identified no evidence that the new inventory was incomplete.

- As an additional confirmation of its completeness, the compiled radiological inventory for the 1984-1993 period was compared against the information found in previous reports. Only one report contained data for the recent period. Because the data were nearly identical to those in the RWMIS database, no detailed comparison was carried out.

- The compiled radiological inventory for the projected period (1994-2003) was compared to the waste generator forecasts. Because the waste generator forecasts were the starting point for evaluating the projected waste, the close agreement with reported estimates in CIDRA is not surprising. As expected and consistent with the assumptions, the best-estimate CIDRA values (after the bias corrections and other refinements are applied) differ substantially from the generator forecasts.

- As a final confirmation of its substantial completeness, the recent inventory (1984-1993) of contaminants was compared against the list of contaminants detected in environmental monitoring at the RWMC. The historical inventory (1952-1983) was also included in the comparison. No radiological contaminants were reliably detected in the monitoring that had not been identified in either the historical or the recent 
inventories. The only nonradiological contaminants detected more than rarely in the environmental monitoring that were not identified in the inventories were three volatile organic compounds: 1,1-dichloroethylene, 1,1-dichloroethane, and dichlorodifluoromethane. These three contaminants may be degradation products or impurities associated with closely related contaminants that were identified in the historical inventory. Detected contaminants also could have originated from sources other than the subject waste (e.g., in effluents from other INEL facilities or from other waste at the RWMC).

- A large quantity of information was assembled and entered into CIDRA on the physical and chemical forms of the waste streams and of the contaminants, and on the packaging of the waste streams.

- Even though the information now residing in CIDRA has been through multiple checks and reviews, the possibility exists for oversights and discrepancies. In addition, new information about the waste is identified from time to time in other INEL programs. As new information is discovered, the database will be revised as necessary. 
xxxvi 


\section{ACRONYMS AND ABBREVIATIONS}

AEC U.S. Atomic Energy Commission

ALE Argonne National Laboratory-East

ANL-E Argonne National Laboratory-East

ANL-W Argonne National Laboratory-West

ANP Aircraft Nuclear Propulsion (Program)

ARA Auxiliary Reactor Area

ARMF Advanced Reactivity Measurement Facility

ARVFS Army Reentry Vehicle Area

ATR Advanced Test Reactor

ATRC Advanced Test Reactor Critical

BAD Best Available Data (database)

BDL below detection limit

BNL Battelle Northwest Laboratories

BORAX Boiling Water Reactor Experiment

BRA baseline risk assessment

CAS Chemical Abstract Services

CEG Combustion Engineering-General Atomics

CERCLA Comprehensive Environmental Response, Compensation, and Liability Act

CFA Central Facilities Area

CFR Code of Federal Regulations

CIDRA Contaminant Inventory Database for Risk Assessment

CTF Containment Test Facility 


\begin{tabular}{|c|c|}
\hline CWS & Chemical Warfare Service \\
\hline D\&D & decontamination and decommissioning \\
\hline DOE & U.S. Department of Energy \\
\hline EBR & Experimental Breeder Reactor \\
\hline ECF & Expended Core Facility \\
\hline EFL & Experimental Fuels Laboratory \\
\hline EMU & Environmental Monitoring Unit \\
\hline EPA & U.S. Environmental Protection Agency \\
\hline EPRI & Electric Power Research Institute \\
\hline ER & environmental restoration \\
\hline ERP & environmental restoration projects \\
\hline ETR & Engineering Test Reactor \\
\hline ETRC & Engineering Test Reactor Critical \\
\hline FCF & Fuel Cycle Facility \\
\hline $\mathrm{FFA} / \mathrm{CO}$ & Federal Facility Agreement and Consent Order \\
\hline FMF & Fuel Manufacturing Facility \\
\hline G-M & Geiger-Müller \\
\hline GCRE & Gas-Cooled Reactor Experiment \\
\hline HDT & historical data task \\
\hline HEPA & high-efficiency particulate air \\
\hline HFEF & Hot Fuel Examination Facility \\
\hline HTRE & Heat Transfer Reactor Experiment \\
\hline ICPP & Idaho Chemical Processing Plant \\
\hline IET & Initial Engine Test (Facility) \\
\hline
\end{tabular}




$\begin{array}{ll}\text { IFR } & \text { Integral Fast Reactor } \\ \text { INEL } & \text { Idaho National Engineering Laboratory } \\ \text { LLW } & \text { low-level waste } \\ \text { L\&O } & \text { Laboratory and Office Building } \\ \text { LOF } & \text { Loss of Fluid (Test Reactor) } \\ \text { LOFT } & \text { Loss of Fluid Test (Reactor) } \\ \text { MAP } & \text { mixed activation products } \\ \text { MFP } & \text { mixed fission products } \\ \text { ML-1 } & \text { Mobile Low-Power Reactor No. 1 } \\ \text { MTA } & \text { Mobile Test Assembly } \\ \text { MTR } & \text { Materials Test Reactor } \\ \text { NCP } & \text { National Contingency Plan } \\ \text { ND } & \text { not detected } \\ \text { NOS } & \text { not otherwise specified } \\ \text { NR } & \text { not reported } \\ \text { NRC } & \text { U.S. Nuclear Regulatory Commission } \\ \text { NRF } & \text { Naval Reactors Facility } \\ \text { NRP } & \text { Naval Reactors Program } \\ \text { NRTS } & \text { National Reactor Testing Station } \\ \text { NWCF } & \text { New Waste Calcining Facility } \\ \text { OECD } & \text { Organization for Economic Cooperation and Development } \\ \text { OFF } & \text { oftsite waste generators not otherwise specified } \\ \text { PA } & \text { performance assessment } \\ \text { PBF } & \text { Power Burst Facility } \\ & \end{array}$

xxxix 


\begin{tabular}{ll} 
PCB & polychlorinated biphenyl \\
PCS & Primary Coolant System \\
PER & Power Excursion Reactor \\
PM & Portable Medium Nuclear Power Plant \\
PQL & practical quantitation limit \\
RCRA & Resource Conservation and Recovery Act \\
RESL & Radiological and Environmental Sciences Laboratory \\
RFP & Rocky Flats Plant \\
RI/FS & remedial investigation/feasibility study \\
RLWTF & Radioactive Liquid Waste Treatment Facility \\
RMF & Reactivity Measurements Facility \\
RML & Radiation Measurements Laboratory \\
RPDT & recent and projected data task \\
RPSSA & Radioactive Parts Security Storage Area \\
RSD & relative standard deviation \\
RSWF & Radioactive Scrap and Waste Facility \\
RWMC & Radioactive Waste Management Complex \\
RWMIS & Radioactive Waste Management Information System \\
SCMS & Sodium Components Maintenance Shop \\
SDA & Subsurface Disposal Area \\
SDS & Submerged Demineralizer System \\
SHADE & shielded hot air drum evaporator \\
SL-1 & Stationary Low-Power Reactor No. 1 \\
SLSF & Sodium Loop Safety Facility \\
SMC & Specific Manufacturing Capability \\
\hline
\end{tabular}




$\begin{array}{ll}\text { SNAP } & \text { Systems for Nuclear Auxiliary Power } \\ \text { SNAPTRAN } & \text { Space Nuclear Auxiliary Power Transient } \\ \text { SPERT } & \text { Special Power Excursion Reactor Test } \\ \text { SPF } & \text { Sodium Process Facility } \\ \text { SRE } & \text { Sodium Reactor Experiment } \\ \text { SS } & \text { special study } \\ \text { TAN } & \text { Test Area North } \\ \text { TMI } & \text { Three-Mile Island } \\ \text { TRA } & \text { Test Reactor Area } \\ \text { TREAT } & \text { Transient Reactor Test (Facility) } \\ \text { TRU } & \text { transuranic } \\ \text { TSA } & \text { Transuranic Storage Area } \\ \text { TSF } & \text { Technical Support Facility } \\ \text { UCL } & \text { upper confidence limit } \\ \text { USGS } & \text { U.S. Geological Survey } \\ \text { VOC } & \text { volatile organic compound } \\ \text { WAG } & \text { waste area group } \\ \text { WERF } & \text { Waste Experimental Reduction Facility } \\ \text { WIPP } & \text { Waste Isolation Pilot Plant } \\ \text { WMC } & \text { Waste Management Complex } \\ \text { WRRTF } & \text { Water Reactor Research Test Facility } \\ \text { ZPPR } & \text { Zero Power Physics Reactor } \\ & \end{array}$




\section{REGULATORY SOURCES CITED}

\section{DOE Orders}

DOE Order 5820.2A, "Radioactive Waste Management," September 26, 1988

\section{Codes of Federal Regulation}

Code of Federal Regulations, 10 CFR 61, "Licensing Requirements for Land Disposal of Radioactive Wastes"

Code of Federal Regulations, 40 CFR 300, "National Oil and Hazardous Substances Pollution Contingency Plan"

\section{Statutes}

Atomic Energy Act

Clean Air Act

Clean Water Act

Comprehensive Environmental Response, Compensation, and Reliability Act (CERCLA)

Federal Water Pollution Control Act

National Environmental Policy Act

Resource Conservation and Recovery Act (RCRA)

Safe Drinking Water Act

Solid Waste Disposal Act

Toxic Substances Control Act

\section{Agreements}

Federal Facility Agreement and Consent Order for the Idaho National Engineering Laboratory, signed December 9, 1991 


\section{A Comprehensive Inventory of Radiological and Nonradiological Contaminants in Waste Buried or Projected to be Buried in the Subsurface Disposal Area of the INEL RWMC During the Years 1984-2003}

\section{INTRODUCTION AND BACKGROUND}

\subsection{Objective and Overview}

This report documents the compilation of a comprehensive inventory of radiological and nonradiological contaminants in waste buried or projected to be buried in the Subsurface Disposal Area (SDA) at the Radioactive Waste Management Complex (RWMC) of the Idaho National Engineering Laboratory (INEL) from 1984 through 2003. The inventory was compiled primarily for performing a future baseline risk assessment (BRA) under the Comprehensive Environmental Response, Compensation, and Liability Act (CERCLA). The project to compile the inventory is referred to as the recent and projected data task (RPDT).

This report is a follow-on to a previous report (EG\&G Idaho 1994) that documents the historical data task (HDT) project. The HDT project covers waste buried at the SDA during the years 1952 through 1983 . The methodologies used in the two reports are essentially identical. Taken together, the two reports encompass the waste buried or projected to be buried in the SDA from 1952 through 2003.

The inventory compiled in this document covers the waste buried from 1984 through 1993 and waste projected to be buried from 1994 through 2003. The 1984-1993 waste is referred to here as the "recent waste." At the time this study was performed, 1993 was the most recent year for which waste disposal data were available. The 1994-2003 waste is referred to here as the "projected waste" because the information is based largely on waste generators' projections, or forecasts, of waste expected to be generated in the future. At the time this study was performed, the year 2003 was the end point for the time period included in the forecasts.

In terms of disposal location, several parts of the SDA are included in the inventory. As explained in the next section of this report, the SDA consists of numerous disposal units. The disposal units covered in this task include the following:

- Pits 17 through 20 (except for the 1982 and 1983 waste that is now in Pit 17)

- The 1984 waste that is in Pits 15 and 16

- Soil Vault Rows 14 through 20

- The 1984 waste that is in Soil Vault Rows 11 and 13. 
These disposal units form a completely complementary set with those addressed in the previous report (EG\&G Idaho 1994). Taken together, the units cover all waste buried in the SDA.

Waste in the Transuranic Storage Area (TSA) is not included in this inventory because it is stored aboveground.

The inventory addresses radioactive waste, as well as the limited quantities of hazardous substances per CERCLA [which encompass hazardous waste per the Resource Conservation and Recovery Act (RCRA) and other hazardous substances] and mixed waste buried in the time period of interest.

Figure 1-1 presents an overview logic flowchart of the activities conducted to develop the inventory.

Several sources of information were used to compile the inventory, including process knowledge, operating logs, previous inventory-related documents, shipping records, information databases, waste generator forecasts, engineering and nuclear physics calculations, and interviews with personnel having knowledge of the facility operations that produced the waste streams.

As was the case with EG\&G Idaho (1994), this task built upon the inventories in previous reports and databases by compiling several types of additional information that are needed for the BRA:

- A more comprehensive inventory of nonradiological contaminants

- Identification of specific radionuclides previously listed under generic names [e.g., mixed fission products (MFP) or mixed activation products (MAP)]

- Physical and chemical forms of the contaminants and of the host waste streams

- Uncertainties in the contaminant quantities.

To confirm its completeness, the inventory was compared with those in other reports and databases, and the reasons for any differences were explored. The list of contaminants was also compared with the list of contaminants detected in environmental monitoring conducted at the SDA.

This report is organized as follows. The remainder of this section provides a brief history and description of the SDA, discusses the regulations and regulatory agreements that create the need for the inventory information, and addresses the potential use of the inventory in other applications. The methods used to collect and compile the information are described in Section 2. Section 3 presents the resulting inventory for instances in which the contaminant quantities are known. Section 4 discusses and attempts estimates for instances in which the contaminant quantities are not known. Section 5 discusses the sources of data uncertainty, the methods used to estimate it, and the development of the upper and lower bounds. The completeness of the compiled inventory is confirmed in Section 6 by comparing it with inventories in existing reports and waste information databases, and with the environmental monitoring results. 


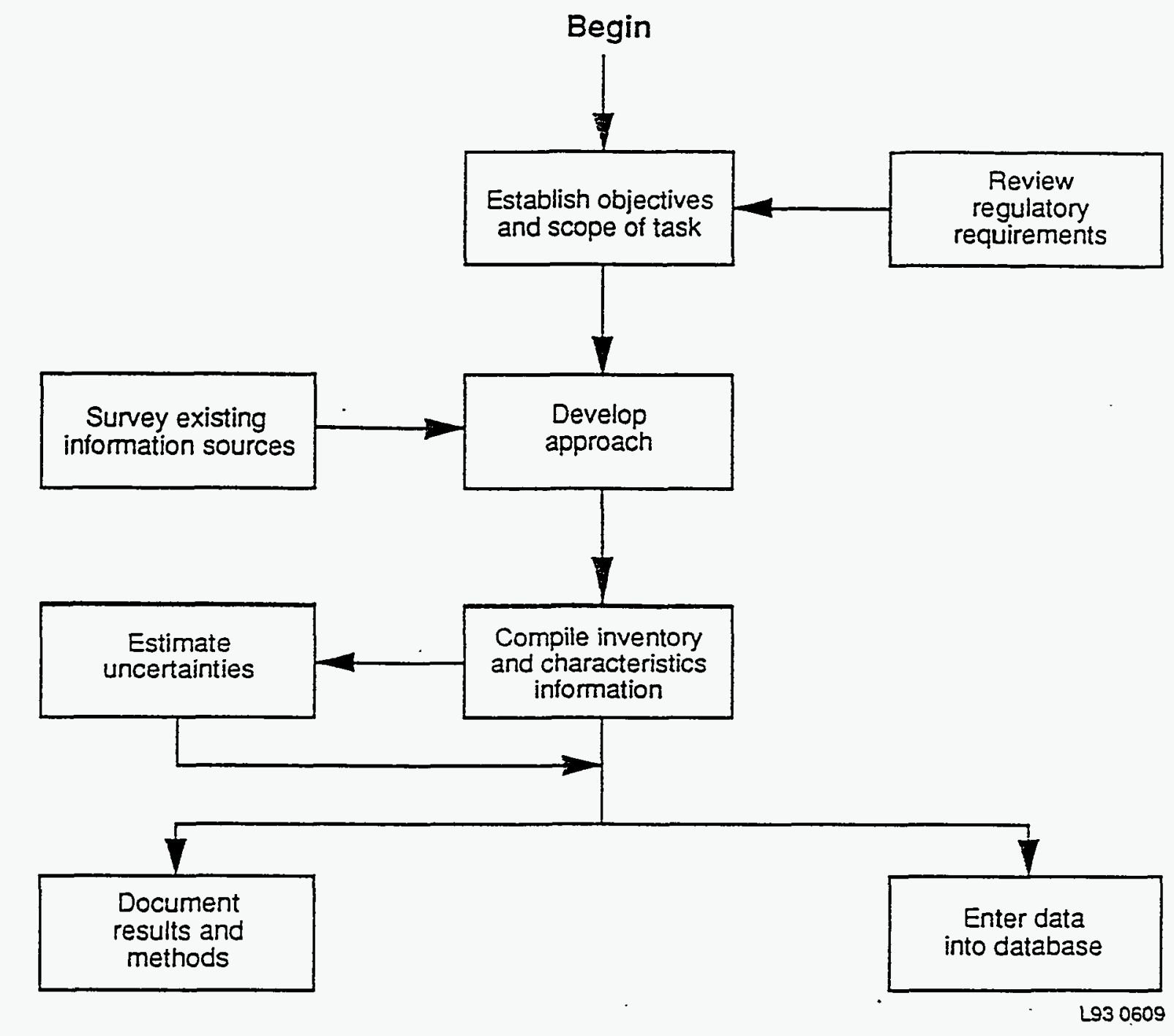

Figure 1-1. Overview logic flowchart for the task. 
To the extent possible, this report is organized so as to be in parallel with the organization of the HDT report (EG\&G Idaho 1994). Each section of this report contains information that corresponds to the analogous information in the corresponding section of the HDT report.

\subsection{Brief History and Description of the SDA ${ }^{a}$}

The RWMC, located in the southwest portion of the INEL, is a solid radioactive waste disposal site. The RWMC consists of the 38.85-ha SDA, the 22.7-ha TSA, and the Administrative Area (see Figure 1-2). Because the waste inventoried in this report was disposed of only in the SDA, the other two areas are mentioned only in passing.

The SDA consists primarily of three types of disposal units: pits, trenches, and soil vaults. For regulatory purposes, these disposal units are divided into various operable units, as shown in Figure 1-2.

Development of the SDA began in 1952 on a 5.3-ha tract of the original 40.5-ha site that had been identified for waste management purposes. The first shipment of radioactive waste from the INEL, which at that time was called the National Reactor Testing Station (NRTS), was buried in Trench 1 in the SDA that same year. Today, there is a total of 58 trenches; the last trench was closed in 1982.

Pits were also excavated, starting in 1957 , because of the large sizes of some waste items and the increased space efficiency of pit disposal. There is a total of 20 pits in the SDA.

Containers of transuranic (TRU)-contaminated waste from the Rocky Flats Plant (RFP) in Colorado were buried at the SDA beginning in 1954 and ending in 1970. The RFP waste was interspersed with the INEL waste in pits and trenches for several years.

By 1957, the original 5.3-ha SDA was nearly filled. The SDA was then expanded eastward and southward to its present size. The expansion also enclosed the Acid Pit, which had been used since 1954 for the disposal of laboratory acids, some of which contained very low levels of radioactivity. The Acid Pit was officially closed in 1961, although records indicate that it possibly was used once in 1967 and once in 1970.

Between 1960 and 1963, the SDA also served as an interim burial ground for waste generated by licensees of the Atomic Energy Commission [AEC, a predecessor agency to the U.S. Department of Energy (DOE)]. Waste from a number of offsite generators across the country was buried at the SDA during this period. Two additional shipments of the (non-RFP) offsite waste were buried in 1967 and 1969.

a. This section was abridged primarily from the detailed RWMC history presented in $A$ History of the Radioactive Waste Management Complex at the Idaho National Engineering Laboratory (EG\&G Idaho 1985). 


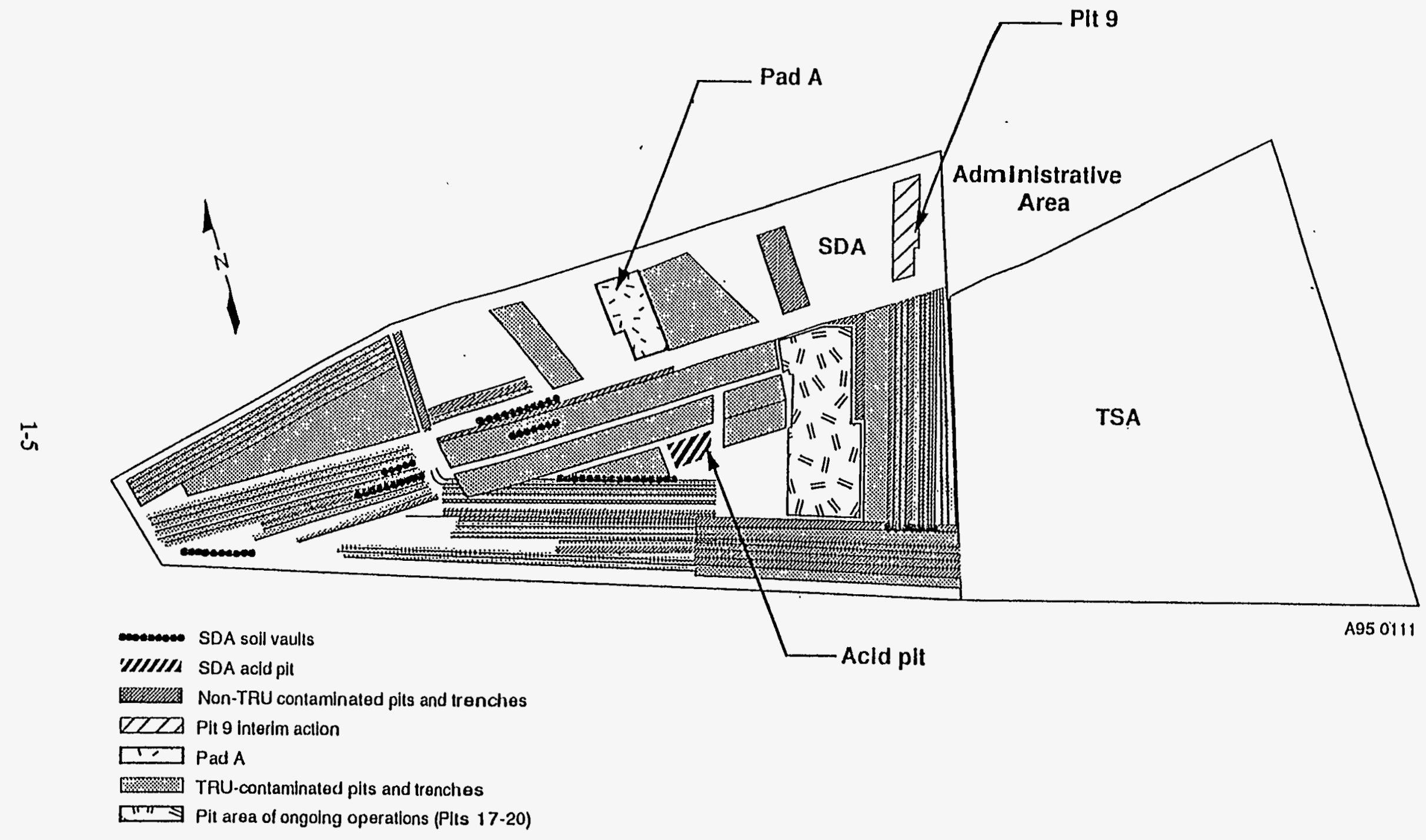

Figure 1-2. Overview layout of the Radioactive Waste Management Complex, including the Subsurface Disposal Area, Transuranic Storage Area, and Administrative Area. 
Numerous changes in SDA waste management practices took place from 1952 to 1970 . The general trend was toward more rigorous disposal practices. Soil-covering frequency, cover thickness, backfill over bedrock before emplacing waste, container designs, and container-stacking practices, as well as waste recordkeeping, evolved and improved over time. Several flood control and diking projects were completed, beginning in 1958 and continuing into the 1980s. Most of these projects were in response to flooding of the SDA by local runoff from snowmelt in 1962, 1969, and 1982.

In 1970, the AEC issued a policy requiring the segregation of waste contaminated with TRU radionuclides and the storage of that waste in a mode permitting later retrieval of contaminationfree containers. A decision was made at the RWMC to store and cover future receipts of TRU waste $^{\mathrm{b}}$ (and suspected TRU waste) aboveground. Accordingly, burial of such waste at the SDA ceased in 1970. Burial of non-TRU waste [low-level waste (LLW)] continues. The 22.7-ha TSA was established at the RWMC in 1970 for aboveground storage of newly received TRU waste, thereby expanding the RWMC to its present size.

In 1972, Pad A was established in the SDA for aboveground disposal of waste suspected of containing TRU radionuclides, but in concentrations less than $10 \mathrm{nCi} / \mathrm{g}$. Pad $\mathrm{A}$ was closed in 1978.

Two programs demonstrated experimental retrieval of part of the waste buried in the SDA. The Initial Drum Retrieval Program (1974-1978) and the Early Waste Retrieval Program (1976-1978) retrieved approximately $150,000 \mathrm{ft}^{3}$ of waste, which was placed on the TSA-R storage pad in the TSA and on Pad A.

b. The current definitions of TRU waste and LLW are as follows, as stated in DOE Order 5820.2A:

Transuranic (TRU) waste-Without regard to source or form, waste that is contaminated with alphaemitting transuranium radionuclides with half-lives greater than 20 years and concentrations greater than $100 \mathrm{nCi} / \mathrm{g}$ at the time of assay.

Low-level waste-Waste that contains radioactivity and is not classified as high-level waste, transuranic waste, or spent nuclear fuel or $11 \mathrm{e}(2)$ byproduct material . . . . Test specimens of fissionable material irradiated for research and development only, and not for the production of power or plutonium, may be classified as low-level waste, provided that the concentration of transuranics is less than 100 $\mathrm{nCi} / \mathrm{g}$.

Prior to 1984 , the lower limit of transuranic radionuclide activity for defining TRU waste was $10 \mathrm{nCi} / \mathrm{g}$, rather than the currently specified $100 \mathrm{nCi} / \mathrm{g}$.

Much of the LLW and TRU waste disposed of in the SDA from 1952 through early 1984 (Nelson 1984) is mixed waste: waste containing both radioactive and hazardous chemical components as defined by the Atomic Energy Act and RCRA, respectively. 
In 1977, the use of soil vaults for the disposal of high-radiation-level waste began in the SDA. Soil vaults eventually replaced trenches for the disposal of such waste. The vaults are drilled in rows, as shown in Figure 1-2. As of this writing, final preparations are underway to dispose of future high-radiation-level waste in concrete vaults placed in pits.

In 1980, disposal of LLW from Argonne National Laboratory-East (ANL-E) in Illinois began at the SDA. Disposal of LLW from that generator ceased in 1988.

Beginning in 1984, DOE was required to bring all of its facilities that managed hazardous waste or mixed waste into compliance with RCRA. Acceptance of mixed waste for disposal at the SDA was discontinued in April 1984 (Nelson 1984). [An exception is contaminated lead used as shielding in waste containers, for which disposal was allowed as late as December 31, 1987 (Rodgers 1985, Rodgers 1986, Rodgers 1987).] Therefore, after that date, nonradiological contaminants identified in the RCRA regulations are not expected to be found in the waste disposed of in the SDA.

\subsection{Pertinent Regulations and Agreements}

This section describes the regulatory framework under which this task was performed.

Under CERCLA (or Superfund) of 1980, as amended, Federal agencies that have facilities included on the U.S. Environmental Protection Agency's (EPA's) National Priorities List are required to enter into agreements with the EPA. These interagency agreements are designed to expedite remedial actions in response to the release (actual or potential) of hazardous substances to the environment at those facilities.

On December 21, 1989, the INEL was added to the EPA's National Priorities List of Superfund sites. On December 9, 1991, a Federal Facility Agreement and Consent Order (FFA/CO) for the INEL was signed and approved by DOE, EPA, and the State of Idaho Department of Health and Welfare. The goal of this agreement is to ensure that INEL releases of hazardous substances are thoroughly investigated in accordance with the National Contingency Plan (NCP, see 40 CFR 300) and that appropriate response actions are taken as necessary to protect human health and the environment. One of the INEL waste area groups (WAGs) defined under the FFA/CO is WAG-7, the RWMC.

Under 40 CFR 300.430 (d)(2), the NCP requires the following:

"The lead agency shall characterize the nature of and threat posed by the hazardous substances and hazardous materials and gather data necessary to assess the extent to which the release poses a threat to human health or the environment ...."

The RPDT and the HDT (EG\&G Idaho 1994) focused on the first part of the above regulation, i.e., "characterize the nature of . . . the hazardous substances and hazardous 
materials"c disposed of in the SDA. The BRA that this task supports will address the second portion of the requirement.

More detailed requirements concerning the characterization of hazardous substances are found in 40 CFR 300.430 (d)(2) (iii) and (iv). The information collected is to cover

". . the general characteristics of the waste, including quantities, state, concentration, toxicity, propensity to bioaccumulate, persistence, and mobility" and "the extent to which the source can be adequately identified and characterized."

The RPDT addressed most of the above requirement for the 1984-2003 time period. The remainder of the requirement will be addressed in the BRA.

Guidance on complying with the NCP regulations is provided in, among other sources, the Risk Assessment Guidance for Superfund, Volume 1, Human Health Evaluation Manual, Part A (EPA 1989). Section 4 of that manual lists "determination of the nature of the wastes" as one of the primary data-collection components of the remedial investigation/feasibility study (RI/FS) under the NCP. Available site information must be reviewed, including "information on amounts of hazardous substances disposed (e.g., from site records)."

The RPDT was planned and conducted with close attention to the above regulations and guidance. The intent was that the resulting inventory of contaminants comply fully with all applicable requirements.

\subsection{Other Uses of the Results}

In addition to its use for the BRA, the inventory information has other potential uses. Although not targeted specifically for use in evaluating remedial alternatives, much of the present information may be useful for such purposes. The information collected on chemical and physical properties of the waste may be helpful in evaluating treatment alternatives, assessing health and safety hazards to workers, and identifying potential operational problems.

Caution: Other applications of this information may be appropriate only if the nature of the application is compatible with the purpose of the present study. The suitability of this information (which was developed for risk assessments under CERCLA) for use in other applications may be affected. For example, the degree of conservatism appropriate in inventory information depends on the application. For some applications, best-estimate values are appropriate. For other applications, more conservative values are appropriate. In evaluations such as safety analyses, highly conservative, upper-limit values are generally appropriate.

c. Generally throughout this report, the term "contaminants" is used in place of "hazardous substances and hazardous materials." 
Although a major effort has been devoted to compiling this inventory, new information may be identified that could require modification of the inventory. Furthermore, some information concerning certain contaminants may never be located because of the lack of records. 


\section{References for Section 1}

EG\&G Idaho, 1994, A Comprehensive Inventory of Radiological and Nonradiological Contaminants in Waste Buried in the Subsurface Disposal Area of the INEL RWMC During the Years 1952-1983, EGG-WM-10903, EG\&G Idaho, Inc., June 1994.

EG\&G Idaho, 1985, $A$ History of the Radioactive Waste Management Complex at the Idaho National Engineering Laboratory, WM-F1-81-003, Revision 3, EG\&G Idaho, Inc., July 1985.

EPA, 1989, Risk Assessment Guidance for Superfund, Volume I, Human Health Evaluation Manual, Part $A$, interim final, EPA/540/1-89/002, U.S. Environmental Protection Agency, December 1989.

Nelson, J. H., 1984, letter to distribution, "Radioactive Mixed Waste," JHN-52-84, EG\&G Idaho, Inc., April 24, 1984.

Rodgers, A. D., 1985, letter to distribution, "Radioactive Waste Containing Lead," ADR-23-85, EG\&G Idaho, Inc., March 29, 1985.

Rodgers, A. D., 1986, letter to distribution, "Elimination of Lead from Low-Level Waste," ADR-53-86, EG\&G Idaho, Inc., June 24, 1986.

Rodgers, A. D., 1987, letter to distribution, "Use of Lead in Low-Level Waste Packages Schedule Exception," ADR-46-88, EG\&G Idaho, Inc., December 16, 1987. 


\section{METHODOLOGY FOR DATA COLLECTION AND COMPILATION}

This section describes the methods by which the waste inventory information was identified, collected, compiled, reviewed, and entered into a database. Except for Section 2.4, which discusses the method for estimating contaminant quantities in future waste, the methods used in the RPDT were essentially identical to those used in the HDT (EG\&G Idaho 1994).

\subsection{Overview}

The first step in a risk assessment is to identify and quantify all radiological and nonradiological contaminants in the waste with the potential to harm humans or the environment.

Waste disposal at the SDA began in 1952. Disposal requirements and practices at that time did not include the current requirements for waste characterization. Certainly, it was not envisioned at that time that the information provided about the waste would be used later to perform a formal risk assessment, so complete information about the waste was not obtained when it was generated and disposed of. During the 1984-1993 time period, the collection of information for newly generated waste improved gradually, although there were still some information gaps in this time period. However, as discussed later, inventory information can be and has been compiled that is sufficiently comprehensive and reliable to support a risk assessment.

One way in which contaminants are often identified is through a sampling and analysis program. Drilling, sampling, and analysis to determine an appropriate inventory for the SDA is not considered feasible or practical for several reasons: (a) the area is quite large; (b) drilling into disposal units containing radioactive waste is hazardous; and (c) the contaminants are distributed unevenly over the area, some places in concentrated form and some places in dilute form. Even a massive drilling and sampling campaign would not result in an inventory in which high confidence could be placed because of the heterogeneity of the waste.

Information and inventories concerning the waste buried at the SDA have been compiled in many previous efforts for various uses (although few of the efforts addressed waste disposed of after 1970). Some of the compilations have been entered into databases. (Sections 2.2 and 2.3 discuss existing documents and databases, respectively, that contain information on the buried waste.) Some of the compilations pertain to the entire SDA; others pertain to only one of the many disposal units. Most of the compilations were derived from shipping records. (Section 2.3 discusses some of the deficiencies in the shipping records.) Many of the inventory compilation efforts addressed only the radioactive component of the waste. Further, waste information obtained for one purpose often does not provide all of the parameters needed when used for a different purpose. After investigation, it was concluded that the existing compilations of waste inventory information were very useful, but not adequate to support a risk assessment of the SDA under CERCLA.

In view of the limitations of the above approaches, a different approach was devised to collect the information. The approach emphasized the use of process knowledge. 
First, the facilities that generated or that are expected to generate the SDA waste during 1984-2003 were divided into six groups, as follows:

- Test Area North (TAN)

- Test Reactor Area (TRA)

- Idaho Chemical Processing Plant (ICPP)

- Naval Reactors Facility (NRF)

- Argonne National Laboratory-West (ANL-W)

- Other generators - this covers all other onsite facilities (including environmental restoration activities and decontamination and decommissioning $[D \& D]$ programs as waste generators at those facilities) and all offsite facilities.

In the HDT report (EG\&G Idaho 1994), RFP was another major waste generator. However, no waste from RFP was buried in the SDA during the time period covered in this study.

Figure 2-1 shows the geographic locations of the major and smaller waste generators at the INEL. In addition, waste with a very small amount of radioactivity $(<1 \mathrm{Ci})$ is projected to be generated at the INEL Research Center in Idaho Falls. The one offsite generator is discussed in Section 2.5.6.

Six lead data gatherers were appointed to compile information on the waste from the six generators. In nearly every case, each lead data gatherer either was working at or had previously worked at the waste generator location whose information he was assigned to collect, and was familiar with the operational activities that generated the waste. Thus, the approach was primarily one of evaluating the waste based (where possible) on knowledge of the specific processes that generated it, as well as on review of pertinent records, databases, forecasts, and reports, rather than on simply rereviewing the shipping records.

Figure 2-2 depicts the flow of information in this approach. The rectangles represent items of information, and the ovals represent technical activities performed on the information. Section 2 describes the data-gathering activities depicted in Figure 2-2.

The upper left portion of the figure shows the principal sources of information used by the data gatherers. The data gatherers used process knowledge and plant operating records, inventory and other reports, shipping records (and databases of such records), interviews with plant employees (including retired employees), engineering and nuclear physics calculations, waste generator forecasts, and other records.

The question next arose about the level at which the waste should be characterized. The goal was to divide a given generator's waste, for data-gathering purposes, so that the resulting information would be organized in the most useful way for application to the risk assessment. 


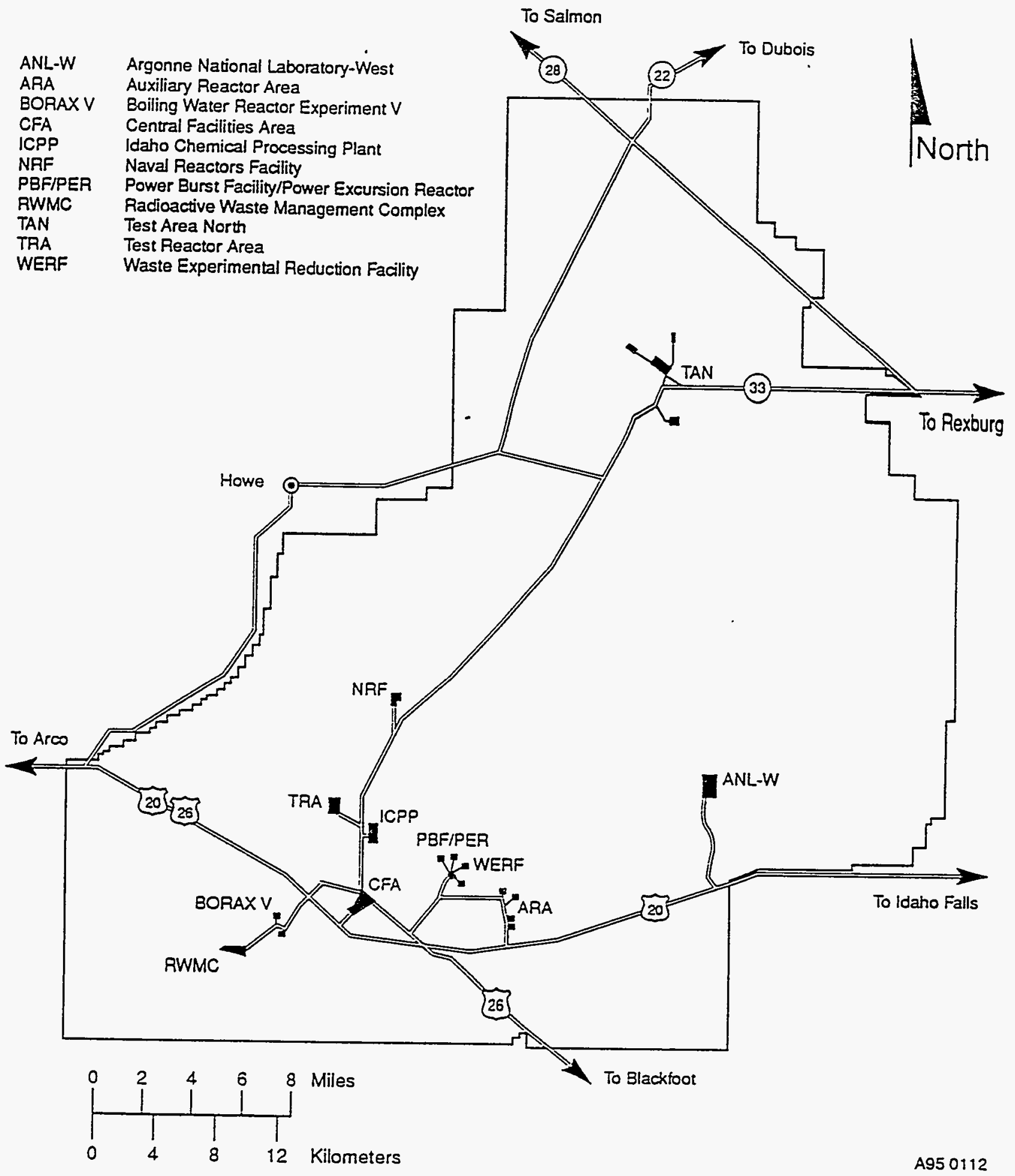

Figure 2-1. Locations of the Idaho National Engineering Laboratory waste generators in 1984-2003 and the location of the Radioactive Waste Management Complex. 


\section{Process knowledge \\ and plant operating}

records

Inventory and ollier

technical reports

Engineering and

nuclear physics

calculations

\section{Shipping and}

disposal records;

RWMIS database

Interviews with
plant personnel

\section{Waste generator}

forecasts

Other sources

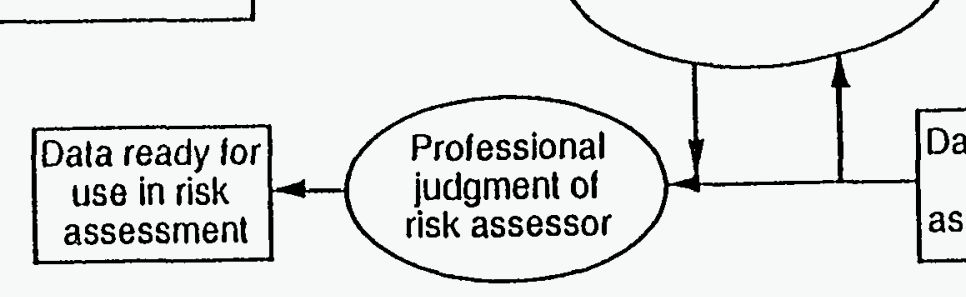

Use of othe

analylical tools

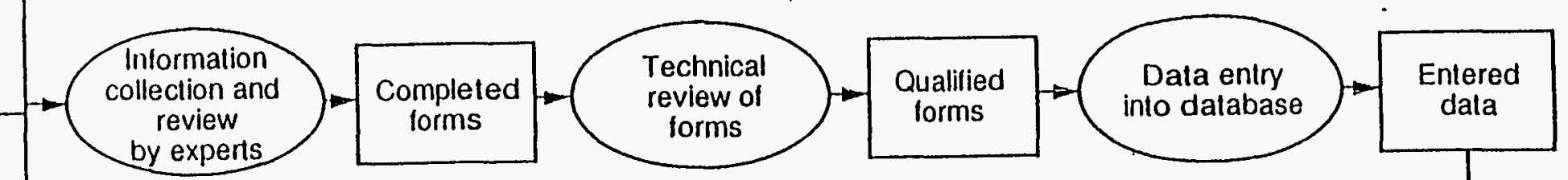

forms
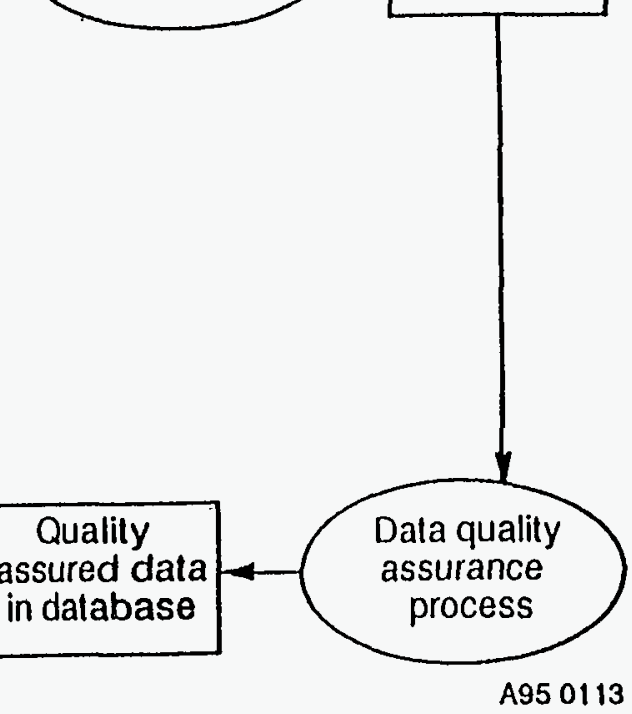

Figure 2-2. Approach for information flow in developing the inventory. 
Characterization of waste at the generator level would not provide sufficient detail because the waste from a given generator varied greatly in form, constituents, and characteristics.

Characterizing each waste container individually was obviously not feasible. Even if information were available on the contents of each waste container (which it is not), the number of containers involved is in the hundreds of thousands.

The approach used was to divide the waste from a given generator into "waste streams." (Dividing the waste into streams was strictly for purposes of convenience in organizing the data and did not in any way restrict the data that could be gathered.) Although the definition used herein for a waste stream is rather flexible, the term generally refers to a collection of waste containers whose contents are similar. In some cases, streams could be defined that were fairly uniform from one container to another. For example, all of the beryllium reflectors from TRA were defined as one waste stream. On the other hand, for a minor building that produced a very small amount of assorted waste, all waste from the building was generally lumped together into one, nonuniform stream.

Applying this approach led to dividing the waste from a given major generator into anywhere from 1 to 15 waste streams for either the recent or projected period. The total number of streams was 99 , a manageable number, for the recent plus projected waste.

A standardized, five-page data form (see Appendix A) was used to record the information collected for each waste stream. The form indicates the generator, building, and assigned number of the waste stream from that building; the volume, physical and chemical form, and containment of the waste stream itself; the quantities (including uncertainties) and physical and chemical form of the nonradiological contaminants and radiological contaminants in the stream; the source(s) and reliability of the information; and the assumptions made in dealing with the stream. A five-page form (plus continuation pages as needed) was completed for each of the 99 streams that were identified.

Many of the information items on the data forms were established as computer-searchable data fields with prescribed lists of possible answers. However, to allow the broadest flexibility in describing the waste, several "free" fields were included on the forms where verbal descriptions could be entered to whatever level of detail was needed. Although such free fields cannot be rolled up using the database, some of the information in the free fields is invaluable in understanding subtle characteristics of the waste that affect parameters such as the mobility of the contaminants.

Candidate nonradiological and radiological contaminants for Parts $C$ and $D$ of the data forms (see Appendix A) were addressed as follows.

All radionuclides identified in the waste streams were included on Part D. The radionuclide $\mathrm{K}-40$ was excluded from the inventory, however, based on the following rationale. The database of shipping records for 1984-1993 includes several K-40 entries in waste from several generators, totaling $0.17 \mathrm{Ci}$. No $\mathrm{K}-40$ entries were identified in the waste generator forecasts. Except for the generation of K-40 by the activation of potassium used in specialized nuclear reactors, no credible mechanism could be identified for the production of $\mathrm{K}-40$ in the waste. Therefore, the K-40 
entries in the shipping records are believed to be spurious, the result of attributing natural background radiation from $\mathrm{K}-40$ to radiation from $\mathrm{K}-40$ in the waste. One possible exception might be certain waste from ANL-W, where potassium is used in nuclear reactors; however, the ANL-W data gatherer indicated that there was no K-40 in the waste from ANL-W.

$\mathrm{K}-40$ is a very long-lived (half-life of 1.28 billion years) radionuclide. It occurs naturally worldwide, constituting $0.0117 \%$ of the potassium in the earth's crust (General Electric Company 1989). K-40 also is found naturally in human bodies worldwide in sufficient concentrations to produce radiation doses of 14 to $27 \mathrm{mrem} / \mathrm{yr}$ to various organs (NCRPM 1987). The average concentration of naturally occurring K-40 in INEL surface and near-surface sediments is $19 \mathrm{pCi} / \mathrm{g}$ (Hoff et al. 1993). These sediments are used for backfill in the SDA. The amount of naturally occurring K-40 in the backfill in Pits 17-20, where most of the waste addressed in this document has been or will be buried, was calculated to be approximately $5.2 \mathrm{Ci}$. This value is considerably larger than the $0.17 \mathrm{Ci}$ of $\mathrm{K}-40$ listed in shipping records as being in the waste. Because the total radioactivity of K-40 in the backfill is much larger than that listed in the shipping records and because the K-40 entries are believed to be spurious, $\mathrm{K}-40$ was not included in the inventory compiled in this document.

Candidate nonradiological contaminants for Part $\mathrm{C}$ were addressed by screening against two lists. One list consisted of the hazardous substances designated by the EPA under CERCLA. The list included chemicals designated under the Federal Water Pollution Control Act, Solid Waste Disposal Act, Clean Air Act, Clean Water Act, RCRA, and Toxic Substances Control Act. The second list covered contaminants listed in the National Primary Drinking Water Standards of the Safe Drinking Water Act. If there was any question about whether to include a nonradiological contaminant, it was included. One class of nonradiological contaminants not included on Part $\mathrm{C}$ was metals commonly found in alloy form in structural components, i.e., nickel and chromium, which are used in stainless steel. A literature review and analysis (Weidner 1993) indicated that, considering the extremely slow corrosion rate of stainless steel in the RWMC soil and the very limited solubility of nickel and chromium at the $\mathrm{pH}$ of interest, the mobility of these chemicals under these circumstances is expected to be extremely limited.

The data were collected separately for the two time periods of interest (1984-1993 and 1994-2003) because the collection methods differed somewhat. The method for the recent waste (1984-1993) was identical to that for the 1952-1983 waste (EG\&G Idaho 1994) and is discussed throughout Section 2. The special provisions required to address the projected waste (1994-2003) are discussed in Section 2.4.

The steps in Figure 2-2 are discussed in more detail in the remainder of Section 2. The use of source documents is discussed in Section 2.2. Section 2.3 describes the use of an existing database of shipping and disposal records. The method for estimating contaminant quantities in future waste is described in Section 2.4. Section 2.5 provides a detailed description of how the waste information was obtained for each waste generator.

After the information was collected and entered onto data forms, it was subjected to a qualification process (discussed in Section 2.6) and entered into a contaminant inventory database for risk assessment (described in Section 2.7). The database for the information gathered in the 
current study is the same database used for the 1952-1983 information (EG\&G Idaho 1994). Finally, with the use of other analytical tools and the professional judgment of risk assessors, the data are ready for use in risk assessments.

\subsection{Use of Source Documents}

As indicated in Figure 2-2, technical reports and other documents containing inventory and related information about the waste buried or projected to be buried in the SDA were one of the primary sources of information collected in the current study. This section discusses the types of reports available and describes how the reports were used.

A large number of documents contain useful information about the waste buried or projected to be buried in the SDA. The types of documents range from brief letters to comprehensive technical reports. In scope, the documents range from narrow (addressing only one waste stream from one generator) to comprehensive (fairly complete inventories), although none of the documents cover the full scope required for the BRA. Some of the documents are devoted solely to discussions of inventory, while others address inventory only briefly as part of another topic, such as the characteristics of waste to be processed in a proposed treatment facility. Many of the documents contain data extracted from previous documents. The dates of the documents range from the 1950 s to the present. (Because this study addresses waste buried starting in 1984, most of the documents that were used date from 1984 onward.) Some of the documents offer crucial information, while others are of limited value.

Because the existing documents were of considerable value to the current study, as many as possible were identified and evaluated for their applicability. Data gatherers reviewed the documents related to their assigned generator and incorporated the information, as appropriate, into the present data-gathering effort.

One type of document of particular use for the projected waste was the waste generator forecasts. These forecasts are discussed in Section 2.4. Program planning documents were also useful for the projected waste.

For each waste stream, the data gatherer specified the sources of information on Part $E$ of the data form (see Appendix A). If a document was the source of an item of information, the box titled "reports" was marked on the data form, and the title, author, report number, and date were entered. On many data forms, the data gatherers also compared the inventory specified in a reference report against sometimes-conflicting data from other sources of information, made a judgment as to which data were considered more credible, and indicated the basis for the judgment.

Approximately 60 specific reports and letters are referenced and discussed in later parts of Section 2. 


\subsection{Use of the Radioactive Waste Management Information System}

In addition to process knowledge, technical reports, shipping records, and interviews, existing databases were searched to obtain information. The principal database accessed in the current task was the Radioactive Waste Management Information System (RWMIS).

\subsubsection{Description of RWMIS}

RWMIS (Litteer 1988) is a mainframe electronic database developed in 1971 that resides on an IBM 3083 computer. Information reported in RWMIS includes all airborne (onsite effluent), liquid, and solid radioactive waste shipped to or generated at the INEL. The purpose of RWMIS is to provide an inventory of radioactive waste stored or disposed of at the RWMC and radioactive effluents generated at the INEL.

The data in RWMIS originated from shipping and disposal forms $\mathrm{s}^{\mathrm{a}}$ that accompanied the waste when it was shipped for storage or disposal.

The database consists of summary waste shipping and disposal records for the years 1954 to 1970 (nothing from 1952 to 1954), waste shipment records for 1971 to 1986, and containerby-container records from 1986 to the present. Shipment-specific waste information data prior to 1971 are not included in the user-accessible database. These pre-1971 records are referred to as the Best Available Data (BAD) database. Records in RWMIS for 1971 to 1983, and 1984 to the present, are referred to as the historical database and the current database, respectively.

RWMIS is a hierarchical database consisting of a parent-master (shipment information) and two children: a nuclide information child and a container information child. The parent-master has a one-to-many relationship with the nuclide and container information children.

The primary fields in RWMIS and a brief description of each are provided in Table 2-1.

Verification of the data entered into RWMIS is performed according to a process described in Litteer (1988).

\subsubsection{RWMIS Download for the Current Task}

A download of the current mainframe electronic databases from NOMAD to an IBM personal computer dBASE environment was performed to support the RPDT. The download was performed for the years 1984-1993.

To facilitate the use of RWMIS in the dBASE environment, the data were downloaded into three relational databases. These databases consisted of the master (as stored in RWMIS), a nuclide information database (with key information from the master), and a container information database (with key information from the master). A verification procedure was written and

a. For simplicity, shipping and disposal forms are generally referred to herein as "shipping records." 
Table 2-1. Primary information fields in the Radioactive Waste Management Information System database.

\begin{tabular}{ll} 
Primary RWMIS fields & \multicolumn{1}{c}{ Description } \\
\hline Waste origin & $\begin{array}{l}\text { The site (area and building/location) at which the waste was } \\
\text { generated. }\end{array}$ \\
Waste type & The physical phase of the waste (i.e., liquid or solid). \\
Radioactive & A flag that specifies whether or not the shipment is radioactive. \\
Report date & $\begin{array}{l}\text { The date generally identifies the date that the shipment form was } \\
\text { completed. It usually appears on the form as the date of approval } \\
\text { for shipment of the waste. }\end{array}$ \\
Waste description & $\begin{array}{l}\text { A generic description of the shipment. In most cases, this field also } \\
\text { includes radiation readings taken at contact and at } 1 \text { m from the }\end{array}$ \\
shipment. & The gross volume of the waste shipment in cubic meters. \\
Gross volume & The gross weight of the waste shipment in grams. \\
Gross weight & The gross curies in the waste shipment. \\
Gross curies & The date of waste disposal or storage. \\
Disposal date & The type of waste container. \\
Container type & $\begin{array}{l}\text { The curie quantity of each nuclide in the waste shipment. } \\
\text { Container number }\end{array}$ \\
The number of waste containers in the waste shipment. \\
Container volume
\end{tabular}


implemented to ensure that the integrity of the RWMIS databases was maintained during the download. In the RWMIS mainframe environment, a count was made of the number of records, and all numerical fields were summed. The same checks were made on the download (dBASE) version of the database. All inconsistencies were resolved before the data were used.

An application was developed to display the RWMIS data in a convenient form, called a technical note, for the RPDT.

The download version of RWMIS was used as one source of information to support the RPDT.

\subsubsection{RWMIS Limitations}

Section 2.1 indicated that existing compilations of SDA waste inventory information-both reports and databases-were very useful, but not adequate to support risk assessments under the FFA/CO. This section provides more detail on why the RWMIS database could not serve as the sole source of inventory information.

A primary limitation of RWMIS is that it contains very little information concerning nonradiological contaminants in the waste.

Prior to 1986, RWMIS stored data only on a shipment basis. The curies (or grams) identified with each isotope are specified for the entire shipment and not for individual containers. This limitation makes it difficult, for example, to determine if the contents of an individual container should be classified as TRU waste or LLW.

Although post-1986 data are available in RWMIS on a shipment basis, the current data form does not accept textual descriptions of the waste, but rather content codes only. For waste that does not fall conveniently within a content code, certain detailed descriptions previously available in text may not be captured electronically.

From a risk assessment perspective, there are several other deficiencies in the RWMIS database, although some of the deficiencies have been remedied for waste generated recently. The deficiencies reflect a lack of either detail or completeness. Some of the deficiencies are:

- Entries with only one radionuclide identified, e.g., Pu-239, whereas knowledge of the waste-generating process indicates that other radionuclides must also be present

- Entries with only the element specified, e.g., uranium, with no designation of a particular radionuclide

- Entries with only MAP or MFP identified, with no designation of particular radionuclides

- Entries with equal amounts of MAP or MFP identified, suggesting that no rigorous estimate of radionuclide breakdown was performed 
- Entries with only one fission product identified, e.g., Cs-137, whereas knowledge of the waste-generating process indicates that others must also be present

- $\quad$ Entries with only one activation product identified, e.g., Co-60, whereas others must also be present

- Entries with unidentified radionuclides, e.g., unidentified beta-gamma, unidentified alpha

- Entries with no chemical form specified

- $\quad$ Entries with no physical form specified

- Entries that are actually for temporarily stored waste.

\subsection{Method for Estimating Contaminant Quantities in Future Waste}

\subsubsection{Background}

The inventory addressed in this study includes waste expected to be generated in the future, as well as waste already generated. The quantities and characteristics (e.g., contaminant concentrations) of waste that will be generated in the future cannot be predicted with certainty. Unforeseeable changes in many factors could substantially affect the quantities and characteristics of the waste that will be generated. Examples are changes in program funding, changes in the regulations that govern waste management, changes in facility operations, and unpredicted outcomes of decisions made in environmental restoration (ER) programs that generate waste.

To estimate the quantities of contaminants in future waste, therefore, requires that numerous assumptions be made. The assumptions are typically based on patterns of waste generation in the past, recent trends, and projections of future funding levels and facility operations.

\subsubsection{Available Projections of Future Waste}

Information on projected contaminants in future waste is somewhat limited.

Since 1977, near the end of each calendar year, the INEL waste generators have forecasted their future generation of waste. The waste generator forecasts consist of approximately 20 sets of forms completed by the various generators. The forecasts cover the upcoming year and the nine following years. Revisions to individual generator forecasts are sometimes provided between the annual cycles.

The most recent generator forecasts available when this task was performed cover the waste expected to be generated in calendar years 1994 and 1995, by quarter, and in calendar years 1996 through 2003. The generator forecasts include information on the type, volume, total 
radioactivity, and radionuclide distribution for each "waste stream characterization number." Approximately 170 such numbers are in use. The radionuclide distributions supplied in the generator forecasts range from very simple (one radionuclide) to quite detailed (about 20 radionuclides). For some streams, particularly streams generated by $D \& D$, no radioactivity total or distribution was supplied by the generator. No generator forecast information was provided from some of the ER WAGs.

The generator forecasts are compiled by RWMIS personnel in an annual letter (e.g., Randall 1994). The compilations are rollups over all waste streams from a given generator. Also, the compilations do not include radionuclide distributions. Any generator forecasts with "unknown" entries for total radioactivity appear as zero radioactivity on the rollups, even though the waste volume appears as a non-zero value.

Neither the generator forecasts nor the compilation provides any information on the nonradiological contaminants in the waste to be disposed of in the SDA. (Nonradiological contaminants in waste disposed of in the SDA were greatly reduced starting in 1984.)

Another compilation of projections for future waste is given in a report produced semiannually covering the ER and D\&D activities (e.g., DOE 1993 and its subsequent updates). Again, no information is presented for some of the WAGs. The report provides more detailed information on the source, type, and management plans for the waste than does the annual compilation letter described above. However, it does not provide any information on radiological or nonradiological contaminants in the waste to be disposed of at the SDA. Also, the projections do not extend very far into the future. No waste from ER or D\&D is projected in the report to be disposed of in the SDA after 2001, although D\&D may generate a considerable amount of waste requiring disposal in the SDA after 2001.

\subsubsection{Accuracy of Past Projections}

The radioactivity values in past generator forecasts were compared in detail against those listed when the waste was actually disposed of at the SDA. The comparisons reveal that, although the accuracy of the projections has improved somewhat over the years, it is still limited.

An early version of the Waste Management Plan, Annual Update (EG\&G Idaho 1988) evaluated the accuracy of the generator forecasts for waste disposed of from 1978 through 1986. In 6 of the 9 years, the forecasts overestimated the future annual amounts of radioactivity in the waste by anywhere from a factor of 2 to a factor of 7 . In 3 of the 9 years, the forecasts proved to be too low. Those differences ranged from about $10 \%$ to a factor of 5 .

For the current study, the radioactivity values in generator forecasts made in the four most recent years were compared with those listed when the waste was actually disposed of. The detailed statistical analysis is presented in Section 5.5.2. The conclusion is that, on the whole, the forecasts of radioactivity are biased upward by a factor of approximately 4 . There is no reason to believe that the bias exhibited in the recent past has changed. Therefore, the same bias was assumed to affect the projections that were made in late 1993 in Randall (1994). 


\subsubsection{Waste-Projection Approach Selected for the Present Study}

The waste generator forecasts, the most recent of which extend generally through 2003, were used as the starting point for projecting the waste characteristics for 1994-2003. The forecasts are considered the best data available and are the official projections for the INEL. (As discussed in Section 2.4.3, the recent waste generator forecasts of radiological contaminants have exhibited an overall upward bias of a factor of about 4 . The upward bias and some other limitations of the forecasts were adjusted for as discussed below.)

The approach for the projected waste was as follows:

- A set of waste streams was developed in the current study for waste disposed of in the past years, 1984-1993 (the recent period).

- The data gatherers discussed the projected 1994-2003 waste with the person(s) who prepared the forecasts for their respective generators. In some cases, the data gatherers were the same people who had prepared the generator forecasts. The data gatherers also reviewed any program planning or other documents that could provide useful information for projecting waste generation.

- The 1993 generator forecasts for the period 1994-2003, by waste stream, were compared against the actual waste streams for 1984-1993. For each major generator, a decision was made by the data gatherer on whether to use the waste stream organization in the generator forecasts or that for the 1984-1993 waste, or a combination of the two. If the current study identified additional streams in the 1994-2003 period (not listed in the generator forecasts), that information was also factored in. The result of this step was a set of waste streams to use for 1994-2003.

- Unless there was a valid reason to change them, the generator forecasts of total annual radioactivity in each waste stream in 1994-2003 were used as a starting point. The upward bias was corrected through multiplication by a factor of 0.25 if the generator forecasts were used directly to project the total radioactivity. (In some special cases, waste with well-characterized radioactivity has already been generated, but is still awaiting disposal. The factor of 0.25 was not applied in such situations.) The radioactivity in the ER-generated waste for which information was not submitted in the annual generator forecast-WAG 8 (NRF) and WAG 9 (ANL-W)-was estimated and added in.

- By the use of methods appropriate to the generator and the waste stream, (e.g., nuclear physics calculations, discussions with generator technical personnel), the generator's radionuclide distributions for each waste stream were modified as necessary. For example, adjustments to the distribution of U-234, U-235, and U-238 were made as described in Section 3.1. 
- A correction was applied to any waste radioactivity projections that had been based on extrapolations of data derived from the Geiger-Müller (G-M) counter survey method. The bias of this method, the derivation of the correction, and the application of the correction to past waste and projected waste are described in Section 5.

The generator forecasts do not address nonradiological contaminants in the waste. In this study, the projections of nonradiological contaminants are based on a combination of information sources: program planning documents, interviews, and extrapolations from corresponding waste streams of the 1984-1993 time period.

\subsubsection{Volumetric Disposal Capacity of the SDA}

The volume of waste that can be disposed of in the SDA is limited. The limited remaining space available for disposal of future waste has been a subject of concern for several years. Periodic studies have been performed to project the remaining lifetime so that adequate disposal capability will be ensured.

Because of this limitation, a check was made to determine whether all of the waste projected to be generated through the year 2003 could be accommodated in the SDA. The most recently published projections (DOE 1994a) indicate that initial closure of the SDA could begin as early as the year 2004 and be completed by 2007 . However, ongoing studies are investigating means of extending the lifetime of the SDA well beyond those dates. The conclusion is that the SDA can be expected to accommodate all of the waste projected to require disposal through at least the year 2003. Therefore, questions about the future closure of the SDA are not expected to impact the present study.

\subsection{Data Collection Methods}

This section discusses the methods used to collect the waste information for each of the six waste generators. Because the waste and the available information differed from one generator to another, and even from one stream to another, the data-collection methods also differed from stream to stream.

The discussion of the methods is presented in two ways, as described below.

First, Sections 2.5.1 through 2.5.6 describe, in general terms, the waste generator of interest, the processes by which the waste was generated, the availability of information for the waste from that generator, and the data-collection approach selected.

Second, information on the assumptions and the sources of information for every waste stream is available on the data forms for the various streams. As discussed in Section 2.7, the data forms have been entered into a database. A printout of the entire contents of the database is provided in Appendix B, Volumes 2 through 5 of this report.

An alphanumeric designator is used to uniquely identify each waste stream. The first part of the designator is a (generally) three-letter code representing the name of the major generator. The second part is a three-digit code representing the building number where all or most of the 
stream originated. The third part is a number representing the sequence of the waste stream identified from the given building. A suffix is added to the end of the waste stream number to indicate if the stream is recent $(\mathrm{R})$ or projected $(\mathrm{P})$. Thus, the designator TRA-603-21R represents the 21st waste stream identified and characterized from Building 603 at TRA; the stream was produced in the recent time period.

The stream numbers for the current study are coordinated with those from the study of the 1952-1983 waste (EG\&G Idaho 1994) in a common database. For example, suppose that building TRA-601 produced three waste streams (TRA-601-1, TRA-601-2, and TRA-601-3) during 1952-1983. If building TRA-601 produced a new waste stream in the recent period, it would be designated TRA-601-4R. If, on the other hand, stream TRA-601-1 continued in the recent period, it would be designated TRA-601-1R. If stream TRA-601-2 was no longer generated in the recent period, no entry for TRA-601-2R would appear. Thus, some gaps appear in the stream numbers during the recent and projected periods.

Information about waste produced at the various generators before 1984 is available in a previous companion report (EG\&G Idaho 1994).

\subsubsection{Test Area North}

The Generator. TAN lies at the north end of the INEL, about 27 mi northeast of the Central Facilities Area (CFA) (see Figure 2-1). TAN was designed and constructed in the early 1950s to support the General Electric Aircraft Nuclear Propulsion (ANP) Program, the mission of which was to test the concept of the nuclear-powered airplane. For a 9-year period, until the program was canceled by the U.S. Congress in 1961, the program was involved in the testing of three versions of a full-scale, nuclear-powered aircraft engine (Wilks 1962). The program support facilities consisted of the Technical Support Facility (TSF), where technical support facility personnel were officed; the Initial Engine Test (IET) Facility; the hot shop, a large hot cell into which the engines could be moved for repair, assembly, and disassembly; and some smaller hot cells, built for the examination of individual irradiated fuel pieces or other irradiated specimens. The IET and hot shop were connected by a double set of rail tracks that allowed the engines to be moved back and forth.

Also located in the TAN area, west of the TSF, was the Loss of Fluid Test (LOFT) Facility, a scaled-down version of a nuclear-powered utility generating station. The Mobile Test Assembly (MTA), which contained the LOFT reactor vessel and the primary coolant system, was mounted on a flat car that could be moved on the double set of rail tracks to the TAN hot shop for repair and disassembly. This facility was used from 1978 through 1985 by the U.S. Nuclear Regulatory Commission (NRC) to conduct tests to determine the validity of nuclear safety codes and to identify critical parameters for accident scenarios. The last two LOFT tests, LP-FP-1 and LP-FP-2, conducted under the auspices of the Organization for Economic Cooperation and Development (OECD) in 1984 and 1985, were accident scenarios to determine the fate of fission products during and after a fuel-damaging accident. The last test, LP-FP-2, was to simulate, to a limited extent, the conditions that existed in the Three Mile Island (TMI) Unit 2 generating station in March 1979. 
The ANP hangar building, TAN-629, was occupied by the Specific Manufacturing Capability (SMC) project starting in 1985. The project produced armor plate for U.S. Army tanks.

After the termination of the ANP Program in 1961, the TAN facilities were used to support the LOFT Program and many miscellaneous projects. In 1984, the commencement of this study period, the LOFT Program was preparing to conduct the LP-FP-1 test; the IET Facility was shut down, with no operations occurring there; and the TAN hot shop was receiving the EPICOR and Submerged Demineralizer System liners from the TMI plant. These vessels, filled with various organic and inorganic resins, had been used to decontaminate the 600,000 gal of highly contaminated water that had leaked to the reactor building basement from the TMI primary coolant system. The TSF supported the LOFT Program and the TMI Support Program. Other facilities (TAN-603, TAN-623, and TAN-653) also supported these two programs. TAN-629 was used as a storage facility in 1984. In the subsequent 10-year period, from 1984 through 1993, various TAN facilities supported the SMC, the TMI fuel/fuel debris receipt and storage for DOE, the Prototypical Consolidation Demonstration Program, the Dry Fuel Cask Storage Program, and many smaller projects.

The activities projected to occur at TAN during the period 1994-2003 are uncertain. However, the TMI fuel/fuel debris and other spent fuel currently stored in the TAN pool is projected to be moved into dry storage at ICPP over the next 6 or 7 years (DOE 1994b). Waste to be generated during this operation will be disposed of at the RWMC (DOE 1994b). Also, SMC will generate some waste.

Generation of the Waste. Most of the waste produced at TAN during the period 1984-1993 was a result of the specific test evaluation and production programs just described.

LOFT conducted the LP-FP-1 test in 1984 (Adams 1985) and the LP-FP-2 test in July 1985 (Adams et al. 1985; Carboneau et al. 1987). Following the LP-FP-2 test, which released a significant amount of fission products from the fuel to the primary coolant system (PCS), the LOFT containment building was stripped of all hardware. The material removed was sent to the RWMC as waste. The rail flat car-mounted MTA, which contained the LOFT reactor vessel and the PCS, had the components removed, including the reactor vessel, and they were sent to the RWMC as waste.

The SMC process used depleted uranium and created a waste stream containing principally sand-blast grit contaminated with depleted uranium.

Operations performed in the hot cells and hot shop complex supported the packaging of TMI abnormal waste and the grouting of Submerged Demineralizer System resin liners into high integrity containers. These operations, which created the most LLW, began just before 1984 and were completed in 1990.

In 1984, the highly contaminated TMI control rod drive screws were received in the hot shop. In addition to the principal operations of grouting of the TMI liner resins, work supporting the LOFT FP-1 and FP-2 center fuel module examinations was performed in the hot cells and hot 
shop. In 1985, Virginia Electric Power Co. fuel, H. B. Robinson fuel, and Peach Bottom fuel were transferred from the shipping casks to dry storage casks. In 1986, the Dry Rod Consolidation Technology Project was demonstrated in the TAN hot cells. In mid-1987, the TMI fuel/fuel debris shipments began to arrive at the TAN hot shop for storage in the TAN pool. This fuel receipt and storage operation continued until mid-1990. All of these activities resulted in the generation of waste.

Since the activities at TAN during 1994-2003 are uncertain, but are expected to be minor in scope, generation of future waste at TAN for disposal at the RWMC is also expected to be minor.

General Availability of Information. TAN waste information is available in RWMIS. TAN hot shop and TAN hot cell logs for the time period are available from the Federal repository and were reviewed. Specific project reports and letters were also sources of information.

For the period 1994-2003, minimal information is available in the waste generator forecasts and a limited number of programmatic documents.

Data-Collection Approach. The general data-collection approach used for the period 1984-1993 involved reviewing the information in RWMIS, facility operating logs, and specific project reports, and interviewing plant personnel.

Some minor incongruities were identified in the record for waste generated at TAN. For example, TAN building designations were not always adhered to when designating where the waste was generated (e.g., LOF-647 was used instead of TAN-647).

Another incongruity at the beginning of the recent period was that, occasionally, a particular facility would send waste to the RWMC that was generated at another facility but labeled as waste from that particular facility. For example, TAN-607 was sending waste from the Water Reactor Research Test Facility (WRRTF) and other locations to the RWMC labeled as TAN-607 waste (Mullen 1994).

For the period 1994-2003, waste generator forecasts, discussions with knowledgeable TAN operations personnel, and a draft environmental assessment (DOE 1994b) were the principal sources of information.

Descriptions of Waste Streams. The TAN waste for 1984-1993 was divided into 12 waste streams (see Table 2-2). Some of these streams were extensions of the waste streams identified in the previous report (EG\&G Idaho 1994) on historical (1952-1983) waste burial.

The TAN waste for 1994-2003 was divided into five waste streams (see Table 2-3). Again, some of these streams are extensions of previous waste streams. 
Table 2-2. Waste streams generated at Test Area North during 1984-1993.

\begin{tabular}{cl}
$\begin{array}{c}\text { Waste stream } \\
\text { number }\end{array}$ & \multicolumn{1}{c}{ Description of waste } \\
\hline TAN-603-2R & Noncompactible waste resulting from sump cleanout operations \\
TAN-607-6R & Hot cell/hot shop waste \\
TAN-623-1R & Sewage sludge \\
TAN-629-1R & Hangar cleanout to prepare for SMC move-in \\
TAN-629-2R & $\begin{array}{l}\text { Sand-blast grit contaminated with depleted uranium and scrap pieces of } \\
\text { depleted uranium from SMC operations }\end{array}$ \\
TAN-630-1R & Compactible waste \\
TAN-647-1R & Unneeded and stored equipment \\
TAN-650-1R & Compactible waste generated following LOFT tests \\
TAN-650-2R & LOFT LP-FP-2 resins \\
TAN-650-3R & LOFT facility parts and systems \\
TAN-668-1R & $\begin{array}{l}\text { Contaminated soil from construction of heavy equipment cleaning facility } \\
\text { at entrance to hot shop }\end{array}$ \\
TAN-DFN-1R & Waste generated in a decontamination facility \\
\hline
\end{tabular}

Table 2-3. Waste streams expected to be generated at Test Area North during 1994-2003.

\begin{tabular}{cl}
\hline $\begin{array}{c}\text { Waste stream } \\
\text { number }\end{array}$ & \multicolumn{1}{c}{ Description of waste } \\
\hline TAN-607-6P & Hot cell/hot shop waste \\
TAN-623-1P & Sewage sludge \\
TAN-629-2P & $\begin{array}{l}\text { Sand-blast grit contaminated with depleted uranium and scrap pieces of } \\
\text { depleted uranium from SMC operations }\end{array}$ \\
TAN-629-3P & $\begin{array}{l}\text { Contact-handled waste for incineration } \\
\text { TAN-629-4P }\end{array}$ \\
\hline
\end{tabular}




\subsubsection{Test Reactor Area}

The Generator. TRA is located approximately $5 \mathrm{mi}$ north of CFA and approximately $2 \mathrm{mi}$ west of ICPP at the INEL (see Figure 2-1). During the recent time period, the major operating facility at TRA has been the Advanced Test Reactor (ATR), which has been in operation since 1969. In addition to the ATR and its support facilities, the following facilities and laboratories have been or are currently operating at TRA:

- Materials Test Reactor (MTR) (1952-1970)

- $\quad$ Engineering Test Reactor (ETR) (1957-1981)

- $\quad$ TRA hot cells (1952 to present)

- Radiation Measurements Laboratory (RML) (1952 to present)

- Nuclear physics laboratories (1953 to present)

- Radiochemistry laboratories (1952 to present)

- Advanced Test Reactor Critical (ATRC) (1968 to present)

- Engineering Test Reactor Critical (ETRC) (1957-1980)

- Reactivity Measurements Facility (RMF) (1956-1960)

- Advanced Reactivity Measurement Facility (ARMF) (1960-1992)

- Gamma facility

- Metallurgical laboratories

- Hydraulics test facility

- Nuclear materials inspection storage facility

- Maintenance shops.

The ATR uses highly enriched uranium (i.e., 93\% U-235 by mass) as its nuclear fuel. The fuel is contained in fuel element assemblies that are composed of multiple fuel plates. The central core of each fuel plate contains a matrix of uranium and aluminum called $\mathrm{UAL}_{\mathrm{x}}$, and is covered by an outer layer of pure aluminum. The reactor core is cooled and neutron-moderated with water. The ATR has a beryllium reflector that surrounds the reactor core. This beryllium is replaced approximately every 6 years; therefore, a large quantity of it has been and will be disposed of at the RWMC. 
Each reactor and each critical facility has a canal that is used for storing irradiated and unirradiated fuel and irradiated experiment assemblies. Irradiated fuel is stored in the facility canal for a cooling period and then shipped to ICPP for processing.

The major role of a test reactor is to test the physical, chemical, and nuclear properties of materials during and after exposure to highly intense neutron/gamma fields. Experiments are placed in the reactor core or in the reflector adjacent to the reactor core. The size of the experiments varies from a small irradiation capsule to a major irradiation loop. The standard loop experiment consists of a pressurized water piping system with its own cleanup system, and is designed to provide the controlled physical and chemical conditions for the test region. Typical conditions that are monitored and controlled include the temperature, pressure, and $\mathrm{pH}$ of the experiment coolant. The major sponsors of the test reactors have been and continue to be the Bettis Atomic Power Laboratory and the Knolls Atomic Power Laboratory, funded by the Naval Reactors Program (NRP) of DOE and its predecessor agencies. Experiments from these users are designed as specified by the sponsor. After completion of the irradiation, the test internals are generally transferred to the sponsor's facilities for disassembly and examination, or to the TRA hot cells.

The ATR (TRA-670) began full-power operation in 1969. Its core is in the shape of a four-leaf clover. There are nine major regions for experiments. The power for each region can be tailored to meet the experimenter's requirements. The maximum power level of the ATR is $250 \mathrm{MW}$; however, it typically operates at a power level of about $125 \mathrm{MW}$. The core loading for the ATR is approximately $40 \mathrm{~kg}$ of U-235. During the recent period, it has been necessary to change the beryllium reflector and core internals approximately every 6 years.

From 1969 to 1992, the ATR was operated almost exclusively for the NRP. Since 1992, there has been some diversity in the experiments conducted in the ATR; however, the NRP still remains the primary user of the facility. In addition to NRP experiments, isotope production experiments and experiments for the New Production Reactor Program have been conducted.

To support reactor safety assurance and experiment needs, the ATR has a critical assembly, ATRC, which is a nuclear mockup of the ATR. The major function of the ATRC is to measure reactor criticality and the effect that experiments would have on criticality. The ATRC operates at low power levels (less than $1 \mathrm{~kW}$ ). At these power levels, the fuel and core structural parts can be handled without the use of remote-handling equipment or shielding.

The RMF and its successor, the ARMF, were designed to be critical assemblies for precisely measuring the neutron cross-section of materials slated for use in or produced by reactors. The RMF was located in the canal of the MTR and used unirradiated MTR fuel elements. It typically operated at less than $100 \mathrm{~W}$. The ARMF replaced the RMF and was located in a separate building (TRA-660) east of the MTR building. The ARMF contains two critical assemblies, ARMF-I and ARMF-II, which share a common canal. In 1969, ARMF-II was reconfigured to support the fast reactor development program. A block of U-238 was placed in the center of the core. After this conversion, the ARMF-II was renamed the Coupled Fast Reactivity Measurement Facility. In 1992, these reactors were placed on temporary inactive status. 
The TRA hot cells have been an integral part of test reactor support operations since the early 1960s. They are used for disassembly and examination of irradiated samples and experiment assemblies from the test reactors. During this period of time, almost all naval loop experiment assemblies were and are shipped to the Expended Core Facility (ECF) at NRF for disassembly and examination following irradiation in the ATR. The TRA hot cells were and are used to support the test reactor non-naval loop experiments. One major support operation was and is the processing of cobalt and iridium produced in the ATR in their isotope production program.

Future operations at TRA are expected to be somewhat different from those of today. The naval loop experiments and isotope production will continue; however, the mix of operations is expected to change.

Generation of the Waste. The waste shipped from TRA to the RWMC comes primarily from the operation of the ATR and the examination of irradiated experiment assemblies in the TRA hot cells. This radioactive waste contains radioactive fission products produced in the nuclear fuel and radionuclides produced by neutron activation. The nuclear fuel-produced radioactivity is typically classified as MFP; however, some activation products are associated with certain fuels. Neutron activation products are typically classified as MAP. The actual distribution of specific nuclides in either MFP or MAP depends on the reactor fuel and the process that generated the waste.

Until 1992, the irradiated fuel was reprocessed at ICPP; since then, it has been placed into storage at ICPP. The irradiated fuel is normally sent as intact assemblies to ICPP. Therefore, only a minor component of the activity produced at the ATR is left at TRA. This component is the result of fission products leaking through the reactor fuel cladding into the reactor coolant. Once in the coolant, the fission products can potentially contaminate all items in contact with the coolant. This includes materials inside the reactor vessel, and pipes, pumps, and cleanup systems associated with the primary coolant.

In addition to fuel leakage, there can also be leakage of radioactivity from the fueled experiments. This primarily contaminates the experiment coolant and cleanup system, and secondarily contaminates the main reactor coolant. When these experiments are disassembled in the TRA hot cells, the irradiated components and the handling equipment, along with rags, etc., are contaminated and become waste.

The filters in the reactor and hot cell ventilation systems also contain some of the fission products produced in the reactor fuel and fueled experiments. Although the reactors are water-cooled, there have been experiments in which the coolant has been gaseous. In those cases, the filters from cleanup systems of those experiments were contaminated and eventually sent to the RWMC.

Activation products are produced when neutrons are captured or otherwise interact to produce radionuclides. Neutron interactions can occur in the reactor fuel, and the radionuclides are carried along with the fission products. Neutrons can also interact with reactor and experiment structural components, resulting in radionuclides becoming fixed contamination in those components and also through corrosion in the reactor or experiment coolant. Once in the coolant system, the radionuclides can potentially contaminate the same items as the fission 
products. Therefore, for radioactive waste generated by test reactor operations and support activities, there will be a mixture of fission products and activation products.

In addition to fission products and activation products, TRU radionuclides are produced in a reactor. These radionuclides are produced by multiple neutron capture events, combined with beta and alpha decay. The test reactors were used to produce minor amounts of TRU radionuclides, generally in the microcurie range. Most TRU radionuclides not bound in reactor fuel were brought here from offsite producers.

The hot cells are the second largest generator of waste at TRA. In addition to experiments in the test reactors, the TRA hot cells have been used to process experiments performed outside TRA. These include the severe fuel damage experiments performed at the Power Burst Facility (PBF) and fuel samples from the damaged TMI-2 reactor. The PBF and TMI fuel contains lowenriched uranium (approximately $4 \%$ U-235 by mass). The radionuclide distributions in these fuels are different from those in the test reactor fuels. In addition, the activation products due to the zircaloy cladding are different from activation products generated by test reactors.

Almost all items removed from the hot cells are considered to be radioactive. If there is no further need for these items, they are classified as radioactive waste.

The critical facilities (i.e., ATRC and ARMF) contribute small amounts of radioactive waste, most of which is carried into the facilities on samples and experiments from the test reactors or from non-TRA facilities. In most cases, the mix between fission products and activation products is about the same as that found for the test reactors.

The radiochemistry and physics laboratories at TRA handle small quantities of radioactive materials as part of their research, typically on the order of microcuries to millicuries. The hot cell and the californium cell in the alpha wing (TRA-661) are possible exceptions. The radiochemistry programs have used the alpha-wing hot cell for the separation of transuranics and other research efforts. The californium cell contains microgram amounts of Cf-252 used to produce nanocurie amounts of fission products for nuclear decay measurements. The alpha-wing solid waste has higher concentrations of alpha-emitters from the decay of TRU nuclides. The remainder of the radiochemistry and physics laboratories generate waste similar in content to reactor plant waste.

The gamma facility operating during this time period uses irradiated fuel elements from the ATR and is located in the ATR canal. Waste from this gamma facility is included with the ATR canal waste.

Radioactive liquid waste from TRA was disposed of in the TRA waste retention basins (if low to moderate activity) or sent to ICPP for processing (if moderate to high activity).

With respect to nonradiological contaminants in TRA waste sent to the RWMC, the major generator was the ATR. The primary contaminant is beryllium. This waste is generated when a reactor reflector is replaced. 
The following are examples of waste streams sent to the RWMC from TRA:

- Ion-exchange resins used in the reactor coolant systems

- Core and experiment loop components constructed of aluminum or stainless steel; they generally contain activation products

- Contaminated rags and floor sweepings

- Contaminated concrete, bricks, and wood

- Irradiated beryllium from the reactor reflector changeouts

- Contaminated sludge from the resin beds, etc.

Waste to be generated from 1994-2003 is expected to be similar to that generated from 1984-1993.

General Availability of Information. The main sources of data pertaining to waste shipments from TRA in the period 1984-1993 are RWMIS and selected technical reports and letters. The RWMIS values and those in annual waste management reports for 1984-1993 agree reasonably well.

Projections for waste expected to be shipped from TRA in the period 1994-2003 are available in a letter (Keating 1993). The letter forecasts waste volumes, total activities, and radionuclide distributions for various waste streams.

Data-Collection Approach. The approach selected for data collection for TRA waste for the period 1983-1994 was to use RWMIS entries and shipping records for the waste volumes and radioactivity. These sources were then supplemented with other information sources as necessary to develop or refine the radionuclide distributions. The other sources were various reports referenced herein, as well as nuclear physics considerations and calculations.

Reports and shipping records provide varying degrees of completeness in specifying radionuclide distributions. The following information describes how the available records and reports were combined with nuclear physics evaluations to project a reasonably complete distribution of radionuclides having the appropriate total amount of radioactivity.

Table 2-4 is the master list of radionuclides considered in estimating the nuclide-by-nuclide activity breakdown of the waste generated at TRA. This list is a composite based on (a) a performance assessment of dose at the RWMC performed in 1993, (b) the reporting requirements imposed by the NRC on waste from operating commercial power reactors (10 CFR 61), and (c) their expected importance in TRA waste. Based on an activity buildup calculation using the ORIGEN2 computer code (Graff 1980; Schnitzler 1994) for a typical ATR fuel element irradiation history, the activity for any radionuclide with an atomic number or mass greater than that of $\mathrm{Cm}-244$ is too weak to be reportable and is not included. 
Table 2-4. Master list of radionuclides evaluated for waste from the Test Reactor Area.

\begin{tabular}{|c|c|c|c|c|}
\hline Nuclide & $\begin{array}{c}\text { Half-life }^{\mathrm{a}} \\
\text { (years) }\end{array}$ & $\begin{array}{l}\text { Decay } \\
\text { mode }\end{array}$ & $\begin{array}{l}\text { Fission } \\
\text { product }\end{array}$ & $\begin{array}{c}\text { Activation } \\
\text { product }\end{array}$ \\
\hline Am-241 & 433 & $\alpha$ & - & $\mathrm{X}$ \\
\hline C-14 & $5.7 \times 10^{3}$ & $\beta$ & - & $x$ \\
\hline Ce-144 & 0.78 & $\beta+\gamma$ & $\mathrm{X}$ & - \\
\hline Co- 60 & 5.3 & $\beta+\gamma$ & - & $\mathrm{X}$ \\
\hline $\mathrm{Cm}-242$ & 0.45 & $\alpha$ & - & $\mathrm{X}$ \\
\hline $\mathrm{Cm}-244$ & 18.1 & $\alpha$ & - & $\mathrm{X}$ \\
\hline Cs-137 & 30.2 & $\beta+\gamma$ & $\mathrm{X}$ & - \\
\hline Fe-55 & 2.73 & $\beta$ & - & $X$ \\
\hline Eu-152 & 13.5 & $\beta+\gamma$ & $\mathrm{X}$ & - \\
\hline Eu-154 & 8.6 & $\beta+\gamma$ & $\mathrm{x}$ & - \\
\hline Eu-155 & 4.7 & $\beta+\gamma$ & $\mathrm{X}$ & - \\
\hline $\mathrm{H}-3$ & 12.3 & $\beta$ & $\mathrm{X}$ & $\mathrm{X}$ \\
\hline I-129 & $1.6 \times 10^{7}$ & $\beta+\gamma$ & $\mathrm{x}$ & - \\
\hline Nb-94 & $2.0 \times 10^{4}$ & $\beta$ & - & $\mathrm{X}$ \\
\hline Ni-59 & $7.6 \times 10^{4}$ & $\beta$ & - & $\mathrm{X}$ \\
\hline $\mathrm{Ni}-63$ & 100 & $\beta$ & - & $X$ \\
\hline Np-237 & $2.1 \times 10^{6}$ & $\alpha$ & - & $\mathrm{X}$ \\
\hline Pu-238 & 87.7 & $\alpha$ & - & $X$ \\
\hline Pu-239 & $2.4 \times 10^{4}$ & $\alpha$ & - & $X$ \\
\hline $\mathrm{Pu}-240$ & $6.6 \times 10^{3}$ & $\alpha, \mathrm{sf}$ & - & $\mathrm{X}$ \\
\hline
\end{tabular}


Table 2-4. (continued).

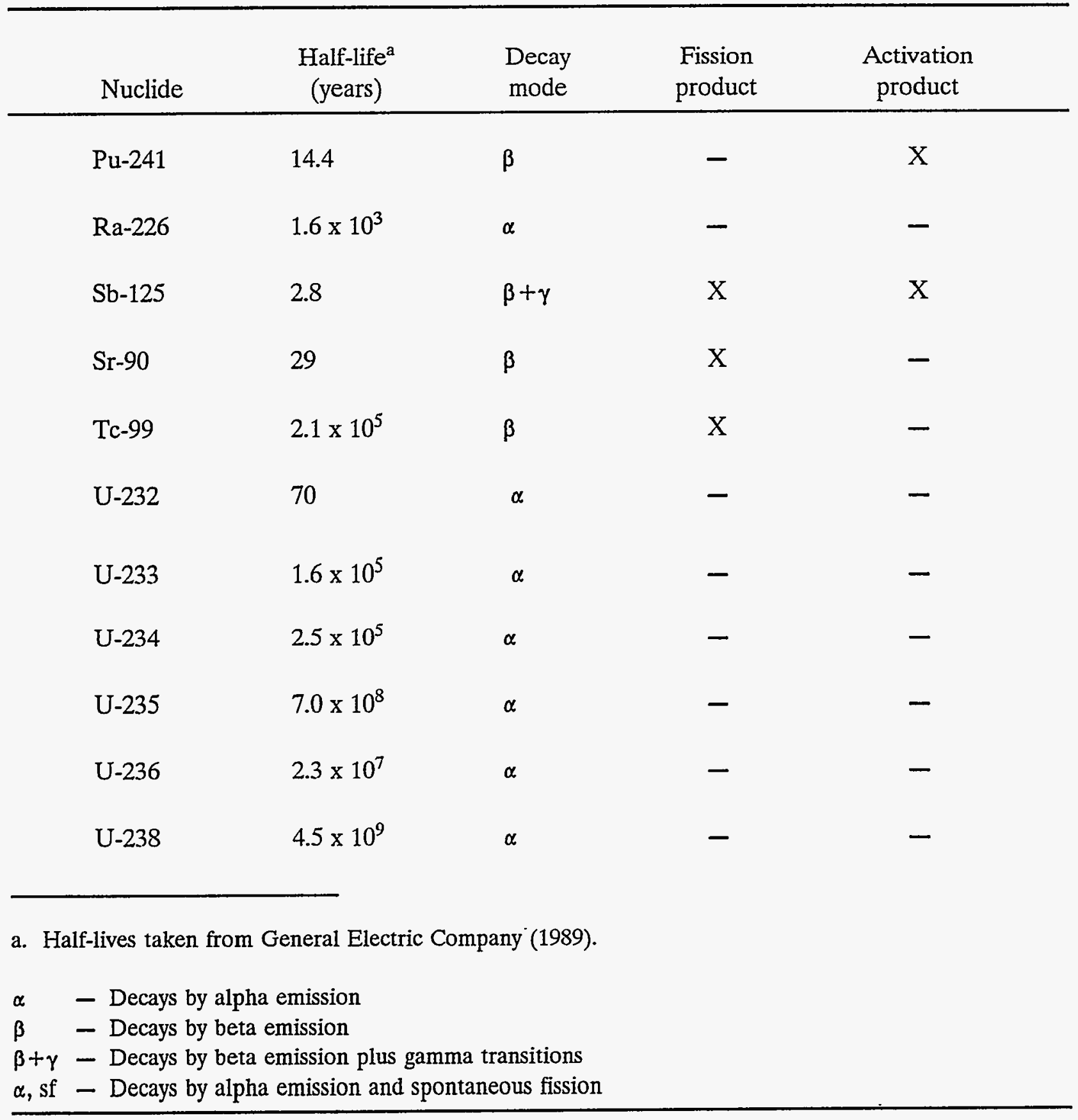


Radioactive waste generated at TRA has been reported as individual nuclides, MFP, MAP, unidentified beta-gamma, or unidentified alpha. Most waste streams or waste generation processes at TRA contain all types of activity; however, the relative mix differs. Because there are different mixes, it was decided that the waste should be categorized according to the generator mode or generic content, rather than by activity. Based on a review of commercial power plant waste reports (e.g., EPRI 1987), three general categories of waste were identified by analogy for TRA:

- Dry radioactive waste not otherwise specified

- $\quad$ Sludge

- Reactor coolant resin.

The radionuclides for each of the waste categories and the respective activity scaling factors (radioactivity distributions; see Section 5.4.3 for a more detailed discussion) for each waste category are listed in Tables 2-5 through 2-7. INEL data for the scaling factors of difficult-tomeasure radionuclides in TRA waste are limited. Therefore, many of the scaling factors for these radionuclides were taken from data gathered (EPRI 1987) on commercial nuclear power reactors. There are limitations in applying those data to waste from INEL test reactors, but these data are the most applicable data that are available.

The scaling factors are based on fractional activities consistent with the assumption that measurement of total activity via the G-M method would include only gamma activity. (The G-M method and its limitations are discussed in detail in Section 5.) The approach followed to generate tables for which more than one data source was used is described in Harker and Akers (1994) and in Harker (1995a).

For the years 1984-1993, annual reports, topical reports, and letters that indicate waste-generating activities, as well as RWMIS, were used. The following approach was used:

- Reports containing nuclide-by-nuclide distributions. The individual activities, as they are listed in the report, were used. In most cases, if an error was not stated, an assumed measurement error was assigned.

- $\quad$ Reports containing nuclide-by-nuclide distributions plus MAP, MFP, unidentified beta-gamma, and/or unidentified alpha. The waste was identified as one of the three waste categories listed above. The MAP, MFP, and beta-gamma activities were summed to get a total activity of overall gamma-emitters. A nuclide-by-nuclide distribution was calculated based on this total gamma activity and the corresponding activity scaling factors for that waste category. The explicit nuclide distribution, the calculated waste category nuclide distribution, and the calculated alpha nuclide distribution were all added as separate tables. 
Table 2-5. Nuclides and activity scaling factors for dry radioactive waste from the Test Reactor Area.

\begin{tabular}{|c|c|c|}
\hline Nuclide & $\begin{array}{l}\text { Activity } \\
\text { scaling } \\
\text { factor }\end{array}$ & Data source \\
\hline $\mathrm{H}-3^{\mathrm{b}}$ & $8.2 \times 10^{-2}$ & EPRI $(1987)^{c}$ \\
\hline C-14 & $1.1 \times 10^{-3}$ & EPRI $(1987)^{c}$ \\
\hline $\mathrm{Fe}-55$ & 1.9 & EPRI (1987) ${ }^{\mathrm{c}}$ \\
\hline Co- 60 & $6.7 \times 10^{-1}$ & EPRI $(1987)^{c}$ \\
\hline $\mathrm{Ni}-59$ & $5.7 \times 10^{-4}$ & Evans et al. (1984) ${ }^{d}$ \\
\hline $\mathrm{Ni}-63$ & $3.2 \times 10^{-1}$ & $\operatorname{EPRI}(1987)^{\mathrm{c}}$ \\
\hline Sr-90 & $9.2 \times 10^{-4}$ & $\operatorname{EPRI}(1987)^{c}$ \\
\hline Tc-99 & $1.8 \times 10^{-4}$ & EPRI $(1987)^{c}$ \\
\hline $\mathrm{I}-129$ & $4.4 \times 10^{-8}$ & Harker $(1995 b)^{e}$ \\
\hline Cs-137 & $2.0 \times 10^{-1}$ & EPRI $(1987)^{c}$ \\
\hline Ce-144 & $4.7 \times 10^{-3}$ & EPRI $(1987)^{c}$ \\
\hline $\mathrm{Eu}-154$ & $2.9 \times 10^{-6}$ & Evans et al. (1984) ${ }^{\mathrm{d}}$ \\
\hline $\mathrm{Eu}-155$ & $9.4 \times 10^{-3}$ & Graff (1980) and Schnitzler (1994) \\
\hline U-234 & $2.1 \times 10^{-6}$ & Graff (1980) and Schnitzler (1994) \\
\hline U-235 & $4.5 \times 10^{-8}$ & Graff (1980) and Schnitzler (1994) \\
\hline U-236 & $8.0 \times 10^{-7}$ & Graff (1980) and Schnitzler (1994) \\
\hline Np-237 & $1.2 \times 10^{-6}$ & Graff (1980) and Schnitzler (1994) \\
\hline Pu-238 & $5.4 \times 10^{-5}$ & EPRI $(1987)^{c}$ \\
\hline Pu-239 & $5.4 \times 10^{-5}$ & EPRI $(1987)^{c}$ \\
\hline $\mathrm{Pu}-240$ & $5.6 \times 10^{-6}$ & Graff (1980) and Schnitzler (1994) \\
\hline $\mathrm{Pu}-241$ & $5.9 \times 10^{-3}$ & EPRI $(1987)^{c}$ \\
\hline
\end{tabular}


Table 2-5. (continued).

\begin{tabular}{lll}
\hline & $\begin{array}{c}\text { Activity } \\
\text { scaling } \\
\text { factor }\end{array}$ & \multicolumn{1}{c}{ Data source } \\
\hline Nuclide & $2.7 \times 10^{-5}$ & EPRI (1987) \\
Am-241 & $2.7 \times 10^{-5}$ & EPRI (1987) ${ }^{\mathrm{c}}$ \\
Cm-242 & $2.5 \times 10^{-5}$ & EPRI (1987) \\
Cm-244 & &
\end{tabular}

a. It was assumed that the measured activity was determined by a predominantly gamma-sensitive device (e.g., G-M counter, NaI scintillation detector). As such, only gamma activity was reported. However, there were cases where the gamma activity was increased to account for the beta-emitters. This correction was not universally applied and, in many cases, not even noted. To be conservative, it was assumed that the reported activity (MAP, MFP, unidentified beta-gama) includes only gamma activity. The scaling factors listed in this table have taken the beta activity into account. Therefore, the sum of the scaling factors is a number greater than unity. The difference between the sum and unity is the relative beta activity. See Harker (1995a) for details on how the scaling factors were derived.

b. There is a question as to whether tritium is present at the fraction indicated in this table for all dry waste. It is present in dry waste that has direct contact with the reactor coolant and, in some cases, where there has been secondary contact. The tritium scaling factor listed in this table represents a history of experience with pressurized water reactors and should give numbers that are valid on the average. However, in those cases where there was evidence that tritium was not present or was present in much lower concentrations, the scaling factor for tritium in the table was not used. A note to this effect was placed with that data entry.

c. Dry active waste generated by all commercial pressurized water reactors in the United States.

d. Activation products in 304 stainless steel.

e. The factor was based on the ratio of I-131 activity to Cs-137 activity in ATR primary coolant water and on ratios of I-129, I-131, and Cs-137 activities calculated with ORIGEN2.

f. ORIGEN2 calculation based on irradiating an ATR fuel element for 85 days at $8 \mathrm{MW}$ per element and allowing it to decay for 1 year. 
Table 2-6. Nuclides and activity scaling factors for sludge waste from the Test Reactor Area.

\begin{tabular}{|c|c|c|}
\hline Nuclide & $\begin{array}{c}\text { Activity } \\
\text { scaling } \\
\text { factor }\end{array}$ & Data source \\
\hline $\mathrm{H}-3^{\mathrm{b}}$ & $1.0 \times 10^{-1}$ & EPRI $(1987)^{c}$ \\
\hline C-14 & $1.0 \times 10^{-2}$ & EPRI (1987) ${ }^{c}$ \\
\hline Fe-55 & $7.7 \times 10^{-1}$ & EPRI (1987) \\
\hline Co- 60 & $8.7 \times 10^{-1}$ & EPRI (1987) ${ }^{c}$ \\
\hline $\mathrm{Ni}-59$ & $4.0 \times 10^{-3}$ & $\operatorname{Resin}^{\mathrm{d}}$ \\
\hline $\mathrm{Ni}-63$ & $3.2 \times 10^{-1}$ & EPRI (1987) \\
\hline Sr-90 & $6.4 \times 10^{-4}$ & EPRI $(1987)^{c}$ \\
\hline Tc-99 & $1.1 \times 10^{-4}$ & EPRI (1987) ${ }^{c}$ \\
\hline $\mathrm{I}-129$ & $3.0 \times 10^{-8}$ & Harker $(1995 b)^{e}$ \\
\hline Cs-137 & $1.3 \times 10^{-1}$ & EPRI $(1987)^{c}$ \\
\hline Ce-144 & $4.2 \times 10^{-2}$ & EPRI (1987) \\
\hline Eu-154 & $3.1 \times 10^{-3}$ & $\operatorname{Resin}^{d}$ \\
\hline Eu-155 & $1.3 \times 10^{-3}$ & $\operatorname{Resin}^{\mathrm{d}}$ \\
\hline U-234 & $2.2 \times 10^{-6}$ & $\operatorname{Resin}^{d}$ \\
\hline U-235 & $4.8 \times 10^{-8}$ & $\operatorname{Resin}^{d}$ \\
\hline U-236 & $8.5 \times 10^{-7}$ & $\operatorname{Resin}^{\mathrm{d}}$ \\
\hline Np-237 & $1.3 \times 10^{-6}$ & $\operatorname{Resin}^{\mathrm{d}}$ \\
\hline $\mathrm{Pu}-238$ & $3.3 \times 10^{-5}$ & EPRI (1987) \\
\hline $\mathrm{Pu}-239$ & $3.4 \times 10^{-5}$ & EPRI (1987) ${ }^{c}$ \\
\hline $\mathrm{Pu}-240$ & $2.1 \times 10^{-5}$ & $\operatorname{Resin}^{\mathrm{d}}$ \\
\hline $\mathrm{Pu}-241$ & $3.7 \times 10^{-3}$ & EPRI $(1987)^{c}$ \\
\hline
\end{tabular}


Table 2-6. (continued).

\begin{tabular}{lll}
\hline Nuclide & $\begin{array}{c}\text { Activity } \\
\text { scaling } \\
\text { factor }\end{array}$ & \multicolumn{1}{c}{ Data source } \\
\hline Am-241 & $1.4 \times 10^{-5}$ & EPRI (1987) \\
Cm-242 & $2.7 \times 10^{-5}$ & EPRI (1987) \\
Cm-244 & $1.3 \times 10^{-5}$ & EPRI (1987) \\
U-238 & $2.9 \times 10^{-9}$ & Graff (1980) and Schnitzler (1994)
\end{tabular}

a. It was assumed that the measured activity was determined by a predominantly gamma-sensitive device (e.g., G-M counter, NaI scintillation detector). As such, only gamma activity was reported. However, there were cases where the gamma activity was increased to account for the beta-emitters. This correction was not universally applied and, in many cases, not even noted. To be conservative, it was assumed that the reported activity (MAP, MFP, unidentified beta-gama) includes only gamma activity. The scaling factors listed in this table have taken the beta activity into account. Therefore, the sum of the scaling factors is a number greater than unity. The difference between the sum and unity is the relative beta activity. See Harker (1995a) for details on how the scaling factors were derived.

b. There is a question as to whether tritium is present at the fraction indicated in this table for all dry waste. It is present in dry waste that has direct contact with the reactor coolant and, in some cases, where there has been secondary contact. The tritium scaling factor listed in this table represents a history of experience with pressurized water reactors and should give numbers that are valid on the average. However, in those cases where there was evidence that tritium was not present or was present in much lower concentrations, the scaling factor for tritium in the table was not used. A note to this effect was placed with that data entry.

c. Sludge waste generated by all commercial pressurized water reactors in the United States.

d. Activities relative to Co-60 (for Ni-59), to Cs-137 (for Eu-154, Eu-155, U-234, U-235, U-236, Np-237), or to Pu-239 (for Pu-240) are assumed to be the same as those listed for resins (see Table 2-7).

e. The factor was based on the ratio of I-131 activity to Cs-137 activity in ATR primary coolant water and on ratios of I-129, I-131, and Cs-137 activities calculated with ORIGEN2.

f. ORIGEN2 calculation based on an ATR fuel element irradiated for 85 days at $8 \mathrm{MW}$ per element and allowed to decay for 1 year. Activity is scaled to Pu-239 activity as measured by gamma spectrometry. 
Table 2-7. Nuclides and activity scaling factors for reactor coolant resin from the Test Reactor Area.

\begin{tabular}{|c|c|c|}
\hline Nuclide & $\begin{array}{l}\text { Activity }^{\mathrm{a}} \\
\text { scaling } \\
\text { factor }\end{array}$ & Data source \\
\hline $\mathrm{H}-3$ & $5.0 \times 10^{-4}$ & $\mathrm{ATR}^{\mathrm{b}}$ \\
\hline $\mathrm{C}-14$ & $4.3 \times 10^{-3}$ & $\operatorname{EPRI}(1987)^{c}$ \\
\hline $\mathrm{Fe}-55$ & $2.0 \times 10^{-1}$ & EPRI (1987) \\
\hline $\mathrm{Ni}-59$ & $2.8 \times 10^{-3}$ & $\mathrm{ATR}^{\mathrm{b}}$ \\
\hline $\mathrm{Ni}-63$ & $2.8 \times 10^{-1}$ & $\mathrm{ATR}^{\mathrm{b}}$ \\
\hline Co-60 & $6.8 \times 10^{-1}$ & $\mathrm{ATR}^{\mathrm{b}}$ \\
\hline Sr-90 & $2.8 \times 10^{-1}$ & $\mathrm{ATR}^{\mathrm{b}}$ \\
\hline Tc-99 & $1.5 \times 10^{-5}$ & $\mathrm{ATR}^{\mathrm{b}}$ \\
\hline $\mathrm{I}-129$ & $6.8 \times 10^{-8}$ & Harker $(1995 b)^{d}$ \\
\hline Cs-137 & $3.1 \times 10^{-1}$ & $\mathrm{ATR}^{\mathrm{b}}$ \\
\hline Ce-144 & $6.7 \times 10^{-3}$ & $\mathrm{ATR}^{\mathrm{b}}$ \\
\hline Eu-154 & $7.3 \times 10^{-3}$ & $\mathrm{ATR}^{\mathrm{b}}$ \\
\hline Eu-155 & $3.1 \times 10^{-3}$ & $\mathrm{ATR}^{\mathrm{b}}$ \\
\hline U-234 & $4.2 \times 10^{-6}$ & Graff (1980) and Schnitzler (1994) \\
\hline U-235 & $9.2 \times 10^{-8}$ & Graff (1980) and Schnitzler (1994) \\
\hline U-236 & $1.6 \times 10^{-6}$ & Graff (1980) and Schnitzler (1994) \\
\hline Np-237 & $2.6 \times 10^{-6}$ & Graff (1980) and Schnitzler (1994) \\
\hline $\mathrm{Pu}-238$ & $1.8 \times 10^{-4}$ & $\mathrm{ATR}^{\mathrm{b}}$ \\
\hline Pu-239 & $4.6 \times 10^{-5}$ & $\mathrm{ATR}^{\mathrm{b}}$ \\
\hline Pu-240 & $2.8 \times 10^{-5}$ & Graff (1980) and Schnitzler $(1994)^{\mathrm{e}}$ \\
\hline $\mathrm{Pu}-241$ & $1.5 \times 10^{-2}$ & $\mathrm{ATR}^{\mathrm{b}}$ \\
\hline
\end{tabular}


Table 2-7. (continued).

\begin{tabular}{|c|c|c|}
\hline Nuclide & $\begin{array}{l}\text { Activity } \\
\text { scaling } \\
\text { factor }\end{array}$ & Data source \\
\hline Am-241 & $4.2 \times 10^{-3}$ & $\operatorname{ATR}^{b}$ \\
\hline $\mathrm{Cm}-242$ & $2.8 \times 10^{-4}$ & $\mathrm{ATR}^{\mathrm{b}}$ \\
\hline $\mathrm{Cm}-244$ & $1.3 \times 10^{-4}$ & $\mathrm{ATR}^{\mathrm{b}}$ \\
\hline
\end{tabular}

a. It was assumed that the measured activity was determined by a predominantly gamma-sensitive device (e.g., G-M counter, NaI scintillation detector). As such, only gamma activity was reported. However, there were cases where the gamma activity was increased to account for the beta-emitters. This correction was not universally applied, and in many cases, not even noted. To be conservative, it was assumed that the reported activity (MAP, MFP, unidentified beta-gama) includes only gamma activity. The scaling factors listed in this table have taken the beta activity into account. Therefore, the sum of the scaling factors is a number greater than unity. The difference between the sum and unity is the relative beta activity. See Harker (1995a) for details on how the scaling factors were derived.

b. Activities scaled to Cs-137 (for H-3, Sr-90, Tc-99, Eu-154, Eu-155), to Co-60 (for Ni-59, Ni-63), or to Pu-239 (for Pu-238, Pu-241, Am-241, Cm-242, Cm-244) as measured for ATR resin shipment 92026 (see Harker and Akers 1994) are assumed to be representative for all resin shipments.

c. Assumed reactor coolant resin C-14 activity relative to Co-60 as reported for pressurized water reactors is representative of the ATR resin C-14 to Co-60 activity ratio.

d. The factor was based on the ratio of I-131 activity to Cs-137 activity in ATR primary coolant water and on ratios of I-129, I-131, and Cs-137 activities calculated with ORIGEN2.

e. ORIGEN2 calculation based on an ATR fuel element irradiated for 85 days at $8 \mathrm{MW}$ per element and allowed to decay for 1 year. Activity is scaled to $\mathrm{Pu}-239$ activity as measured by gamma spectrometry. 
As the preceding and following discussions imply, radionuclide distributions were developed from process knowledge and nuclear physics calculations for each category of waste stream. Therefore, no single, uniform assumption was used for the distribution of generic radioactivity terms such as MAP and MFP in shipping records.

It is noted that, for some TRA waste streams, two entries for the same radionuclide in the same year appear on the datasheets. In such cases, the bounds are different on the different entries because parts of the total activity were determined by different methods. For example, one entry for Cs-137 in a given stream for a given year was obtained from laboratory measurements. Another entry for Cs-137 for the same stream and year was obtained by distributing a MFP term using scaling factors.

The approach selected for data collection for TRA waste for the period 1994-2003 was to use one of two methods, depending on the waste stream. Either (a) the activity values in the generator forecast (Keating 1993) were used, or (b) the RWMIS values for the recent period (1984-1993) were used to obtain the average annual activity and this value was assumed to apply also for the projected waste. The INEL D\&D Long-Range Plan (Buckland et al. 1993) was also used as an information source for waste to be generated by D\&D activities at TRA.

Description of Waste Streams. The TRA waste for 1984-1993 was divided into 14 waste streams (see Table 2-8). Many of these streams were extensions of some of the waste streams identified in the previous report on historical (1952-1983) waste burial.

The TRA waste for 1994-2003 was divided into eight waste streams (see Table 2-9), including three streams of D\&D waste from TRA. Again, many of these streams are extensions of previous waste streams.

\subsubsection{Idaho Chemical Processing Plant}

The Generator. ICPP is located near the center of the INEL between CFA and TRA (see Figure 2-1). The primary purpose of this facility was to recover U-235 from expended military and test reactor fuels.

The facility originally included a process building containing dissolvers to dissolve the fuel assemblies in nitric and hydrofluoric acids, and a solvent extraction system that used tributyl phosphate, hexone, and nitric acid to recover the uranium. Laboratory, water treatment, and evaporator facilities were also part of the complex. A storage pool, housed in a separate building, to store the fuel under water until a processing campaign was underway was also part of the system.

In the early 1960s, a fluidized bed waste calciner was constructed and operated to convert the highly radioactive liquid waste, resulting from processing the fuel, to a dry, granular, solid. This was replaced by the New Waste Calcining Facility (NWCF) in the late 1970s.

Also, in the early 1970s, an improved and larger fuel storage pool was constructed and placed into operation. About 1973, a new building was joined onto the original fuel storage facility to store dry graphite-type fuel, for which no uranium recovery process existed. 
Table 2-8. Waste streams generated at the Test Reactor Area during 1984-1993.

\begin{tabular}{|c|c|}
\hline $\begin{array}{l}\text { Waste stream } \\
\text { number }\end{array}$ & Description of waste \\
\hline TRA-603-1R & Resins \\
\hline TRA-603-4R & Core and loop components \\
\hline TRA-603-6R & Sludge \\
\hline TRA-603-7R & Glass \\
\hline TRA-603-15R & Metal (aluminum, stainless steel, etc.) \\
\hline TRA-603-18R & Rags, floor sweepings, and glassware \\
\hline TRA-603-21R & Construction materials, concrete, brick, sand, soil, and asphalt \\
\hline TRA-603-26R & Lead \\
\hline TRA-603-27R & Noncompactible waste such as glass and metal \\
\hline TRA-603-28R & $\begin{array}{l}\text { Combination of glass, halogenated plastic, absorbed liquid, metal chips, } \\
\text { wire, etc. }\end{array}$ \\
\hline TRA-632-2R & $\begin{array}{l}\text { Hot cell waste consisting of small amounts of metal, glassware, plastic } \\
\text { bottles, etc. }\end{array}$ \\
\hline TRA-632-3R & Absorbed liquids \\
\hline TRA-642-7R & Various combustible materials such as paper, wood, plastic, rags, and wipes \\
\hline TRA-670-1R & Beryllium reflectors from the ATR \\
\hline
\end{tabular}


Table 2-9. Waste streams expected to be generated at the Test Reactor Area during 1994-2003.

Waste stream number

Description of waste

$\begin{array}{ll}\text { TRA-603-1P } & \text { Resins } \\ \text { TRA-603-4P } & \text { Core and loop components } \\ \text { TRA-603-15P } & \text { Metal (aluminum, stainless steel, etc.) } \\ \text { TRA-603-27P } & \text { Noncompactible waste such as glass and metal } \\ \text { TRA-670-1P } & \text { Beryllium reflectors from the ATR } \\ \text { D+DTRA-603-1P } & \text { Construction material such as soil, concrete, and rubble } \\ \text { D+DTRA-603-2P } & \text { Metal (aluminum, stainless steel, etc.) } \\ \text { D+DTRA-603-3P } & \text { Noncompactible waste such as glass and metal }\end{array}$

During the period 1984-1993, expended fuels were received, stored, and processed, and the liquid waste was calcined. The dry, granular solids produced by calcination were stored in underground, stainless-steel bins, where they will remain until a process is developed to convert these solids to a nonleachable form, such as a glass, and the resulting product is placed in a permanent repository.

In 1992, a decision was made by DOE to discontinue processing of all fuels at ICPP. Currently and in the projected period (1994-2003), the principal operations at ICPP are limited to the storage of fuel and the calcination of high-level liquid waste.

A project is underway to move all of the fuel stored in the old fuel storage basin to the newer fuel storage basin. Also, efforts are underway to develop a flowsheet to calcine the stored, sodium-containing, liquid waste, which cannot be calcined using the flowsheet developed for the aluminum- and zirconium-containing waste calcined in the past. If calcination cannot be accomplished, it will be necessary to develop an alternative method to solidify the sodium-containing waste. New projects are being considered for implementation as the mission of ICPP changes.

Generation of the Waste. Most of the radioactive waste produced at ICPP remains in storage at that facility. Raffinates resulting from the dissolution and recovery of uranium from the expended nuclear fuels, waste solutions resulting from the decontamination of process cells and equipment, and waste solutions produced by concentrating radioactive liquids in the process equipment waste evaporator are stored in underground stainless-steel tanks. This waste is later processed in the fluidized bed calciner at ICPP to convert the liquid to a granular solid. The solids are stored in underground, stainless-steel bins. 
The processing of irradiated fuels produced thousands of gallons of high-level radioactive liquid waste containing several million curies of radionuclides. These radionuclides are nearly all retained at ICPP, either as liquid waste stored in the underground stainless-steel tanks or as granular solids stored in the underground stainless-steel bins, where they are being depleted slowly by radioactive decay.

LLW is generated routinely from cleanup operations, equipment modifications and replacement, and decontamination of equipment. This waste includes blotting paper, rags, anti-contamination clothing, plastic bags, glassware, rubber gloves, metal structural materials (usually stainless steel), filters, roofing materials, asphalt, concrete, wood, and occasionally metal vessels, and casks and fuel storage racks that have been decontaminated to a low level of radioactivity. No fuel end boxes, which contributed the majority of radioactivity sent from ICPP to the RWMC at an earlier date, were disposed of during this time period (1984-1993).

Although changes in the mission of ICPP may produce different kinds of high-level radioactive waste in the period 1994-2003, this waste very likely will be stored at ICPP for some time. The waste that will be shipped from ICPP to the RWMC will probably not be substantially different from that produced in the 1984-1993 period. It will probably consist of cleanup materials such as rags and blotting paper, and construction materials such as steel and concrete from decontamination and decommissioning operations and modifications to existing structures.

General Availability of Information. The primary source of information available for the ICPP waste is the RWMIS printouts for 1984-1993, and technical note printouts compiled from the RWMIS records for the same time period. These technical note printouts summarized the RWMIS values for all of the waste shipments from each building. They provided the total curies, radionuclide distribution, type of container, volume, and weight. A content code that described the type of material in each waste shipment was also available from RWMIS records for each building.

Projections for waste expected to be shipped from ICPP in the period 1994-2003 are available primarily from ICPP solid radioactive waste forecasts. These forecasts are essentially extensions for waste resulting from existing or planned operations, and could change substantially as the mission of ICPP changes.

Data-Collection Approach. The approach to collect data for the period 1984-1993 was to obtain RWMIS technical note printouts for each building at ICPP, and to record the volume, total curies, amounts of various radionuclides, and type of waste container used for each building. Then, the content codes for the waste from each building were obtained from the RWMIS records, and the description of the waste was obtained by using these content codes. Contacts with knowledgeable individuals were made to provide additional detail about the waste.

Data for the projected waste (1994-2003) were obtained from the solid radioactive waste forecasts for ICPP. Curie values for the individual radionuclides were obtained from these forecasts. The waste descriptions were obtained either from the forecasts or from individuals who prepared the forecasts. 
Description of Waste Streams. The ICPP waste for the period 1984-1993 was divided into eight waste streams (see Table 2-10).

One waste stream is expected to be produced at ICPP for the period 1994-2003 (see Table 2-11).

\subsubsection{Naval Reactors Facility}

The Generator. NRF is located in the western part of the INEL about 14 mi northnortheast of the RWMC (see Figure 2-1).

NRF was established in 1950 when construction began on the prototype power plant for the U.S. Navy's first nuclear-powered submarine, the USS NAUTILUS. This prototype, later named S1W, was developed to test the propulsion plant design and to train Navy personnel to operate reactors in preparation for duty on nuclear-powered submarines and ships in the fleet. Two additional naval reactors prototypes were subsequently built at NRF, A1W in 1957 and S5G in 1965. The basic mission of these other prototypes was the same as for the original prototype-to test propulsion plant designs and to train Navy personnel. The S1W plant was shut down in October 1989, the A1W plant was shut down in January 1994, and the S5G plant is scheduled to be shut down in 1995 .

ECF, built at NRF in 1958, was designed to receive irradiated naval reactor fuel, perform examinations on the fuel elements, remove excess structural material from the fuel elements, and transfer the fuel elements to ICPP. ECF has also received and examined naval fuel test specimens that have been irradiated in other reactors, such as the ATR. The fuels are handled remotely under water in the ECF water pits. The water serves as a transparent shielding medium in which a number of procedures can be carried out, including disassembling, cutting, sawing, milling, and visually examining various parts of the fuel elements. Some procedures are also carried out in hot cells at ECF.

Future operations at NRF will change somewhat from past operations. There will be no operating reactor plants at NRF. A1W and S5G will be undergoing defueling and inactivation operations. ECF will likely continue to examine spent fuel elements from naval cores.

Generation of the Waste. LLW is generated by the naval reactor prototypes as a result of activities such as reactor coolant sampling, maintenance, repair, inactivation, and refueling/defueling actions that require interface with the contaminated plant internals. LLW is generated at ECF as a result of fuel examination work. The majority of the waste originating at the prototype plants is compactible and largely incinerable waste (e.g., plastic bags, rubber gloves, blotter paper, and other materials used to contain contamination) with very low levels of radioactivity. In addition to this compactible and largely incinerable waste, there have also been occasional metal valves and piping sections that are noncompactible and that can contain higher quantities of radioactivity. Metal tanks and drums containing spent ion-exchange resins and sludge from water reprocessing systems add to the noncompactible component of the waste streams. 
Table 2-10. Waste streams generated at the Idaho Chemical Processing Plant during 1984-1993.

Waste stream number

Description of waste

CPP-601-8R Waste from the fuel processing building resulting from replacement and/or removal of equipment, asbestos, and materials used for decontamination of the facility

CPP-604-2R Pieces of equipment, insulated piping, contaminated soil, asbestos, and cleaning materials such as cloth, paper, plastic, etc.

CPP-605-1R High-efficiency particulate air (HEPA) filters, metal, soil, concrete, cleanup materials such as paper, cloth, plastic, etc., from the facility that contains the off-gas cleanup system

CPP-610-1R Building materials, equipment, cleanup materials, metal, filters, fuel storage racks, and lead sheets and bricks, all from various areas

CPP-649-1R Filters from the Atmospheric Protection System, and construction materials from upgrading of the facility

CPP-659-1R Metals, construction materials, and cleanup materials such as paper, cloth, plastic, and concrete from the NWCF

CPP-666-1R Waste from 16 buildings, mostly construction materials, fuel charging casks, cleanup materials, and liquids solidified in Portland cement

CPP-684-1R Waste from the Remote Analytical Facility: construction materials and cleanup materials

Table 2-11. Waste streams expected to be generated at the Idaho Chemical Processing Plant during 1994-2003.

Waste stream number Description of waste

CPP-All-1P Contaminated structural materials, mostly metals and concrete, and cleanup materials, such as blotting paper, rags, anti-contamination clothing, plastic, etc. Waste from all areas at ICPP will be shipped directly to the RWMC. Other combustible and noncombustible waste will be shipped to the Waste Experimental Reduction Facility (WERF) for processing and reported as WERF waste. 
The majority of both the radioactivity and the volume of waste that is transferred from NRF to the RWMC comes from ECF. Most of the radioactivity emerging from ECF is in highly corrosion-resistant metal structural materials removed during the naval fuel examinations. This material is loaded into metal containers which, in turn, fit into large shielded shipping casks. These casks are then taken to the RWMC, where the metal containers are removed and buried.

The only difference in the NRF waste between the time periods 1984-1993 and 1994-2003 is in the quantities of waste shipped. The operations and processes that give rise to these waste streams are substantially the same as in the past.

General Availability of Information. The main sources of data pertaining to waste shipments from NRF in the period 1984-1993 are Bartolomucci (1989) and Nieslanik (1994). The Nieslanik letter, in turn, relies on the RWMIS database of shipping and disposal records, an internal NRF database, shipping records, technical work record books, and shipping logs. These two letters document efforts made by NRF to improve the information available on (a) the distribution of radionuclides within the identified NRF waste streams and (b) the total radioactivity shipped from NRF in the scrap casks during 1984-1993.

The method used by NRF to determine the total activity and radionuclide distribution in scrap cask inserts shipped from NRF from 1976 through 1989 was outlined in Bartolomucci (1989). This method was based on knowledge of the metal alloys in the reactor core structural materials and the reactor core radiation history. This information allowed NRF to calculate the extent of expected neutron activation of the core structural material. As pointed out in the letter, this technique is similar to the calculation methods used to determine power levels and lifetimes for nuclear cores and has been validated empirically. The same method was used for the scrap cask shipments between 1990 through 1993 that were dealt with in Nieslanik (1994).

Projections for waste expected to be shipped from NRF in the period 1994-2003 are available in a waste generator forecast letter (Charter 1993) that forecasts volumes, activities, and radionuclide distributions for a number of waste streams.

Data-Collection Approach. The approach selected for data collection for NRF waste during the period 1984-1993 was to take data from Bartolomucci (1989), Nieslanik (1994), and the RWMIS database. The figures from all sources were checked against each other. They agreed closely since they all were derived from the same basic set of NRF records.

The approach selected for data collection for the period 1994-2003 was to use the NRF forecasts (Charter 1993), supplemented by information gathered for the 1984-1993 period for those streams expected to continue to be generated.

Description of Waste Streams. The NRF waste for 1984-1993 was divided into six waste streams (see Table 2-12). These streams were extensions of some of the waste streams identified in the previous report on historical (1952-1983) waste burial. 
Table 2-12. Waste streams generated at the Naval Reactors Facility during 1984-1993.

Waste stream

number

Description of waste

NRF-617-1R Low-level compactible and noncompactible waste resulting from operation of the prototype reactors and related activities

NRF-617-2R Lead and asbestos

NRF-618-4R Structural components removed from Navy nuclear fuel modules (end boxes, etc.), 1984-1988

NRF-618-6R Solidified sludge, resin, waste liquids in vermiculite, Radioactive Waste Disposal System (RWDS) modules

NRF-618-7R Low-level compactible and noncompactible waste resulting from work at the ECF water pits and hot cells

NRF-618-8R Structural components removed from Navy nuclear fuel modules (end boxes, etc.), 1989-1993

The NRF waste for 1994-2003 was divided into three waste streams, again extensions of previous waste streams (see Table 2-13).

As stated previously, the majority of the radioactivity from NRF came from ECF in scrap cask inserts. Three NRF waste streams, NRF-618-4R (1984-1988), NRF-618-8R (1989-1993), and NRF-618-8P (1994-2003), encompass this waste. The waste was divided into these three streams based on the three indicated sequential time periods and because of changes in radionuclide distribution in those time periods.

\subsubsection{Argonne National Laboratory-West}

The Generator. ANL-W is located in the southeastern part of the INEL, approximately 35 mi west of Idaho Falls (see Figure 2-1).

The mission of ANL-W has been, since the beginning of operation, the research and development of liquid metal-cooled reactors and advanced nuclear power plant technology. The primary focus for ANL-W research until 1994 was the Integral Fast Reactor (IFR) Project integrated with an onsite fuel recycling process called pyroprocessing. The objectives were to increase reactor safety, reduce radioactive waste components and concentrations, and improve reactor fuel efficiency. 
Table 2-13. Waste streams expected to be generated at the Naval Reactors Facility during 1994-2003.

Waste stream

number Description of waste

NRF-618-6P Solidified sludge, resin, waste liquids in vermiculite, RWDS modules

NRF-618-7P Low-level compactible and noncompactible waste resulting from work at the $S 5 G$ prototype and at the ECF water pits and hot cells

NRF-618-8P Structural components removed from Navy nuclear fuel modules (end boxes, etc.), 1994-2003

ANL-W consists of seven major complexes: the Experimental Breeder Reactor-II (EBR-II), the Transient Reactor Test Facility (TREAT), the Zero Power Physics Reactor (ZPPR), the Hot Fuel Examination Facility (HFEF), the Fuel Cycle Facility (FCF), the Fuel Manufacturing Facility (FMF), the Laboratory and Office Building (L\&O), and support facilities such as the Radioactive Liquid Waste Treatment Facility (RLWTF), the Sodium Components Maintenance Shop (SCMS), and the Sodium Process Facility (SPF).

EBR-II consists of a sodium-cooled reactor with a thermal power rating of $62.5 \mathrm{MW}$, an intermediate closed loop of secondary sodium, and a steam plant that produces $19 \mathrm{MW}$ of electrical power through a conventional turbine generator. The original emphasis in the design and operation of EBR-II was to demonstrate a complete breeder reactor power plant with onsite reprocessing of metallic fuel. The demonstration was successfully carried out from 1964 to 1969 . The emphasis at EBR-II was then shifted to irradiation testing of fuels and materials for future, larger liquid metal reactors. The EBR-II has also been used to provide electrical power for ANL-W and the INEL. The EBR-II cooling tower, SCMS, and SPF are also associated with EBR-II. The SCMS facility is used to remove sodium from reactor components for repair or replacement.

The TREAT reactor is an uranium oxide-fueled, graphite-moderated, air-cooled reactor. It was designed to produce short, controlled bursts of nuclear energy in order to simulate accident conditions leading to nuclear fuel damage. The reactor became operational in 1959. Tests at TREAT provide data on fuel cladding damage, fuel motion, coolant channel'blockages, molten fuel/coolant interactions, and potential explosive forces during an accident.

ZPPR is the national facility for testing the physics properties of advanced, fast-spectrum reactors. ZPPR is designed to study the properties of experimental reactor cores. Experimental cores are built by hand-loading plates of reactor materials into drawers, which are then put into the designed pattern. The designs are tested at low power levels to determine characteristics of the core.

FCF (formerly called HFEF/S) became operational in 1964 and was used to demonstrate pyrometallurgical fuel reprocessing for EBR-II fuel during the first few years of operation. In 
that mode of operation, a remotely operated production line was used for processing and refabricating spent EBR-II fuel and returning it to the reactor. After successful demonstration of this process in 1969, this mission was discontinued, and the facility was used to examine irradiated fuels and material experiments from EBR-II and TREAT and to provide other reactor support services such as spent fuel transfer to ICPP. FCF consists of two hot cells, one with an air atmosphere and the other with an inert argon-gas atmosphere. There are a total of 23 hot cell work stations around the outside perimeter of the FCF hot cells and four active work stations in the center work space of the argon cell. FCF is now being modified for use in demonstrating new remote recycling and refabrication fuel cycle processes for DOE. The facility has been upgraded and reequipped with new process equipment to carry out this demonstration.

$\mathrm{HFEF}$ (formerly $\mathrm{HFEF} / \mathrm{N}$ ) went into operation in 1975 and is used for examining irradiation experiments. Examinations conducted in the HFEF provide data that are essential for determining the performance and conditions of fuels and materials irradiated in the EBR-II reactor, the TREAT reactor, and other DOE reactor facilities. HFEF consists of two shielded hot cells: the decontamination cell, which contains an air atmosphere, and the main cell, which contains an argon gas atmosphere. Each of the 21 work stations in HFEF is equipped with shielded windows and master/slave manipulators. The main cell is used for work involving exposure of materials such as sodium, plutonium, and other materials that would react chemically with air.

A 250-kW TRIGA research reactor is located in the basement of HFEF and provides a source of neutrons for radiography. The Neutron Radiography Facility is equipped with two beam tubes and two separate radiography stations for neutron radiography of irradiated components. Facilities for decontaminating and repairing hot cell equipment and manipulators are also located within the HFEF.

The HFEF is currently being used for the examination and characterization of contacthandled TRU waste from RFP destined for the Waste Isolation Pilot Plant (WIPP).

The FMF contains the entire operation for the manufacturing of metallic fuel elements within a single building. The building contains a casting furnace and large gloveboxes for encapsulating and bonding the cast fuel slugs in a stainless-steel jacket.

Within the L\&O Building is the analytical laboratory, which consists of hot cells, chemistry laboratories, and the Experimental Fuels Laboratory (EFL). The analytical laboratory provides chemistry support for ANL-W in the areas of environmental compliance, fuel chemistry, sodium/water chemistry, and waste classification analysis. The EFL is used in the development and fabrication of prototype metallic nuclear fuels.

The RLWTF receives low-level radioactive liquid waste from ANL-W facilities and stores the waste in storage tanks before evaporation in the shielded hot air drum evaporators (SHADEs). The L\&O Building, FCF, and HFEF pipe liquid waste to the RLWTF facility directly. The RLWTF began operating in June 1983. Prior to this date, the low-level liquid evaporation process took place in the basement of the L\&O Building. 
During 1994-2003, it is expected that EBR-II and possibly other ANL-W facilities will be shut down. Some facilities will continue to operate, albeit with a revised mission related to waste research rather than fast reactor research. Activities related to the shutdown will take place over a period of several years.

Generation of the Waste. LLW generated at ANL-W for disposal at the RWMC SDA consists of contact-handled and remote-handled waste. Contact-handled LLW is generated in the FMF, L\&O Building, FCF, HFEF, TREAT, ZPPR, EBR-II, SCMS, and RLWTF facilities. This waste is generated by routine facility operations, maintenance, monitoring, and modification. The waste includes filters, machinery components, scrap tools, SHADE units, incinerables and compactibles that exceed radiation limits for compactible waste, and metal items not suitable for sizing. Remote-handled LLW is generated in the FCF and HFEF. The majority of the remotehandled waste is generated from hot cell activities and includes obsolete or broken equipment, subassembly parts, highly contaminated rags and decontamination materials, various metal scrap, and glass.

The majority of the volume and radioactivity (curies) in ANL-W waste disposed of at the SDA in the past and forecasted for the future can be attributed to the FCF and HFEF waste streams. For the period 1984-1993, the FCF and HFEF remote-handled waste streams contributed the vast majority of the radioactivity in ANL-W waste. However, the volumes disposed of from the FCF and HFEF remote-handled waste streams made up less than $2 \%$ of the total volume of ANL-W waste disposed of. The FCF and HFEF contact-handled waste streams contributed approximately $72 \%$ of the total volume, but less than $1 \%$ of the total radioactivity.

During 1994-2003, the activities that generate the waste will change somewhat to reflect the shutdown activities. However, the quantity and nature of the waste are not expected to change significantly. About half of the total ANL-W waste volume sent to the SDA will be from the FCF contact-handled waste stream. Nearly all of the total activity in ANL-W waste sent to the SDA will be from the HFEF remote-handled waste stream.

General Availability of Information. The main sources of data pertaining to the waste from ANL-W in the time period 1984-1993 are the ANL-W shipping records and waste characterization reports used for approval of waste receipts at the RWMC.

Data available for the 1994-2003 projected waste includes the waste generator forecast of Grant (1993), and waste characterization reports for ongoing ANL-W waste streams.

Data-Collection Approach. The data collection approach used for the 1984-1993 period was to enter the ANL-W shipping record information into a spreadsheet/database and sort the data by shipment year, waste destination, generating facility, waste type, etc., to arrive at the total volumes of waste and total radioactivity from each facility, the waste container types, and the waste types. The radionuclide breakdowns for each facility were determined using the results of current waste sample analyses. Waste stream characteristics were gathered from ANL-W waste characterization reports. 
The 1984-1993 total radioactivity for each shipment was assumed to be accurate in the shipping records. Distribution of radionuclide activity was modified to account for previous entries of MFP and MAP.

Data reported in the worksheets for waste expected to be shipped from ANL-W to the . RWMC SDA for the time period 1994-2003 were gathered from the ANL-W radioactive waste forecast (e.g., Grant 1993) and waste characterization reports. Recent waste sample analysis results were used to determine the facility-specific radionuclide breakdowns.

Description of Waste Streams. The ANL-W waste sent to the SDA for the time period 1984-1993 is divided into eight waste streams (see Table 2-14). Some of these waste streams were extensions of the waste streams identified in the previous report on historical (1952-1983) waste burial.

The ANL-W waste projected to be sent to the SDA for the time period 1994-2003 is divided into 11 waste streams, eight of which are extensions of the waste streams for the 1984-1993 time period and three that are nonroutine, one-time waste streams (see Table 2-15).

\subsubsection{Other Generators}

The Generators. "Other" generators for the recent time period include one offsite generator, ANL-E (termed ALE in RWMIS), and seven onsite generators: the Auxiliary Reactor Area (ARA), CFA, PBF, RWMC, D\&D, WERF, and Combustion Engineering-General Atomics (CEG). Some of these generators produced more than one waste stream, but the total radioactivity produced was very small, amounting to less than $0.1 \%$ of the total radioactivity received at the RWMC for burial in the SDA from all waste generators during 1984-1993.

The ALE is located near Chicago, Illinois. Waste was received from this facility beginning in 1980 , and the last shipments were received in 1988. No additional waste is expected to be received at the INEL from this generator. Most of this waste was produced from research activities.

ARA is located in the south-central portion of the INEL. It was known as the Army Reactor Area until 1965, when the Army's programs at the INEL were phased out. Waste was produced during the time period 1984-1987 as the result of additional cleanup of the area, which had been subjected to D\&D earlier. No waste was sent to the RWMC SDA from this facility after 1987.

CFA is also located in the south-central portion of the INEL. Some of the facilities in use at CFA were built in the 1940s and 1950s to support and house Naval Gunnery Range personnel. These facilities have been modified continually over the last 40 years to meet the changing needs of the INEL. CFA currently operates as a centralized location for support of the other INEL facilities, including administrative support, service shops, sanitary landfill, warehousing, security support, laboratory services, training, medical services, and receiving and storage. Small amounts of waste are produced from these operations. 
Table 2-14. Waste streams generated at Argonne National Laboratory-West during 1984-1993.

Waste stream

number

Description of waste

ANL-704-1R Contact-handled, nonprocessible LLW generated during the manufacturing of metallic fuels and facility operations in the FMF and Fuel Assembly Storage Building facilities

ANL-752-1R Contact-handled, nonprocessible LLW generated during L\&O facility operations, maintenance, modifications, and monitoring

ANL-765-1R Contact-handled, nonprocessible LLW generated during FCF operations, maintenance, modifications, and monitoring

ANL-765-2R Remote-handled, subassembly LLW generated during nuclear fuel and materials experiments in the FCF

ANL-785-1R Remote-handled, subassembly LLW generated during nuclear fuel and materials experiments in the HFEF

ANL-785-2R Contact-handled, nonprocessible LLW generated during HFEF operations, maintenance, modifications, and monitoring

ANL-793-1R Contact-handled, nonprocessible LLW generated during SCMS, EBR-II, TREAT, and ZPPR facility operations, maintenance, modifications, and monitoring

ANL-798-1R Contact-handled, nonprocessible LLW generated during facility maintenance, monitoring, and the evaporation of low-level liquid waste in the SHADEs 
Table 2-15. Waste steams expected to be generated at Argonne National Laboratory-West during 1994-2003.

Waste stream .

number

ANL-704-1P

ANL-752-1P

ANL-763-1P

ANL-765-1P

ANL-765-2P

ANL-785-1P

ANL-785-2P

ANL-793-1P

ANL-798-1P

ANL-INC-1P

ANL-COM-1P
Contact-handled, nonprocessible LLW generated during the manufacturing of metallic fuels and facility operations in the FMF

Contact-handled, nonprocessible LLW generated during L\&O facility operations, maintenance, modifications, and monitoring

Contact-handled LLW consisting of sludge solidified with grout, soil, rocks, and concrete pieces generated during the cleanup of the EBR-II leach pit (not routine, generated in 1993, shipped in 1994, no future generation)

Contact-handled, nonprocessible LLW generated during FCF operations, maintenance, modifications, and monitoring

Remote-handled, subassembly LLW generated during nuclear fuel and materials experiments in the FCF

Remote-handled, subassembly LLW generated during nuclear fuel and materials experiments in the HFEF

Contact-handled, nonprocessible LLW generated during HFEF operations, maintenance, modifications, and monitoring

Contact-handled, nonprocessible LLW generated during SCMS, EBR-II, TREAT, and ZPPR facility operations, maintenance, modifications, and monitoring

Contact-handled, nonprocessible LLW generated during facility maintenance, monitoring, and the evaporation of low-level liquid waste in the SHADEs

Incinerable LLW from maintenance and facility operations (generated from 1992 through 1994, to be shipped to Scientific Ecology Group (SEG) for incineration in 1995 and the resulting ash to be shipped to the SDA in 1995)

Compactible LLW from maintenance and facility operations (to be shipped to WERF in 1995 for compaction and the resulting compacted waste to be shipped to the SDA in 1995) 
The PBF area is located approximately 6 mi northeast of CFA. This area originally contained reactors constructed for the Special Power Excursion Reactor Test (SPERT) experiments. Four SPERT reactors were built beginning in the late 1950 s as part of an early investigation involving reactor transient behavior tests and safety studies on water-moderated, enriched-fuel reactor systems. All of the reactors have been removed, and most of the facilities have undergone D\&D. PBF presently consists of the PBF reactor area (north of SPERT-I), PBF control area, Waste Engineering Development Facility (at the SPERT-II site), WERF at the SPERT-III site, and Mixed Waste Storage Facility (SPERT-IV). Waste from WERF is reported separately from the PBF waste.

Small amounts of waste are generated by operations at the RWMC itself.

The D\&D of INEL nuclear facilities has been in progress as a separate function since 1975. Areas subjected to D\&D activities that produced waste during the time period 1984-1993 are the ARA, the Boiling Water Reactor Experiment V (BORAX V) area, the Army Reentry Vehicle Area (ARVFS), CFA, the LOFT area [now called the Containment Test Facility (CTF) area], the Heat Transfer Reactor area at TAN, the IET area at TAN, the MTR area at TRA, and the Power Excursion Reactor area (PER or SPERT).

WERF receives waste from all INEL facilities for treatment. Three treatment processes are involved: incineration, waste sizing, and compaction. The primary purpose of these treatments is to reduce the volume of the waste so that less space is required for burial in the SDA. The incineration process handles combustible waste, and the volume reduction averages about 200:1. The ash is disposed of in the SDA without further treatment if it passes the EPA toxicity leach test. If it does not pass this test, it is stabilized with Portland cement before disposal. The waste sizing process uses manually operated torches and mechanical cutting devices, including saws and shears. Both metallic and wood structures are sized. The average size reduction is 5:1. The compaction process uses a unit with a compaction force of 200 tons. The waste is compacted into metal containers for disposal in the SDA. The average size reduction for this process is $5: 1$.

At present, only waste sizing and compaction are in operation at WERF. Waste incineration is shut down and is expected to restart in 1995.

The other generators for the time period 1994-2003 include five of the generators from 1984-1993 (ARA, CFA, D\&D, WERF, and RWMC), and one new generator [environmental restoration projects (ERP)]. The total activity from these streams is projected to be very small compared with the total activity projected for disposal at the SDA during 1994-2003.

Generation of the Waste. Waste produced by the other generators includes scrap metals, combustible materials slightly contaminated with radionuclides, and a variety of wastes associated with research and development and the cleanup of facilities.

Waste from ARA consists primarily of cleanup waste resulting from the past short-term operation of the Army Gas-Cooled Reactor Experiment (GCRE), the Mobile Low-Power Reactor No. 1 (ML-1), the Stationary Low-Power Reactor No. 1 (SL-1), and the radiochemistry laboratory. 
Waste from CFA is from several facilities, including the CFA laundry, machine shops, maintenance shops, sewage treatment facilities, and the Radiological and Environmental Sciences Laboratory (RESL). It includes combustibles and biological waste.

Waste generated by $\mathrm{D} \& \mathrm{D}$ operations consists primarily of surface-contaminated metal, concrete, and soil resulting from the dismantling and decommissioning of buildings and building components.

The PBF area radioactive waste was produced from earlier operations of the four SPERT reactors. This waste is primarily metals and combustibles.

Virtually all of the waste shipped from WERF to the SDA originated at other INEL facilities. WERF produced (a) ash by incinerating combustible materials, (b) metals from the size reduction of large pieces of metal equipment by sawing and cutting, and (c) compacted waste by compacting large pieces of metal and wood in a compactor.

Waste was produced at the RWMC itself, usually by decontamination of equipment.

The offsite generator, ALE, produced waste primarily as a result of conducting research in physical, biomedical, and environmental sciences that involved the use of radioactive materials. Some of the waste arose from performing modifications to existing research facilities.

The waste generator CEG processed a lithium target prepared and irradiated at TRA. The target was sent offsite to CEG for processing, but the waste was returned to the INEL for burial at the SDA because the tritium had been generated at TRA. This was a one-time experiment associated with research for the New Production Reactor (NPR) project, which has been canceled.

The waste produced by the other generators for burial in the SDA during 1994-2003 is expected to be similar to the waste produced during 1984-1993. The radioactivity is expected to be small, and the volumes are expected to be similar or smaller. Two exceptions are that no shipments of waste from the offsite generator ANL-E are expected, and no shipments are expected from CEG. CEG was a one-time generator for NPR experiments. Waste from PBF is projected to contain insignificant amounts of activity in comparison to the other generators. This assumes that PBF remains shut down with no plans to inactivate the reactor.

General Availability of Information. The main sources of information available for the other generators for the period 1984-1993 were technical notes produced from information in RWMIS, RWMIS itself, and topical reports. Numerous reports were available on the D\&D projects: Moser (1986), Schoonen (1984), Kaiser (1984), Suckel (1984), Smith (1984), Smith (1985a), Smith and Scott (1984), Bradford (1984), Smith (1985b), Stoll (1987), Browder and Wills (1985), McCusker (1989), Arave and Rodman (1992), Evans and Perry (1993), Moser (1984), Moser (1993), Hansen (1993), Dolenc (1986), and Rhoades (1988). These reports are useful for determining if any hazardous materials were disposed of in the SDA, since only radioactive materials are recorded in RWMIS. Individual waste shipment records were not available, but the RWMIS records generally contained considerable detail pertaining to the activities of the individual radionuclides in each waste shipment. 
Projections of waste to be shipped from other generators to the RWMC in the period 1994-2003 were available from several radioactive waste forecasts: Hitz and Skinner (1993), Keating (1993), Kaiser (1993), Leonard (1994), Banister (1993), Gibbon (1993), Ellison et al. (1993), Miley and Bishoff (1993), Luptak (1993), Miller (1993), and Sayer and Lewis-Kido (1993). Many of the individuals who prepared these forecasts were contacted to clarify specific points. Other documents provided useful information for projecting future waste: EG\&G Idaho (1993). Klassy and Keller (1994), Buckland et al. (1993), and Maheras et al. (1994).

Data-Collection Approach. The approach used to obtain data for the other generators for the 1984-1993 period involved using the technical notes for each waste generator. This source provided the volume, total number of curies, radionuclide distribution, and type of container. The content codes associated with the waste for a particular waste generator were then obtained from the RWMIS records, and a description of the waste was determined from these codes. Several reports, as listed in the previous section, were also reviewed to obtain information.

The approach used to obtain data for the other generators for the 1994-2003 period was to review the radioactive waste forecasts for this period to obtain the necessary information, and to contact the individuals who prepared the forecasts for further clarification of specific points.

Description of Waste Streams. The waste generated by the other facilities in the period 1984-1993 was divided into a total of 15 streams (see Table 2-16).

The waste generated by the other facilities in the period 1994-2003 was divided into a total of eight streams (see Table 2-17).

\subsection{Data Qualification Process}

As shown in Figure 2-2, after the waste information for each generator was collected and entered onto data forms (one form for each waste stream), the information was subjected to a qualification process. That process is described briefly here.

Completed draft forms were logged in at a central point, and copies were reviewed by the technical lead personnel for the task. The completed draft forms were reviewed on points such as completeness, clarity, consistency, reasonableness of assumptions, use of appropriate scientific units, possible duplication or overlap of coverage with forms completed for other waste streams, and compatibility with the structure of the database.

The review comments were discussed with the data gatherer who had prepared the draft forms. After agreement was reached on resolution of the comments, the original preparer made any necessary revisions to the forms.

The forms were then logged in again at the central point and transmitted to the database personnel for entry. All data entered into the database (discussed in Section 2.7) were independently checked for correct entry. During data entry, several validation tables were used to ensure that only valid information was entered into several data fields. The validation tables 
Table 2-16. Waste streams generated by other generators during 1984-1993.

Waste stream

number

Description of waste

ARA-626-2R

Waste from cleanup of the hot cell, including combustible waste such as paper, cloth, plastic, and wood

ALE-317-1R Primarily biological waste, such as tissue, feces, and other waste from small animals such as dogs and mice

ALE-317-2R Cloth, paper, wood, plastic, cut-up scrap, cut-up glove boxes, and undefined general plant waste

ALE-317-3R

HEPA and other types of filters

ALE-317-4R

Construction materials from modifications of buildings and repair of roads, including paving and roofing materials, concrete, soil, and brick

ALE-317-5R Liquids absorbed in dry materials such as vermiculite; also, sludge and evaporator bottoms absorbed in dry solids

ALE-317-6R Metals

CEG-CEG-1R A powder produced by crushing small silicon carbide particles containing lithium target material and solidified in Aquaset; this waste originated as part of the NPR project and was a "one time" waste

CFA-617-2R Liquids absorbed in vermiculite, plastic, paper, cloth, carbon steel, wood, sludge, and some biological waste

D\&D-ALL-1R Piping, valves, evaporators, pumps, concrete, rags, paper, HEPA filters, etc., from D\&D at 11 locations

PBF-620-1R Primarily waste associated with cleanup, including metal tanks, ion-exchange resin, concrete blocks, glass, paper, wood, cloth, etc.

WER-COM-1R Primarily metal and wood that has been reduced in volume by compacting

WER-INC-1R Ash from the incineration of combustible materials, e.g., paper, wood

WER-MET-1R Primarily metals that have been cut into smaller pieces

WMC-WMC-2R Miscellaneous waste, usually from decontamination of equipment 
Table 2-17. Waste streams expected to be generated by other generators during 1994-2003.

Waste stream

number

Description of waste

ARA-ALL-1P Generally pieces of metal, concrete, and rubble resulting from the removal of additional structures at ARA-I, ARA-II, and ARA-III

CFA-625-1P Principally protective clothing and personal protective equipment

D\&D-ARV-1P Concrete, steel, lead, and NaK (after it is treated) from the disassembly and disposal of the ARVFS underground bunker and its contents (stored $\mathrm{NaK})$

ERP-ALL-1P Primarily soil, sludge, and other debris resulting from the remediation of contaminated sites

WER-COM-1P Noncombustible materials, such as light-gauge metal, glass, and acid-producing combustible materials, such as halogen-containing plastics that exceed allowable radiation limits for incineration after compaction in WERF

WER-INC-1P Ash from the incineration at WERF of combustible materials from all of the INEL facilities

WER-MET-1P Metal from all of the INEL facilities that has been reduced in size at WERF by cutting and sawing

WMC-ALL-1P Cleanup materials and miscellaneous waste 
contain prespecified "acceptable" values for the following types of information (data fields): nuclide, chemical name, Chemical Abstract Services (CAS) number, generator, building, etc. As a final check, the database printouts were then reviewed by the data gatherers who had completed the original forms.

The information in this report, including the waste inventory printouts, underwent peer review by technical, program management, regulatory compliance, and waste generator personnel.

\subsection{Contaminant Inventory Database for Risk Assessment}

A convenient method was needed to use the large body of data captured on the data forms provided by the data gatherers for the preceding companion study (EG\&G Idaho 1994) and the present study. Therefore, a database, called the Contaminant Inventory Database for Risk Assessment (CIDRA), was created to manage the data from both studies.

All data contained in CIDRA originated from completed data forms, a blank version of which can be found in Appendix A.

The CIDRA application was created in FOXPRO and is accessible in dBASE.

Textual information captured in the database can be aggregated over different fields in the database (e.g., by waste stream or by generator). However, query and sort capabilities on the text fields are limited. This information was electronically captured to maintain a record of how the waste stream information was obtained and other pertinent details about the waste stream. The data tracking form is hierarchical in that each subsequent section of the form contains more detailed information about a waste stream inventory.

The CIDRA report software application was developed to support reporting. The application can produce the following set of standard reports:

- Hazardous chemicals (Part C) data by various groupings [e.g., waste stream, generator(s)]

- Radionuclides (Part D) information by various groupings [e.g., waste stream, generator(s)].

The information in these reports consists of the quantities and respective units of radiological and nonradiological contaminants.

Report generation is augmented by an algorithm that was developed to perform simplified decay calculations on the radionuclides. The user may specify any date to which decay is calculated, and a data set with the decayed quantities is produced. 


\section{References for Section 2}

Adams, J., 1985, PBF-CANDU Fuel Element Loss-of-Coolant Accident Experiment Test Results Report, EGG-2384, EG\&G Idaho, Inc., May 1985.

Adams, J. P., J. C. Birchley, N. Newman, E. W. Coryell, M. L. Carboneau, S. Guntry, and L. T. Siefken, 1985, Quick-Look Report on OECD LOFT Experiment LP-FP-2, OECD LOFT-T-3804, EG\&G Idaho, Inc., September 1985.

Arave, A. E., and G. R. Rodman, 1992, Final Report of the Decontamination and Decommissioning of the BORAX-V Facility Turbine Building, EGG-2683, EG\&G Idaho, Inc., December 1992.

Banister, M. W., 1993, "Solid Radioactive Waste Forecast for TAN," EG\&G Idaho, Inc., November 18, 1993.

Bartolomucci, J. A., 1989, letter to J. N. Davis, "Curie Content Estimates for ECF Scrap Casks," NRFE-E-1448, Naval Reactors Facility, February 27, 1989.

Bradford, J. D., 1984, Final Report-Decommissioning of the SPERT-III Large Leach Pond at the Idaho National Engineering Laboratory, EGG-2306, EGG-2275, EG\&G Idaho, Inc., April 1984.

Browder, J. H., and E. L. Wills, 1985, Decommissioning of the MTR-605 Process Water Building at the Idaho National Engineering Laboratory, EGG-2361, EG\&G Idaho, Inc., January 1985.

Buckland, R. J., D. J. Kenoyer, and D. M. Preusner, 1993, INEL D\&D Long-Range Plan, EGG-WM-10924, EG\&G Idaho, Inc., October 1993.

Carboneau, M. L., R. L. Nitschke, D. C. Mecham, E. W. Coryell, and J. A. Bagues, 1987, OECD LOFT Fission Product Experiment LP-FP-2 Data Report, OECD LOFT-T-3805, EG\&G Idaho, Inc., May 1987.

Charter, J. L., 1993, letter to K. A. Taylor, "Radioactive Waste Forecasts - Naval Reactors Facility," Letter NRFRC-RCE-2247, November 15, 1993.

DOE, 1993, Waste Stream Projections for Environmental Restoration at the Idaho National Engineering Laboratory, DOE/ID-10417, Revision 2, U.S. Department of Energy, December 1993.

DOE, 1994a, Waste Management Program Strategic Plan, DOE/ID-10429, Revision 1, U.S. Department of Energy, June 1994.

DOE 1994b, Draft Environmental Assessment: Test Area North Pool Stabilization Project, draft, U.S. Department of Energy, February 1995. 
Dolenc, M. R., 1986, Final Report-Decontamination and Decommissioning of the SPERT-I Reactor Building at the Idaho National Engineering Laboratory, EGG-2399, EG\&G Idaho, Inc., February, 1986.

EG\&G Idaho, 1988, Waste Management Plan, Annual Update, Revision 2, December 1988.

EG\&G Idaho, 1993, Waste Experimental Reduction Facility Safety Analysis Report, Volume I, WM-F1-810026, Revision 9, EG\&G Idaho, Inc., June 1993.

EG\&G Idaho, 1994, $A$ Comprehensive Inventory of Radiological and Nonradiological Contaminants in Waste Buried in the Subsurface Disposal Area of the INEL RWMC During the Years 1952-1983, EGG-WM-10903, EG\&G Idaho, Inc., June 1994.

Ellison, J. J., C. M. Hiaring, and W. Malone, 1993, "Solid Radioactive Waste Forecast," EG\&G Idaho, Inc., November 5, 1993.

EPRI, 1987, Updated Scaling Factors in Low Level Radwaste, EPRI NP-5077, Impell Corporation, March 1987.

Evans, J. C., E. L. Lepel, R. W. Sanders, D. L. Wilkerson, W. Silker, C. W. Thomas, K. H. Abel, and D. R. Robertson, 1984, Long-Lived Activation Products in Reactor Materials, NUREG/CR-3474, Battelle Pacific Northwest Laboratory, August 1984.

Evans, T. A., and E. F. Perry, 1993, Final Report of the Remedial Action Taken for the TAN Building 616 Liquid Waste Treatment Facility, EGG-2714, EG\&G Idaho, Inc., September 1993.

General Electric Company, 1989, Nuclides and Isotopes, 14th edition, 1989.

Gibbon, D. O., 1993, "Solid Radioactive Waste Forecast for TAN," EG\&G Idaho, Inc., November 16, 1993.

Graff, A. G., 1980, ORIGEN2-A Revised and Updated Version of the Oak Ridge Isotope Generation and Depletion Code, ORNL-5G21, Oak Ridge National Laboratory, July 1980.

Grant, R. P., 1993, letter to V. C. Randall, "Radioactive Waste Forecast for 1994," Argonne National Laboratory-West, December 20, 1993.

Hansen, C. B., 1993, Final Report for the Decontamination and Decommissioning of the SPERT-IV Waste Holdup Tank Ancillaries, EGG-ER-11000, EG\&G Idaho, Inc., September 1993.

Harker, Y. D., and D. W. Akers, 1994, TRA Activity Weighting Factors/Physical and Chemical Properties of ${ }^{14} \mathrm{C},{ }^{99} \mathrm{~T} c$, and ${ }^{129} \mathrm{I}$, ER-WAG7-51, engineering design file, EG\&G Idaho, Inc., October 1994. 
Harker, Y. D., 1995a, Scaling Factors for Waste Activities Measured by G-M Method, EDF-ER-WAG7-57, engineering design file, Lockheed Idaho Technologies Company, February 1995.

Harker, Y. D., 1995b, letter to T. H. Smith, "I-129 Act. in TRA Sections of HDT and RPDT Reports," YDH-2T-95, Lockheed Idaho Technologies Company, April 1995.

Hitz, J. R., and R. L. Skinner, 1993, letter to K. A Taylor, "Solid Radioactive Waste Forecast," RLS-018-93, Westinghouse Idaho Nuclear Company, Inc., November 15, 1993.

Hoff, D. L., R. G. Mitchell, R. Moore, and L. Bingham, 1993, The Idaho National Engineering Laboratory Site Environmental Report for Calendar Year 1992, DOE/ID-12082(93), U.S. Department of Energy, June 1993.

Kaiser, L. L., 1984, Decontamination and Decommissioning MTR-657 Plug Storage Facility, EGG-2286, EG\&G Idaho, Inc., January 1984.

Kaiser, K A, 1993, "Solid Radioactive Waste Forecasts," EG\&G Idaho, Inc., November 15, 1993.

Keating, S. J., 1993, letter to V. C. Randall, "Test Reactor Area (TRA) Radioactive Waste Forecasts," SJK-005-93, EG\&G Idaho, Inc., November 17, 1993.

Klassy, C. E., and D. E. Keller, 1994, Auditable Safety Analysis for the Storage and Handling of the EBR-I NaK, EGG-ER-11160, Revision 0, EG\&G Idaho, Inc., March 1994.

Klossner, K. A., 1993, letter to K. A. Taylor, "Solid Radioactive Waste Forecast," KAK-16-93, Babcock \& Wilcox Idaho, Inc., November 15, 1993.

Leonard, P. R., 1994, letter to K. A. Taylor, "NRF Forecast for Waste Sent to WERF," PRL-15-94, EG\&G Idaho, Inc., August 1994.

Litteer, D. L., 1988, Idaho National Engineering Laboratory Radioactive Waste Management Information System (RWMIS) Solid Data Users Manual, DOE/ID-10188, Revision 2, U.S. Department of Energy, September 1988.

Luptak, A. L., 1993, "Solid Radioactive Waste Forecast," EG\&G Idaho, Inc., November 15, 1993.

Maheras, S. J., A. S. Rood, S. O. Magnuson, M. E. Sussman, and R. N. Bhatt, 1994, Radioactive Waste Management Complex Low-Level Waste Radiological Performance Assessment, EGG-WM-8773, EG\&G Idaho, Inc., May 1994.

McCusker, T. K., 1989, Final Report: Decontamination and Decommissioning of Heat Transfer Reactor Experiment Test Assemblies HTRE-2 and HTRE-3, EGG-2575, EG\&G Idaho, Inc., September 1989.

Miley, D. M., and J. R. Bishoff, 1993, "Solid Radioactive Waste Forecast," EG\&G Idaho, Inc., October 18, 1993. 
Miller, D. L., 1993, "Solid Radioactive Waste Forecast," EG\&G Idaho, Inc., November 8, 1993.

Moser, C. L., 1993, Final Report-CPP-603 Chloride Removal System Decontamination and Decommissioning, WINCO-1124, Westinghouse Idaho Nuclear Company, Inc., February 1993.

Moser, C. L., 1984, Final Report-ICPP BIF Filter Room Decontamination and Decommissioning, WINCO-1028, Westinghouse Idaho Nuclear Company, Inc., December 1984.

Moser, C. L., 1986, Final Report-Decontamination and Decommissioning of RALA Off-gas Cell and Storage Tank, WINCO-1036, Westinghouse Idaho Nuclear Company, Inc., February 1986.

Mullen, C. K., 1994, letter to H. K. Peterson, "Transmittal of Memories of Test Area North (TAN) Wastes," CKM-01-94, EG\&G Idaho, August 29, 1994.

NCRPM, 1987, Exposure of the Population in the United States and Canada from Natural Background Radiation, Report No. 94, National Council on Radiation Protection and Measurements, December 1987.

Nieslanik, R. W., 1994, letter to T. H. Smith, "NRF Comments to the Radioactive Waste Management Complex (RWMC) Waste Inventory Report," NRFEM-RR-1122, Naval Reactors Facility, March 29, 1994.

Randall, V. C., 1994, letter to J. A. Roche, "Transmittal of 1994 and 10-Year Radioactive Waste Forecasts," VCR-03-94, EG\&G Idaho, Inc., January 24, 1994.

Rhoades, W. A., 1988, Final Report-Decontamination and Decommissioning of the Auxiliary Reactor Area IV Facility, EGG-2518, EG\&G Idaho, Inc., March 1988.

Sayer, R. D., and G. Lewis-Kido, 1993, "Solid Radioactive Waste Forecast," EG\&G Idaho, Inc., October 6, 1993.

Schnitzler, G. B., 1994, letter to E. B. Nieschmidt, "Radioisotopes in ATR Fuel Elements," BGS-2-94, EG\&G Idaho, Inc., February 10, 1994.

Schoonen, D. H., 1984, Reactor Vessel Decommissioning Project, EGG-2298, EG\&G Idaho, Inc., September 1984.

Smith, D. L., 1984, Decontamination and Decommissioning of the TAN/TSF-3 Concrete Pad, EGG-2292, EG\&G Idaho, Inc., April 1984.

Smith, D. L., and J. G. Scott, 1984, Final Report-Decontamination and Decommissioning of CPP-601 Process Cells " $A$," "B," "C," "D," and "L," EGG-2304, EG\&G Idaho, Inc., September 1984.

Smith, D. L., 1985a, Decontamination and Decommissioning of the BORAX-V Leach Pond, EGG-2300, EG\&G Idaho, Inc., January 1985. 
Smith, D. L., 1985b, Final Report Decontamination and Decommissioning of MTR-603 HB-2 Cubicle, EGG-2431, EG\&G Idaho, Inc., December 1985.

Stoll, F. E., 1987, Final Report of the Decontamination and Decommissioning of the Initial Engine Test Facility and the IET Two-Inch Hot-Waste Line, EGG-2468, EG\&G Idaho, Inc., April 1987.

Suckel, R. A., 1984, Final Report-Decontamination and Decommissioning of the SPERT-I Seepage Pit at the Idaho National Engineering Laboratory, EGG-2291, EG\&G Idaho, Inc., November 1984.

Weidner, J. R., 1993, letter to T. H. Smith, "Corrosion Properties of Stainless Steel at the RWMC and the Potential Release of Nickel and Chromium into the Environment," JRW-13-93, EG\&G Idaho, August 12, 1993.

Wilks, P. H., 1962, Comprehensive Technical Report, General Electric Direct-Air-Cycle Aircraft Nuclear Propulsion Program, Nuclear Safety, APEX-921, General Electric Company, 1962. 


\section{RESULTS}

This section discusses the results of compiling the contaminant inventory information for data form entries with a known quantity. Section 3.1 provides an introduction, summary rollup tables of the inventory over all generators, and explanatory information for the recent (1984-1993) and projected (1994-2003) time periods. Sections 3.2 through 3.7 present corresponding rollup tables and discussions for the six individual major waste generators for the same time periods.

Because Section 3 contains a very large number of tables, the tables are placed at the end of the section for the convenience of the reader.

Had there been entries whose contaminant quantities were "unknown" on the data forms, they would have been discussed in Section 4. However, no such entries resulted for the recent and projected time periods.

\subsection{Introduction and Totals}

\subsubsection{Introduction and Conventions Followed}

All information on the contaminant inventory and on the waste characteristics gathered in this task resides in the CIDRA database. Appendix B (Volumes 2 through 5 of this report) contains a complete printout of the information in CDRA. For each of the 99 waste streams identified, the data forms provide the compiled information concerning the stream, the contaminant quantities and characteristics, the sources of information, and the assumptions made regarding the contaminants for the recent (1984-1993) and projected (1994-2003) time periods.

Tables 3-1 through 3-4 provide the total best-estimate quantities of each contaminant in the inventory, covering all waste streams from all generators. Tables 3-1 and 3-2 represent the nonradiological contaminants in terms of grams; Tables 3-3 and 3-4 list the radiological contaminants in terms of curies at the time of disposal.

These tables and all other tables of contaminant inventories in this section are given for the recent (1984-1993) and projected (1994-2003) time periods. The tables are designated with an "a" or "b." The "a" tables present the contaminants in the waste in order of best estimate quantity; the "b" tables, in alphabetical order.

The upper and lower bounds on the quantities of the contaminants are also given in the tables. Section 5 discusses the statistical methodology used for evaluating the uncertainties in the inventories and for calculating the upper and lower bounds. Section 5 also discusses the major sources of uncertainty, which vary depending on the waste generator and the time period, (i.e., recent or projected).

All inventories in this report are given to only two significant digits. The specification of more significant digits would give an erroneous impression of the accuracy to which the inventories can be estimated. 
The task described in this report went beyond the compilation of an inventory based on waste-related records. The task also considered the technical adequacy of the measurement methods by which the inventory data were originally generated. As a result, although many (generally minor) revisions were made to the estimated contaminant quantities in individual waste streams, major "across-the-board" revisions, based on technical considerations, were also incorporated. As discussed primarily in Section 5, these revisions affect many waste streams. The total inventories in Tables 3-1 through 3-4 are, therefore, significantly different from the corresponding quantities reported in RWMIS and in waste generator forecasts. The differences and their bases are discussed in detail in Section 6.

A brief but important explanation is needed about the handling of radioactive decay products (progeny) in the inventory of radiological contaminants, e.g., in Tables 3-3 and 3-4. Because of radioactive decay, the progeny of radionuclides begin forming (growing in) as soon as the parent radionuclides are formed. The relative abundance of the progeny compared with that of the parent depends on the relative half-lives of the parent and progeny, and on the time elapsed since the production of the parent. For some radionuclides that are often predominant in waste inventories, the half-lives of the progeny are very short compared with those of the parents. Example combinations of parent and progeny are Sr-90 and Y-90, Cs-137 and Ba-137m (metastable), and Ru-106 and Rh-106m. In such cases, radioactive equilibrium (termed "secular equilibrium") is established very quickly (within hours or days) between the parent and the progeny. In these particular circumstances, each curie of the parent radionuclide is in equilibrium with one curie of the progeny (unless branching occurs).

Some of the preparers of the original shipping and other records included secular equilibrium considerations in the data entries, while others did not. In the present task, the inventories generally were not adjusted to reflect secular equilibrium. Instead, the adjustment was deferred to the risk assessment. This approach allows easier comparison of the inventory with previous inventory compilations. Adjustments for secular equilibrium will be made before using the inventory in the risk assessment and will be combined with the effort involving complete radioactive decay calculations. The abundance of the progeny will be calculated in computer codes developed for that purpose or in decay schemes built into environmental transport codes.

Because the subject progeny have very short half-lives, they exist only as long as the parent radionuclide exists. Therefore, omitting the progeny from the inventory at the time of waste disposal will not affect the inventory of the progeny used in the risk assessment, for times longer than a few days or weeks. The equilibrium that is quickly established in producing the progeny will be modeled in the radioactive decay equations.

For easier comparison of the inventory with previous inventory compilations, no effort was devoted to deleting radionuclides with very short half-lives. Again, complete calculations of radioactive decay will be performed before using the inventory in the risk assessment.

Although radioactive decay and ingrowth are not factored into this inventory and are deferred for evaluation in the risk assessment, one other nuclear physics consideration is factored into the inventory. The consideration is the relative percentages of U-234, U-235, and U-238 in uranium entries in the inventory. In natural uranium, the relative percentages of these radionuclides by mass are $0.0055 \%, 0.72 \%$, and $99.2745 \%$, respectively. By radioactivity, the 
percentages are approximately $48 \%, 3 \%$, and $49 \%$, respectively. When natural uranium is enriched in the concentration of U-235 for use in nuclear reactors or weapons, in facilities designed for that purpose, the relative proportions of the three radionuclides change considerably. Many of the waste streams in the inventory contain uranium, but the records generally identified only the one or two uranium radionuclides that were predominant by mass. In the present study, a more thorough approach was taken for all streams listed in the records as containing $>0.1 \mathrm{Ci}$ of any of the three listed uranium radionuclides. For those streams, the degree of enrichment of the uranium (e.g., enrichment corresponding to that of depleted uranium, natural uranium, slightly enriched uranium, or highly enriched uranium) was estimated based on the source and nature of the waste. Standard curves (Rich et al. 1988; EG\&G Idaho 1985) were consulted that indicate the relative proportions of the uranium radionuclides for various degrees of enrichment. The appropriate mixture of uranium radionuclides was then ascribed to the uranium in the waste stream, totaling the same amount of uranium as the records indicated.

Some contaminants (e.g., uranium) are not only radioactive, but they also present nonradiological hazards. Such contaminants are listed in this report under only the radiological heading. The nonradiological hazards of materials that are radioactive will be considered in the risk assessment.

As the titles of all the inventory tables for radiological contaminants indicate, the radioactivity is given as of the various times of disposal.

For each nonradiological contaminant in the tables, the CAS number is given.

The current inventory is not suitable for direct, immediate use in the risk assessment. As Figure 2-2 indicates, the risk assessor needs to apply additional calculations and judgment before using the inventory values in environmental transport codes and other risk assessment methods. Use of the information requires careful consideration of factors such as (a) the physical and chemical characteristics of individual waste streams and of contaminants within a waste stream, (b) waste packaging methods, (c) likely burial methods for the particular type of waste at the particular time, and (d) any migration of contaminants that might have occurred to date. A discussion of this evaluation process is beyond the scope of the present document.

\subsubsection{Rollup of Nonradiological Contaminants Over All Generators}

Table 3-1 lists the nonradiological contaminants identified in the inventory for the recent period. Lead estimated at $9.8 \mathrm{E}+07 \mathrm{~g}$ and beryllium at $6.3 \mathrm{E}+06 \mathrm{~g}$ are the principal contaminants. They are followed by asbestos estimated at $2.3 \mathrm{E}+06 \mathrm{~g}$, copper at $2.3 \mathrm{E}+04 \mathrm{~g}$, zirconium oxide at $4.5 \mathrm{E}+03 \mathrm{~g}$, and chromium at $2.9 \mathrm{E}+01 \mathrm{~g}$. Other contaminants present in very small quantities, ranging from 2.0 to $0.5 \mathrm{~g}$, are mercury, cadmium, and arsenic.

In the projected time period (see Table 3-2), the principal contaminants are beryllium estimated at $5.0 \mathrm{E}+07 \mathrm{~g}$, asbestos at $1.1 \mathrm{E}+06 \mathrm{~g}$, and chromium at $1.9 \mathrm{E}+01 \mathrm{~g}$. Barium, cadmium, lead, arsenic, and mercury are also present, but in very small quantities ranging from about 7 to $0.01 \mathrm{~g}$. 
The minimal amounts of nonradiological contaminants in the waste during the recent and projected periods reflect cessation of the receipt of mixed waste at the SDA, as discussed in Section 1.2. Lead was disposed of in the SDA as late as 1987 , however, so a substantial quantity of lead was identified in the inventory for the recent period.

\subsubsection{Rollup of Radiological Contaminants Over All Generators}

Table 3-3 lists the radiological contaminants identified in the inventory for the recent time period (1984-1993). The estimated total inventory is 2.8 million $\mathrm{Ci}$ at the time of disposal. The largest entry is the activation product $\mathrm{Co}-60$ at 1.4 million $\mathrm{Ci}$, with a half-life of about 5 years. This contaminant constitutes about half of the activity in the waste. Other predominant activation products include Ni-63 at 480,000 Ci (100-year half-life), Co-58 at 200,000 Ci (half-life of less than 1 year) and $\mathrm{Fe}-55$ at $160,000 \mathrm{Ci}$ (2.7-year half-life).

The third largest entry is tritium ( $\mathrm{H}-3$ ) at $300,000 \mathrm{Ci}$. This constitutes about one-tenth of the activity in the waste. The vast majority of the $\mathrm{H}-3$ was generated as an activation product in beryllium, as discussed in Section 2.5.2. Tritium has a half-life of about 12 years.

The predominant fission products include Cs-137 at 3,100 Ci, Sb-125 at 2,900 Ci, Sr-90 at $580 \mathrm{Ci}$, its decay product $\mathrm{Y}-90$ at $200 \mathrm{Ci}$, and Ce-144 at $210 \mathrm{Ci}$.

As shown in Table 3-3, actinides (many of which are very long-lived) are present. Those with the largest activity are Pu-241 at $17 \mathrm{Ci}$ and $\mathrm{Th}-228$ at $10 \mathrm{Ci}$. Several others are present in very small activities, including Am-241, U-234, Pu-239, U-232, U-238, Ra-226, Pu-238, U-235, $\mathrm{Cm}-242, \mathrm{Cm}-244$, and Pu-240.

The activities of several of the radionuclides in Table 3-3 were estimated in this study almost exclusively by means of calculations with nuclear physics computer codes. (The calculations either were performed as part of this study or had been performed previously and were extracted from the reports referenced in Section 2.) These radionuclides were frequently not listed on shipping records because their radiation is difficult to detect. The radiation exhibits either weak or no gamma rays, and is often absorbed within the waste materials or the container walls. Examples of these radionuclides are $\mathrm{H}-3, \mathrm{C}-14, \mathrm{Sr}-90$, Tc-99, and I-129. As Section 6.2 shows, the calculated activities of radionuclides of this type are larger than the corresponding activities indicated in the shipping record compilations of RWMIS.

Table 3-4 lists the radiological contaminants identified in the inventory for the projected time period (1994-2003). The total inventory is 3.8 million $\mathrm{Ci}$ at the projected times of disposal. The largest entry is tritium (H-3) at 2,600,000 $\mathrm{Ci}$. This contaminant constitutes almost three-fourths of the activity in the waste. The vast majority of the $\mathrm{H}-3$ is generated as an activation product in beryllium. Other predominant activation products are Co-60 at 790,000 Ci, Co-58 at $100,000 \mathrm{Ci}, \mathrm{Ni}-63$ at $69,000 \mathrm{Ci}, \mathrm{Mn}-54$ at $65,000 \mathrm{Ci}, \mathrm{Fe}-55$ at $38,000 \mathrm{Ci}$, and $\mathrm{Cr}-51$ at $26,000 \mathrm{Ci}$.

The predominant fission products include Cs-137 at 1,600 Ci, Sr-90 at $82 \mathrm{Ci}, \mathrm{Eu}-155$ at $72 \mathrm{Ci}, \mathrm{Y}-90$ at $69 \mathrm{Ci}$, and $\mathrm{Ce}-144$ at $58 \mathrm{Ci}$. 
As shown in Table 3-4, actinides are present: $\mathrm{Pu}-241$ at $46 \mathrm{Ci}$ and several others in smaller activities (e.g., $\mathrm{Pu}-239, \mathrm{Pu}-238, \mathrm{Cm}-242$, and $\mathrm{Am}-241$ ).

\subsection{Test Area North}

\subsubsection{Nonradiological Contaminants}

Table 3-5 indicates that lead was the only nonradiological contaminant in the TAN waste sent to the SDA in the 1984-1993 time period. The quantity was 5.4E+06 g. No nonradiological contaminants are anticipated for the 1994-2003 time period.

\subsubsection{Radiological Contaminants}

Tables 3-6 and 3-7 list the inventory of radiological contaminants in the waste from TAN for the time periods 1984-1993 and 1994-2003, respectively.

For 1984-1993, the best estimate for the total radioactivity is approximately $2,200 \mathrm{Ci}$. During this period, waste from TAN was contaminated principally with fission products from the TMI abnormal waste and fuel that DOE accepted to repackage, and store or dispose of. The LOFT reactor and primary coolant system components constituted a slight perturbation from this normal contamination distribution.

The chief radionuclides in the TAN waste were the fission products Cs-137, Sr-90, and Cs-134. These three fission products constituted approximately $90 \%$ of the activity. Most of the remaining activity is due to the activation products Ni-63, Co-60, Mn-54, and Fe-55. The nickel, cobalt, manganese, and iron originate in structural materials. These are relatively immobile. Plutonium and uranium radionuclides with very long half-lives are present in small activities.

For 1994-2003, the best estimate for the total radioactivity is approximately $1.5 \mathrm{Ci}$. The largest contributor, which accounts for almost half of the activity, is Cs-137. The next two largest contributors are Sr-90 and Cs-134. Uranium radionuclides are present in very small activities.

\subsection{Test Reactor Area}

\subsubsection{Nonradiological Contaminants}

Tables 3-8 and 3-9 list the inventory of nonradiological contaminants in the waste from TRA for the 1984-1993 and 1994-2003 time periods, respectively. Beryllium, at 6.3 million g, is the largest contributor for the period 1984-1993 and the sole contributor for the 1994-2003 period at 50 million g. The beryllium represents the mass of the beryllium reflectors removed from the ATR reactor during the time period 1984-1993 and the projected mass for the 1994-2003 time period.

During 1987, about 1.6E $+06 \mathrm{~g}$ of lead was sent to the RWMC from TRA. This lead was probably buried in the SDA (Rodgers 1986, Rodgers 1987). An exception to the prohibition on burying mixed waste in the SDA was allowed until December 31, 1987. This exception permitted 
lead shielding to be buried at the SDA along with the waste it shielded. Contaminated and clean lead shipped after 1987 is temporarily stored above ground at the RWMC so that it can be retrieved for reuse, decontamination, or recycling.

\subsubsection{Radiological Contaminants}

Tables 3-10 and 3-11 list the inventory of radiological contaminants in the waste from TRA for the 1984-1993 and 1994-2003 time periods, respectively.

For $1984-1993$, the best estimate for the total radioactivity is approximately $320,000 \mathrm{Ci}$. Tritium (H-3) is the dominant radionuclide in the TRA waste, constituting about $91 \%$ of the activity in the waste at $290,000 \mathrm{Ci}$. Tritium was an activation product formed in the beryllium reflectors in the reactor cores. Tritium was also formed as a fission product of ternary fission.

Other major contributors are the activation products $\mathrm{Co}-60, \mathrm{Fe}-55, \mathrm{Ni}-63$, and $\mathrm{Cr}-51$, and the fission products Cs-137, Ce-144, Cs-134, Sb-125, and Sr-90. The dominant radionuclides in the TRA waste are what would generally be expected based on the nature of the reactor operations that generated the waste.

TRA is the principal generator of three radionuclides that are of particular interest because of their very long half-lives and relatively high mobilities in groundwater, even though their activities are not large: C-14, Tc-99, and I-129. As discussed in Section 2.5.2, the estimated activities of these three radionuclides are based primarily on (a) nuclear physics calculations performed for the current task and (b) Tables 2-5 through 2-7, which in turn derive from calculations and laboratory data obtained at the INEL and at the Electric Power Research Institute (EPRI) (see Harker 1995a and 1995b). The activities are considerably higher than those listed in the shipping records for these three radionuclides, because the activities are not measured in routine surveys and are, therefore, not listed in most shipping records. There is considerable uncertainty in the present estimates,

Another radionuclide of potential interest in the TRA waste is Nb-94. This radionuclide is formed by neutron activation of niobium collars that are attached to the beryllium reflectors from ATR. Nb-94 is small in activity but very long-lived. Ongoing studies, separate from this effort, are refining the estimated activity of $\mathrm{Nb}-94$. When the ongoing studies are completed, the potential effect on this inventory and on risk assessments using this inventory will be evaluated.

For 1994-2003, the best estimate for the total radioactivity is approximately 2.8 million $\mathrm{Ci}$. Tritium is the dominant radionuclide, constituting about $94 \%$ of the activity. The radionuclide distribution is similar to that for the period 1984-1993.

\subsection{Idaho Chemical Processing Plant}

\subsubsection{Nonradiological Contaminants}

Table 3-12 lists the inventory of nonradiological contaminants in waste from ICPP for the recent time period (1984-1993). The nonradiological contaminants were lead at 78 million $g$ and asbestos at 1.2 million g. The lead was primarily in the form of lead sheets and lead bricks that 
had been used for shielding, and the asbestos was from insulation. Usually, the insulation was removed and disposed of during modification of a building or as part of an asbestos abatement program.

No. organic or inorganic liquids were sent to the SDA from ICPP during the period 1984-1993, unlike the period 1952-1983 when many thousands of gallons were disposed of in an area that eventually became part of the SDA (EG\&G Idaho 1994).

No nonradiological contaminants from ICPP are expected to be disposed of in the SDA in the period 1994-2003.

\subsubsection{Radiological Contaminants}

Tables 3-13 and 3-14 list the inventory of radiological contaminants in the waste from ICPP for the 1984-1993 and 1994-2003 time periods, respectively.

For the 1984-1993 period, the total best-estimate radioactivity is approximately $670 \mathrm{Ci}$. The radiological contaminants are primarily fission products that were released from the fuel elements during chemical processing. The dominant fission products are Ce-144, Pr-144, Cs-137, Sr-90, $\mathrm{Y}-90, \mathrm{Ru}-106$, and $\mathrm{Rh}-106$. This $670 \mathrm{Ci}$ is much less than the activity sent during the period 1952-1983. This reduction in activity reflects changes in programs and in methods for handling the waste. For example, no end boxes were cut from fuel elements and shipped to the SDA in the period 1984-1993, since they were removed at the reactor facility before the fuel was shipped to ICPP. The end box waste stream produced approximately 500,000 $\mathrm{Ci}$ for disposal in the 1952-1983 period.

The activity in the ICPP waste for 1994-2003 is expected to be even less than for the 1984-1993 period. An estimated $160 \mathrm{Ci}$ is projected. This reduction reflects the increased. emphasis on minimization of waste and changes in programs.

\subsection{Naval Reactors Facility}

\subsubsection{Nonradiological Contaminants}

Table 3-15 lists the nonradiological contaminants in the NRF-generated waste buried in the SDA during the 1984-1993 time period. The lead at $640,000 \mathrm{~g}$ is from radionuclide-contaminated lead shielding, and the asbestos at $580,000 \mathrm{~g}$ is from pipe insulation.

No nonradiological contaminants are expected to be disposed of in the SDA in NRF waste for 1994-2003.

\subsubsection{Radiological Contaminants}

Tables 3-16 and 3-17 list the inventory of radionuclide contaminants in the waste from NRF for the 1984-1993 and 1994-2003 time periods, respectively. 
For the 1984-1993 period, the total best-estimate is approximately $970,000 \mathrm{Ci}$. The majority of the activity is from the activation products $\mathrm{Ni}-63$ (about half of the activity), Co-60 (about one-fourth of the activity) and Fe-55 (about $15 \%$ of the activity). The other major contributors are Co-58, Ta-182, Sn-119m, W-185, and Nb-95.

The majority of the radioactivity in the waste from NRF is in the form of solid, monolithic pieces of activated metal (core structural materials). In addition, significant fractions of the activity are short-lived radionuclides and some of that activity has decayed since burial. The activation products such as $\mathrm{Ni}-63$, Co-60, and Fe-55 are entrapped in large pieces of stainless steel.

The radionuclides and their activities are what one would expect to see in the waste from a reactor facility such as NRF. From the reactors, one would expect to see compactible waste with small concentrations of activated metals. From ECF, one would expect to see activated metals associated with core structural materials and some fission products resulting from the examination of fuel samples.

The best-estimate activity for the $1994-2003$ time period is approximately $140,000 \mathrm{Ci}$. The distribution is similar to that for the period 1984-1993. Ni-63 and Co-60 are each about one-third and $\mathrm{Fe}-55$ is about $20 \%$ of the total activity. The same conclusions can be drawn regarding halflives and mobility. The lower total activity relative to the previous periods reflects a projected decreasing level of naval fuel examination work over the coming decade.

\subsection{Argonne National Laboratory-West}

\subsubsection{Nonradiological Contaminants}

Tables 3-18 and 3-19 list the inventory of nonradiological contaminants in the waste from ANL-W for the 1984-1993 and 1994-2003 time periods, respectively.

For 1984-1993, the primary nonradiological contaminants were lead at 9.5 million $\mathrm{g}$ and asbestos at 410,000 g. The lead was used for shielding inside inserts. Asbestos is not classified as hazardous waste per RCRA; therefore, asbestos contaminated with radionuclides is still acceptable for burial at the SDA. It was generated primarily during facility maintenance and modification operations. Asbestos waste resulted from the removal of insulation, pipe lagging, laboratory counter tops, and other asbestos-containing materials.

Except for the virtual disappearance of lead from the inventory, the nonradiological contaminants in the ANL-W waste for 1994-2003 are similar to those for the 1984-1993 time period. The asbestos, which is the predominant contaminant at $100,000 \mathrm{~g}$, is a result of $\mathrm{D} \& \mathrm{D}$ efforts, and facility maintenance and modifications. 


\subsubsection{Radiological Contaminants}

Tables 3-20 and 3-21 list the inventory of radiological contaminants in the waste from ANL-W for the 1984-1993 and 1994-2003 time periods, respectively.

The best estimate for the total radioactivity in 1984-1993 is approximately 1.5 million $\mathrm{Ci}$. During this time period, the largest contributors to the activity are activation products. Co- 60 makes up about three-fourths of the activity with 1.1 million $\mathrm{Ci}$. The next two largest contributors are $\mathrm{Co}-58$ at $180,000 \mathrm{Ci}$ and $\mathrm{Mn}-54$ at 120,000 $\mathrm{Ci}$. Other key activation products are $\mathrm{Cr}-51$, Fe-59, and H-3. The predominant fission products include Sr-90, Cs-137, Y-90, and Ce-144. Long-lived radionuclides are present in small activities, e.g., U-234, Pu-239, U-238, and U-235.

For 1994-2003, most of the waste produced is from D\&D. The best estimate for the total radioactivity is approximately $810,000 \mathrm{Ci}$. The distribution of the radionuclides in the waste for this time period is similar to that in 1984-1993. The largest contributor to the activity is Co-60 at $620,000 \mathrm{Ci}$. The next two largest contributors are $\mathrm{Co}-58$ at $97,000 \mathrm{Ci}$ and $\mathrm{Mn}-54$ at $65,000 \mathrm{Ci}$. Other key radionuclides in terms of activity are $\mathrm{Cr}-51$ and $\mathrm{Fe}-59$.

\subsection{Other Generators}

Inventories for nine waste generators are reported in this section. These are Argonne National Laboratory-East (designated ALE); Auxiliary Reactor Area (ARA); Combustion Engineering-General Atomic (CEG); Central Facilities Area (CFA); Decontamination and Decommissioning projects (D\&D); environmental restoration projects (ERP); Power Burst Facility (PBF); Waste Experimental Reduction Facility (WER); and Waste Management Complex (WMC). These are known collectively as the "other" generators.

\subsubsection{Nonradiological Contaminants}

Tables 3-22 and 3-23 list the combined inventories of nonradiological contaminants in waste from the other generators for the recent period (1984-1993) and the projected period (1994-2003), respectively.

For the recent time period, the only generators of the nonradiological contaminants were PBF and the D\&D projects. The principal contaminants were lead at 2.5 million $\mathrm{g}$ and asbestos at $75,000 \mathrm{~g}$. Small amounts of arsenic, cadmium, chromium, mercury, and lead were constituents of sludge removed from the waste holdup tank at the SPERT-IV reactor site. This sludge was mixed with Portland cement for disposal. The copper was in the form of electrical wire.

The only nonradiological contaminant projected for the time period 1994-2003 is asbestos at 1 million $g$ from ARA. The asbestos is from the disassembly and removal of facilities at ARA-I, ARA-II, and ARA-III. 


\subsubsection{Radiological Contaminants}

Tables 3-24 and 3-25 list the combined inventory of radiological contaminants in the waste from other generators for the periods 1984-1993 and 1994-2003, respectively.

For 1984-1993, the total best estimate is approximately $3,200 \mathrm{Ci}$. The predominant radionuclide is $\mathrm{H}-3$ at $2,800 \mathrm{Ci}$, primarily from experiments at ALE and CEG. Small amounts of other radionuclides were present, including Cs-137 at $270 \mathrm{Ci}$, Sr-90 at $49 \mathrm{Ci}$, and Cs-134 at $25 \mathrm{Ci}$.

During the 1994-2003 period, the total best estimate is approximately $510 \mathrm{Ci}$, primarily from projected $\mathrm{D} \& \mathrm{D}$ operations. The predominant radionuclides are the activation products $\mathrm{Co}-60$ at $190 \mathrm{Ci}$ and $\mathrm{Ni}-63$ at $130 \mathrm{Ci}$. The fission products Cs-137, Ce-144, Sr-90, and Y-90 are also present in smaller amounts. $\mathrm{H}-3$ is projected at $23 \mathrm{Ci}$. These radionuclides account for approximately $95 \%$ of the total activity in the waste. No waste is anticipated from ALE (it has not shipped waste to the INEL since 1988). CEG also is not a contributor in this timeframe, as the waste from this generator was produced from experiments associated with the NPR project, which has been canceled. PBF is not a contributor either, as waste from PBF is projected to contain insignificant radioactivity in comparison to the other generators. This assumes that PBF remains shut down and inactivation of the PBF reactor does not occur. 
Table 3-1a. Inventory of nonradiological contaminants (listed by quantity) from all generators for the years 1984-1993.

\begin{tabular}{clllc}
\hline $\begin{array}{c}\text { CAS } \\
\text { number }\end{array}$ & \multicolumn{1}{c}{ Chemical } & $\begin{array}{c}\text { Best } \\
\text { estimate } \\
(\mathrm{g})\end{array}$ & $\begin{array}{c}\text { Lower } \\
\text { bound }\end{array}$ & $\begin{array}{c}\text { Upper } \\
\text { bound }\end{array}$ \\
\hline $7439-92-1$ & Lead & $9.8 \mathrm{E}+07$ & $8.1 \mathrm{E}+07$ & $1.1 \mathrm{E}+08$ \\
$7440-41-7$ & Beryllium & $6.3 \mathrm{E}+06$ & $6.3 \mathrm{E}+06$ & $6.4 \mathrm{E}+06$ \\
$1332-21-4$ & Asbestos & $2.3 \mathrm{E}+06$ & $1.5 \mathrm{E}+06$ & $3.1 \mathrm{E}+06$ \\
$7440-50-8$ & Copper & $2.3 \mathrm{E}+04$ & $1.1 \mathrm{E}+04$ & $4.5 \mathrm{E}+04$ \\
$1314-23-4$ & Zirconium oxide & $4.5 \mathrm{E}+03$ & $3.8 \mathrm{E}+03$ & $5.2 \mathrm{E}+03$ \\
$7440-47-3$ & Chromium & $2.9 \mathrm{E}+01$ & $1.4 \mathrm{E}+01$ & $4.4 \mathrm{E}+01$ \\
$7439-97-6$ & Mercury & $2.0 \mathrm{E}+00$ & $1.0 \mathrm{E}+00$ & $3.0 \mathrm{E}+00$ \\
$7440-43-9$ & Cadmium & $1.8 \mathrm{E}+00$ & $1.5 \mathrm{E}+00$ & $2.0 \mathrm{E}+00$ \\
$7440-38-2$ & Arsenic & $5.0 \mathrm{E}-01$ & $2.5 \mathrm{E}-01$ & $7.5 \mathrm{E}-01$ \\
\hline
\end{tabular}

Table 3-1b. Inventory of nonradiological contaminants (listed alphabetically) from all generators for the years 1984-1993.

\begin{tabular}{clccc}
\hline $\begin{array}{c}\text { CAS } \\
\text { number }\end{array}$ & \multicolumn{1}{c}{ Chemical } & $\begin{array}{c}\text { Best } \\
\text { estimate } \\
(\mathrm{g})\end{array}$ & $\begin{array}{c}\text { Lower } \\
\text { bound }\end{array}$ & $\begin{array}{r}\text { Upper } \\
\text { bound }\end{array}$ \\
\hline $7440-38-2$ & Arsenic & $5.0 \mathrm{E}-01$ & $2.5 \mathrm{E}-01$ & $7.5 \mathrm{E}-01$ \\
$1332-21-4$ & Asbestos & $2.3 \mathrm{E}+06$ & $1.5 \mathrm{E}+06$ & $3.1 \mathrm{E}+06$ \\
$7440-41-7$ & Beryllium & $6.3 \mathrm{E}+06$ & $6.3 \mathrm{E}+06$ & $6.4 \mathrm{E}+06$ \\
$7440-43-9$ & Cadmium & $1.8 \mathrm{E}+00$ & $1.5 \mathrm{E}+00$ & $2.0 \mathrm{E}+00$ \\
$7440-47-3$ & Chromium & $2.9 \mathrm{E}+01$ & $1.4 \mathrm{E}+01$ & $4.4 \mathrm{E}+01$ \\
$7440-50-8$ & Copper & $2.3 \mathrm{E}+04$ & $1.1 \mathrm{E}+04$ & $4.5 \mathrm{E}+04$ \\
$7439-92-1$ & Lead & $9.8 \mathrm{E}+07$ & $8.1 \mathrm{E}+07$ & $1.1 \mathrm{E}+08$ \\
$7439-97-6$ & Mercury & $2.0 \mathrm{E}+00$ & $1.0 \mathrm{E}+00$ & $3.0 \mathrm{E}+00$ \\
$1314-23-4$ & Zirconium oxide & $4.5 \mathrm{E}+03$ & $3.8 \mathrm{E}+03$ & $5.2 \mathrm{E}+03$ \\
\hline
\end{tabular}


Table 3-2a. Inventory of nonradiological contaminants (listed alphabetically) from all generators for the years 1994-2003.

\begin{tabular}{cllcr}
\hline $\begin{array}{c}\text { CAS } \\
\text { number }\end{array}$ & \multicolumn{1}{c}{ Chemical } & $\begin{array}{c}\text { Best } \\
\text { estimate } \\
(\mathrm{g})\end{array}$ & $\begin{array}{c}\text { Lower } \\
\text { bound }\end{array}$ & $\begin{array}{r}\text { Upper } \\
\text { bound }\end{array}$ \\
\hline $7440-41-7$ & Beryllium & $5.0 \mathrm{E}+07$ & $5.0 \mathrm{E}+07$ & $5.1 \mathrm{E}+07$ \\
$1332-21-4$ & Asbestos & $1.1 \mathrm{E}+06$ & $1.0 \mathrm{E}+05$ & $2.1 \mathrm{E}+06$ \\
$7440-47-3$ & Chromium & $1.9 \mathrm{E}+01$ & $9.5 \mathrm{E}+00$ & $2.8 \mathrm{E}+01$ \\
$7440-39-3$ & Barium & $7.3 \mathrm{E}+00$ & $3.7 \mathrm{E}+00$ & $1.1 \mathrm{E}+01$ \\
$7440-43-9$ & Cadmium & $5.8 \mathrm{E}+00$ & $3.4 \mathrm{E}+00$ & $8.3 \mathrm{E}+00$ \\
$7439-92-1$ & Lead & $1.6 \mathrm{E}+00$ & $1.2 \mathrm{E}+00$ & $1.9 \mathrm{E}+00$ \\
$7440-38-2$ & Arsenic & $2.1 \mathrm{E}-01$ & $1.0 \mathrm{E}-01$ & $3.2 \mathrm{E}-01$ \\
$7439-97-6$ & Mercury & $1.3 \mathrm{E}-02$ & $1.1 \mathrm{E}-02$ & $1.5 \mathrm{E}-02$ \\
\hline
\end{tabular}

Table 3-2b. Inventory of nonradiological contaminants (listed alphabetically) from all generators for the years 1994-2003.

\begin{tabular}{cllll}
\hline $\begin{array}{c}\text { CAS } \\
\text { number }\end{array}$ & \multicolumn{1}{c}{ Chemical } & $\begin{array}{c}\text { Best } \\
\text { estimate } \\
(\mathrm{g})\end{array}$ & $\begin{array}{c}\text { Lower } \\
\text { bound }\end{array}$ & $\begin{array}{c}\text { Upper } \\
\text { bound }\end{array}$ \\
\hline $7440-38-2$ & Arsenic & $2.1 \mathrm{E}-01$ & $1.0 \mathrm{E}-01$ & $3.2 \mathrm{E}-01$ \\
$1332-21-4$ & Asbestos & $1.1 \mathrm{E}+06$ & $1.0 \mathrm{E}+05$ & $2.1 \mathrm{E}+06$ \\
$7440-39-3$ & Barium & $7.3 \mathrm{E}+00$ & $3.7 \mathrm{E}+00$ & $1.1 \mathrm{E}+01$ \\
$7440-41-7$ & Beryllium & $5.0 \mathrm{E}+07$ & $5.0 \mathrm{E}+07$ & $5.1 \mathrm{E}+07$ \\
$7440-43-9$ & Cadmium & $5.8 \mathrm{E}+00$ & $3.4 \mathrm{E}+00$ & $8.3 \mathrm{E}+00$ \\
$7440-47-3$ & Chromium & $1.9 \mathrm{E}+01$ & $9.5 \mathrm{E}+00$ & $2.8 \mathrm{E}+01$ \\
$7439-92-1$ & Lead & $1.6 \mathrm{E}+00$ & $1.2 \mathrm{E}+00$ & $1.9 \mathrm{E}+00$ \\
$7439-97-6$ & Mercury & $1.3 \mathrm{E}-02$ & $1.1 \mathrm{E}-02$ & $1.5 \mathrm{E}-02$ \\
\hline
\end{tabular}


Table 3-3a. Inventory of radiological contaminants (listed by quantity) from all generators for the years 1984-1993 (activity at time of disposal).

\begin{tabular}{|c|c|c|c|c|}
\hline Radionuclide & $\begin{array}{c}\text { Best } \\
\text { estimate } \\
\text { (Ci) }\end{array}$ & $\begin{array}{c}\text { Percent } \\
\text { of total } \\
(\%)\end{array}$ & $\begin{array}{l}\text { Lower } \\
\text { bound }\end{array}$ & $\begin{array}{l}\text { Upper } \\
\text { bound }\end{array}$ \\
\hline Co-60 & $1.4 \mathrm{E}+06$ & 50.8 & $9.3 E+05$ & $2.0 \mathrm{E}+06$ \\
\hline $\mathrm{Ni}-63$ & $4.8 E+05$ & 17.2 & $4.3 \mathrm{E}+05$ & $5.2 \mathrm{E}+05$ \\
\hline $\mathrm{H}-3$ & $3.0 E+05$ & 10.7 & $1.0 \mathrm{E}+05$ & $6.8 \mathrm{E}+05$ \\
\hline Co-58 & $2.0 \mathrm{E}+05$ & 7.1 & $2.5 E+04$ & $7.5 E+05$ \\
\hline $\mathrm{Fe}-55$ & $1.6 \mathrm{E}+05$ & 5.7 & $1.4 \mathrm{E}+05$ & $1.8 \mathrm{E}+05$ \\
\hline $\mathrm{Mn}-54$ & $1.2 \mathrm{E}+05$ & 4.2 & $1.2 \mathrm{E}+04$ & $4.8 \mathrm{E}+05$ \\
\hline Cr-51 & $4.7 \mathrm{E}+04$ & 1.7 & $5.4 \mathrm{E}+03$ & $1.9 \mathrm{E}+05$ \\
\hline Ta-182 & $1.8 \mathrm{E}+04$ & 0.6 & $1.6 \mathrm{E}+04$ & $2.0 \mathrm{E}+04$ \\
\hline $\mathrm{Fe}-59$ & $1.5 E+04$ & 0.5 & $1.5 \mathrm{E}+03$ & $6.0 \mathrm{E}+04$ \\
\hline Sn-119m & $8.8 E+03$ & 0.3 & $7.6 \mathrm{E}+03$ & $1.0 \mathrm{E}+04$ \\
\hline W-185 & $6.4 \mathrm{E}+03$ & 0.2 & $5.6 \mathrm{E}+03$ & $7.3 E+03$ \\
\hline $\mathrm{Nb}-95$ & $3.8 E+03$ & 0.1 & $2.6 \mathrm{E}+03$ & $5.4 \mathrm{E}+03$ \\
\hline Hf-181 & $3.4 \mathrm{E}+03$ & 0.1 & $3.0 \mathrm{E}+03$ & $3.9 \mathrm{E}+03$ \\
\hline Cs-137 & $3.1 E+03$ & 0.1 & $1.1 \mathrm{E}+03$ & $7.0 \mathrm{E}+03$ \\
\hline $\mathrm{Sb}-125$ & $2.9 E+03$ & 0.1 & $2.4 \mathrm{E}+03$ & $3.4 \mathrm{E}+03$ \\
\hline $\mathrm{Hf}-175$ & $2.8 \mathrm{E}+03$ & 0.1 & $2.5 \mathrm{E}+03^{-}$ & $3.2 \mathrm{E}+03$ \\
\hline $\mathrm{Zr}-95$ & $2.1 E+03$ & 0.1 & $1.4 \mathrm{E}+03$ & $3.0 \mathrm{E}+03$ \\
\hline $\mathrm{Ni}-59$ & $1.4 \mathrm{E}+03$ & $<0.05$ & $1.1 \mathrm{E}+03$ & $1.8 \mathrm{E}+03$ \\
\hline $\mathrm{Zn}-65$ & $1.0 \mathrm{E}+03$ & $<0.05$ & $8.5 E+00$ & $7.2 \mathrm{E}+03$ \\
\hline Sr-90 & $5.8 \mathrm{E}+02$ & $<0.05$ & $4.4 \mathrm{E}+01$ & $2.6 \mathrm{E}+03$ \\
\hline Ce-144 & $2.1 E+02$ & $<0.05$ & $3.9 \mathrm{E}+01$ & $6.8 \mathrm{E}+02$ \\
\hline Y-90 & $2.0 \mathrm{E}+02$ & $<0.05$ & $3.5 \mathrm{E}+01$ & $6.7 \mathrm{E}+02$ \\
\hline Cs-134 & $1.4 \mathrm{E}+02$ & $<0.05$ & $6.1 E+00$ & $7.7 \mathrm{E}+02$ \\
\hline Sn-117m & $1.2 \mathrm{E}+02$ & $<0.05$ & $6.1 \mathrm{E}-01$ & $8.7 \mathrm{E}+02$ \\
\hline Pr-144 & $1.1 \mathrm{E}+02$ & $<0.05$ & $1.9 \mathrm{E}+01$ & $3.7 \mathrm{E}+02$ \\
\hline Ru-106 & $6.4 \mathrm{E}+01$ & $<0.05$ & $1.3 \mathrm{E}+01$ & $2.0 \mathrm{E}+02$ \\
\hline Rh-106 & 6.1E+01 & $<0.05$ & $1.1 \mathrm{E}+01$ & $2.0 \mathrm{E}+02$ \\
\hline
\end{tabular}


Table 3-3a. (continued).

\begin{tabular}{|c|c|c|c|c|}
\hline Radionuclide & $\begin{array}{c}\text { Best } \\
\text { estimate } \\
\text { (Ci) }\end{array}$ & $\begin{array}{c}\text { Percent } \\
\text { of total } \\
(\%)\end{array}$ & $\begin{array}{l}\text { Lower } \\
\text { bound }\end{array}$ & $\begin{array}{l}\text { Upper } \\
\text { bound }\end{array}$ \\
\hline Sc-46 & $5.0 \mathrm{E}+01$ & $<0.05$ & $2.6 \mathrm{E}-01$ & $3.6 E+02$ \\
\hline $\mathrm{Te}-125 \mathrm{~m}$ & $4.2 \mathrm{E}+01$ & $<0.05$ & $2.2 \mathrm{E}-01$ & $3.0 \mathrm{E}+02$ \\
\hline $\mathrm{C}-14$ & $4.0 \mathrm{E}+01$ & $<0.05$ & 4.1E-01 & $2.8 \mathrm{E}+02$ \\
\hline Eu-155 & $3.9 \mathrm{E}+01$ & $<0.05$ & $5.1 \mathrm{E}-01$ & $2.6 \mathrm{E}+02$ \\
\hline Sn-113 & $2.4 \mathrm{E}+01$ & $<0.05$ & $2.1 \mathrm{E}-01$ & $1.7 \mathrm{E}+02$ \\
\hline $\mathrm{Pu}-241$ & $1.7 \mathrm{E}+01$ & $<0.05$ & $1.0 \mathrm{E}-01$ & $1.2 \mathrm{E}+02$ \\
\hline Th-228 & $1.0 \mathrm{E}+01$ & $<0.05$ & $8.4 \mathrm{E}+00$ & $1.2 \mathrm{E}+01$ \\
\hline $\mathrm{Ba}-137 \mathrm{~m}$ & $4.6 \mathrm{E}+00$ & $<0.05$ & $3.0 \mathrm{E}+00$ & $6.8 \mathrm{E}+00$ \\
\hline $\mathrm{Eu}-152$ & 4. $1 \mathrm{E}+00$ & $<0.05$ & $2.0 \mathrm{E}-01$ & $2.2 \mathrm{E}+01$ \\
\hline Am-241 & $3.7 \mathrm{E}+00$ & $<0.05$ & $2.7 \mathrm{E}-02$ & $2.6 \mathrm{E}+01$ \\
\hline U-234 & $3.5 \mathrm{E}+00$ & $<0.05$ & $3.3 E+00$ & $3.7 \mathrm{E}+00$ \\
\hline Eu-154 & $3.3 \mathrm{E}+00$ & $<0.05$ & $3.5 \mathrm{E}-01$ & $1.4 \mathrm{E}+01$ \\
\hline Sr-89 & $3.0 \mathrm{E}+00$ & $<0.05$ & 3.7E-02 & $2.0 \mathrm{E}+01$ \\
\hline Ce-141 & $2.9 \mathrm{E}+00$ & $<0.05$ & $5.4 \mathrm{E}-02$ & $1.8 \mathrm{E}+01$ \\
\hline La-140 & $2.8 \mathrm{E}+00$ & $<0.05$ & $4.9 \mathrm{E}-02$ & $1.8 \mathrm{E}+01$ \\
\hline $\mathrm{Na}-24$ & $2.7 \mathrm{E}+00$ & $<0.05$ & $2.0 \mathrm{E}-02$ & $1.9 \mathrm{E}+01$ \\
\hline $\mathrm{Ba}-140$ & $2.4 \mathrm{E}+00$ & $<0.05$ & 4.1E-02 & $1.6 \mathrm{E}+01$ \\
\hline Pu-239 & $2.4 \mathrm{E}+00$ & $<0.05$ & $2.4 \mathrm{E}-01$ & $1.0 \mathrm{E}+01$ \\
\hline Pm-147 & $2.4 \mathrm{E}+00$ & $<0.05$ & $1.2 \mathrm{E}-02$ & $1.7 \mathrm{E}+01$ \\
\hline U-232 & $2.2 \mathrm{E}+00$ & $<0.05$ & $1.8 \mathrm{E}+00$ & $2.7 \mathrm{E}+00$ \\
\hline $\mathrm{Ag}-110$ & $1.9 \mathrm{E}+00$ & $<0.05$ & $1.0 \mathrm{E}-02$ & $1.4 \mathrm{E}+01$ \\
\hline U-238 & $1.6 \mathrm{E}+00$ & $<0.05$ & $1.6 \mathrm{E}+00$ & $1.7 \mathrm{E}+00$ \\
\hline Co-57 & $1.5 \mathrm{E}+00$ & $<0.05$ & $8.6 \mathrm{E}-02$ & $7.8 \mathrm{E}+00$ \\
\hline $\mathrm{Mn}-56$ & $1.3 E+00$ & $<0.05$ & $6.6 \mathrm{E}-03$ & $9.5 \mathrm{E}+00$ \\
\hline Gd-153 & $1.3 \mathrm{E}+00$ & $<0.05$ & $1.1 \mathrm{E}-02$ & $9.2 \mathrm{E}+00$ \\
\hline $\mathrm{Ra}-226$ & $1.1 \mathrm{E}+00$ & $<0.05$ & $8.7 \mathrm{E}-01$ & $1.4 \mathrm{E}+00$ \\
\hline $\mathrm{I}-132$ & $1.0 \mathrm{E}+00^{\circ}$ & $<0.05$ & $5.6 \mathrm{E}-03$ & $7.3 \mathrm{E}+00$ \\
\hline
\end{tabular}


Table 3-3a. (continued).

\begin{tabular}{|c|c|c|c|c|}
\hline Radionuclide & $\begin{array}{c}\text { Best } \\
\text { estimate } \\
\text { (Ci) }\end{array}$ & $\begin{array}{l}\text { Percent } \\
\text { of total } \\
(\%)\end{array}$ & $\begin{array}{l}\text { Lower } \\
\text { bound }\end{array}$ & $\begin{array}{l}\text { Upper } \\
\text { bound }\end{array}$ \\
\hline Ir-192 & $6.6 \mathrm{E}-01$ & $<0.05$ & $5.4 \mathrm{E}-03$ & $4.6 \mathrm{E}+00$ \\
\hline $\mathrm{Na}-22$ & $5.4 \mathrm{E}-01$ & $<0.05$ & $3.6 \mathrm{E}-02$ & $2.6 E+00$ \\
\hline Tc-99 & $5.0 \mathrm{E}-01$ & $<0.05$ & $2.8 \mathrm{E}-03$ & $3.6 \mathrm{E}+00$ \\
\hline $\mathrm{Pu}-238$ & $3.6 \mathrm{E}-01$ & $<0.05$ & $8.5 \mathrm{E}-03$ & $2.2 \mathrm{E}+00$ \\
\hline Nb-94 & $2.0 \mathrm{E}-01$ & $<0.05$ & $8.9 \mathrm{E}-04$ & $1.5 E+00$ \\
\hline$V-48$ & $2.0 \mathrm{E}-01$ & $<0.05$ & 4.4E-03 & $1.2 \mathrm{E}+00$ \\
\hline Ru-103 & $1.9 \mathrm{E}-01$ & $<0.05$ & $2.5 \mathrm{E}-03$ & $1.3 E+00$ \\
\hline U-235 & $1.6 \mathrm{E}-01$ & $<0.05$ & $1.5 \mathrm{E}-01$ & $1.6 \mathrm{E}-01$ \\
\hline $\mathrm{I}-131$ & $1.1 \mathrm{E}-01$ & $<0.05$ & $2.2 \mathrm{E}-03$ & 7.2E-01 \\
\hline Y-93 & $1.1 \mathrm{E}-01$ & $<0.05$ & $5.6 \mathrm{E}-04$ & $8.0 \mathrm{E}-01$ \\
\hline $\mathrm{Cm}-242$ & $8.8 \mathrm{E}-02$ & $<0.05$ & $6.8 \mathrm{E}-04$ & $6.2 \mathrm{E}-01$ \\
\hline In-113m & $8.2 \mathrm{E}-02$ & $<0.05$ & 4.4E-03 & 4.2E-01 \\
\hline $\mathrm{Cm}-244$ & 7.6E-02 & $<0.05$ & $5.2 \mathrm{E}-04$ & $5.4 \mathrm{E}-01$ \\
\hline $\mathrm{Pu}-240$ & $5.7 \mathrm{E}-02$ & $<0.05$ & $2.4 \mathrm{E}-03$ & 3.1E-01 \\
\hline Se-75 & $4.5 \mathrm{E}-02$ & $<0.05$ & $8.0 \mathrm{E}-04$ & $2.9 \mathrm{E}-01$ \\
\hline Au-198 & $2.4 \mathrm{E}-02$ & $<0.05$ & $1.3 \mathrm{E}-03$ & $1.2 \mathrm{E}-01$ \\
\hline Mo-99 & $2.3 \mathrm{E}-02$ & $<0.05$ & $1.6 \mathrm{E}-04$ & $1.6 \mathrm{E}-01$ \\
\hline $\mathrm{Ag}-110 \mathrm{~m}$ & $1.8 \mathrm{E}-02$ & $<0.05$ & $1.3 \mathrm{E}-04$ & $1.2 \mathrm{E}-01$ \\
\hline Sb-124 & $1.1 \mathrm{E}-02$ & $<0.05$ & $2.4 \mathrm{E}-04$ & 7.1E-02 \\
\hline Cd-109 & $1.1 \mathrm{E}-02$ & $<0.05$ & $5.6 \mathrm{E}-05$ & $7.9 \mathrm{E}-02$ \\
\hline Re-188 & $9.3 \mathrm{E}-03$ & $<0.05$ & 4.7E-05 & $6.8 \mathrm{E}-02$ \\
\hline Te-132 & $5.6 \mathrm{E}-03$ & $<0.05$ & $3.3 \mathrm{E}-04$ & $2.8 \mathrm{E}-02$ \\
\hline Sr-91 & $4.4 \mathrm{E}-03$ & $<0.05$ & $2.2 \mathrm{E}-05$ & $3.2 \mathrm{E}-02$ \\
\hline Np-237 & $3.7 \mathrm{E}-03$ & $<0.05$ & $2.2 \mathrm{E}-05$ & 2.7E-02 \\
\hline Y-88 & $3.0 \mathrm{E}-03$ & $<0.05$ & $1.5 \mathrm{E}-05$ & $2.2 \mathrm{E}-02$ \\
\hline U-236 & $2.3 \mathrm{E}-03$ & $<0.05$ & $1.1 \mathrm{E}-03$ & $4.1 \mathrm{E}-03$ \\
\hline $\mathrm{I}-129$ & $2.1 \mathrm{E}-03$ & $<0.05$ & 3.1E-05 & $1.4 \mathrm{E}-02$ \\
\hline
\end{tabular}


Table 3-3a. (continued).

\begin{tabular}{|c|c|c|c|c|}
\hline Radionuclide & $\begin{array}{c}\text { Best } \\
\text { estimate } \\
\text { (Ci) }\end{array}$ & $\begin{array}{c}\text { Percent } \\
\text { of total } \\
(\%)\end{array}$ & $\begin{array}{l}\text { Lower } \\
\text { bound }\end{array}$ & $\begin{array}{l}\text { Upper } \\
\text { bound }\end{array}$ \\
\hline Sr-92 & $1.6 \mathrm{E}-03$ & $<0.05$ & $8.2 \mathrm{E}-06$ & $1.2 \mathrm{E}-02$ \\
\hline I-133 & $1.5 \mathrm{E}-03$ & $<0.05$ & $7.6 \mathrm{E}-06$ & $1.1 \mathrm{E}-02$ \\
\hline $\mathrm{Br}-82$ & $1.0 \mathrm{E}-03$ & $<0.05$ & $5.1 \mathrm{E}-06$ & 7.3E-03 \\
\hline Ce-139 & $3.0 \mathrm{E}-04$ & $<0.05$ & $1.5 \mathrm{E}-06$ & $2.2 \mathrm{E}-03$ \\
\hline $\mathrm{Ag}-108 \mathrm{~m}$ & $1.1 \mathrm{E}-07$ & $<0.05$ & $5.5 \mathrm{E}-10$ & 7.7E-07 \\
\hline $\mathrm{Pu}-242$ & $1.2 \mathrm{E}-08$ & $<0.05$ & $6.0 \mathrm{E}-11$ & $8.9 \mathrm{E}-08$ \\
\hline Total & $2.8 \mathrm{E}+06$ & 99.6 & & \\
\hline
\end{tabular}


Table 3-3b. Inventory of radiological contaminants (listed alphabetically) from all generators for the years 1984-1993 (activity at time of disposal).

\begin{tabular}{|c|c|c|c|c|}
\hline Radionuclide & $\begin{array}{c}\text { Best } \\
\text { estimate } \\
\text { (Ci) }\end{array}$ & $\begin{array}{l}\text { Percent } \\
\text { of total } \\
(\%)\end{array}$ & $\begin{array}{l}\text { Lower } \\
\text { bound }\end{array}$ & $\begin{array}{l}\text { Upper } \\
\text { bound }\end{array}$ \\
\hline $\mathrm{Ag}-108 \mathrm{~m}$ & $1.1 \mathrm{E}-07$ & $<0.05$ & $5.5 \mathrm{E}-10$ & 7.7E-07 \\
\hline $\mathrm{Ag}-110$ & $1.9 \mathrm{E}+00$ & $<0.05$ & $1.0 \mathrm{E}-02$ & $1.4 \mathrm{E}+01$ \\
\hline $\mathrm{Ag}-110 \mathrm{~m}$ & $1.8 \mathrm{E}-02$ & $<0.05$ & $1.3 \mathrm{E}-04$ & $1.2 \mathrm{E}-01$ \\
\hline Am-241 & $3.7 \mathrm{E}+00$ & $<0.05$ & $2.7 \mathrm{E}-02$ & $2.6 \mathrm{E}+01$ \\
\hline $\mathrm{Au}-198$ & $2.4 \mathrm{E}-02$ & $<0.05$ & $1.3 \mathrm{E}-03$ & $1.2 \mathrm{E}-01$ \\
\hline $\mathrm{Ba}-137 \mathrm{~m}$ & $4.6 \mathrm{E}+00$ & $<0.05$ & $3.0 \mathrm{E}+00$ & $6.8 \mathrm{E}+00$ \\
\hline $\mathrm{Ba}-140$ & $2.4 \mathrm{E}+00$ & $<0.05$ & $4.1 \mathrm{E}-02$ & $1.6 \mathrm{E}+01$ \\
\hline $\mathrm{Br}-82$ & $1.0 \mathrm{E}-03$ & $<0.05$ & $5.1 \mathrm{E}-06$ & $7.3 \mathrm{E}-03$ \\
\hline C-14 & $4.0 \mathrm{E}+01$ & $<0.05$ & $4.1 \mathrm{E}-01$ & $2.8 \mathrm{E}+02$ \\
\hline $\mathrm{Cd}-109$ & $1.1 \mathrm{E}-02$ & $<0.05$ & $5.6 \mathrm{E}-05$ & $7.9 \mathrm{E}-02$ \\
\hline Ce-139 & $3.0 \mathrm{E}-04$ & $<0.05$ & $1.5 \mathrm{E}-06$ & $2.2 \mathrm{E}-03$ \\
\hline Ce-141 & $2.9 \mathrm{E}+00$ & $<0.05$ & $5.4 \mathrm{E}-02$ & $1.8 \mathrm{E}+01$ \\
\hline Ce-144 & $2.1 \mathrm{E}+02$ & $<0.05$ & $3.9 \mathrm{E}+01$ & $6.8 \mathrm{E}+02$ \\
\hline $\mathrm{Cm}-242$ & $8.8 \mathrm{E}-02$ & $<0.05$ & $6.8 \mathrm{E}-04$ & $6.2 \mathrm{E}-01$ \\
\hline $\mathrm{Cm}-244$ & $7.6 \mathrm{E}-02$ & $<0.05$ & $5.2 \mathrm{E}-04$ & $5.4 \mathrm{E}-01$ \\
\hline Co-57 & $1.5 \mathrm{E}+00$ & $<0.05$ & $8.6 \mathrm{E}-02$ & $7.8 \mathrm{E}+00$ \\
\hline Co-58 & $2.0 \mathrm{E}+05$ & 7.1 & $2.5 \mathrm{E}+04$ & $7.5 \mathrm{E}+05$ \\
\hline Co-60 & $1.4 \mathrm{E}+06$ & 50.8 & $9.3 E+05$ & $2.0 \mathrm{E}+06$ \\
\hline $\mathrm{Cr}-51$ & $4.7 \mathrm{E}+04$ & 1.7 & $5.4 \mathrm{E}+03$ & $1.9 \mathrm{E}+05$ \\
\hline Cs-134 & $1.4 \mathrm{E}+02$ & $<0.05$ & $6.1 E+00$ & $7.7 \mathrm{E}+02$ \\
\hline Cs-137 & $3.1 E+03$ & 0.1 & $1.1 \mathrm{E}+03$ & $7.0 \mathrm{E}+03$ \\
\hline Eu-152 & $4.1 \mathrm{E}+00$ & $<0.05$ & $2.0 \mathrm{E}-01$ & $2.2 \mathrm{E}+01$ \\
\hline Eu-154 & $3.3 \mathrm{E}+00$ & $<0.05$ & $3.5 \mathrm{E}-01$ & $1.4 \mathrm{E}+01$ \\
\hline Eu-155 & $3.9 E+01$ & $<0.05$ & $5.1 \mathrm{E}-01$ & $2.6 \mathrm{E}+02$ \\
\hline $\mathrm{Fe}-55$ & $1.6 \mathrm{E}+05$ & 5.7 & $1.4 \mathrm{E}+05$ & $1.8 \mathrm{E}+05$ \\
\hline $\mathrm{Fe}-59$ & $1.5 \mathrm{E}+04$ & 0.5 & $1.5 \mathrm{E}+03$ & $6.0 \mathrm{E}+04$ \\
\hline Gd-153 & $1.3 \mathrm{E}+00$ & $<0.05$ & $1.1 \mathrm{E}-02$ & $9.2 \mathrm{E}+00$ \\
\hline
\end{tabular}


Table 3-3b. (continued).

\begin{tabular}{|c|c|c|c|c|}
\hline Radionuclide & $\begin{array}{c}\text { Best } \\
\text { estimate } \\
\text { (Ci) }\end{array}$ & $\begin{array}{c}\text { Percent } \\
\text { of total } \\
(\%)\end{array}$ & $\begin{array}{l}\text { Lower } \\
\text { bound }\end{array}$ & $\begin{array}{l}\text { Upper } \\
\text { bound }\end{array}$ \\
\hline $\mathrm{H}-3$ & $3.0 \mathrm{E}+05$ & 10.7 & $1.0 \mathrm{E}+05$ & $6.8 \mathrm{E}+05$ \\
\hline Hf-181 & $3.4 \mathrm{E}+03$ & 0.1 & $3.0 \mathrm{E}+03$ & $3.9 \mathrm{E}+03$ \\
\hline Hf -175 & $2.8 \mathrm{E}+03$ & 0.1 & $2.5 E+03$ & $3.2 \mathrm{E}+03$ \\
\hline $\mathrm{I}-129$ & $2.1 \mathrm{E}-03$ & $<0.05$ & $3.1 \mathrm{E}-05$ & $1.4 \mathrm{E}-02$ \\
\hline $\mathrm{I}-131$ & $1.1 \mathrm{E}-01$ & $<0.05$ & $2.2 \mathrm{E}-03$ & $7.2 \mathrm{E}-01$ \\
\hline I-132 & $1.0 \mathrm{E}+00$ & $<0.05$ & $5.6 \mathrm{E}-03$ & $7.3 E+00$ \\
\hline I-133 & $1.5 \mathrm{E}-03$ & $<0.05$ & $7.6 \mathrm{E}-06$ & $1.1 \mathrm{E}-02$ \\
\hline In-113m & $8.2 \mathrm{E}-02$ & $<0.05$ & $4.4 \mathrm{E}-03$ & $4.2 \mathrm{E}-01$ \\
\hline Ir-192 & $6.6 \mathrm{E}-01$ & $<0.05$ & $5.4 \mathrm{E}-03$ & $4.6 \mathrm{E}+00$ \\
\hline La-140 & $2.8 \mathrm{E}+00$ & $<0.05$ & $4.9 \mathrm{E}-02$ & $1.8 \mathrm{E}+01$ \\
\hline Mn-54 & $1.2 E+05$ & 4.2 & $1.2 \mathrm{E}+04$ & $4.8 \mathrm{E}+05$ \\
\hline $\mathrm{Mn}-56$ & $1.3 E+00$ & $<0.05$ & $6.6 \mathrm{E}-03$ & $9.5 \mathrm{E}+00$ \\
\hline Mo-99 & $2.3 \mathrm{E}-02$ & $<0.05$ & $1.6 \mathrm{E}-04$ & $1.6 \mathrm{E}-01$ \\
\hline $\mathrm{Na}-22$ & $5.4 \mathrm{E}-01$ & $<0.05$ & $3.6 \mathrm{E}-02$ & $2.6 \mathrm{E}+00$ \\
\hline $\mathrm{Na}-24$ & $2.7 \mathrm{E}+00$ & $<0.05$ & $2.0 \mathrm{E}-02$ & $1.9 \mathrm{E}+01$ \\
\hline Nb-94 & $2.0 \mathrm{E}-01$ & $<0.05$ & $8.9 \mathrm{E}-04$ & $1.5 \mathrm{E}+00$ \\
\hline $\mathrm{Nb}-95$ & $3.8 E+03$ & 0.1 & $2.6 \mathrm{E}+03$ & $5.4 \mathrm{E}+03$ \\
\hline $\mathrm{Ni}-59$ & $1.4 \mathrm{E}+03$ & $<0.05$ & $1.1 \mathrm{E}+03$ & $1.8 \mathrm{E}+03$ \\
\hline $\mathrm{Ni}-63$ & $4.8 \mathrm{E}+05$ & 17.2 & $4.3 \mathrm{E}+05$ & $5.2 E+05$ \\
\hline Np-237 & 3.7E-03 & $<0.05$ & $2.2 \mathrm{E}-05$ & $2.7 \mathrm{E}-02$ \\
\hline Pm-147 & $2.4 \mathrm{E}+00$ & $<0.05$ & $1.2 \mathrm{E}-02$ & $1.7 \mathrm{E}+01$ \\
\hline Pr-144 & $1.1 E+02$ & $<0.05$ & $1.9 \mathrm{E}+01$ & $3.7 E+02$ \\
\hline $\mathrm{Pu}-238$ & $3.6 \mathrm{E}-01$ & $<0.05$ & $8.5 \mathrm{E}-03$ & $2.2 E+00$ \\
\hline Pu-239 & $2.4 \mathrm{E}+00$ & $<0.05$ & $2.4 \mathrm{E}-01$ & $1.0 \mathrm{E}+01$ \\
\hline $\mathrm{Pu}-240$ & $5.7 \mathrm{E}-02$ & $<0.05$ & $2.4 \mathrm{E}-03$ & 3.1E-01 \\
\hline $\mathrm{Pu}-241$ & $1.7 \mathrm{E}+01$ & $<0.05$ & $1.0 \mathrm{E}-01$ & $1.2 \mathrm{E}+02$ \\
\hline $\mathrm{Pu}-242$ & $1.2 \mathrm{E}-08$ & $<0.05$ & $6.0 \mathrm{E}-11$ & $8.9 \mathrm{E}-08$ \\
\hline
\end{tabular}


Table 3-3b. (continued).

\begin{tabular}{lllll}
\hline Radionuclide & $\begin{array}{c}\text { Best } \\
\text { estimate } \\
(\mathrm{Ci})\end{array}$ & $\begin{array}{c}\text { Percent } \\
\text { of total } \\
(\%)\end{array}$ & $\begin{array}{c}\text { Lower } \\
\text { bound }\end{array}$ & $\begin{array}{c}\text { Upper } \\
\text { bound }\end{array}$ \\
\hline Ra-226 & $1.1 \mathrm{E}+00$ & $<0.05$ & $8.7 \mathrm{E}-01$ & $1.4 \mathrm{E}+00$ \\
Re-188 & $9.3 \mathrm{E}-03$ & $<0.05$ & $4.7 \mathrm{E}-05$ & $6.8 \mathrm{E}-02$ \\
Rh-106 & $6.1 \mathrm{E}+01$ & $<0.05$ & $1.1 \mathrm{E}+01$ & $2.0 \mathrm{E}+02$ \\
Ru-103 & $1.9 \mathrm{E}-01$ & $<0.05$ & $2.5 \mathrm{E}-03$ & $1.3 \mathrm{E}+00$ \\
Ru-106 & $6.4 \mathrm{E}+01$ & $<0.05$ & $1.3 \mathrm{E}+01$ & $2.0 \mathrm{E}+02$ \\
Sb-124 & $1.1 \mathrm{E}-02$ & $<0.05$ & $2.4 \mathrm{E}-04$ & $7.1 \mathrm{E}-02$ \\
Sb-125 & $2.9 \mathrm{E}+03$ & 0.1 & $2.4 \mathrm{E}+03$ & $3.4 \mathrm{E}+03$ \\
Sc-46 & $5.0 \mathrm{E}+01$ & $<0.05$ & $2.6 \mathrm{E}-01$ & $3.6 \mathrm{E}+02$ \\
Se-75 & $4.5 \mathrm{E}-02$ & $<0.05$ & $8.0 \mathrm{E}-04$ & $2.9 \mathrm{E}-01$ \\
Sn-113 & $2.4 \mathrm{E}+01$ & $<0.05$ & $2.1 \mathrm{E}-01$ & $1.7 \mathrm{E}+02$ \\
Sn-117m & $1.2 \mathrm{E}+02$ & $<0.05$ & $6.1 \mathrm{E}-01$ & $8.7 \mathrm{E}+02$ \\
Sn-119m & $8.8 \mathrm{E}+03$ & 0.3 & $7.6 \mathrm{E}+03$ & $1.0 \mathrm{E}+04$ \\
Sr-89 & $3.0 \mathrm{E}+00$ & $<0.05$ & $3.7 \mathrm{E}-02$ & $2.0 \mathrm{E}+01$ \\
Sr-90 & $5.8 \mathrm{E}+02$ & $<0.05$ & $4.4 \mathrm{E}+01$ & $2.6 \mathrm{E}+03$ \\
Sr-91 & $4.4 \mathrm{E}-03$ & $<0.05$ & $2.2 \mathrm{E}-05$ & $3.2 \mathrm{E}-02$ \\
Sr-92 & $1.6 \mathrm{E}-03$ & $<0.05$ & $8.2 \mathrm{E}-06$ & $1.2 \mathrm{E}-02$ \\
Ta-182 & $1.8 \mathrm{E}+04$ & 0.6 & $1.6 \mathrm{E}+04$ & $2.0 \mathrm{E}+04$ \\
Tc-99 & $5.0 \mathrm{E}-01$ & $<0.05$ & $2.8 \mathrm{E}-03$ & $3.6 \mathrm{E}+00$ \\
Te-125m & $4.2 \mathrm{E}+01$ & $<0.05$ & $2.2 \mathrm{E}-01$ & $3.0 \mathrm{E}+02$ \\
Te-132 & $5.6 \mathrm{E}-03$ & $<0.05$ & $3.3 \mathrm{E}-04$ & $2.8 \mathrm{E}-02$ \\
Th-228 & $1.0 \mathrm{E}+01$ & $<0.05$ & $8.4 \mathrm{E}+00$ & $1.2 \mathrm{E}+01$ \\
U-232 & $2.2 \mathrm{E}+00$ & $<0.05$ & $1.8 \mathrm{E}+00$ & $2.7 \mathrm{E}+00$ \\
U-234 & $3.5 \mathrm{E}+00$ & $<0.05$ & $3.3 \mathrm{E}+00$ & $3.7 \mathrm{E}+00$ \\
U-235 & $1.6 \mathrm{E}-01$ & $<0.05$ & $1.5 \mathrm{E}-01$ & $1.6 \mathrm{E}-01$ \\
U-236 & $2.3 \mathrm{E}-03$ & $<0.05$ & $1.1 \mathrm{E}-03$ & $4.1 \mathrm{E}-03$ \\
U-238 & $1.6 \mathrm{E}+00$ & $<0.05$ & $1.6 \mathrm{E}+00$ & $1.7 \mathrm{E}+00$ \\
V-48 & $2.0 \mathrm{E}-01$ & $<0.05$ & $4.4 \mathrm{E}-03$ & $1.2 \mathrm{E}+00$ \\
\hline
\end{tabular}


Table 3-3b. (continued).

\begin{tabular}{lcccc}
\hline Radionuclide & $\begin{array}{c}\text { Best } \\
\text { estimate } \\
(\mathrm{Ci})\end{array}$ & $\begin{array}{c}\text { Percent } \\
\text { of total } \\
(\%)\end{array}$ & $\begin{array}{c}\text { Lower } \\
\text { bound }\end{array}$ & $\begin{array}{c}\text { Upper } \\
\text { bound }\end{array}$ \\
\hline $\mathrm{W}-185$ & $6.4 \mathrm{E}+03$ & 0.2 & $5.6 \mathrm{E}+03$ & $7.3 \mathrm{E}+03$ \\
$\mathrm{Y}-88$ & $3.0 \mathrm{E}-03$ & $<0.05$ & $1.5 \mathrm{E}-05$ & $2.2 \mathrm{E}-02$ \\
$\mathrm{Y}-90$ & $2.0 \mathrm{E}+02$ & $<0.05$ & $3.5 \mathrm{E}+01$ & $6.7 \mathrm{E}+02$ \\
$\mathrm{Y}-93$ & $1.1 \mathrm{E}-01$ & $<0.05$ & $5.6 \mathrm{E}-04$ & $8.0 \mathrm{E}-01$ \\
$\mathrm{Zn}-65$ & $1.0 \mathrm{E}+03$ & $<0.05$ & $8.5 \mathrm{E}+00$ & $7.2 \mathrm{E}+03$ \\
Zr-95 & $2.1 \mathrm{E}+03$ & 0.1 & $1.4 \mathrm{E}+03$ & $3.0 \mathrm{E}+03$ \\
Total & $2.8 \mathrm{E}+06$ & 99.6 & & \\
\hline
\end{tabular}


Table 3-4a. Inventory of radiological contaminants (listed by quantity) from all generators for the years 1994-2003 (activity at time of disposal).

\begin{tabular}{|c|c|c|c|c|}
\hline Radionuclide & $\begin{array}{c}\text { Best } \\
\text { estimate } \\
(\mathrm{Ci})\end{array}$ & $\begin{array}{c}\text { Percent } \\
\text { of total } \\
(\%)\end{array}$ & $\begin{array}{l}\text { Lower } \\
\text { bound }\end{array}$ & $\begin{array}{l}\text { Upper } \\
\text { bound }\end{array}$ \\
\hline $\mathrm{H}-3$ & $2.6 \mathrm{E}+06$ & 70.4 & $1.3 E+06$ & $5.0 \mathrm{E}+06$ \\
\hline Co- 60 & $7.9 \mathrm{E}+05$ & 21.0 & $3.1 \mathrm{E}+05$ & $1.7 \mathrm{E}+06$ \\
\hline Co-58 & $1.0 \mathrm{E}+05$ & 2.7 & $5.9 \mathrm{E}+03$ & $5.0 \mathrm{E}+05$ \\
\hline $\mathrm{Ni}-63$ & $6.9 \mathrm{E}+04$ & 1.8 & $2.5 \mathrm{E}+04$ & $1.5 \mathrm{E}+05$ \\
\hline $\mathrm{Mn}-54$ & $6.5 \mathrm{E}+04$ & 1.7 & $3.5 \mathrm{E}+03$ & $3.3 \mathrm{E}+05$ \\
\hline Fe-55 & $3.8 \mathrm{E}+04$ & 1.0 & $1.7 \mathrm{E}+04$ & $7.6 \mathrm{E}+04$ \\
\hline $\mathrm{Cr}-51$ & $2.6 \mathrm{E}+04$ & 0.7 & $1.6 \mathrm{E}+03$ & $1.3 \mathrm{E}+05$ \\
\hline $\mathrm{Fe}-59$ & $8.1 E+03$ & 0.2 & $4.4 \mathrm{E}+02$ & 4.1E+04 \\
\hline Ta-182 & $7.6 \mathrm{E}+03$ & 0.2 & $2.4 \mathrm{E}+03$ & $1.8 \mathrm{E}+04$ \\
\hline $\mathrm{Nb}-95$ & $6.8 \mathrm{E}+03$ & 0.2 & $2.2 \mathrm{E}+03$ & $1.6 \dot{\mathrm{E}}+04$ \\
\hline $\mathrm{Zr}-95$ & $3.2 \mathrm{E}+03$ & 0.1 & $1.0 \mathrm{E}+03$ & $7.7 E+03$ \\
\hline Cs-137 & $1.6 \mathrm{E}+03$ & $<0.05$ & $6.3 \mathrm{E}+02$ & $3.3 \mathrm{E}+03$ \\
\hline $\mathrm{Ni}-59$ & $1.9 \mathrm{E}+02$ & $<0.05$ & $1.9 \mathrm{E}+00$ & $1.3 E+03$ \\
\hline C-14 & $9.5 \mathrm{E}+01$ & $<0.05$ & $7.4 \mathrm{E}+00$ & $4.3 \mathrm{E}+02$ \\
\hline Sr-90 & $8.2 E+01$ & $<0.05$ & $1.1 \mathrm{E}+01$ & $3.1 E+02$ \\
\hline Eu-155 & $7.2 \mathrm{E}+01$ & $<0.05$ & $4.4 \mathrm{E}+00$ & $3.5 \mathrm{E}+02$ \\
\hline Y-90 & $6.9 \mathrm{E}+01$ & $<0.05$ & $7.0 \mathrm{E}+00$ & $2.9 \mathrm{E}+02$ \\
\hline $\mathrm{Ce}-144$ & $5.8 \mathrm{E}+01$ & $<0.05$ & $7.2 \mathrm{E}+00$ & $2.3 E+02$ \\
\hline Pu-241 & $4.6 \mathrm{E}+01$ & $<0.05$ & $3.0 \mathrm{E}+00$ & $2.2 \mathrm{E}+02$ \\
\hline Cs-134 & $5.0 \mathrm{E}+00$ & $<0.05$ & $8.5 \mathrm{E}-01$ & $1.7 \mathrm{E}+01$ \\
\hline $\mathrm{Sb}-125$ & $4.1 \mathrm{E}+00$ & $<0.05$ & $3.7 \mathrm{E}-01$ & $1.8 \mathrm{E}+01$ \\
\hline Pr-144 & $2.6 \mathrm{E}+00$ & $<0.05$ & $2.5 \mathrm{E}-01$ & $1.1 \mathrm{E}+01$ \\
\hline $\mathrm{Nb}-94$ & $1.9 \mathrm{E}+00$ & $<0.05$ & $1.9 \mathrm{E}-02$ & $1.3 E+01$ \\
\hline Eu-154 & $1.4 \mathrm{E}+00$ & $<0.05$ & $1.6 \mathrm{E}-01$ & $5.5 E+00$ \\
\hline Tc-99 & $1.4 \mathrm{E}+00$ & $<0.05$ & $8.6 \mathrm{E}-02$ & $6.7 \mathrm{E}+00$ \\
\hline Ir-192 & $1.4 \mathrm{E}+00$ & $<0.05$ & $1.4 \mathrm{E}-01$ & $5.7 \mathrm{E}+00$ \\
\hline $\mathrm{Zn}-65$ & $1.2 \mathrm{E}+00$ & $<0.05$ & $6.5 \mathrm{E}-02$ & $6.1 \mathrm{E}+00$ \\
\hline
\end{tabular}


Table 3-4a. (continued).

\begin{tabular}{|c|c|c|c|c|}
\hline Radionuclide & $\begin{array}{l}\text { Best } \\
\text { estimate } \\
\text { (Ci) }\end{array}$ & $\begin{array}{c}\text { Percent } \\
\text { of total } \\
(\%)\end{array}$ & $\begin{array}{l}\text { Lower } \\
\text { bound }\end{array}$ & $\begin{array}{l}\text { Upper } \\
\text { bound }\end{array}$ \\
\hline $\mathrm{Ba}-137 \mathrm{~m}$ & $1.1 E+00$ & $<0.05$ & $6.1 \mathrm{E}-03$ & $8.0 \mathrm{E}+00$ \\
\hline Eu-152 & $6.9 \mathrm{E}-01$ & $<0.05$ & $3.8 \mathrm{E}-02$ & $3.5 E+00$ \\
\hline $\mathrm{Pu}-239$ & $4.2 \mathrm{E}-01$ & $<0.05$ & $2.7 \mathrm{E}-02$ & $2.0 \mathrm{E}+00$ \\
\hline $\mathrm{Pu}-238$ & 4.1E-01 & $<0.05$ & $2.6 \mathrm{E}-02$ & $2.0 \mathrm{E}+00$ \\
\hline Ru-106 & 4.0E-01 & $<0.05$ & $3.4 \mathrm{E}-02$ & $1.8 \mathrm{E}+00$ \\
\hline Rh-106 & $3.9 \mathrm{E}-01$ & $<0.05$ & $3.2 \mathrm{E}-02$ & $1.7 E+00$ \\
\hline $\mathrm{Cm}-242$ & $2.2 \mathrm{E}-01$ & $<0.05$ & $1.6 \mathrm{E}-02$ & $1.0 \mathrm{E}+00$ \\
\hline Am-241 & $2.1 \mathrm{E}-01$ & $<0.05$ & $1.3 \mathrm{E}-02$ & $1.0 \mathrm{E}+00$ \\
\hline $\mathrm{Cm}-244$ & $1.9 \mathrm{E}-01$ & $<0.05$ & $1.2 \mathrm{E}-02$ & $9.3 E-01$ \\
\hline Hf- 181 & $1.6 \mathrm{E}-01$ & $<0.05$ & $8.8 \mathrm{E}-03$ & $8.3 \mathrm{E}-01$ \\
\hline $\mathrm{Ag}-108$ & $1.6 \mathrm{E}-01$ & $<0.05$ & $5.2 \mathrm{E}-03$ & 9.4E-01 \\
\hline Ce-141 & $1.4 \mathrm{E}-01$ & $<0.05$ & $8.1 \mathrm{E}-03$ & $6.7 \mathrm{E}-01$ \\
\hline Co-57 & $1.2 \mathrm{E}-01$ & $<0.05$ & $4.5 \mathrm{E}-03$ & $6.8 \mathrm{E}-01$ \\
\hline La-140 & $1.1 \mathrm{E}-01$ & $<0.05$ & $6.5 \mathrm{E}-03$ & $5.4 \mathrm{E}-01$ \\
\hline $\mathrm{Na}-22$ & $1.1 \mathrm{E}-01$ & $<0.05$ & $6.1 \mathrm{E}-03$ & $5.5 \mathrm{E}-01$ \\
\hline Sn-113 & $6.3 \mathrm{E}-02$ & $<0.05$ & $3.7 \mathrm{E}-03$ & $3.1 \mathrm{E}-01$ \\
\hline In-113m & $5.4 \mathrm{E}-02$ & $<0.05$ & $3.1 \mathrm{E}-03$ & $2.7 \mathrm{E}-01$ \\
\hline U-238 & $5.2 \mathrm{E}-02$ & $<0.05$ & $3.2 \mathrm{E}-02$ & $7.8 \mathrm{E}-02$ \\
\hline $\mathrm{I}-129$ & $5.1 \mathrm{E}-02$ & $<0.05$ & $6.2 \mathrm{E}-03$ & $2.0 \mathrm{E}-01$ \\
\hline U-234 & $5.0 \mathrm{E}-02$ & $<0.05$ & $3.1 \mathrm{E}-02$ & $7.6 \mathrm{E}-02$ \\
\hline $\mathrm{Pu}-240$ & $4.5 \mathrm{E}-02$ & $<0.05$ & $3.0 \mathrm{E}-03$ & $2.2 \mathrm{E}-01$ \\
\hline Ba-140 & $4.2 \mathrm{E}-02$ & $<0.05$ & $1.5 \mathrm{E}-03$ & $2.4 \mathrm{E}-01$ \\
\hline Sc-46 & 3.7E-02 & $<0.05$ & $2.0 \mathrm{E}-03$ & $1.9 \mathrm{E}-01$ \\
\hline Sn-117m & $3.4 \mathrm{E}-02$ & $<0.05$ & $2.0 \mathrm{E}-03$ & $1.7 \mathrm{E}-01$ \\
\hline $\mathrm{I}-131$ & $2.5 \mathrm{E}-02$ & $<0.05$ & $1.5 \mathrm{E}-03$ & $1.2 \mathrm{E}-01$ \\
\hline Mo-99 & $2.4 \mathrm{E}-02$ & $<0.05$ & $1.3 \mathrm{E}-03$ & $1.2 \mathrm{E}-01$ \\
\hline Np-237 & $1.7 \mathrm{E}-02$ & $<0.05$ & $4.3 \mathrm{E}-04$ & $1.0 \mathrm{E}-01$ \\
\hline
\end{tabular}


Table 3-4a. (continued).

\begin{tabular}{lcccc}
\hline Radionuclide & $\begin{array}{c}\text { Best } \\
\text { estimate } \\
(\mathrm{Ci})\end{array}$ & $\begin{array}{c}\text { Percent } \\
\text { of total } \\
(\%)\end{array}$ & $\begin{array}{c}\text { Lower } \\
\text { bound }\end{array}$ & $\begin{array}{c}\text { Upper } \\
\text { bound }\end{array}$ \\
\hline Ru-103 & $1.6 \mathrm{E}-02$ & $<0.05$ & $8.8 \mathrm{E}-04$ & $8.2 \mathrm{E}-02$ \\
$\mathrm{Au}-198$ & $1.6 \mathrm{E}-02$ & $<0.05$ & $9.0 \mathrm{E}-04$ & $8.0 \mathrm{E}-02$ \\
$\mathrm{Se}-75$ & $9.4 \mathrm{E}-03$ & $<0.05$ & $5.1 \mathrm{E}-04$ & $4.8 \mathrm{E}-02$ \\
$\mathrm{U}-236$ & $6.0 \mathrm{E}-03$ & $<0.05$ & $2.9 \mathrm{E}-03$ & $1.1 \mathrm{E}-02$ \\
$\mathrm{Te}-132$ & $2.9 \mathrm{E}-03$ & $<0.05$ & $1.6 \mathrm{E}-04$ & $-1.5 \mathrm{E}-02$ \\
$\mathrm{Sb}-124$ & $2.4 \mathrm{E}-03$ & $<0.05$ & $1.3 \mathrm{E}-04$ & $1.2 \mathrm{E}-02$ \\
$\mathrm{U}-235$ & $1.7 \mathrm{E}-03$ & $<0.05$ & $1.3 \mathrm{E}-03$ & $2.3 \mathrm{E}-03$ \\
$\mathrm{Ag}-110 \mathrm{~m}$ & $9.7 \mathrm{E}-04$ & $<0.05$ & $5.2 \mathrm{E}-05$ & $4.9 \mathrm{E}-03$ \\
$\mathrm{Sr}-89$ & $5.4 \mathrm{E}-04$ & $<0.05$ & $2.9 \mathrm{E}-05$ & $2.7 \mathrm{E}-03$ \\
$\mathrm{Xe}-133$ & $\frac{5.0 \mathrm{E}-04}{3.8 \mathrm{E}+06}$ & $<0.05$ & $2.7 \mathrm{E}-05$ & $2.5 \mathrm{E}-03$ \\
\cline { 5 - 6 } & & 100.0 & & \\
\hline
\end{tabular}


Table 3-4b. Inventory of radiological contaminants (listed alphabetically) from all generators for the years 1994-2003 (activity at time of disposal).

\begin{tabular}{|c|c|c|c|c|}
\hline Radionuclide & $\begin{array}{c}\text { Best } \\
\text { estimate } \\
\text { (Ci) }\end{array}$ & $\begin{array}{l}\text { Percent } \\
\text { of total } \\
(\%)\end{array}$ & $\begin{array}{l}\text { Lower } \\
\text { bound }\end{array}$ & $\begin{array}{l}\text { Upper } \\
\text { bound }\end{array}$ \\
\hline Ag-108 & $1.6 \mathrm{E}-01$ & $<0.05$ & $5.2 \mathrm{E}-03$ & $9.4 \mathrm{E}-01$ \\
\hline $\mathrm{Ag}-110 \mathrm{~m}$ & 9.7E-04 & $<0.05$ & $5.2 \mathrm{E}-05$ & 4.9E-03 \\
\hline Am-241 & 2.1E-01 & $<0.05$ & $1.3 \mathrm{E}-02$ & $1.0 \mathrm{E}+00$ \\
\hline Au-198 & $1.6 E-02$ & $<0.05$ & $9.0 \mathrm{E}-04$ & 8.0E-02 \\
\hline $\mathrm{Ba}-137 \mathrm{~m}$ & $1.1 E+00$ & $<0.05$ & 6.1E-03 & $8.0 \mathrm{E}+00$ \\
\hline $\mathrm{Ba}-140$ & 4.2E-02 & $<0.05$ & $1.5 \mathrm{E}-03$ & 2.4E-01 \\
\hline C-14 & $9.5 E+01$ & $<0.05$ & $7.4 \mathrm{E}+00$ & $4.3 E+02$ \\
\hline Ce-141 & $1.4 \mathrm{E}-01$ & $<0.05$ & 8.1E-03 & $6.7 \mathrm{E}-01$ \\
\hline Ce-144 & $5.8 \mathrm{E}+01$ & $<0.05$ & $7.2 \mathrm{E}+00$ & $2.3 E+02$ \\
\hline $\mathrm{Cm}-242$ & $2.2 \mathrm{E}-01$ & $<0.05$ & $1.6 \mathrm{E}-02$ & $1.0 \mathrm{E}+00$ \\
\hline $\mathrm{Cm}-244$ & $1.9 \mathrm{E}-01$ & $<0.05$ & $1.2 \mathrm{E}-02$ & $9.3 \mathrm{E}-01$ \\
\hline Co-57 & $1.2 \mathrm{E}-01$ & $<0.05$ & 4.5E-03 & $6.8 \mathrm{E}-01$ \\
\hline Co-58 & $1.0 \mathrm{E}+05$ & 2.7 & $5.9 E+03$ & $5.0 \mathrm{E}+05$ \\
\hline Co-60 & $7.9 E+05$ & 21.0 & $3.1 E+05$ & $1.7 \mathrm{E}+06$ \\
\hline $\mathrm{Cr}-51$ & $2.6 \mathrm{E}+04$ & 0.7 & $1.6 \mathrm{E}+03$ & $1.3 \mathrm{E}+05$ \\
\hline Cs-134 & $5.0 \mathrm{E}+00$ & $<0.05$ & $8.5 \mathrm{E}-01$ & $1.7 \mathrm{E}+01$ \\
\hline Cs-137 & $1.6 \mathrm{E}+03$ & $<0.05$ & $6.3 E+02$ & $3.3 E+03$ \\
\hline Eu-152 & $6.9 \mathrm{E}-01$ & $<0.05$ & 3.8E-02 & $3.5 \mathrm{E}+00$ \\
\hline Eu-154 & $1.4 \mathrm{E}+00$ & $<0.05$ & $1.6 \mathrm{E}-01$ & $5.5 \mathrm{E}+00$ \\
\hline Eu-155 & $7.2 E+01$ & $<0.05$ & $4.4 E+00$ & $3.5 \mathrm{E}+02$ \\
\hline $\mathrm{Fe}-55$ & $3.8 E+04$ & 1.0 & $1.7 E+04$ & $7.6 \mathrm{E}+04$ \\
\hline $\mathrm{Fe}-59$ & $8.1 E+03$ & 0.2 & $4.4 E+02$ & $4.1 E+04$ \\
\hline $\mathrm{H}-3$ & $2.6 E+06$ & 70.4 & $1.3 E+06$ & $5.0 \mathrm{E}+06$ \\
\hline Hf- 181 & $1.6 \mathrm{E}-01$ & $<0.05$ & 8.8E-03 & 8.3E-01 \\
\hline I-129 & $5.1 \mathrm{E}-02$ & $<0.05$ & $6.2 \mathrm{E}-03$ & $2.0 \mathrm{E}-01$ \\
\hline $\mathrm{I}-131$ & $2.5 \mathrm{E}-02$ & $<0.05$ & $1.5 \mathrm{E}-03$ & $1.2 \mathrm{E}-01$ \\
\hline In-113m & $5.4 \mathrm{E}-02$ & $<0.05$ & 3.1E-03 & 2.7E-01 \\
\hline
\end{tabular}


Table 3-4b. (continued).

\begin{tabular}{|c|c|c|c|c|}
\hline Radionuclide & $\begin{array}{c}\text { Best } \\
\text { estimate } \\
\text { (Ci) }\end{array}$ & $\begin{array}{c}\text { Percent } \\
\text { of total } \\
(\%)\end{array}$ & $\begin{array}{l}\text { Lower } \\
\text { bound }\end{array}$ & $\begin{array}{l}\text { Upper } \\
\text { bound }\end{array}$ \\
\hline $\mathrm{I} r-192$ & $1.4 E+00$ & $<0.05$ & $1.4 \mathrm{E}-01$ & $5.7 E+00$ \\
\hline La-140 & $1.1 \mathrm{E}-01$ & $<0.05$ & $6.5 \mathrm{E}-03$ & 5.4E-01 \\
\hline Mn-54 & $6.5 E+04$ & 1.7 & $3.5 \mathrm{E}+03$ & $3.3 E+05$ \\
\hline Mo-99 & $2.4 \mathrm{E}-02$ & $<0.05$ & $1.3 \mathrm{E}-03$ & $1.2 \mathrm{E}-01$ \\
\hline $\mathrm{Na}-22$ & $1.1 \mathrm{E}-01$ & $<0.05$ & $6.1 \mathrm{E}-03$ & $5.5 \mathrm{E}-01$ \\
\hline $\mathrm{Nb}-94$ & $1.9 \mathrm{E}+00$ & $<0.05$ & $1.9 \mathrm{E}-02$ & $1.3 \mathrm{E}+01$ \\
\hline $\mathrm{Nb}-95$ & $6.8 E+03$ & 0.2 & $2.2 E+03$ & $1.6 \mathrm{E}+04$ \\
\hline $\mathrm{Ni}-59$ & $1.9 E+02$ & $<0.05$ & $1.9 E+00$ & $1.3 \mathrm{E}+03$ \\
\hline $\mathrm{Ni}-63$ & $6.9 E+04$ & 1.8 & $2.5 \mathrm{E}+04$ & $1.5 \mathrm{E}+05$ \\
\hline Np-237 & $1.7 \mathrm{E}-02$ & $<0.05$ & $4.3 E-04$ & $1.0 \mathrm{E}-01$ \\
\hline $\operatorname{Pr}-144$ & $2.6 \mathrm{E}+00$ & $<0.05$ & 2.5E-01 & $1.1 \mathrm{E}+01$ \\
\hline Pu-238 & 4.1E-01 & $<0.05$ & $2.6 \mathrm{E}-02$ & $2.0 \mathrm{E}+00$ \\
\hline $\mathrm{Pu}-239$ & 4.2E-01 & $<0.05$ & 2.7E-02 & $2.0 \mathrm{E}+00$ \\
\hline $\mathrm{Pu}-240$ & 4.5E-02 & $<0.05$ & $3.0 \mathrm{E}-03$ & 2.2E-01 \\
\hline $\mathrm{Pu}-241$ & $4.6 E+01$ & $<0.05$ & $3.0 E+00$ & $2.2 \mathrm{E}+02$ \\
\hline Rh-106 & 3.9E-01 & $<0.05$ & $3.2 E-02$ & $1.7 E+00$ \\
\hline $\mathrm{Ru}-103$ & $1.6 \mathrm{E}-02$ & $<0.05$ & $8.8 \mathrm{E}-04$ & $8.2 \mathrm{E}-02$ \\
\hline Ru-106 & 4.0E-01 & $<0.05$ & $3.4 \mathrm{E}-02$ & $1.8 E+00$ \\
\hline Sb-124 & $2.4 E-03$ & $<0.05$ & $1.3 E-04$ & $1.2 \mathrm{E}-02$ \\
\hline Sb-125 & $4.1 \mathrm{E}+00$ & $<0.05$ & 3.7E-01 & $1.8 \mathrm{E}+01$ \\
\hline Sc-46 & 3.7E-02 & $<0.05$ & $2.0 \mathrm{E}-03$ & $1.9 \mathrm{E}-01$ \\
\hline Se-75 & $9.4 E-03$ & $<0.05$ & 5.1E-04 & 4.8E-02 \\
\hline Sn-113 & $6.3 \mathrm{E}-02$ & $<0.05$ & 3.7E-03 & $3.1 \mathrm{E}-01$ \\
\hline $\mathrm{Sn}-117 \mathrm{~m}$ & $3.4 \mathrm{E}-02$ & $<0.05$ & $2.0 \mathrm{E}-03$ & $1.7 \mathrm{E}-01$ \\
\hline Sr-89 & $5.4 \mathrm{E}-04$ & $<0.05$ & 2.9E-05 & $2.7 \mathrm{E}-03$ \\
\hline Sr-90 & $8.2 E+01$ & $<0.05$ & $1.1 E+01$ & $3.1 E+02$ \\
\hline Ta-182 & $7.6 E+03$ & 0.2 & $2.4 \mathrm{E}+03$ & $1.8 \mathrm{E}+04$ \\
\hline
\end{tabular}


Table 3-4b. (continued).

\begin{tabular}{|c|c|c|c|c|}
\hline Radionuclide & $\begin{array}{c}\text { Best } \\
\text { estimate } \\
\text { (Ci) }\end{array}$ & $\begin{array}{l}\text { Percent } \\
\text { of total } \\
(\%)\end{array}$ & $\begin{array}{l}\text { Lower } \\
\text { bound }\end{array}$ & $\begin{array}{l}\text { Upper } \\
\text { bound }\end{array}$ \\
\hline Tc-99 & $1.4 E+00$ & $<0.05$ & $8.6 \mathrm{E}-02$ & $6.7 \mathrm{E}+00$ \\
\hline Te-132 & 2.9E-03 & $<0.05$ & $1.6 \mathrm{E}-04$ & $1.5 E-02$ \\
\hline U-234 & $5.0 \mathrm{E}-02$ & $<0.05$ & 3.1E-02 & $7.6 \mathrm{E}-02$ \\
\hline $\mathrm{U}-235$ & 1.7E-03 & $<0.05$ & $1.3 \mathrm{E}-03$ & 2.3E-03 \\
\hline U-236 & $6.0 \mathrm{E}-03$ & $<0.05$ & $2.9 \mathrm{E}-03$ & $1.1 E-02$ \\
\hline $\mathrm{U}-238$ & $5.2 \mathrm{E}-02$ & $<0.05$ & $3.2 \mathrm{E}-02$ & 7.8E-02 \\
\hline $\mathrm{Xe}-133$ & $5.0 \mathrm{E}-04$ & $<0.05$ & $2.7 \mathrm{E}-05$ & $2.5 \mathrm{E}-03$ \\
\hline$Y-90$ & $6.9 E+01$ & $<0.05$ & $7.0 \mathrm{E}+00$ & $2.9 E+02$ \\
\hline $\mathrm{Zn}-65$ & $1.2 E+00$ & $<0.05$ & $6.5 \mathrm{E}-02$ & $6.1 E+00$ \\
\hline $\mathrm{Zr}-95$ & $3.2 E+03$ & 0.1 & $1.0 \mathrm{E}+03$ & $7.7 E+03$ \\
\hline Total & $3.8 E+06$ & 100.0 & & \\
\hline
\end{tabular}


Table 3-5a. Inventory of nonradiological contaminants (listed by quantity) from Test Area North for the years 1984-1993.

\begin{tabular}{ccccc}
\hline $\begin{array}{c}\text { CAS } \\
\text { number }\end{array}$ & Chemical & $\begin{array}{c}\text { Best } \\
\text { estimate } \\
(\mathrm{g})\end{array}$ & $\begin{array}{c}\text { Lower } \\
\text { bound }\end{array}$ & $\begin{array}{c}\text { Upper } \\
\text { bound }\end{array}$ \\
\hline $7439-92-1$ & Lead & $5.4 E+06$ & $4.9 \mathrm{E}+06$ & $5.9 \mathrm{E}+06$ \\
\hline
\end{tabular}

Table 3-5b. Inventory of nonradiological contaminants (listed alphabetically) from Test Area North for the years 1984-1993.

\begin{tabular}{ccccc}
\hline $\begin{array}{c}\text { CAS } \\
\text { number }\end{array}$ & Chemical & $\begin{array}{c}\text { Best } \\
\text { estimate } \\
(\mathrm{g})\end{array}$ & $\begin{array}{c}\text { Lower } \\
\text { bound }\end{array}$ & $\begin{array}{c}\text { Upper } \\
\text { bound }\end{array}$ \\
\hline $7439-92-1$ & Lead & $5.4 \mathrm{E}+06$ & $4.9 \mathrm{E}+06$ & $5.9 \mathrm{E}+06$ \\
\hline
\end{tabular}


Table 3-6a. Inventory of radiological contaminants (listed by quantity) from Test Area North for the years 1984-1993 (activity at time of disposal).

\begin{tabular}{|c|c|c|c|c|}
\hline Radionuclide & $\begin{array}{c}\text { Best } \\
\text { estimate } \\
\text { (Ci) }\end{array}$ & $\begin{array}{c}\text { Percent } \\
\text { of total } \\
(\%)\end{array}$ & $\begin{array}{l}\text { Lower } \\
\text { bound }\end{array}$ & $\begin{array}{l}\text { Upper } \\
\text { bound }\end{array}$ \\
\hline Cs-137 & $1.7 \mathrm{E}+03$ & 76.4 & $3.1 E+02$ & $5.5 \mathrm{E}+03$ \\
\hline Sr-90 & $2.6 \mathrm{E}+02$ & 11.8 & $4.5 \mathrm{E}+00$ & $1.7 \mathrm{E}+03$ \\
\hline $\mathrm{Ni}-63$ & $8.1 \mathrm{E}+01$ & 3.7 & $9.8 \mathrm{E}+00$ & $3.2 \mathrm{E}+02$ \\
\hline $\mathrm{Co}-60$ & $6.4 \mathrm{E}+01$ & 2.9 & $1.2 \mathrm{E}+01$ & $2.1 \mathrm{E}+02$ \\
\hline Cs-134 & $4.6 \mathrm{E}+01$ & 2.1 & $6.5 \mathrm{E}-01$. & $3.0 \mathrm{E}+02$ \\
\hline $\mathrm{Mn}-54$ & $2.5 E+01$ & 1.1 & $1.6 \mathrm{E}-01$ & 1.8E+02 \\
\hline $\mathrm{Fe}-55$ & $2.4 \mathrm{E}+01$ & 1.1 & $2.9 \mathrm{E}+00$ & $9.4 \mathrm{E}+01$ \\
\hline Co-58 & $1.0 \mathrm{E}+01$ & 0.5 & $6.3 \mathrm{E}-02$ & $7.6 \mathrm{E}+01$ \\
\hline Ce-144 & $6.5 \mathrm{E}+00$ & 0.3 & $5.5 \mathrm{E}-02$ & $4.6 \mathrm{E}+01$ \\
\hline Sb-125 & $1.4 \mathrm{E}+00$ & 0.1 & $1.4 \mathrm{E}-02$ & $9.4 \mathrm{E}+00$ \\
\hline $\mathrm{H}-3$ & $1.2 \mathrm{E}+00$ & $<0.05$ & $1.2 \mathrm{E}-02$ & $8.0 \mathrm{E}+00$ \\
\hline U-238 & $9.7 \mathrm{E}-01$ & $<0.05$ & $9.2 \mathrm{E}-01$ & $1.0 \mathrm{E}+00$ \\
\hline U-234 & $2.7 \mathrm{E}-01$ & $<0.05$ & 2.6E-01 & $2.9 \mathrm{E}-01$ \\
\hline $\mathrm{Ru}-106$ & $1.9 \mathrm{E}-01$ & $<0.05$ & $1.6 \mathrm{E}-03$ & $1.3 \mathrm{E}+00$ \\
\hline Ba-140 & $7.6 \mathrm{E}-02$ & $<0.05$ & $4.0 \mathrm{E}-04$ & $5.5 \mathrm{E}-01$ \\
\hline Am-241 & $3.6 \mathrm{E}-02$ & $<0.05$ & $1.9 \mathrm{E}-04$ & $2.6 \mathrm{E}-01$ \\
\hline $\mathrm{Cr}-51$ & $1.7 \mathrm{E}-02$ & $<0.05$ & $1.1 \mathrm{E}-04$ & $1.2 \mathrm{E}-01$ \\
\hline $\mathrm{Ag}-110 \mathrm{~m}$ & $1.6 \mathrm{E}-02$ & $<0.05$ & 9.3E-05 & $1.1 \mathrm{E}-01$ \\
\hline U-235 & $1.3 \mathrm{E}-02$ & $<0.05$ & $1.2 \mathrm{E}-02$ & $1.4 \mathrm{E}-02$ \\
\hline C-14 & $1.2 \mathrm{E}-02$ & $<0.05$ & $6.5 \mathrm{E}-05$ & $9.0 \mathrm{E}-02$ \\
\hline Pu-239 & $8.1 \mathrm{E}-03$ & $<0.05$ & $4.8 \mathrm{E}-05$ & $5.8 \mathrm{E}-02$ \\
\hline $\mathrm{I}-131$ & 7.1E-03 & $<0.05$ & 7.8E-05 & 4.8E-02 \\
\hline $\mathrm{Pu}-241$ & $6.5 \mathrm{E}-03$ & $<0.05$ & $3.4 \mathrm{E}-05$ & 4.7E-02 \\
\hline St-89 & $3.0 \mathrm{E}-03$ & $<0.05$ & $1.6 \mathrm{E}-05$ & 2.1E-02 \\
\hline Tc-99 & $2.7 \mathrm{E}-03$ & $<0.05$ & $1.4 \mathrm{E}-05$ & $2.0 \mathrm{E}-02$ \\
\hline $\mathrm{Cm}-244$ & $1.1 \mathrm{E}-03$ & $<0.05$ & $6.0 \mathrm{E}-06$ & $8.2 \mathrm{E}-03$ \\
\hline Eu-155 & $1.0 \mathrm{E}-03$ & $<0.05$ & $5.6 \mathrm{E}-06$ & 7.3E-03 \\
\hline
\end{tabular}


Table 3-6a. (continued).

\begin{tabular}{lllll}
\hline Radionuclide & $\begin{array}{c}\text { Best } \\
\text { estimate } \\
(\mathrm{Ci})\end{array}$ & $\begin{array}{c}\text { Percent } \\
\text { of total } \\
(\%)\end{array}$ & $\begin{array}{c}\text { Lower } \\
\text { bound }\end{array}$ & $\begin{array}{c}\text { Upper } \\
\text { bound }\end{array}$ \\
\hline I-129 & $2.7 \mathrm{E}-04$ & $<0.05$ & $1.4 \mathrm{E}-06$ & $1.9 \mathrm{E}-03$ \\
Pu-238 & $2.2 \mathrm{E}-04$ & $<0.05$ & $1.2 \mathrm{E}-06$ & $1.6 \mathrm{E}-03$ \\
Fe-59 & $1.9 \mathrm{E}-04$ & $<0.05$ & $1.0 \mathrm{E}-06$ & $1.4 \mathrm{E}-03$ \\
Pu-240 & $1.3 \mathrm{E}-04$ & $<0.05$ & $6.8 \mathrm{E}-07$ & $9.3 \mathrm{E}-04$ \\
Eu-154 & $1.0 \mathrm{E}-05$ & $<0.05$ & $5.6 \mathrm{E}-08$ & $7.6 \mathrm{E}-05$ \\
Nb-94 & $3.4 \mathrm{E}-06$ & $<0.05$ & $1.8 \mathrm{E}-08$ & $2.5 \mathrm{E}-05$ \\
Eu-152 & $2.4 \mathrm{E}-06$ & $<0.05$ & $1.2 \mathrm{E}-08$ & $1.7 \mathrm{E}-05$ \\
$\mathrm{U}-236$ & $5.5 \mathrm{E}-07$ & $<0.05$ & $2.6 \mathrm{E}-07$ & $1.0 \mathrm{E}-06$ \\
Np-237 & $6.0 \mathrm{E}-08$ & $<0.05$ & $3.2 \mathrm{E}-10$ & $4.4 \mathrm{E}-07$ \\
Cm-242 & $4.9 \mathrm{E}-08$ & $<0.05$ & $2.6 \mathrm{E}-10$ & $3.6 \mathrm{E}-07$ \\
Pu-242 & $1.2 \mathrm{E}-08$ & $<0.05$ & $6.0 \mathrm{E}-11$ & $8.9 \mathrm{E}-08$ \\
Total & $2.2 \mathrm{E}+03$ & 100.0 & & \\
\hline
\end{tabular}


Table 3-6b. Inventory of radiological contaminants (listed alphabetically) from Test Area North for the years 1984-1993 (activity at time of disposal).

\begin{tabular}{|c|c|c|c|c|}
\hline Radionuclide & $\begin{array}{c}\text { Best } \\
\text { estimate } \\
(\mathrm{Ci})\end{array}$ & $\begin{array}{c}\text { Percent } \\
\text { of total } \\
(\%)\end{array}$ & $\begin{array}{l}\text { Lower } \\
\text { bound }\end{array}$ & $\begin{array}{l}\text { Upper } \\
\text { bound }\end{array}$ \\
\hline $\mathrm{Ag}-110 \mathrm{~m}$ & $1.6 \mathrm{E}-02$ & $<0.05$ & $9.3 \mathrm{E}-05$ & $1.1 \mathrm{E}-01$ \\
\hline Am-241 & $3.6 \mathrm{E}-02$ & $<0.05$ & $1.9 \mathrm{E}-04$ & $2.6 \mathrm{E}-01$ \\
\hline Ba-140 & $7.6 \mathrm{E}-02$ & $<0.05$ & $4.0 \mathrm{E}-04$ & $5.5 \mathrm{E}-01$ \\
\hline C-14 & $1.2 \mathrm{E}-02$ & $<0.05$ & $6.5 \mathrm{E}-05$ & $9.0 \mathrm{E}-02$ \\
\hline Ce-144 & $6.5 \mathrm{E}+00$ & 0.3 & $5.5 \mathrm{E}-02$ & $4.6 \mathrm{E}+01$ \\
\hline $\mathrm{Cm}-242$ & 4.9E-08 & $<0.05$ & $2.6 \mathrm{E}-10$ & $3.6 \mathrm{E}-07$ \\
\hline $\mathrm{Cm}-244$ & $1.1 \mathrm{E}-03$ & $<0.05$ & $6.0 \mathrm{E}-06$ & $8.2 \mathrm{E}-03$ \\
\hline Co-58 & $1.0 \mathrm{E}+01$ & 0.5 & $6.3 \mathrm{E}-02$ & $7.6 \mathrm{E}+01$ \\
\hline Co-60 & $6.4 \mathrm{E}+01$ & 2.9 & $1.2 \mathrm{E}+01$ & $2.1 \mathrm{E}+02$ \\
\hline $\mathrm{Cr}-51$ & $1.7 \mathrm{E}-02$ & $<0.05$ & $1.1 \mathrm{E}-04$ & $1.2 \mathrm{E}-01$ \\
\hline Cs-134 & $4.6 \mathrm{E}+01$ & 2.1 & $6.5 \mathrm{E}-01$ & $3.0 \mathrm{E}+02$ \\
\hline Cs-137 & $1.7 \mathrm{E}+03$ & 76.4 & $3.1 \mathrm{E}+02$ & $5.5 \mathrm{E}+03$ \\
\hline Eu-152 & $2.4 \mathrm{E}-06$ & $<0.05$ & $1.2 \mathrm{E}-08$ & $1.7 \mathrm{E}-05$ \\
\hline Eu-154 & $1.0 \mathrm{E}-05$ & $<0.05$ & $5.6 \mathrm{E}-08$ & 7.6E-05 \\
\hline Eu-155 & $1.0 \mathrm{E}-03$ & $<0.05$ & $5.6 \mathrm{E}-06$ & $7.3 \mathrm{E}-03$ \\
\hline $\mathrm{Fe}-55$ & $2.4 \mathrm{E}+01$ & 1.1 & $2.9 \mathrm{E}+00$ & $9.4 \mathrm{E}+01$ \\
\hline $\mathrm{Fe}-59$ & $1.9 \mathrm{E}-04$ & $<0.05$ & $1.0 \mathrm{E}-06$ & $1.4 \mathrm{E}-03$ \\
\hline $\mathrm{H}-3$ & $1.2 \mathrm{E}+00$ & $<0.05$ & $1.2 \mathrm{E}-02$ & $8.0 \mathrm{E}+00$ \\
\hline $\mathrm{I}-129$ & $2.7 \mathrm{E}-04$ & $<0.05$ & $1.4 \mathrm{E}-06$ & $1.9 \mathrm{E}-03$ \\
\hline $\mathrm{I}-131$ & $7.1 \mathrm{E}-03$ & $<0.05$ & $7.8 \mathrm{E}-05$ & $4.8 \mathrm{E}-02$ \\
\hline $\mathrm{Mn}-54$ & $2.5 \mathrm{E}+01$ & 1.1 & $1.6 \mathrm{E}-01$ & $1.8 \mathrm{E}+02$ \\
\hline Nb-94 & $3.4 \mathrm{E}-06$ & $<0.05$ & $1.8 \mathrm{E}-08$ & $2.5 \mathrm{E}-05$ \\
\hline $\mathrm{Ni}-63$ & $8.1 \mathrm{E}+01$ & 3.7 & $9.8 \mathrm{E}+00$ & $3.2 \mathrm{E}+02$ \\
\hline Np-237 & $6.0 \mathrm{E}-08$ & $<0.05$ & $3.2 \mathrm{E}-10$ & 4.4E-07 \\
\hline $\mathrm{Pu}-238$ & $2.2 \mathrm{E}-04$ & $<0.05$ & $1.2 \mathrm{E}-06$ & $1.6 \mathrm{E}-03$ \\
\hline $\mathrm{Pu}-239$ & $8.1 \mathrm{E}-03$ & $<0.05$ & $4.8 \mathrm{E}-05$ & $5.8 \mathrm{E}-02$ \\
\hline Pu-240 & $1.3 \mathrm{E}-04$ & $<0.05$ & $6.8 \mathrm{E}-07$ & $9.3 \mathrm{E}-04$ \\
\hline
\end{tabular}


Table 3-6b. (continued).

\begin{tabular}{lllll}
\hline Radionuclide & $\begin{array}{c}\text { Best } \\
\text { estimate } \\
(\mathrm{Ci})\end{array}$ & $\begin{array}{c}\text { Percent } \\
\text { of total } \\
(\%)\end{array}$ & $\begin{array}{c}\text { Lower } \\
\text { bound }\end{array}$ & $\begin{array}{c}\text { Upper } \\
\text { bound }\end{array}$ \\
\hline Pu-241 & $6.5 \mathrm{E}-03$ & $<0.05$ & $3.4 \mathrm{E}-05$ & $4.7 \mathrm{E}-02$ \\
Pu-242 & $1.2 \mathrm{E}-08$ & $<0.05$ & $6.0 \mathrm{E}-11$ & $8.9 \mathrm{E}-08$ \\
Ru-106 & $1.9 \mathrm{E}-01$ & $<0.05$ & $1.6 \mathrm{E}-03$ & $1.3 \mathrm{E}+00$ \\
Sb-125 & $1.4 \mathrm{E}+00$ & 0.1 & $1.4 \mathrm{E}-02$ & $9.4 \mathrm{E}+00$ \\
Sr-89 & $3.0 \mathrm{E}-03$ & $<0.05$ & $1.6 \mathrm{E}-05$ & $2.1 \mathrm{E}-02$ \\
Sr-90 & $2.6 \mathrm{E}+02$ & 11.8 & $4.5 \mathrm{E}+00$ & $1.7 \mathrm{E}+03$ \\
Tc-99 & $2.7 \mathrm{E}-03$ & $<0.05$ & $1.4 \mathrm{E}-05$ & $2.0 \mathrm{E}-02$ \\
$\mathrm{U}-234$ & $2.7 \mathrm{E}-01$ & $<0.05$ & $2.6 \mathrm{E}-01$ & $2.9 \mathrm{E}-01$ \\
$\mathrm{U}-235$ & $1.3 \mathrm{E}-02$ & $<0.05$ & $1.2 \mathrm{E}-02$ & $1.4 \mathrm{E}-02$ \\
$\mathrm{U}-236$ & $5.5 \mathrm{E}-07$ & $<0.05$ & $2.6 \mathrm{E}-07$ & $1.0 \mathrm{E}-06$ \\
$\mathrm{U}-238$ & $9.7 \mathrm{E}-01$ & $<0.05$ & $9.2 \mathrm{E}-01$ & $1.0 \mathrm{E}+00$ \\
Total & $2.2 \mathrm{E}+03$ & 100.0 & & \\
\hline
\end{tabular}


Table 3-7a. Inventory of radiological contaminants (listed by quantity) from the Test Area North for the years 1994-2003 (activity at time of disposal).

\begin{tabular}{lcccl}
\hline Radionuclide & $\begin{array}{c}\text { Best } \\
\text { estimate } \\
(\mathrm{Ci})\end{array}$ & $\begin{array}{c}\text { Percent } \\
\text { of total } \\
(\%)\end{array}$ & $\begin{array}{c}\text { Lower } \\
\text { bound }\end{array}$ & $\begin{array}{c}\text { Upper } \\
\text { bound }\end{array}$ \\
\hline Cs-137 & $7.2 \mathrm{E}-01$ & 46.4 & $2.6 \mathrm{E}-01$ & $1.6 \mathrm{E}+00$ \\
Sr-90 & $4.5 \mathrm{E}-01$ & 29.2 & $2.4 \mathrm{E}-02$ & $2.3 \mathrm{E}+00$ \\
Cs-134 & $3.3 \mathrm{E}-01$ & 21.3 & $1.8 \mathrm{E}-02$ & $1.7 \mathrm{E}+00$ \\
$\mathrm{U}-238$ & $3.2 \mathrm{E}-02$ & 2.1 & $1.7 \mathrm{E}-02$ & $5.6 \mathrm{E}-02$ \\
$\mathrm{U}-234$ & $1.3 \mathrm{E}-02$ & 0.8 & $6.9 \mathrm{E}-03$ & $2.3 \mathrm{E}-02$ \\
Co-60 & $1.4 \mathrm{E}-03$ & 0.1 & $5.0 \mathrm{E}-04$ & $3.2 \mathrm{E}-03$ \\
$\mathrm{U}-235$ & $6.6 \mathrm{E}-04$ & $<0.05$ & $4.0 \mathrm{E}-04$ & $1.0 \mathrm{E}-03$ \\
Total & $1.5 \mathrm{E}+00$ & 99.9 & & \\
\hline
\end{tabular}

Table 3-7b. Inventory of radiological contaminants (listed alphabetically) from the Test Area North for the years 1994-2003 (activity at time of disposal).

\begin{tabular}{lcccl}
\hline Radionuclide & $\begin{array}{c}\text { Best } \\
\text { estimate } \\
(\mathrm{Ci})\end{array}$ & $\begin{array}{c}\text { Percent } \\
\text { of total } \\
(\%)\end{array}$ & $\begin{array}{c}\text { Lower } \\
\text { bound }\end{array}$ & $\begin{array}{c}\text { Upper } \\
\text { bound }\end{array}$ \\
\hline Co-60 & $1.4 \mathrm{E}-03$ & 0.1 & $5.0 \mathrm{E}-04$ & $3.2 \mathrm{E}-03$ \\
Cs-134 & $3.3 \mathrm{E}-01$ & 21.3 & $1.8 \mathrm{E}-02$ & $1.7 \mathrm{E}+00$ \\
Cs-137 & $7.2 \mathrm{E}-01$ & 46.4 & $2.6 \mathrm{E}-01$ & $1.6 \mathrm{E}+00$ \\
Sr-90 & $4.5 \mathrm{E}-01$ & 29.2 & $2.4 \mathrm{E}-02$ & $2.3 \mathrm{E}+00$ \\
$\mathrm{U}-234$ & $1.3 \mathrm{E}-02$ & 0.8 & $6.9 \mathrm{E}-03$ & $2.3 \mathrm{E}-02$ \\
$\mathrm{U}-235$ & $6.6 \mathrm{E}-04$ & $<0.05$ & $4.0 \mathrm{E}-04$ & $1.0 \mathrm{E}-03$ \\
$\mathrm{U}-238$ & $3.2 \mathrm{E}-02$ & 2.1 & $1.7 \mathrm{E}-02$ & $5.6 \mathrm{E}-02$ \\
\cline { 5 - 5 } Total & $1.5 \mathrm{E}+00$ & 99.9 & & \\
\hline
\end{tabular}


Table 3-8a. Inventory of nonradiological contaminants (listed by quantity) from the Test Reactor Area for the years 1984-1993.

\begin{tabular}{clccc}
\hline $\begin{array}{c}\text { CAS } \\
\text { number }\end{array}$ & Chemical & $\begin{array}{c}\text { Best } \\
\text { estimate } \\
(\mathrm{g})\end{array}$ & $\begin{array}{c}\text { Lower } \\
\text { bound }\end{array}$ & $\begin{array}{c}\text { Upper } \\
\text { bound }\end{array}$ \\
\hline $7440-41-7$ & Beryllium & $6.3 \mathrm{E}+06$ & $6.3 \mathrm{E}+06$ & $6.4 \mathrm{E}+06$ \\
$7439-92-1$ & Lead & $1.6 \mathrm{E}+06$ & $2.0 \mathrm{E}-09$ & $3.1 \mathrm{E}+06$ \\
\hline
\end{tabular}

Table 3-8b. Inventory of nonradiological contaminants (listed alphabetically) from the Test Reactor Area for the years 1984-1993.

\begin{tabular}{lllcc}
\hline $\begin{array}{c}\text { CAS } \\
\text { number }\end{array}$ & Chemical & $\begin{array}{c}\text { Best } \\
\text { estimate } \\
(\mathrm{g})\end{array}$ & $\begin{array}{c}\text { Lower } \\
\text { bound }\end{array}$ & $\begin{array}{c}\text { Upper } \\
\text { bound }\end{array}$ \\
\hline $7440-41-7$ & Beryllium & $6.3 \mathrm{E}+06$ & $6.3 \mathrm{E}+06$ & $6.4 \mathrm{E}+06$ \\
$7439-92-1$ & Lead & $1.6 \mathrm{E}+06$ & $2.0 \mathrm{E}-09$ & $3.1 \mathrm{E}+06$ \\
\hline
\end{tabular}


Table 3-9a. Inventory of nonradiological contaminants (listed by quantity) from the Test Reactor Area for the years 1994-2003.

\begin{tabular}{ccccc}
\hline $\begin{array}{c}\text { CAS } \\
\text { number }\end{array}$ & Chemical & $\begin{array}{c}\text { Best } \\
\text { estimate } \\
(\mathrm{g})\end{array}$ & $\begin{array}{c}\text { Lower } \\
\text { bound }\end{array}$ & $\begin{array}{c}\text { Upper } \\
\text { bound }\end{array}$ \\
\hline $7440-41-7$ & Beryllium & $5.0 \mathrm{E}+07$ & $5.0 \mathrm{E}+07$ & $5.1 \mathrm{E}+07$ \\
\hline
\end{tabular}

Table 3-9b. Inventory of nonradiological contaminants (listed alphabetically) from the Test Reactor Area for the years 1994-2003.

\begin{tabular}{ccccc}
\hline $\begin{array}{c}\text { CAS } \\
\text { number }\end{array}$ & Chemical & $\begin{array}{c}\text { Best } \\
\text { estimate } \\
(\mathrm{g})\end{array}$ & $\begin{array}{c}\text { Lower } \\
\text { bound }\end{array}$ & $\begin{array}{c}\text { Upper } \\
\text { bound }\end{array}$ \\
\hline $7440-41-7$ & Beryllium & $5.0 \mathrm{E}+07$ & $5.0 \mathrm{E}+07$ & $5.1 \mathrm{E}+07$ \\
\hline
\end{tabular}


Table 3-10a. Inventory of radiological contaminants (listed by quantity) from the Test Reactor Area for the years 1984-1993 (activity at time of disposal).

\begin{tabular}{|c|c|c|c|c|}
\hline Radionuclide & $\begin{array}{c}\text { Best } \\
\text { estimate } \\
\text { (Ci) }\end{array}$ & $\begin{array}{c}\text { Percent } \\
\text { of total } \\
(\%)\end{array}$ & $\begin{array}{l}\text { Lower } \\
\text { bound }\end{array}$ & $\begin{array}{l}\text { Upper } \\
\text { bound }\end{array}$ \\
\hline $\mathrm{H}-3$ & $2.9 \mathrm{E}+05$ & 91.2 & $1.0 \mathrm{E}+05$ & $6.7 \mathrm{E}+05$ \\
\hline Co-60 & $1.2 \mathrm{E}+04$ & 3.7 & $3.4 \mathrm{E}+03$ & $3.1 E+04$ \\
\hline $\mathrm{Fe}-55$ & $6.8 \mathrm{E}+03$ & 2.1 & $1.2 \mathrm{E}+03$ & $2.2 E+04$ \\
\hline $\mathrm{Ni}-63$ & $4.0 \mathrm{E}+03$ & 1.2 & $4.2 E+02$ & $1.7 \mathrm{E}+04$ \\
\hline $\mathrm{Cr}-51$ & $2.5 \mathrm{E}+03$ & 0.8 & $5.3 \mathrm{E}+01$ & $1.6 \mathrm{E}+04$ \\
\hline$Z n-65$ & $1.0 \mathrm{E}+03$ & 0.3 & $8.5 E+00$ & $7.2 E+03$ \\
\hline Cs-137 & $8.8 \mathrm{E}+02$ & 0.3 & $2.2 E+02$ & $2.5 E+03$ \\
\hline $\mathrm{Mn}-54$ & $1.6 \mathrm{E}+02$ & $<0.05$ & $2.1 E+00$ & $1.1 E+03$ \\
\hline Nb-95 & $1.4 \mathrm{E}+02$ & $<0.05$ & $9.2 \mathrm{E}-01$ & $1.0 \mathrm{E}+03$ \\
\hline $\mathrm{Zr}-95$ & $1.4 \mathrm{E}+02$ & $<0.05$ & $2.2 \mathrm{E}+00$ & $8.9 \mathrm{E}+02$ \\
\hline Sn- $117 m$ & $1.2 \mathrm{E}+02$ & $<0.05$ & $6.1 \mathrm{E}-01$ & $8.7 \mathrm{E}+02$ \\
\hline Sn-119m & $7.5 \mathrm{E}+01$ & $<0.05^{\circ}$ & $5.6 \mathrm{E}-01$ & $5.3 E+02$ \\
\hline Ce-144 & $6.6 \mathrm{E}+01$ & $<0.05$ & $2.2 \mathrm{E}+00$ & $3.8 \mathrm{E}+02$ \\
\hline Cs-134 & $6.6 E+01$ & $<0.05$ & $1.2 \mathrm{E}+00$ & $4.2 \mathrm{E}+02$ \\
\hline Co-58 & $5.9 \mathrm{E}+01$ & $<0.05$ & $1.0 \mathrm{E}+00$ & $3.8 \mathrm{E}+02$ \\
\hline $\mathrm{Sb}-125$ & $5.0 \mathrm{E}+01$ & $<0.05$ & $6.0 \mathrm{E}-01$ & $3.4 \mathrm{E}+02$ \\
\hline Sc-46 & $5.0 \mathrm{E}+01$ & $<0.05$ & $2.6 \mathrm{E}-01$ & $3.6 \mathrm{E}+02$ \\
\hline $\mathrm{Te}-125 \mathrm{~m}$ & 4.2E+01 & $<0.05$ & $2.2 \mathrm{E}-01$ & $3.0 \mathrm{E}+02$ \\
\hline $\mathrm{Ni}-59$ & $3.1 \mathrm{E}+01$ & $<0.05$ & $1.5 \mathrm{E}-01$ & $2.3 E+02$ \\
\hline C-14 & $3.0 \mathrm{E}+01$ & $<0.05$ & $1.7 \mathrm{E}-01$ & $2.2 \mathrm{E}+02$ \\
\hline Eu-155 & $2.6 \mathrm{E}+01$ & $<0.05$ & $1.5 \mathrm{E}-01$ & $1.9 \mathrm{E}+02$ \\
\hline Sr-90 & $2.6 \mathrm{E}+01$ & $<0.05$ & $6.7 \mathrm{E}-01$ & $1.6 \mathrm{E}+02$ \\
\hline Sn-113 & $2.2 \mathrm{E}+01$ & $<0.05$ & $1.6 \mathrm{E}-01$ & $1.6 \mathrm{E}+02$ \\
\hline $\mathrm{Pu}-241$ & $1.7 \mathrm{E}+01$ & $<0.05$ & $1.0 \mathrm{E}-01$ & $1.2 \mathrm{E}+02$ \\
\hline Am-241 & $3.4 \mathrm{E}+00$ & $<0.05$ & $2.1 \mathrm{E}-02$ & $2.4 \mathrm{E}+01$ \\
\hline Sr-89 & $3.0 \mathrm{E}+00$ & $<0.05$ & 3.7E-02 & $2.0 \mathrm{E}+01$ \\
\hline Ce-141 & $2.9 \mathrm{E}+00$ & $<0.05$ & $5.4 \mathrm{E}-02$ & $1.8 \mathrm{E}+01$ \\
\hline
\end{tabular}


Table 3-10a. (continued).

\begin{tabular}{|c|c|c|c|c|}
\hline Radionuclide & $\begin{array}{l}\text { Best } \\
\text { estimate } \\
\text { (Ci) }\end{array}$ & $\begin{array}{l}\text { Percent } \\
\text { of total } \\
(\%)\end{array}$ & $\begin{array}{l}\text { Lower } \\
\text { bound }\end{array}$ & $\begin{array}{l}\text { Upper } \\
\text { bound }\end{array}$ \\
\hline Hf-175 & $2.8 \mathrm{E}+00$ & $<0.05$ & $1.5 \mathrm{E}-02$ & $2.0 \mathrm{E}+01$ \\
\hline $\mathrm{Na}-24$ & $2.7 E+00$ & $<0.05$ & $2.0 \mathrm{E}-02$ & $1.9 \mathrm{E}+01$ \\
\hline La-140 & $2.5 \mathrm{E}+00$ & $<0.05$ & $3.2 \mathrm{E}-02$ & $1.6 \mathrm{E}+01$ \\
\hline Pm-147 & $2.4 \mathrm{E}+00$ & $<0.05$ & $1.2 \mathrm{E}-02$ & $1.7 \mathrm{E}+01$ \\
\hline $\mathrm{Ba}-140$ & $2.1 E+00$ & $<0.05$ & $2.7 \mathrm{E}-02$ & $1.4 \mathrm{E}+01$ \\
\hline $\mathrm{Ag}-110$ & $1.9 \mathrm{E}+00$ & $<0.05$ & $1.0 \mathrm{E}-02$ & $1.4 \mathrm{E}+01$ \\
\hline Hf-181 & $1.7 \mathrm{E}+00$ & $<0.05$ & 2.4E-02 & $1.1 \mathrm{E}+01$ \\
\hline $\operatorname{Pr}-144$ & $1.4 \mathrm{E}+00$ & $<0.05$ & $1.3 \mathrm{E}-02$ & $9.7 \mathrm{E}+00$ \\
\hline Mn-56 & $1.3 E+00$ & $<0.05$ & $6.6 \mathrm{E}-03$ & $9.5 \mathrm{E}+00$ \\
\hline Gd-153 & $1.3 E+00$ & $<0.05$ & $1.1 \mathrm{E}-02$ & $9.2 \mathrm{E}+00$ \\
\hline $\mathrm{I}-132$ & $1.0 \mathrm{E}+00$ & $<0.05$ & $5.6 \mathrm{E}-03$ & $7.3 \mathrm{E}+00$ \\
\hline Eu-152 & $9.9 \mathrm{E}-01$ & $<0.05$ & $5.2 \mathrm{E}-03$ & $7.2 \mathrm{E}+00$ \\
\hline Fe-59 & $8.6 \mathrm{E}-01$ & $<0.05$ & $5.1 \mathrm{E}-03$ & $6.2 \mathrm{E}+00$ \\
\hline Ir-192 & $6.6 \mathrm{E}-01$ & $<0.05$ & $5.4 \mathrm{E}-03$ & $4.6 \mathrm{E}+00$ \\
\hline Tc-99 & $5.0 \mathrm{E}-01$ & $<0.05$ & $2.7 \mathrm{E}-03$ & $3.6 \mathrm{E}+00$ \\
\hline Eu-154 & $4.9 \mathrm{E}-01$ & $<0.05$ & $1.2 \mathrm{E}-02$ & $3.0 \mathrm{E}+00$ \\
\hline $\mathrm{Nb}-94$ & $2.0 \mathrm{E}-01$ & $<0.05$ & $8.9 \mathrm{E}-04$ & $1.5 \mathrm{E}+00$ \\
\hline $\mathrm{Ru}-103$ & $1.9 \mathrm{E}-01$ & $<0.05$ & $2.5 \mathrm{E}-03$ & $1.3 E+00$ \\
\hline $\mathrm{Pu}-238$ & $1.6 \mathrm{E}-01$ & $<0.05$ & 9.7E-04 & $1.1 \mathrm{E}+00$ \\
\hline Pu-239 & $1.5 \mathrm{E}-01$ & $<0.05$ & $8.6 \mathrm{E}-04$ & $1.1 \mathrm{E}+00$ \\
\hline Y-93 & $1.1 \mathrm{E}-01$ & $<0.05$ & $5.6 \mathrm{E}-04$ & $8.0 \mathrm{E}-01$ \\
\hline $\mathrm{Cm}-242$ & $8.8 \mathrm{E}-02$ & $<0.05$ & $6.8 \mathrm{E}-04$ & $6.2 \mathrm{E}-01$ \\
\hline $\mathrm{Cm}-244$ & $7.5 \mathrm{E}-02$ & $<0.05$ & $4.9 \mathrm{E}-04$ & $5.4 \mathrm{E}-01$ \\
\hline $\mathrm{I}-131$ & $6.9 \mathrm{E}-02$ & $<0.05$ & $5.1 \mathrm{E}-04$ & $4.9 \mathrm{E}-01$ \\
\hline Se-75 & $4.5 \mathrm{E}-02$ & $<0.05$ & $8.0 \mathrm{E}-04$ & $2.9 \mathrm{E}-01$ \\
\hline Mo-99 & $2.3 \mathrm{E}-02$ & $<0.05$ & $1.6 \mathrm{E}-04$ & $1.6 \mathrm{E}-01$ \\
\hline $\mathrm{Pu}-240$ & $1.7 \mathrm{E}-02$ & $<0.05$ & $1.1 \mathrm{E}-04$ & $1.2 \mathrm{E}-01$ \\
\hline
\end{tabular}


Table 3-10a. (continued).

\begin{tabular}{lllll}
\hline Radionuclide & $\begin{array}{c}\text { Best } \\
\text { estimate } \\
(\mathrm{Ci})\end{array}$ & $\begin{array}{c}\text { Percent } \\
\text { of total } \\
(\%)\end{array}$ & $\begin{array}{c}\text { Lower } \\
\text { bound }\end{array}$ & $\begin{array}{r}\text { Upper } \\
\text { bound }\end{array}$ \\
\hline Co-57 & $1.7 \mathrm{E}-02$ & $<0.05$ & $1.1 \mathrm{E}-04$ & $1.2 \mathrm{E}-01$ \\
Cd-109 & $1.1 \mathrm{E}-02$ & $<0.05$ & $5.6 \mathrm{E}-05$ & $7.9 \mathrm{E}-02$ \\
Re-188 & $9.3 \mathrm{E}-03$ & $<0.05$ & $4.7 \mathrm{E}-05$ & $6.8 \mathrm{E}-02$ \\
U-238 & $7.8 \mathrm{E}-03$ & $<0.05$ & $6.7 \mathrm{E}-03$ & $9.0 \mathrm{E}-03$ \\
Ta-182 & $7.6 \mathrm{E}-03$ & $<0.05$ & $5.9 \mathrm{E}-05$ & $5.4 \mathrm{E}-02$ \\
Sb-124 & $6.9 \mathrm{E}-03$ & $<0.05$ & $5.6 \mathrm{E}-05$ & $4.8 \mathrm{E}-02$ \\
U-235 & $6.1 \mathrm{E}-03$ & $<0.05$ & $5.1 \mathrm{E}-03$ & $7.3 \mathrm{E}-03$ \\
U-234 & $6.0 \mathrm{E}-03$ & $<0.05$ & $3.0 \mathrm{E}-03$ & $1.1 \mathrm{E}-02$ \\
Sr-91 & $4.4 \mathrm{E}-03$ & $<0.05$ & $2.2 \mathrm{E}-05$ & $3.2 \mathrm{E}-02$ \\
Np-237 & $3.7 \mathrm{E}-03$ & $<0.05$ & $2.2 \mathrm{E}-05$ & $2.7 \mathrm{E}-02$ \\
Y-88 & $3.0 \mathrm{E}-03$ & $<0.05$ & $1.5 \mathrm{E}-05$ & $2.2 \mathrm{E}-02$ \\
U-236 & $2.3 \mathrm{E}-03$ & $<0.05$ & $1.1 \mathrm{E}-03$ & $4.1 \mathrm{E}-03$ \\
I-129 & $1.8 \mathrm{E}-03$ & $<0.05$ & $2.1 \mathrm{E}-05$ & $1.2 \mathrm{E}-02$ \\
Sr-92 & $1.6 \mathrm{E}-03$ & $<0.05$ & $8.2 \mathrm{E}-06$ & $1.2 \mathrm{E}-02$ \\
I-133 & $1.5 \mathrm{E}-03$ & $<0.05$ & $7.6 \mathrm{E}-06$ & $1.1 \mathrm{E}-02$ \\
Br-82 & $1.0 \mathrm{E}-03$ & $<0.05$ & $5.1 \mathrm{E}-06$ & $7.3 \mathrm{E}-03$ \\
Te-132 & $3.0 \mathrm{E}-04$ & $<0.05$ & $1.5 \mathrm{E}-06$ & $2.2 \mathrm{E}-03$ \\
Ce-139 & $3.0 \mathrm{E}-04$ & $<0.05$ & $1.5 \mathrm{E}-06$ & $2.2 \mathrm{E}-03$ \\
Ag-108m & $1.1 \mathrm{E}-07$ & $<0.05$ & $5.5 \mathrm{E}-10$ & $7.7 \mathrm{E}-07$ \\
\hline Total & $3.2 \mathrm{E}+05$ & 99.6 & & $\cdot$ \\
\hline
\end{tabular}


Table 3-10b. Inventory of radiological contaminants (listed alphabetically) from the Test Reactor Area for the years 1984-1993 (activity at time of disposal).

\begin{tabular}{|c|c|c|c|c|}
\hline Radionuclide & $\begin{array}{c}\text { Best } \\
\text { estimate } \\
\text { (Ci) }\end{array}$ & $\begin{array}{c}\text { Percent } \\
\text { of total } \\
(\%)\end{array}$ & $\begin{array}{l}\text { Lower } \\
\text { bound }\end{array}$ & $\begin{array}{l}\text { Upper } \\
\text { bound }\end{array}$ \\
\hline $\mathrm{Ag}-108 \mathrm{~m}$ & $1.1 \mathrm{E}-07$ & $<0.05$ & $5.5 \mathrm{E}-10$ & 7.7E-07 \\
\hline $\mathrm{Ag}-110$ & $1.9 E+00$ & $<0.05$ & $1.0 \mathrm{E}-02$ & $1.4 \mathrm{E}+01$ \\
\hline Am-241 & $3.4 \mathrm{E}+00$ & $<0.05$ & $2.1 \mathrm{E}-02$ & $2.4 \mathrm{E}+01$ \\
\hline Ba-140 & $2.1 \mathrm{E}+00$ & $<0.05$ & $2.7 \mathrm{E}-02$ & $1.4 \mathrm{E}+01$ \\
\hline $\mathrm{Br}-82$ & $1.0 \mathrm{E}-03$ & $<0.05$ & $5.1 \mathrm{E}-06$ & 7.3E-03 \\
\hline C-14 & $3.0 \mathrm{E}+01$ & $<0.05$ & $1.7 \mathrm{E}-01$ & $2.2 \mathrm{E}+02$ \\
\hline Cd-109 & $1.1 \mathrm{E}-02$ & $<0.05$ & $5.6 \mathrm{E}-05$ & $7.9 \mathrm{E}-02$ \\
\hline Ce-139 & $3.0 \mathrm{E}-04$ & $<0.05$ & $1.5 \mathrm{E}-06$ & $2.2 \mathrm{E}-03$ \\
\hline Ce-141 & $2.9 \mathrm{E}+00$ & $<0.05$ & $5.4 \mathrm{E}-02$ & $1.8 \mathrm{E}+01$ \\
\hline Ce-144 & $6.6 \mathrm{E}+01$ & $<0.05$ & $2.2 \mathrm{E}+00$ & $3.8 E+02$ \\
\hline $\mathrm{Cm}-242$ & $8.8 \mathrm{E}-02$ & $<0.05$ & $6.8 \mathrm{E}-04$ & $6.2 \mathrm{E}-01$ \\
\hline $\mathrm{Cm}-244$ & $7.5 \mathrm{E}-02$ & $<0.05$ & $4.9 \mathrm{E}-04$ & $5.4 \mathrm{E}-01$ \\
\hline Co-57 & $1.7 \mathrm{E}-02$ & $<0.05$ & $1.1 \mathrm{E}-04$ & $1.2 \mathrm{E}-01$ \\
\hline Co-58 & $5.9 \mathrm{E}+01$ & $<0.05$ & $1.0 \mathrm{E}+00$ & $3.8 \mathrm{E}+02$ \\
\hline Co-60 & $1.2 E+04$ & 3.7 & $3.4 \mathrm{E}+03$ & $3.1 E+04$ \\
\hline Cr-51 & $2.5 E+03$ & 0.8 & $5.3 \mathrm{E}+01$ & $1.6 \mathrm{E}+04$ \\
\hline Cs-134 & $6.6 \mathrm{E}+01$ & $<0.05$ & $1.2 \mathrm{E}+00$ & $4.2 E+02$ \\
\hline Cs-137 & $8.8 E+02$ & 0.3 & $2.2 \mathrm{E}+02$ & $2.5 \mathrm{E}+03$ \\
\hline Eu-152 & $9.9 \mathrm{E}-01$ & $<0.05$ & $5.2 \mathrm{E}-03$ & $7.2 E+00$ \\
\hline Eu-154 & $4.9 \mathrm{E}-01$ & $<0.05$ & $1.2 \mathrm{E}-02$ & $3.0 \mathrm{E}+00$ \\
\hline Eu-155 & $2.6 \mathrm{E}+01$ & $<0.05$ & $1.5 \mathrm{E}-01$ & $1.9 \mathrm{E}+02$ \\
\hline $\mathrm{Fe}-55$ & $6.8 \mathrm{E}+03$ & 2.1 & $1.2 \mathrm{E}+03$ & $2.2 E+04$ \\
\hline $\mathrm{Fe}-59$ & $8.6 \mathrm{E}-01$ & $<0.05$ & $5.1 \mathrm{E}-03$ & $6.2 \mathrm{E}+00$ \\
\hline Gd-153 & $1.3 E+00$ & $<0.05$ & $1.1 \mathrm{E}-02$ & $9.2 \mathrm{E}+00$ \\
\hline $\mathrm{H}-3$ & $2.9 E+05$ & 91.2 & $1.0 \mathrm{E}+05$ & $6.7 \mathrm{E}+05$ \\
\hline Hf-175 & $2.8 \mathrm{E}+00$ & $<0.05$ & $1.5 \mathrm{E}-02$ & $2.0 \mathrm{E}+01$ \\
\hline Hf-181 & $1.7 \dot{\mathrm{E}}+00$ & $<0.05$ & 2.4E-02 & $1.1 \mathrm{E}+01$ \\
\hline
\end{tabular}


Table 3-10b. (continued).

\begin{tabular}{|c|c|c|c|c|}
\hline Radionuclide & $\begin{array}{l}\text { Best } \\
\text { estimate } \\
\text { (Ci) }\end{array}$ & $\begin{array}{c}\text { Percent } \\
\text { of total } \\
(\%)\end{array}$ & $\begin{array}{l}\text { Lower } \\
\text { bound }\end{array}$ & $\begin{array}{l}\text { Upper } \\
\text { bound }\end{array}$ \\
\hline I-129 & $1.8 \mathrm{E}-03$ & $<0.05$ & $2.1 \mathrm{E}-05$ & $1.2 \mathrm{E}-02$ \\
\hline I-131 & $6.9 \mathrm{E}-02$ & $<0.05$ & $5.1 \mathrm{E}-04$ & $4.9 \mathrm{E}-01$ \\
\hline $\mathrm{I}-132$ & $1.0 \mathrm{E}+00$ & $<0.05$ & $5.6 \mathrm{E}-03$ & $7.3 \mathrm{E}+00$ \\
\hline I-133 & $1.5 \mathrm{E}-03$ & $<0.05$ & $7.6 \mathrm{E}-06$ & $1.1 \mathrm{E}-02$ \\
\hline Ir-192 & $6.6 \mathrm{E}-01$ & $<0.05$ & $5.4 \mathrm{E}-03$ & $4.6 \mathrm{E}+00$ \\
\hline La-140 & $2.5 \mathrm{E}+00$ & $<0.05$ & $3.2 \mathrm{E}-02$ & $1.6 \mathrm{E}+01$ \\
\hline $\mathrm{Mn}-54$ & $1.6 E+02$ & $<0.05$ & $2.1 E+00$ & $1.1 \mathrm{E}+03$ \\
\hline$M n-56$ & $1.3 E+00$ & $<0.05$ & $6.6 \mathrm{E}-03$ & $9.5 \mathrm{E}+00$ \\
\hline Mo-99 & 2.3E-02 & $<0.05$ & $1.6 \mathrm{E}-04$ & $1.6 \mathrm{E}-01$ \\
\hline $\mathrm{Na}-24$ & $2.7 \mathrm{E}+00$ & $<0.05$ & $2.0 \mathrm{E}-02$ & $1.9 \mathrm{E}+01$ \\
\hline Nb-94 & $2.0 \mathrm{E}-01$ & $<0.05$ & $8.9 \mathrm{E}-04$ & $1.5 \mathrm{E}+00$ \\
\hline $\mathrm{Nb}-95$ & $1.4 \mathrm{E}+02$ & $<0.05$ & $9.2 \mathrm{E}-01$ & $1.0 \mathrm{E}+03$ \\
\hline $\mathrm{Ni}-59$ & $3.1 \mathrm{E}+01$ & $<0.05$ & $1.5 \mathrm{E}-01$ & $2.3 \mathrm{E}+02$ \\
\hline $\mathrm{Ni}-63$ & $4.0 \mathrm{E}+03$ & 1.2 & $4.2 \mathrm{E}+02$ & $1.7 \mathrm{E}+04$ \\
\hline Np-237 & $3.7 \mathrm{E}-03$ & $<0.05$ & $2.2 \mathrm{E}-05$ & 2.7E-02 \\
\hline Pm-147 & $2.4 \mathrm{E}+00$ & $<0.05$ & $1.2 \mathrm{E}-02$ & $1.7 \mathrm{E}+01$ \\
\hline $\operatorname{Pr}-144$ & $1.4 \mathrm{E}+00$ & $<0.05$ & $1.3 \mathrm{E}-02$ & $9.7 \mathrm{E}+00$ \\
\hline $\mathrm{Pu}-238$ & $1.6 \mathrm{E}-01$ & $<0.05$ & $9.7 \mathrm{E}-04$ & $1.1 \mathrm{E}+00$ \\
\hline Pu-239 & $1.5 \mathrm{E}-01$ & $<0.05$ & $8.6 \mathrm{E}-04$ & $1.1 \mathrm{E}+00$ \\
\hline $\mathrm{Pu}-240$ & $1.7 \mathrm{E}-02$ & $<0.05$ & $1.1 \mathrm{E}-04$ & $1.2 \mathrm{E}-01$ \\
\hline $\mathrm{Pu}-241$ & $1.7 \mathrm{E}+01$ & $<0.05$ & $1.0 \mathrm{E}-01$ & $1.2 \mathrm{E}+02$ \\
\hline Re-188 & $9.3 \mathrm{E}-03$ & $<0.05$ & 4.7E-05 & $6.8 \mathrm{E}-02$ \\
\hline Ru-103 & $1.9 \mathrm{E}-01$ & $<0.05$ & $2.5 \mathrm{E}-03$ & $1.3 \mathrm{E}+00$ \\
\hline Sb-124 & $6.9 \mathrm{E}-03$ & $<0.05$ & $5.6 \mathrm{E}-05$ & 4.8E-02 \\
\hline $\mathrm{Sb}-125$ & $5.0 \mathrm{E}+01$ & $<0.05$ & $6.0 \mathrm{E}-01$ & $3.4 \mathrm{E}+02$ \\
\hline Sc-46 & $5.0 \mathrm{E}+01$ & $<0.05$ & $2.6 \mathrm{E}-01$ & $3.6 \mathrm{E}+02$ \\
\hline $\mathrm{Se}-75$ & $4.5 \mathrm{E}-02$ & $<0.05$ & $8.0 \mathrm{E}-04$ & $2.9 \mathrm{E}-01$ \\
\hline
\end{tabular}


Table 3-10b. (continued).

\begin{tabular}{|c|c|c|c|c|}
\hline Radionuclide & $\begin{array}{c}\text { Best } \\
\text { estimate } \\
\text { (Ci) }\end{array}$ & $\begin{array}{c}\text { Percent } \\
\text { of total } \\
(\%)\end{array}$ & $\begin{array}{l}\text { Lower } \\
\text { bound }\end{array}$ & $\begin{array}{l}\text { Upper } \\
\text { bound }\end{array}$ \\
\hline Sn-113 & $2.2 \mathrm{E}+01$ & $<0.05$ & $1.6 \mathrm{E}-01$ & $1.6 \mathrm{E}+02$ \\
\hline $\mathrm{Sn}-117 \mathrm{~m}$ & $1.2 \mathrm{E}+02$ & $<0.05$ & $6.1 \mathrm{E}-01$ & $8.7 \mathrm{E}+02$ \\
\hline Sn-119m & $7.5 \mathrm{E}+01$ & $<0.05$ & $5.6 \mathrm{E}-01$ & $5.3 \mathrm{E}+02$ \\
\hline Sr-89 & $3.0 \mathrm{E}+00$ & $<0.05$ & $3.7 \mathrm{E}-02$ & $2.0 \mathrm{E}+01$ \\
\hline Sr-90 & $2.6 \mathrm{E}+01$ & $<0.05$ & $6.7 \mathrm{E}-01$ & $1.6 \mathrm{E}+02$ \\
\hline Sr-91 & $4.4 \mathrm{E}-03$ & $<0.05$ & $2.2 \mathrm{E}-05$ & $3.2 \mathrm{E}-02$ \\
\hline Sr-92 & $1.6 \mathrm{E}-03$ & $<0.05$ & 8.2E-06 & $1.2 \mathrm{E}-02$ \\
\hline Ta-182 & $7.6 \mathrm{E}-03$ & $<0.05$ & $5.9 \mathrm{E}-05$ & $5.4 \mathrm{E}-02$ \\
\hline Tc-99 & $5.0 \mathrm{E}-01$ & $<0.05$ & $2.7 \mathrm{E}-03$ & $3.6 \mathrm{E}+00$ \\
\hline Te-125m & $4.2 E+01$ & $<0.05$ & 2.2E-01 & $3.0 \mathrm{E}+02$ \\
\hline Te-132 & 3.0E-04 & $<0.05$ & $1.5 \mathrm{E}-06$ & $2.2 \mathrm{E}-03$ \\
\hline U-234 & $6.0 \mathrm{E}-03$ & $<0.05$ & $3.0 \mathrm{E}-03$ & $1.1 \mathrm{E}-02$ \\
\hline U-235 & $6.1 \mathrm{E}-03$ & $<0.05$ & $5.1 \mathrm{E}-03$ & $7.3 \mathrm{E}-03$ \\
\hline U-236 & $2.3 \mathrm{E}-03$ & $<0.05$ & $1.1 \mathrm{E}-03$ & $4.1 \mathrm{E}-03$ \\
\hline U-238 & $7.8 \mathrm{E}-03$ & $<0.05$ & $6.7 \mathrm{E}-03$ & $9.0 \mathrm{E}-03$ \\
\hline Y-88 & $3.0 \mathrm{E}-03$ & $<0.05$ & $1.5 \mathrm{E}-05$ & $2.2 \mathrm{E}-02$ \\
\hline Y-93 & $1.1 \mathrm{E}-01$ & $<0.05$ & $5.6 \mathrm{E}-04$ & $8.0 \mathrm{E}-01$ \\
\hline $\mathrm{Zn}-65$ & $1.0 \mathrm{E}+03$ & 0.3 & $8.5 \mathrm{E}+00$ & $7.2 \mathrm{E}+03$ \\
\hline Zr-95 & $1.4 \mathrm{E}+02$ & $<0.05$ & $2.2 \mathrm{E}+00$ & $8.9 \mathrm{E}+02$ \\
\hline Total & $3.2 \mathrm{E}+05$ & 99.6 & & \\
\hline
\end{tabular}


Table 3-11a. Inventory of radiological contaminants (listed by quantity) from the Test Reactor Area for the years 1994-2003 (activity at time of disposal).

\begin{tabular}{|c|c|c|c|c|}
\hline Radionuclide & $\begin{array}{c}\text { Best } \\
\text { estimate } \\
\text { (Ci) }\end{array}$ & $\begin{array}{c}\text { Percent } \\
\text { of total } \\
(\%)\end{array}$ & $\begin{array}{l}\text { Lower } \\
\text { bound }\end{array}$ & $\begin{array}{l}\text { Upper } \\
\text { bound }\end{array}$ \\
\hline $\mathrm{H}-3$ & $2.6 \mathrm{E}+06$ & 94.0 & $1.3 \mathrm{E}+06$ & $5.0 \mathrm{E}+06$ \\
\hline Co-60 & $1.3 E+05$ & 4.7 & $9.6 \mathrm{E}+03$ & $6.3 E+05$ \\
\hline $\mathrm{Ni}-63$ & $2.2 E+04$ & 0.8 & $3.0 \mathrm{E}+03$ & $8.0 E+04$ \\
\hline $\mathrm{Fe}-55$ & $1.4 \mathrm{E}+04$ & 0.5 & $5.0 \mathrm{E}+03$ & $3.0 \mathrm{E}+04$ \\
\hline Cs- 137 & $1.4 E+03$ & $<0.05$ & $5.2 E+02$ & $3.2 E+03$ \\
\hline $\mathrm{Ni}-59$ & $1.9 \mathrm{E}+02$ & $<0.05$ & $1.9 \mathrm{E}+00$ & $1.3 E+03$ \\
\hline C-14 & $8.1 \mathrm{E}+01$ & $<0.05$ & $4.7 \mathrm{E}+00$ & $4.0 \mathrm{E}+02$ \\
\hline Eu-155 & $6.7 \mathrm{E}+01$ & $<0.05$ & $3.7 \mathrm{E}+00$ & $3.4 E+02$ \\
\hline Pu-241 & $4.2 \mathrm{E}+01$ & $<0.05$ & $2.3 E+00$ & $2.1 E+02$ \\
\hline Ce-144 & $3.4 E+01$ & $<0.05$ & $1.9 E+00$ & $1.7 \mathrm{E}+02$ \\
\hline $\mathrm{Cr}-51$ & $2.3 E+01$ & $<0.05$ & $1.2 \mathrm{E}+00$ & $1.2 \mathrm{E}+02$ \\
\hline Sr-90 & $6.9 \mathrm{E}+00$ & $<0.05$ & 4.2E-01 & $3.4 E+01$ \\
\hline $\mathrm{Nb}-94$ & $1.9 \mathrm{E}+00$ & $<0.05$ & $1.9 \mathrm{E}-02$ & $1.3 \mathrm{E}+01$ \\
\hline Tc-99 & $1.3 \mathrm{E}+00$ & $<0.05$ & 7.1E-02 & $6.5 \mathrm{E}+00$ \\
\hline $\mathrm{Zn}-65$ & $1.2 E+00$ & $<0.05$ & $6.5 E-02$ & $6.1 E+00$ \\
\hline Co-58 & $1.1 \mathrm{E}+00$ & $<0.05$ & 5.8E-02 & $5.4 \mathrm{E}+00$ \\
\hline $\mathrm{Mn}-54$ & 5.1E-01 & $<0.05$ & $2.8 E-02$ & $2.6 \mathrm{E}+00$ \\
\hline $\mathrm{Pu}-239$ & $3.9 \mathrm{E}-01$ & $<0.05$ & $2.1 \mathrm{E}-02$ & $2.0 \mathrm{E}+00$ \\
\hline $\mathrm{Pu}-238$ & $3.9 \mathrm{E}-01$ & $<0.05$ & $2.1 E-02$ & $2.0 \mathrm{E}+00$ \\
\hline Pr-144 & $2.2 \mathrm{E}-01$ & $<0.05$ & $1.2 \mathrm{E}-02$ & $1.1 \mathrm{E}+00$ \\
\hline Am-241 & $2.0 \mathrm{E}-01$ & $<0.05$ & $1.1 \mathrm{E}-02$ & 9.8E-01 \\
\hline $\mathrm{Cm}-242$ & 1.9E-01 & $<0.05$ & 1.1E-02 & 9.8E-01 \\
\hline $\mathrm{Cm}-244$ & 1.8E-01 & $<0.05$ & $9.9 E-03$ & 9.1E-01 \\
\hline Hf-181 & $1.6 \mathrm{E}-01$ & $<0.05$ & 8.8E-03 & 8.3E-01 \\
\hline Zr-95 & $1.4 \mathrm{E}-01$ & $<0.05$ & $7.5 \mathrm{E}-03$ & 7.1E-01 \\
\hline $\mathrm{Nb}-95$ & $1.4 \mathrm{E}-01$ & $<0.05$ & $7.4 \mathrm{E}-03$ & $6.9 \mathrm{E}-01$ \\
\hline Cs-134 & $1.3 \mathrm{E}-01$ & $<0.05$ & $7.0 \mathrm{E}-03$ & $6.6 \mathrm{E}-01$ \\
\hline
\end{tabular}


Table 3-11a. (continued).

\begin{tabular}{lcccc}
\hline Radionuclide & $\begin{array}{c}\text { Best } \\
\text { estimate } \\
(\text { Ci })\end{array}$ & $\begin{array}{c}\text { Percent } \\
\text { of total } \\
(\%)\end{array}$ & $\begin{array}{c}\text { Lower } \\
\text { bound }\end{array}$ & $\begin{array}{c}\text { Upper } \\
\text { bound }\end{array}$ \\
\hline Ce-141 & $1.2 \mathrm{E}-01$ & $<0.05$ & $6.6 \mathrm{E}-03$ & $6.2 \mathrm{E}-01$ \\
La-140 & $9.1 \mathrm{E}-02$ & $<0.05$ & $4.9 \mathrm{E}-03$ & $4.6 \mathrm{E}-01$ \\
Pu-240 & $4.1 \mathrm{E}-02$ & $<0.05$ & $2.2 \mathrm{E}-03$ & $2.1 \mathrm{E}-01$ \\
Sc-46 & $3.7 \mathrm{E}-02$ & $<0.05$ & $2.0 \mathrm{E}-03$ & $1.9 \mathrm{E}-01$ \\
Ba-140 & $2.7 \mathrm{E}-02$ & $<0.05$ & $1.4 \mathrm{E}-03$ & $1.4 \mathrm{E}-01$ \\
Mo-99 & $2.4 \mathrm{E}-02$ & $<0.05$ & $1.3 \mathrm{E}-03$ & $1.2 \mathrm{E}-01$ \\
Eu-154 & $2.1 \mathrm{E}-02$ & $<0.05$ & $1.1 \mathrm{E}-03$ & $1.0 \mathrm{E}-01$ \\
Ru-103 & $1.6 \mathrm{E}-02$ & $<0.05$ & $8.8 \mathrm{E}-04$ & $8.2 \mathrm{E}-02$ \\
U-234 & $1.5 \mathrm{E}-02$ & $<0.05$ & $7.0 \mathrm{E}-03$ & $2.9 \mathrm{E}-02$ \\
Fe-59 & $1.2 \mathrm{E}-02$ & $<0.05$ & $6.4 \mathrm{E}-04$ & $6.1 \mathrm{E}-02$ \\
Se-75 & $9.4 \mathrm{E}-03$ & $<0.05$ & $5.1 \mathrm{E}-04$ & $4.8 \mathrm{E}-02$ \\
Np-237 & $9.3 \mathrm{E}-03$ & $<0.05$ & $5.2 \mathrm{E}-04$ & $4.7 \mathrm{E}-02$ \\
U-236 & $5.7 \mathrm{E}-03$ & $<0.05$ & $2.7 \mathrm{E}-03$ & $1.1 \mathrm{E}-02$ \\
Xe-133 & $5.0 \mathrm{E}-04$ & $<0.05$ & $2.7 \mathrm{E}-05$ & $2.5 \mathrm{E}-03$ \\
I-129 & $3.4 \mathrm{E}-04$ & $<0.05$ & $1.8 \mathrm{E}-05$ & $1.7 \mathrm{E}-03$ \\
U-235 & $3.2 \mathrm{E}-04$ & $<0.05$ & $1.5 \mathrm{E}-04$ & $6.1 \mathrm{E}-04$ \\
I-131 & $2.5 \mathrm{E}-04$ & $<0.05$ & $1.4 \mathrm{E}-05$ & $1.3 \mathrm{E}-03$ \\
\hline Total & $2.8 \mathrm{E}+06$ & 100.0 & & \\
\hline & & & &
\end{tabular}


Table 3-11b. Inventory of radiological contaminants (listed alphabetically) from the Test Reactor Area for the years 1994-2003 (activity at time of disposal).

\begin{tabular}{|c|c|c|c|c|}
\hline Radionuclide & $\begin{array}{c}\text { Best } \\
\text { estimate } \\
\text { (Ci) }\end{array}$ & $\begin{array}{c}\text { Percent } \\
\text { of total } \\
(\%)\end{array}$ & $\begin{array}{l}\text { Lower } \\
\text { bound }\end{array}$ & $\begin{array}{l}\text { Upper } \\
\text { bound }\end{array}$ \\
\hline Am-241 & $2.0 \mathrm{E}-01$ & $<0.05$ & 1.1E-02 & $9.8 \mathrm{E}-01$ \\
\hline $\mathrm{Ba}-140$ & 2.7E-02 & $<0.05$ & $1.4 \mathrm{E}-03$ & $1.4 \mathrm{E}-01$ \\
\hline C-14 & $8.1 E+01$ & $<0.05$ & $4.7 \mathrm{E}+00$ & $4.0 \mathrm{E}+02$ \\
\hline Ce-141 & $1.2 \mathrm{E}-01$ & $<0.05$ & $6.6 \mathrm{E}-03$ & $6.2 \mathrm{E}-01$ \\
\hline Ce-144 & $3.4 \mathrm{E}+01$ & $<0.05$ & $1.9 \mathrm{E}+00$ & $1.7 E+02$ \\
\hline $\mathrm{Cm}-242$ & $1.9 \mathrm{E}-01$ & $<0.05$ & $1.1 E-02$ & $9.8 E-01$ \\
\hline $\mathrm{Cm}-244$ & $1.8 \mathrm{E}-01$ & $<0.05$ & $9.9 E-03$ & $9.1 \mathrm{E}-01$ \\
\hline Co-58 & $1.1 E+00$ & $<0.05$ & $5.8 \mathrm{E}-02$ & $5.4 \mathrm{E}+00$ \\
\hline Co-60 & $1.3 E+05$ & 4.7 & $9.6 \mathrm{E}+03$ & $6.3 E+05$ \\
\hline $\mathrm{Cr}-51$ & $2.3 E+01$ & $<0.05$ & $1.2 \mathrm{E}+00$ & $1.2 E+02$ \\
\hline Cs-134 & 1.3E-01 & $<0.05$ & $7.0 \mathrm{E}-03$ & $6.6 \mathrm{E}-01$ \\
\hline Cs-137 & $1.4 \mathrm{E}+03$ & $<0.05$ & $5.2 E+02$ & $3.2 E+03$ \\
\hline Eu-154 & $2.1 E-02$ & $<0.05$ & $1.1 \mathrm{E}-03$ & $1.0 \mathrm{E}-01$ \\
\hline Eu-155 & $6.7 \mathrm{E}+01$ & $<0.05$ & $3.7 E+00$ & $3.4 \mathrm{E}+02$ \\
\hline $\mathrm{Fe}-55$ & $1.4 \mathrm{E}+04$ & 0.5 & $5.0 \mathrm{E}+03$ & $3.0 E+04$ \\
\hline $\mathrm{Fe}-59$ & $1.2 \mathrm{E}-02$ & $<0.05$ & $6.4 \mathrm{E}-04$ & $6.1 \mathrm{E}-02$ \\
\hline $\mathrm{H}-3$ & $2.6 \mathrm{E}+06$ & 94.0 & $1.3 E+06$ & $5.0 \mathrm{E}+06$ \\
\hline Hf- 181 & 1.6E-01 & $<0.05$ & $8.8 \mathrm{E}-03$ & 8.3E-01 \\
\hline $\mathrm{I}-129$ & $3.4 \mathrm{E}-04$ & $<0.05$ & $1.8 \mathrm{E}-05$ & $1.7 \mathrm{E}-03$ \\
\hline $\mathrm{I}-131$ & $2.5 E-04$ & $<0.05$ & $1.4 \mathrm{E}-05$ & $1.3 \mathrm{E}-03$ \\
\hline La-140 & $9.1 \mathrm{E}-02$ & $<0.05$ & $4.9 \mathrm{E}-03$ & 4.6E-01 \\
\hline $\mathrm{Mn}-54$ & 5.1E-01 & $<0.05$ & 2.8E-02 & $2.6 \mathrm{E}+00$ \\
\hline Mo-99 & $2.4 \mathrm{E}-02$ & $<0.05$ & $1.3 \mathrm{E}-03$ & $1.2 \mathrm{E}-01$ \\
\hline $\mathrm{Nb}-94$ & $1.9 \mathrm{E}+00$ & $<0.05$ & $1.9 \mathrm{E}-02$ & $1.3 E+01$ \\
\hline $\mathrm{Nb}-95$ & $1.4 \mathrm{E}-01$ & $<0.05$ & $7.4 \mathrm{E}-03$ & $6.9 \mathrm{E}-01$ \\
\hline $\mathrm{Ni}-59$ & $1.9 E+02$ & $<0.05$ & $1.9 E+00$ & $1.3 E+03$ \\
\hline $\mathrm{Ni}-63$ & $2.2 E+04$ & 0.8 & $3.0 \mathrm{E}+03$ & $8.0 \mathrm{E}+04$ \\
\hline
\end{tabular}


Table 3-11b. (continued).

\begin{tabular}{lllll}
\hline Radionuclide & $\begin{array}{c}\text { Best } \\
\text { estimate } \\
(\mathrm{Ci})\end{array}$ & $\begin{array}{l}\text { Percent } \\
\text { of total } \\
(\%)\end{array}$ & $\begin{array}{c}\text { Lower } \\
\text { bound }\end{array}$ & $\begin{array}{c}\text { Upper } \\
\text { bound }\end{array}$ \\
\hline Np-237 & $9.3 \mathrm{E}-03$ & $<0.05$ & $5.2 \mathrm{E}-04$ & $4.7 \mathrm{E}-02$ \\
Pr-144 & $2.2 \mathrm{E}-01$ & $<0.05$ & $1.2 \mathrm{E}-02$ & $1.1 \mathrm{E}+00$ \\
Pu-238 & $3.9 \mathrm{E}-01$ & $<0.05$ & $2.1 \mathrm{E}-02$ & $2.0 \mathrm{E}+00$ \\
Pu-239 & $3.9 \mathrm{E}-01$ & $<0.05$ & $2.1 \mathrm{E}-02$ & $2.0 \mathrm{E}+00$ \\
Pu-240 & $4.1 \mathrm{E}-02$ & $<0.05$ & $2.2 \mathrm{E}-03$ & $2.1 \mathrm{E}-01$ \\
Pu-241 & $4.2 \mathrm{E}+01$ & $<0.05$ & $2.3 \mathrm{E}+00$ & $2.1 \mathrm{E}+02$ \\
Ru-103 & $1.6 \mathrm{E}-02$ & $<0.05$ & $8.8 \mathrm{E}-04$ & $8.2 \mathrm{E}-02$ \\
Sc-46 & $3.7 \mathrm{E}-02$ & $<0.05$ & $2.0 \mathrm{E}-03$ & $1.9 \mathrm{E}-01$ \\
Se-75 & $9.4 \mathrm{E}-03$ & $<0.05$ & $5.1 \mathrm{E}-04$ & $4.8 \mathrm{E}-02$ \\
Sr-90 & $6.9 \mathrm{E}+00$ & $<0.05$ & $4.2 \mathrm{E}-01$ & $3.4 \mathrm{E}+01$ \\
Tc-99 & $1.3 \mathrm{E}+00$ & $<0.05$ & $7.1 \mathrm{E}-02$ & $6.5 \mathrm{E}+00$ \\
U-234 & $1.5 \mathrm{E}-02$ & $<0.05$ & $7.0 \mathrm{E}-03$ & $2.9 \mathrm{E}-02$ \\
U-235 & $3.2 \mathrm{E}-04$ & $<0.05$ & $1.5 \mathrm{E}-04$ & $6.1 \mathrm{E}-04$ \\
U-236 & $5.7 \mathrm{E}-03$ & $<0.05$ & $2.7 \mathrm{E}-03$ & $1.1 \mathrm{E}-02$ \\
Xe-133 & $5.0 \mathrm{E}-04$ & $<0.05$ & $2.7 \mathrm{E}-05$ & $2.5 \mathrm{E}-03$ \\
Zn-65 & $1.2 \mathrm{E}+00$ & $<0.05$ & $6.5 \mathrm{E}-02$ & $6.1 \mathrm{E}+00$ \\
Zr-95 & $1.4 \mathrm{E}-01$ & $<0.05$ & $7.5 \mathrm{E}-03$ & $7.1 \mathrm{E}-01$ \\
\hline Total & $2.8 \mathrm{E}+06$ & 100.0 & & \\
\hline & & & & \\
\hline
\end{tabular}


Table 3-12a. Inventory of nonradiological contaminants (listed by quantity) from the Idaho Chemical Processing Plant for the years 1984-1993.

\begin{tabular}{clccc}
\hline $\begin{array}{c}\text { CAS } \\
\text { number }\end{array}$ & \multicolumn{1}{c}{$\begin{array}{c}\text { Best } \\
\text { estimate } \\
(\mathrm{g})\end{array}$} & $\begin{array}{c}\text { Lower } \\
\text { bound }\end{array}$ & $\begin{array}{r}\text { Upper } \\
\text { bound }\end{array}$ \\
\hline $7439-92-1$ & Lead & $7.8 \mathrm{E}+07$ & $6.2 \mathrm{E}+07$ & $9.4 \mathrm{E}+07$ \\
$1332-21-4$ & Asbestos & $1.2 \mathrm{E}+06$ & $4.5 \mathrm{E}+05$ & $2.0 \mathrm{E}+06$ \\
\hline
\end{tabular}

Table 3-12b. Inventory of nonradiological contaminants (listed alphabetically) from the Idaho Chemical Processing Plant for the years 1984-1993.

\begin{tabular}{clccc}
\hline $\begin{array}{c}\text { CAS } \\
\text { number }\end{array}$ & \multicolumn{1}{c}{ Chemical } & $\begin{array}{c}\text { Best } \\
\text { estimate } \\
(\mathrm{g})\end{array}$ & $\begin{array}{c}\text { Lower } \\
\text { bound }\end{array}$ & $\begin{array}{c}\text { Upper } \\
\text { bound }\end{array}$ \\
\hline $1332-21-4$ & Asbestos & $1.2 \mathrm{E}+06$ & $4.5 \mathrm{E}+05$ & $2.0 \mathrm{E}+06$ \\
$7439-92-1$ & Lead & $7.8 \mathrm{E}+07$ & $6.2 \mathrm{E}+07$ & $9.4 \mathrm{E}+07$ \\
\hline
\end{tabular}


Table 3-13a. Inventory of radiological contaminants (listed by quantity) from the Idaho Chemical Processing Plant for the years 1984-1993 (activity at time of disposal).

\begin{tabular}{|c|c|c|c|c|}
\hline Radionuclide & $\begin{array}{c}\text { Best } \\
\text { estimate } \\
\text { (Ci) }\end{array}$ & $\begin{array}{c}\text { Percent } \\
\text { of total } \\
(\%)\end{array}$ & $\begin{array}{l}\text { Lower } \\
\text { bound }\end{array}$ & $\begin{array}{l}\text { Upper } \\
\text { bound }\end{array}$ \\
\hline Ce-144 & $1.2 E+02$ & 18.0 & $2.3 E+01$ & $3.9 \mathrm{E}+02$ \\
\hline Pr-144 & $1.1 E+02$ & 16.4 & $1.9 \mathrm{E}+01$ & $3.7 \mathrm{E}+02$ \\
\hline Cs-137 & $9.9 E+01$ & 14.7 & $6.0 \mathrm{E}+01$ & $1.5 \mathrm{E}+02$ \\
\hline Sr-90 & $8.7 \mathrm{E}+01$ & 12.9 & $1.1 E+01$ & $3.3 E+02$ \\
\hline Y-90 & $6.2 E+01$ & 9.2 & $1.1 \mathrm{E}+01$ & $2.0 \mathrm{E}+02$ \\
\hline Ru-106 & $6.1 E+01$ & 9.1 & $1.1 \mathrm{E}+01$ & $2.0 \mathrm{E}+02$ \\
\hline Rh-106 & $6.1 E+01$ & 9.1 & $1.1 E+01$ & $2.0 \mathrm{E}+02$ \\
\hline Sb-125 & $2.8 \mathrm{E}+01$ & 4.2 & $5.0 \mathrm{E}+00$ & $9.2 E+01$ \\
\hline $\mathrm{Zr}-95$ & $1.9 E+01$ & 2.8 & $3.5 \mathrm{E}+00$ & $6.1 \mathrm{E}+01$ \\
\hline $\mathrm{Nb}-95$ & $1.9 \mathrm{E}+01$ & 2.8 & $3.5 E+00$ & $6.1 E+01$ \\
\hline Eu-152 & $3.1 E+00$ & 0.5 & $1.6 \mathrm{E}-01$ & $1.6 \mathrm{E}+01$ \\
\hline Eu-154 & $2.2 E+00$ & 0.3 & $1.1 \mathrm{E}-01$ & 1.1E+01 \\
\hline Eu-155 & 4.5E-01 & 0.1 & 2.3E-02 & $2.3 E+00$ \\
\hline Co- 60 & $1.0 \mathrm{E}-01$ & $<0.05$ & 4.7E-02 & 1.9E-01 \\
\hline Cs-134 & $5.0 \mathrm{E}-02$ & $<0.05$ & $2.6 \mathrm{E}-03$ & $2.6 \mathrm{E}-01$ \\
\hline Total & $6.7 \mathrm{E}+02$ & 100.1 & & \\
\hline
\end{tabular}


Table 3-13b. Inventory of radiological contaminants (listed alphabetically) from the Idaho Chemical Processing Plant for the years 1984-1993 (activity at time of disposal).

\begin{tabular}{lcccc}
\hline Radionuclide & $\begin{array}{c}\text { Best } \\
\text { estimate } \\
(\mathrm{Ci})\end{array}$ & $\begin{array}{c}\text { Percent } \\
\text { of total } \\
(\%)\end{array}$ & $\begin{array}{c}\text { Lower } \\
\text { bound }\end{array}$ & $\begin{array}{c}\text { Upper } \\
\text { bound }\end{array}$ \\
\hline Ce-144 & $1.2 \mathrm{E}+02$ & 18.0 & $2.3 \mathrm{E}+01$ & $3.9 \mathrm{E}+02$ \\
Co-60 & $1.0 \mathrm{E}-01$ & $<0.05$ & $4.7 \mathrm{E}-02$ & $1.9 \mathrm{E}-01$ \\
Cs-134 & $5.0 \mathrm{E}-02$ & $<0.05$ & $2.6 \mathrm{E}-03$ & $2.6 \mathrm{E}-01$ \\
Cs-137 & $9.9 \mathrm{E}+01$ & 14.7 & $6.0 \mathrm{E}+01$ & $1.5 \mathrm{E}+02$ \\
Eu-152 & $3.1 \mathrm{E}+00$ & 0.5 & $1.6 \mathrm{E}-01$ & $1.6 \mathrm{E}+01$ \\
Eu-154 & $2.2 \mathrm{E}+00$ & 0.3 & $1.1 \mathrm{E}-01$ & $1.1 \mathrm{E}+01$ \\
Eu-155 & $4.5 \mathrm{E}-01$ & 0.1 & $2.3 \mathrm{E}-02$ & $2.3 \mathrm{E}+00$ \\
Nb-95 & $1.9 \mathrm{E}+01$ & 2.8 & $3.5 \mathrm{E}+00$ & $6.1 \mathrm{E}+01$ \\
Pr-144 & $1.1 \mathrm{E}+02$ & 16.4 & $1.9 \mathrm{E}+01$ & $3.7 \mathrm{E}+02$ \\
Rh-106 & $6.1 \mathrm{E}+01$ & 9.1 & $1.1 \mathrm{E}+01$ & $2.0 \mathrm{E}+02$ \\
Ru-106 & $6.1 \mathrm{E}+01$ & 9.1 & $1.1 \mathrm{E}+01$ & $2.0 \mathrm{E}+02$ \\
Sb-125 & $2.8 \mathrm{E}+01$ & 4.2 & $5.0 \mathrm{E}+00$ & $9.2 \mathrm{E}+01$ \\
Sr-90 & $8.7 \mathrm{E}+01$ & 12.9 & $1.1 \mathrm{E}+01$ & $3.3 \mathrm{E}+02$ \\
Y-90 & $6.2 \mathrm{E}+01$ & 9.2 & $1.1 \mathrm{E}+01$ & $2.0 \mathrm{E}+02$ \\
Zr-95 & $1.9 \mathrm{E}+01$ & 2.8 & $3.5 \mathrm{E}+00$ & $.6 .1 \mathrm{E}+01$ \\
\hline Total & $6.7 \mathrm{E}+02$ & 100.1 & & \\
\hline
\end{tabular}


Table 3-14a. Inventory of radiological contaminants (listed by quantity) from the Idaho Chemical Processing Plant for the years 1994-2003 (activity at time of disposal).

\begin{tabular}{lcccc}
\hline Radionuclide & $\begin{array}{c}\text { Best } \\
\text { estimate } \\
(\mathrm{Ci})\end{array}$ & $\begin{array}{c}\text { Percent } \\
\text { of total } \\
(\%)\end{array}$ & $\begin{array}{c}\text { Lower } \\
\text { bound }\end{array}$ & $\begin{array}{c}\text { Upper } \\
\text { bound }\end{array}$ \\
\hline Cs-137 & $5.2 \mathrm{E}+01$ & 33.0 & $1.8 \mathrm{E}+01$ & $1.2 \mathrm{E}+02$ \\
Y-90 & $4.9 \mathrm{E}+01$ & 31.0 & $2.6 \mathrm{E}+00$ & $2.5 \mathrm{E}+02$ \\
Sr-90 & $4.9 \mathrm{E}+01$ & 31.0 & $2.6 \mathrm{E}+00$ & $2.5 \mathrm{E}+02$ \\
Cs-134 & $2.2 \mathrm{E}+00$ & 1.4 & $1.2 \mathrm{E}-01$ & $1.1 \mathrm{E}+01$ \\
Pr-144 & $1.9 \mathrm{E}+00$ & 1.2 & $1.0 \mathrm{E}-01$ & $9.6 \mathrm{E}+00$ \\
Ce-144 & $1.9 \mathrm{E}+00$ & 1.2 & $1.0 \mathrm{E}-01$ & $9.6 \mathrm{E}+00$ \\
Eu-154 & $4.8 \mathrm{E}-01$ & 0.3 & $2.6 \mathrm{E}-02$ & $2.4 \mathrm{E}+00$ \\
Sb-125 & $4.0 \mathrm{E}-01$ & 0.2 & $2.2 \mathrm{E}-02$ & $2.0 \mathrm{E}+00$ \\
Ru-106 & $3.1 \mathrm{E}-01$ & 0.2 & $1.7 \mathrm{E}-02$ & $1.6 \mathrm{E}+00$ \\
Rh-106 & $3.1 \mathrm{E}-01$ & 0.2 & $1.7 \mathrm{E}-02$ & $1.6 \mathrm{E}+00$ \\
Eu-155 & $3.1 \mathrm{E}-01$ & 0.2 & $1.7 \mathrm{E}-02$ & $1.6 \mathrm{E}+00$ \\
H-3 & $6.2 \mathrm{E}-02$ & $<0.05$ & $3.4 \mathrm{E}-03$ & $3.2 \mathrm{E}-01$ \\
Co-60 & $3.1 \mathrm{E}-02$ & $<0.05$ & $1.1 \mathrm{E}-02$ & $7.1 \mathrm{E}-02$ \\
I-129 & $1.0 \mathrm{E}-02$ & $<0.05$ & $5.4 \mathrm{E}-04$ & $5.1 \mathrm{E}-02$ \\
\hline Total & $1.6 \mathrm{E}+02$ & 99.9 &. & \\
\hline
\end{tabular}


Table 3-14b. Inventory of radiological contaminants (listed alphabetically) from the Idaho Chemical Processing Plant for the years 1994-2003 (activity at time of disposal).

\begin{tabular}{llccl}
\hline Radionuclide & $\begin{array}{c}\text { Best } \\
\text { estimate } \\
(\mathrm{Ci})\end{array}$ & $\begin{array}{c}\text { Percent } \\
\text { of total } \\
(\%)\end{array}$ & $\begin{array}{c}\text { Lower } \\
\text { bound }\end{array}$ & $\begin{array}{c}\text { Upper } \\
\text { bound }\end{array}$ \\
\hline Ce-144 & $1.9 \mathrm{E}+00$ & 1.2 & $1.0 \mathrm{E}-01$ & $9.6 \mathrm{E}+00$ \\
Co-60 & $3.1 \mathrm{E}-02$ & $<0.05$ & $1.1 \mathrm{E}-02$ & $7.1 \mathrm{E}-02$ \\
Cs-134 & $2.2 \mathrm{E}+00$ & 1.4 & $1.2 \mathrm{E}-01$ & $1.1 \mathrm{E}+01$ \\
Cs-137 & $5.2 \mathrm{E}+01$ & 33.0 & $1.8 \mathrm{E}+01$ & $1.2 \mathrm{E}+02$ \\
Eu-154 & $4.8 \mathrm{E}-01$ & 0.3 & $2.6 \mathrm{E}-02$ & $2.4 \mathrm{E}+00$ \\
Eu-155 & $3.1 \mathrm{E}-01$ & 0.2 & $1.7 \mathrm{E}-02$ & $1.6 \mathrm{E}+00$ \\
H-3 & $6.2 \mathrm{E}-02$ & $<0.05$ & $3.4 \mathrm{E}-03$ & $3.2 \mathrm{E}-01$ \\
I-129 & $1.0 \mathrm{E}-02$ & $<0.05$ & $5.4 \mathrm{E}-04$ & $5.1 \mathrm{E}-02$ \\
Pr-144 & $1.9 \mathrm{E}+00$ & 1.2 & $1.0 \mathrm{E}-01$ & $9.6 \mathrm{E}+00$ \\
Rh-106 & $3.1 \mathrm{E}-01$ & 0.2 & $1.7 \mathrm{E}-02$ & $1.6 \mathrm{E}+00$ \\
Ru-106 & $3.1 \mathrm{E}-01$ & 0.2 & $1.7 \mathrm{E}-02$ & $1.6 \mathrm{E}+00$ \\
Sb-125 & $4.0 \mathrm{E}-01$ & 0.2 & $2.2 \mathrm{E}-02$ & $2.0 \mathrm{E}+00$ \\
Sr-90 & $4.9 \mathrm{E}+01$ & 31.0 & $2.6 \mathrm{E}+00$ & $2.5 \mathrm{E}+02$ \\
Y-90 & $4.9 \mathrm{E}+01$ & 31.0 & $2.6 \mathrm{E}+00$ & $2.5 \mathrm{E}+02$ \\
\hline Total & $1.6 \mathrm{E}+02$ & 99.9 & & \\
\hline
\end{tabular}


Table 3-15a. Inventory of nonradiological contaminants (listed by quantity) from the Naval Reactors Facility for the years 1984-1993.

\begin{tabular}{clccc}
\hline $\begin{array}{c}\text { CAS } \\
\text { number }\end{array}$ & Chemical & $\begin{array}{c}\text { Best } \\
\text { estimate } \\
(\mathrm{g})\end{array}$ & $\begin{array}{c}\text { Lower } \\
\text { bound }\end{array}$ & $\begin{array}{c}\text { Upper } \\
\text { bound }\end{array}$ \\
\hline $7439-92-1$ & Lead & $6.4 \mathrm{E}+05$ & $6.1 \mathrm{E}+05$ & $6.8 \mathrm{E}+05$ \\
$1332-21-4$ & Asbestos & $5.8 \mathrm{E}+05$ & $4.8 \mathrm{E}+05$ & $6.7 \mathrm{E}+05$ \\
\hline
\end{tabular}

Table 3-15b. Inventory of nonradiological contaminants (listed alphabetically) from the Naval Reactors Facility for the years 1984-1993.

\begin{tabular}{|c|c|c|c|c|}
\hline $\begin{array}{c}\text { CAS } \\
\text { number }\end{array}$ & Chemical & $\begin{array}{c}\text { Best } \\
\text { estimate } \\
\text { (g) }\end{array}$ & $\begin{array}{l}\text { Lower } \\
\text { bound }\end{array}$ & $\begin{array}{l}\text { Upper } \\
\text { bound }\end{array}$ \\
\hline $1332-21-4$ & Asbestos & $5.8 \mathrm{E}+05$ & $4.8 \mathrm{E}+05$ & $6.7 \mathrm{E}+05$ \\
\hline $7439-92-1$ & Lead & $6.4 E+05$ & $6.1 E+05$ & $6.8 \mathrm{E}+05$ \\
\hline
\end{tabular}


Table 3-16a. Inventory of radiological contaminants (listed by quantity) from the Naval Reactors Facility for the years 1984-1993 (activity at time of disposal).

\begin{tabular}{|c|c|c|c|c|}
\hline Radionuclide & $\begin{array}{c}\text { Best } \\
\text { estimate } \\
(\mathrm{Ci})\end{array}$ & $\begin{array}{c}\text { Percent } \\
\text { of total } \\
(\%)\end{array}$ & $\begin{array}{l}\text { Lower } \\
\text { bound }\end{array}$ & $\begin{array}{l}\text { Upper } \\
\text { bound }\end{array}$ \\
\hline $\mathrm{Ni}-63$ & $4.7 E+05$ & 48.5 & $4.3 E+05$ & $5.2 E+05$ \\
\hline Co-60 & $2.8 \mathrm{E}+05$ & 28.8 & $2.5 \mathrm{E}+05$ & $3.1 \mathrm{E}+05$ \\
\hline $\mathrm{Fe}-55$ & $1.5 \mathrm{E}+05$ & 15.5 & $1.4 \mathrm{E}+05$ & $1.7 \mathrm{E}+05$ \\
\hline Co-58 & $2.1 \mathrm{E}+04$ & 2.1 & $1.8 \mathrm{E}+04$ & $2.3 E+04$ \\
\hline Ta-182 & $1.8 \mathrm{E}+04$ & 1.8 & $1.6 \mathrm{E}+04$ & $2.0 \mathrm{E}+04$ \\
\hline $\mathrm{Sn}-119 \mathrm{~m}$ & $8.8 \mathrm{E}+03$ & 0.9 & $7.6 \mathrm{E}+03$ & $1.0 \mathrm{E}+04$ \\
\hline W-185 & $6.4 \mathrm{E}+03$ & 0.6 & $5.6 \mathrm{E}+03$ & $7.3 E+03$ \\
\hline $\mathrm{Nb}-95$ & $3.6 \mathrm{E}+03$ & 0.4 & $3.2 E+03$ & $4.1 E+03$ \\
\hline Hf- 181 & $3.4 \mathrm{E}+03$ & 0.4 & $3.0 \mathrm{E}+03$ & $3.9 E+03$ \\
\hline Hf-175 & $2.8 \mathrm{E}+03$ & 0.3 & $2.5 \mathrm{E}+03$ & $3.2 \mathrm{E}+03$ \\
\hline Sb-125 & $2.8 \mathrm{E}+03$ & 0.3 & $2.5 E+03$ & $3.2 \mathrm{E}+03$ \\
\hline $\mathrm{Zr}-95$ & $1.9 E+03$ & 0.2 & $1.7 \mathrm{E}+03$ & $2.2 E+03$ \\
\hline $\mathrm{Ni}-59$ & $1.4 \mathrm{E}+03$ & 0.1 & $1.2 \mathrm{E}+03$ & $1.5 \mathrm{E}+03$ \\
\hline $\mathrm{Mn}-54$ & $3.0 \mathrm{E}+02$ & $<0.05$ & $2.6 \mathrm{E}+02$ & $3.4 \mathrm{E}+02$ \\
\hline $\mathrm{Cr}-51$ & $2.7 \mathrm{E}+02$ & $<0.05$ & $2.3 \mathrm{E}+02$ & $3.0 \mathrm{E}+02$ \\
\hline $\mathrm{H}-3$ & $1.8 \mathrm{E}+01$ & $<0.05$ & $1.6 \mathrm{E}+01$ & $2.0 \mathrm{E}+01$ \\
\hline C-14 & $1.0 \mathrm{E}+01$ & $<0.05$ & $8.7 E+00$ & $1.1 \mathrm{E}+01$ \\
\hline Cs-137 & $6.0 \mathrm{E}+00$ & $<0.05$ & $5.1 E+00$ & $7.0 \mathrm{E}+00$ \\
\hline $\mathrm{Ba}-137 \mathrm{~m}$ & $4.6 \mathrm{E}+00$ & $<0.05$ & $3.0 \mathrm{E}+00$ & $6.8 \mathrm{E}+00$ \\
\hline Sn-113 & $2.0 \mathrm{E}+00$ & $<0.05$ & $1.7 \mathrm{E}+00$ & $2.3 E+00$ \\
\hline Total & $9.7 \mathrm{E}+05$ & 99.9 & & \\
\hline
\end{tabular}


Table 3-16b. Inventory of radiological contaminants (listed alphabetically) from the Naval Reactors Facility for the years 1984-1993 (activity at time of disposal).

\begin{tabular}{|c|c|c|c|c|}
\hline Radionuclide & $\begin{array}{c}\text { Best } \\
\text { estimate } \\
(\mathrm{Ci})\end{array}$ & $\begin{array}{c}\text { Percent } \\
\text { of total } \\
(\%)\end{array}$ & $\begin{array}{l}\text { Lower } \\
\text { bound }\end{array}$ & $\begin{array}{l}\text { Upper } \\
\text { bound }\end{array}$ \\
\hline $\mathrm{Ba}-137 \mathrm{~m}$ & $4.6 \mathrm{E}+00$ & $<0.05$ & $3.0 \mathrm{E}+00$ & $6.8 \mathrm{E}+00$ \\
\hline C-14 & $1.0 \mathrm{E}+01$ & $<0.05$ & $8.7 E+00$ & $1.1 \mathrm{E}+01$ \\
\hline Co-58 & $2.1 E+04$ & 2.1 & $1.8 \mathrm{E}+04$ & $2.3 E+04$ \\
\hline Co- 60 & $2.8 \mathrm{E}+05$ & 28.8 & $2.5 \mathrm{E}+05$ & $3.1 \mathrm{E}+05$ \\
\hline $\mathrm{Cr}-51$ & $2.7 \mathrm{E}+02$ & $<0.05$ & $2.3 E+02$ & $3.0 \mathrm{E}+02$ \\
\hline Cs-137 & $6.0 \mathrm{E}+00$ & $<0.05$ & $5.1 \mathrm{E}+00$ & $7.0 \mathrm{E}+00$ \\
\hline $\mathrm{Fe}-55$ & $1.5 E+05$ & 15.5 & $1.4 \mathrm{E}+05$ & $1.7 \mathrm{E}+05$ \\
\hline $\mathrm{H}-3$ & $1.8 \mathrm{E}+01$ & $<0.05$ & $1.6 \mathrm{E}+01$ & $2.0 \mathrm{E}+01$ \\
\hline Hf-175 & $2.8 E+03$ & 0.3 & $2.5 E+03$ & $3.2 \mathrm{E}+03$ \\
\hline Hf-181 & $3.4 \mathrm{E}+03$ & 0.4 & $3.0 \mathrm{E}+03$ & $3.9 \mathrm{E}+03$ \\
\hline$M n-54$ & $3.0 \mathrm{E}+02$ & $<0.05$ & $2.6 \mathrm{E}+02$ & $3.4 \mathrm{E}+02$ \\
\hline Nb-95 & $3.6 \mathrm{E}+03$ & 0.4 & $3.2 E+03$ & $4.1 \mathrm{E}+03$ \\
\hline $\mathrm{Ni}-59$ & $1.4 \mathrm{E}+03$ & 0.1 & $1.2 \mathrm{E}+03$ & $1.5 \mathrm{E}+03$ \\
\hline $\mathrm{Ni}-63$ & $4.7 E+05$ & 48.5 & $4.3 \mathrm{E}+05$ & $5.2 \mathrm{E}+05$ \\
\hline Sb-125 & $2.8 \mathrm{E}+03$ & 0.3 & $2.5 E+03$ & $3.2 \mathrm{E}+03$ \\
\hline Sn-113 & $2.0 \mathrm{E}+00$ & $<0.05$ & $1.7 \mathrm{E}+00$ & $2.3 E+00$ \\
\hline Sn-119m & $8.8 E+03$ & 0.9 & $7.6 \mathrm{E}+03$ & $1.0 \mathrm{E}+04$ \\
\hline Ta-182 & $1.8 \mathrm{E}+04$ & 1.8 & $1.6 \mathrm{E}+04$ & $2.0 \mathrm{E}+04$ \\
\hline W-185 & $6.4 \mathrm{E}+03$ & 0.6 & $5.6 \mathrm{E}+03$ & $7.3 E+03$ \\
\hline Zr-95 & $1.9 \mathrm{E}+03$ & 0.2 & $1.7 \mathrm{E}+03$ & $2.2 \mathrm{E}+03$ \\
\hline Total & $9.7 \mathrm{E}+05$ & 99.9 & & \\
\hline
\end{tabular}


Table 3-17a. Inventory of radiological contaminants (listed by quantity) from the Naval Reactors Facility for the years 1994-2003 (activity at time of disposal).

\begin{tabular}{|c|c|c|c|c|}
\hline Radionuclide & $\begin{array}{c}\text { Best } \\
\text { estimate } \\
\text { (Ci) }\end{array}$ & $\begin{array}{l}\text { Percent } \\
\text { of total } \\
(\%)\end{array}$ & $\begin{array}{l}\text { Lower } \\
\text { bound }\end{array}$ & $\begin{array}{l}\text { Upper } \\
\text { bound }\end{array}$ \\
\hline $\mathrm{Ni}-63$ & $4.7 \mathrm{E}+04$ & 34.2 & $1.5 \mathrm{E}+04$ & $1.1 \mathrm{E}+05$ \\
\hline Co- 60 & $4.2 \mathrm{E}+04$ & 31.0 & $1.4 \mathrm{E}+04$ & $1.0 \mathrm{E}+05$ \\
\hline $\mathrm{Fe}-55$ & $2.5 \mathrm{E}+04$ & 18.2 & $8.0 \mathrm{E}+03$ & $6.0 \mathrm{E}+04$ \\
\hline Ta-182 & $7.6 \mathrm{E}+03$ & 5.6 & $2.4 \mathrm{E}+03$ & $1.8 \mathrm{E}+04$ \\
\hline $\mathrm{Nb}-95$ & $6.8 \mathrm{E}+03$ & 5.0 & $2.2 \mathrm{E}+03$ & $1.6 \mathrm{E}+04$ \\
\hline Co-58 & $3.5 \mathrm{E}+03$ & 2.5 & $1.1 \mathrm{E}+03$ & $8.4 E+03$ \\
\hline Zr-95 & $3.2 \mathrm{E}+03$ & 2.3 & $1.0 \mathrm{E}+03$ & 7.7E+03 \\
\hline Cr-51 & $1.7 \mathrm{E}+03$ & 1.2 & $5.3 E+02$ & $4.0 \mathrm{E}+03$ \\
\hline C-14 & $9.8 E+00$ & $<0.05$ & $3.1 E+00$ & $2.4 \mathrm{E}+01$ \\
\hline $\mathrm{H}-3$ & $2.8 \mathrm{E}+00$ & $<0.05$ & $8.8 \mathrm{E}-01$ & $6.6 \mathrm{E}+00$ \\
\hline Sr-90 & $1.5 \mathrm{E}-01$ & $<0.05$ & 4.8E-02 & 3.6E-01 \\
\hline Cs-137 & $5.0 \mathrm{E}-02$ & $<0.05$ & $1.8 \mathrm{E}-02$ & $1.1 \mathrm{E}-01$ \\
\hline $\mathrm{Ba}-137 \mathrm{~m}$ & $5.0 \mathrm{E}-02$ & $<0.05$ & $2.7 \mathrm{E}-03$ & $2.5 \mathrm{E}-01$ \\
\hline $\mathrm{Mn}-54$ & $3.8 \mathrm{E}-02$ & $<0.05$ & $3.6 \mathrm{E}-03$ & $1.6 \mathrm{E}-01$ \\
\hline Tc-99 & $2.8 \mathrm{E}-03$ & $<0.05$ & $9.4 \mathrm{E}-04$ & $6.4 \mathrm{E}-03$ \\
\hline I-129 & $2.2 \mathrm{E}-06$ & $<0.05$ & $3.3 \mathrm{E}-07$ & $8.0 \mathrm{E}-06$ \\
\hline Total & $1.4 \mathrm{E}+05$ & 100.0 & & \\
\hline
\end{tabular}


Table 3-17b. Inventory of radiological contaminants (listed alphabetically) from the Naval Reactors Facility for the years 1994-2003 (activity at time of disposal).

\begin{tabular}{lcccc}
\hline Radionuclide & $\begin{array}{c}\text { Best } \\
\text { estimate } \\
(\mathrm{Ci})\end{array}$ & $\begin{array}{c}\text { Percent } \\
\text { of total } \\
(\%)\end{array}$ & $\begin{array}{c}\text { Lower } \\
\text { bound }\end{array}$ & $\begin{array}{c}\text { Upper } \\
\text { bound }\end{array}$ \\
\hline Ba-137m & $5.0 \mathrm{E}-02$ & $<0.05$ & $2.7 \mathrm{E}-03$ & $2.5 \mathrm{E}-01$ \\
C-14 & $9.8 \mathrm{E}+00$ & $<0.05$ & $3.1 \mathrm{E}+00$ & $2.4 \mathrm{E}+01$ \\
Co-58 & $3.5 \mathrm{E}+03$ & 2.5 & $1.1 \mathrm{E}+03$ & $8.4 \mathrm{E}+03$ \\
Co-60 & $4.2 \mathrm{E}+04$ & 31.0 & $1.4 \mathrm{E}+04$ & $1.0 \mathrm{E}+05$ \\
Cr-51 & $1.7 \mathrm{E}+03$ & 1.2 & $5.3 \mathrm{E}+02$ & $4.0 \mathrm{E}+03$ \\
Cs-137 & $5.0 \mathrm{E}-02$ & $<0.05$ & $1.8 \mathrm{E}-02$ & $1.1 \mathrm{E}-01$ \\
Fe-55 & $2.5 \mathrm{E}+04$ & 18.2 & $8.0 \mathrm{E}+03$ & $6.0 \mathrm{E}+04$ \\
H-3 & $2.8 \mathrm{E}+00$ & $<0.05$ & $8.8 \mathrm{E}-01$ & $6.6 \mathrm{E}+00$ \\
I-129 & $2.2 \mathrm{E}-06$ & $<0.05$ & $3.3 \mathrm{E}-07$ & $8.0 \mathrm{E}-06$ \\
Mn-54 & $3.8 \mathrm{E}-02$ & $<0.05$ & $3.6 \mathrm{E}-03$ & $1.6 \mathrm{E}-01$ \\
Nb-95 & $6.8 \mathrm{E}+03$ & 5.0 & $2.2 \mathrm{E}+03$ & $1.6 \mathrm{E}+04$ \\
Ni-63 & $4.7 \mathrm{E}+04$ & 34.2 & $1.5 \mathrm{E}+04$ & $1.1 \mathrm{E}+05$ \\
Sr-90 & $1.5 \mathrm{E}-01$ & $<0.05$ & $4.8 \mathrm{E}-02$ & $3.6 \mathrm{E}-01$ \\
Ta-182 & $7.6 \mathrm{E}+03$ & 5.6 & $2.4 \mathrm{E}+03$ & $1.8 \mathrm{E}+04$ \\
Tc-99 & $2.8 \mathrm{E}-03$ & $<0.05$ & $9.4 \mathrm{E}-04$ & $6.4 \mathrm{E}-03$ \\
Zr-95 & $3.2 \mathrm{E}+03$ & 2.3 & $1.0 \mathrm{E}+03$ & $7.7 \mathrm{E}+03$ \\
\hline Total & $1.4 \mathrm{E}+05$ & 100.0 & & \\
\hline & & & & \\
\hline
\end{tabular}


Table 3-18a. Inventory of nonradiological contaminants (listed by quantity) from Argonne National Laboratory-West for the years 1984-1993.

\begin{tabular}{clccc}
\hline $\begin{array}{c}\text { CAS } \\
\text { number }\end{array}$ & \multicolumn{1}{c}{ Chemical } & $\begin{array}{c}\text { Best } \\
\text { estimate } \\
(\mathrm{g})\end{array}$ & $\begin{array}{c}\text { Lower } \\
\text { bound }\end{array}$ & $\begin{array}{c}\text { Upper } \\
\text { bound }\end{array}$ \\
\hline $7439-92-1$ & Lead & $9.5 \mathrm{E}+06$ & $9.1 \mathrm{E}+06$ & $9.8 \mathrm{E}+06$ \\
$1332-21-4$ & Asbestos & $4.1 \mathrm{E}+05$ & $3.6 \mathrm{E}+05$ & $4.7 \mathrm{E}+05$ \\
$1314-23-4$ & Zirconium oxide & $4.5 \mathrm{E}+03$ & $3.8 \mathrm{E}+03$ & $5.2 \mathrm{E}+03$ \\
$7440-43-9$ & Cadmium & $1.7 \mathrm{E}+00$ & $1.5 \mathrm{E}+00$ & $2.0 \mathrm{E}+00$ \\
$7440-47-3$ & Chromium & $8.2 \mathrm{E}-02$ & $6.9 \mathrm{E}-02$ & $9.5 \mathrm{E}-02$ \\
$7439-97-6$ & Mercury & $9.0 \mathrm{E}-03$ & $7.6 \mathrm{E}-03$ & $1.0 \mathrm{E}-02$ \\
\hline
\end{tabular}

Table 3-18b. Inventory of nonradiological contaminants (listed alphabetically) from Argonne National Laboratory-West for the years 1984-1993.

\begin{tabular}{cllll}
\hline $\begin{array}{c}\text { CAS } \\
\text { number }\end{array}$ & \multicolumn{1}{c}{ Chemical } & $\begin{array}{c}\text { Best } \\
\text { estimate } \\
(\mathrm{g})\end{array}$ & $\begin{array}{c}\text { Lower } \\
\text { bound }\end{array}$ & $\begin{array}{c}\text { Upper } \\
\text { bound }\end{array}$ \\
\hline $1332-21-4$ & Asbestos & $4.1 \mathrm{E}+05$ & $3.6 \mathrm{E}+05$ & $4.7 \mathrm{E}+05$ \\
$7440-43-9$ & Cadmium & $1.7 \mathrm{E}+00$ & $1.5 \mathrm{E}+00$ & $2.0 \mathrm{E}+00$ \\
$7440-47-3$ & Chromium & $8.2 \mathrm{E}-02$ & $6.9 \mathrm{E}-02$ & $9.5 \mathrm{E}-02$ \\
$7439-92-1$ & Lead & $9.5 \mathrm{E}+06$ & $9.1 \mathrm{E}+06$ & $9.8 \mathrm{E}+06$ \\
$7439-97-6$ & Mercury & $9.0 \mathrm{E}-03$ & $7.6 \mathrm{E}-03$ & $1.0 \mathrm{E}-02$ \\
$1314-23-4$ & Zirconium oxide & $4.5 \mathrm{E}+03$ & $3.8 \mathrm{E}+03$ & $5.2 \mathrm{E}+03$ \\
\hline
\end{tabular}


Table 3-19a. Inventory of nonradiological contaminants (listed by quantity) from Argonne National Laboratory-West for the years 1994-2003.

\begin{tabular}{clccc}
\hline $\begin{array}{c}\text { CAS } \\
\text { number }\end{array}$ & \multicolumn{1}{c}{ Chemical } & $\begin{array}{c}\text { Best } \\
\text { estimate } \\
(\mathrm{g})\end{array}$ & $\begin{array}{c}\text { Lower } \\
\text { bound }\end{array}$ & $\begin{array}{c}\text { Upper } \\
\text { bound }\end{array}$ \\
\hline $1332-21-4$ & Asbestos & $1.0 \mathrm{E}+05$ & $9.5 \mathrm{E}+04$ & $1.2 \mathrm{E}+05$ \\
$7440-47-3$ & Chromium & $1.9 \mathrm{E}+01$ & $9.5 \mathrm{E}+00$ & $2.8 \mathrm{E}+01$ \\
$7440-39-3$ & Barium & $7.3 \mathrm{E}+00$ & $3.7 \mathrm{E}+00$ & $1.1 \mathrm{E}+01$ \\
$7440-43-9$ & Cadmium & $5.8 \mathrm{E}+00$ & $3.4 \mathrm{E}+00$ & $8.3 \mathrm{E}+00$ \\
$7439-92-1$ & Lead & $1.6 \mathrm{E}+00$ & $1.2 \mathrm{E}+00$ & $1.9 \mathrm{E}+00$ \\
$7440-38-2$ & Arsenic & $2.1 \mathrm{E}-01$ & $1.0 \mathrm{E}-01$ & $3.2 \mathrm{E}-01$ \\
$7439-97-6$ & Mercury & $1.3 \mathrm{E}-02$ & $1.1 \mathrm{E}-02$ & $1.5 \mathrm{E}-02$ \\
\hline
\end{tabular}

Table 3-19b. Inventory of nonradiological contaminants (listed alphabetically) from Argonne National Laboratory-West for the years 1994-2003.

\begin{tabular}{cllll}
\hline $\begin{array}{c}\text { CAS } \\
\text { number }\end{array}$ & \multicolumn{1}{c}{ Chemical } & $\begin{array}{c}\text { Best } \\
\text { estimate } \\
(\mathrm{g})\end{array}$ & $\begin{array}{c}\text { Lower } \\
\text { bound }\end{array}$ & $\begin{array}{r}\text { Upper } \\
\text { bound }\end{array}$ \\
\hline $7440-38-2$ & Arsenic & $2.1 \mathrm{E}-01$ & $1.0 \mathrm{E}-01$ & $3.2 \mathrm{E}-01$ \\
$1332-21-4$ & Asbestos & $1.0 \mathrm{E}+05$ & $9.5 \mathrm{E}+04$ & $1.2 \mathrm{E}+05$ \\
$7440-39-3$ & Barium & $7.3 \mathrm{E}+00$ & $3.7 \mathrm{E}+00$ & $1.1 \mathrm{E}+01$ \\
$7440-43-9$ & Cadmium & $5.8 \mathrm{E}+00$ & $3.4 \mathrm{E}+00$ & $8.3 \mathrm{E}+00$ \\
$7440-47-3$ & Chromium & $1.9 \mathrm{E}+01$ & $9.5 \mathrm{E}+00$ & $2.8 \mathrm{E}+01$ \\
$7439-92-1$ & Lead & $1.6 \mathrm{E}+00$ & $1.2 \mathrm{E}+00$ & $1.9 \mathrm{E}+00$ \\
$7439-97-6$ & Mercury & $1.3 \mathrm{E}-02$ & $1.1 \mathrm{E}-02$ & $1.5 \mathrm{E}-02$ \\
\hline
\end{tabular}


Table 3-20a. Inventory of radiological contaminants (listed by quantity) from Argonne National Laboratory-West for the years 1984-1993 (activity at time of disposal).

\begin{tabular}{|c|c|c|c|c|}
\hline Radionuclide & $\begin{array}{c}\text { Best } \\
\text { estimate } \\
\text { (Ci) }\end{array}$ & $\begin{array}{l}\text { Percent } \\
\text { of total } \\
(\%)\end{array}$ & $\begin{array}{l}\text { Lower } \\
\text { bound }\end{array}$ & $\begin{array}{l}\text { Upper } \\
\text { bound }\end{array}$ \\
\hline Co-60 & $1.1 \mathrm{E}+06$ & 76.0 & $6.6 \mathrm{E}+05$ & $1.8 \mathrm{E}+06$ \\
\hline Co-58 & $1.8 \mathrm{E}+05$ & 12.0 & $1.8 E+04$ & $7.2 E+05$ \\
\hline$M n-54$ & $1.2 \mathrm{E}+05$ & 8.0 & $1.2 \mathrm{E}+04$ & $4.8 \mathrm{E}+05$ \\
\hline $\mathrm{Cr}-51$ & $4.4 \mathrm{E}+04$ & 3.0 & $4.6 \mathrm{E}+03$ & $1.8 E+05$ \\
\hline $\mathrm{Fe}-59$ & $1.5 E+04$ & 1.0 & $1.5 E+03$ & $6.0 \mathrm{E}+04$ \\
\hline Sr-90 & $1.6 \mathrm{E}+02$ & $<0.05$ & $1.9 \mathrm{E}+01$ & $6.1 E+02$ \\
\hline Cs-137 & $1.5 \mathrm{E}+02$ & $<0.05$ & $8.8 \mathrm{E}+01$ & $2.3 \mathrm{E}+02$ \\
\hline Y-90 & $1.4 \mathrm{E}+02$ & $<0.05$ & $1.4 \mathrm{E}+01$ & $5.8 \mathrm{E}+02$ \\
\hline $\mathrm{H}-3$ & $8.2 E+01$ & $<0.05$ & $4.7 \mathrm{E}+00$ & $4.1 \mathrm{E}+02$ \\
\hline Ce-144 & $1.6 \mathrm{E}+01$ & $<0.05$ & $1.6 \mathrm{E}+00$ & $6.6 \mathrm{E}+01$ \\
\hline Eu-155 & $1.3 E+01$ & $<0.05$ & $1.3 \mathrm{E}+00$ & $5.2 \mathrm{E}+01$ \\
\hline Cs-134 & $6.6 \mathrm{E}+00$ & $<0.05$ & $7.0 \mathrm{E}-01$ & 2.7E+01 \\
\hline Ru-106 & $3.3 E+00$ & $<0.05$ & $1.8 \mathrm{E}-01$ & $1.7 \mathrm{E}+01$ \\
\hline U-234 & $2.5 \mathrm{E}+00$ & $<0.05$ & $2.4 \mathrm{E}+00$ & $2.7 \mathrm{E}+00$ \\
\hline $\mathrm{Pu}-239$ & $1.6 \mathrm{E}+00$ & $<0.05$ & $8.7 \mathrm{E}-02$ & $7.9 \mathrm{E}+00$ \\
\hline Co- 57 & $1.5 \mathrm{E}+00$ & $<0.05$ & $8.3 \mathrm{E}-02$ & $7.8 \mathrm{E}+00$ \\
\hline $\mathrm{Sb}-125$ & $9.5 \mathrm{E}-01$ & $<0.05$ & $1.0 \mathrm{E}-01$ & $3.9 \mathrm{E}+00$ \\
\hline Ta-182 & $6.2 \mathrm{E}-01$ & $<0.05$ & $3.4 \mathrm{E}-02$ & $3.2 \mathrm{E}+00$ \\
\hline Eu-154 & $5.8 \mathrm{E}-01$ & $<0.05$ & $8.6 \mathrm{E}-02$ & $2.1 \mathrm{E}+00$ \\
\hline U-238 & $5.3 \mathrm{E}-01$ & $<0.05$ & $5.0 \mathrm{E}-01$ & $5.6 \mathrm{E}-01$ \\
\hline $\mathrm{Na}-22$ & $5.3 \mathrm{E}-01$ & $<0.05$ & $3.5 \mathrm{E}-02$ & $2.5 \mathrm{E}+00$ \\
\hline $\mathrm{Zr}-95$ & $5.2 \mathrm{E}-01$ & $<0.05$ & $3.0 \mathrm{E}-02$ & $2.6 \mathrm{E}+00$ \\
\hline $\mathrm{Nb}-95$ & $2.1 \mathrm{E}-01$ & $<0.05$ & $1.8 \mathrm{E}-02$ & $9.0 \mathrm{E}-01$ \\
\hline La-140 & $1.4 \mathrm{E}-01$ & $<0.05$ & $7.5 \mathrm{E}-03$ & 7.1E-01 \\
\hline U-235 & $1.1 \mathrm{E}-01$ & $<0.05$ & $1.0 \mathrm{E}-01$ & $1.1 \mathrm{E}-01$ \\
\hline Sn-113 & $9.6 \mathrm{E}-02$ & $<0.05$ & $5.2 \mathrm{E}-03$ & $4.9 \mathrm{E}-01$ \\
\hline In-113m & $8.2 \mathrm{E}-02$ & $<0.05$ & 4.4E-03 & $4.2 \mathrm{E}-01$ \\
\hline
\end{tabular}


Table 3-20a. (continued).

\begin{tabular}{lcccc}
\hline Radionuclide & $\begin{array}{c}\text { Best } \\
\text { estimate } \\
(\mathrm{Ci})\end{array}$ & $\begin{array}{c}\text { Percent } \\
\text { of total } \\
(\%)\end{array}$ & $\begin{array}{c}\text { Lower } \\
\text { bound }\end{array}$ & $\begin{array}{c}\text { Upper } \\
\text { bound }\end{array}$ \\
\hline Sn-117m & $5.2 \mathrm{E}-02$ & $<0.05$ & $2.8 \mathrm{E}-03$ & $2.6 \mathrm{E}-01$ \\
$\mathrm{I}-131$ & $3.8 \mathrm{E}-02$ & $<0.05$ & $2.0 \mathrm{E}-03$ & $1.9 \mathrm{E}-01$ \\
$\mathrm{Au}-198$ & $2.4 \mathrm{E}-02$ & $<0.05$ & $1.3 \mathrm{E}-03$ & $1.2 \mathrm{E}-01$ \\
Te-132 & $5.3 \mathrm{E}-03$ & $<0.05$ & $2.9 \mathrm{E}-04$ & $2.7 \mathrm{E}-02$ \\
$\mathrm{Sb}-124$ & $4.5 \mathrm{E}-03$ & $<0.05$ & $2.4 \mathrm{E}-04$ & $2.3 \mathrm{E}-02$ \\
Ba-140 & $1.8 \mathrm{E}-03$ & $<0.05$ & $9.6 \mathrm{E}-05$ & $9.0 \mathrm{E}-03$ \\
$\mathrm{Ag}-110 \mathrm{~m}$ & $1.8 \mathrm{E}-03$ & $<0.05$ & $9.6 \mathrm{E}-05$ & $9.0 \mathrm{E}-03$ \\
Sr-89 & $9.9 \mathrm{E}-04$ & $<0.05$ & $5.4 \mathrm{E}-05$ & $5.0 \mathrm{E}-03$ \\
$\mathrm{Pu}-240$ & $6.7 \mathrm{E}-05$ & $<0.05$ & $3.6 \mathrm{E}-06$ & $3.4 \mathrm{E}-04$ \\
Total & $1.5 \mathrm{E}+06$ & 100.0 & & \\
\hline
\end{tabular}


Table 3-20b. Inventory of radiological contaminants (listed alphabetically) from Argonne National Laboratory-West for the years 1984-1993 (activity at time of disposal).

\begin{tabular}{|c|c|c|c|c|}
\hline Radionuclide & $\begin{array}{l}\text { Best } \\
\text { estimate } \\
(\mathrm{Ci})\end{array}$ & $\begin{array}{c}\text { Percent } \\
\text { of total } \\
(\%)\end{array}$ & $\begin{array}{l}\text { Lower } \\
\text { bound }\end{array}$ & $\begin{array}{l}\text { Upper } \\
\text { bound }\end{array}$ \\
\hline $\mathrm{Ag}-110 \mathrm{~m}$ & $1.8 \mathrm{E}-03$ & $<0.05$ & $9.6 \mathrm{E}-05$ & $9.0 \mathrm{E}-03$ \\
\hline $\mathrm{Au}-198$ & $2.4 \mathrm{E}-02$ & $<0.05$ & $1.3 \mathrm{E}-03$ & $1.2 \mathrm{E}-01$ \\
\hline Ba-140 & $1.8 \mathrm{E}-03$ & $<0.05$ & $9.6 \mathrm{E}-05$ & $9.0 \mathrm{E}-03$ \\
\hline Ce-144 & $1.6 \mathrm{E}+01$ & $<0.05$ & $1.6 \mathrm{E}+00$ & $6.6 \mathrm{E}+01$ \\
\hline Co-57 & $1.5 \mathrm{E}+00$ & $<0.05$ & $8.3 \mathrm{E}-02$ & $7.8 \mathrm{E}+00$ \\
\hline Co-58 & $1.8 \mathrm{E}+05$ & 12.0 & $1.8 \mathrm{E}+04$ & $7.2 E+05$ \\
\hline Co-60 & $1.1 E+06$ & 76.0 & $6.6 \mathrm{E}+05$ & $1.8 \mathrm{E}+06$ \\
\hline $\mathrm{Cr}-51$ & $4.4 \mathrm{E}+04$ & 3.0 & $4.6 \mathrm{E}+03$ & $1.8 \mathrm{E}+05$ \\
\hline Cs-134 & $6.6 \mathrm{E}+00$ & $<0.05$ & $7.0 \mathrm{E}-01$ & 2.7E+01 \\
\hline Cs- 137 & $1.5 \mathrm{E}+02$ & $<0.05$ & $8.8 \mathrm{E}+01$ & $2.3 \mathrm{E}+02$ \\
\hline $\mathrm{Eu}-154$ & $5.8 \mathrm{E}-01$ & $<0.05$ & $8.6 \mathrm{E}-02$ & $2.1 \mathrm{E}+00$ \\
\hline Eu-155 & $1.3 E+01$ & $<0.05$ & $1.3 \mathrm{E}+00$ & $5.2 \mathrm{E}+01$ \\
\hline $\mathrm{Fe}-59$ & $1.5 \mathrm{E}+04$ & 1.0 & $1.5 E+03$ & $6.0 \mathrm{E}+04$ \\
\hline $\mathrm{H}-3$ & $8.2 \mathrm{E}+01$ & $<0.05$ & $4.7 \mathrm{E}+00$ & $4.1 \mathrm{E}+02$ \\
\hline $\mathrm{I}-131$ & $3.8 \mathrm{E}-02$ & $<0.05$ & $2.0 \mathrm{E}-03$ & $1.9 \mathrm{E}-01$ \\
\hline In-113m & $8.2 \mathrm{E}-02$ & $<0.05$ & $4.4 \mathrm{E}-03$ & $4.2 \mathrm{E}-01$ \\
\hline La-140 & 1.4E-01 & $<0.05$ & $7.5 \mathrm{E}-03$ & 7.1E-01 \\
\hline $\mathrm{Mn}-54$ & $1.2 \mathrm{E}+05$ & 8.0 & $1.2 \mathrm{E}+04$ & $4.8 \mathrm{E}+05$ \\
\hline $\mathrm{Na}-22$ & $5.3 \mathrm{E}-01$ & $<0.05$ & $3.5 \mathrm{E}-02$ & $2.5 \mathrm{E}+00$ \\
\hline $\mathrm{Nb}-95$ & $2.1 \mathrm{E}-01$ & $<0.05$ & $1.8 \mathrm{E}-02$ & $9.0 \mathrm{E}-01$ \\
\hline $\mathrm{Pu}-239$ & $1.6 \mathrm{E}+00$ & $<0.05$ & $8.7 \mathrm{E}-02$ & $7.9 \mathrm{E}+00$ \\
\hline Pu-240 & $6.7 \mathrm{E}-05$ & $<0.05$ & $3.6 \mathrm{E}-06$ & 3.4E-04 \\
\hline Ru-106 & $3.3 E+00$ & $<0.05$ & $1.8 \mathrm{E}-01$ & $1.7 \mathrm{E}+01$ \\
\hline Sb-124 & $4.5 \mathrm{E}-03$ & $<0.05$ & $2.4 \mathrm{E}-04$ & $2.3 \mathrm{E}-02$ \\
\hline Sb-125 & $9.5 \mathrm{E}-01$ & $<0.05$ & $1.0 \mathrm{E}-01$ & $3.9 E+00$ \\
\hline Sn-113 & $9.6 \mathrm{E}-02$ & $<0.05$ & $5.2 \mathrm{E}-03$ & $4.9 \mathrm{E}-01$ \\
\hline Sn-117m & $5.2 \mathrm{E}-02$ & $<0.05$ & $2.8 \mathrm{E}-03$ & $2.6 \mathrm{E}-01$ \\
\hline
\end{tabular}


Table 3-20b. (continued).

\begin{tabular}{lllll}
\hline Radionuclide & $\begin{array}{c}\text { Best } \\
\text { estimate } \\
(\mathrm{Ci})\end{array}$ & $\begin{array}{c}\text { Percent } \\
\text { of total } \\
(\%)\end{array}$ & $\begin{array}{c}\text { Lower } \\
\text { bound }\end{array}$ & $\begin{array}{c}\text { Upper } \\
\text { bound }\end{array}$ \\
\hline Sr-89 & $9.9 \mathrm{E}-04$ & $<0.05$ & $5.4 \mathrm{E}-05$ & $5.0 \mathrm{E}-03$ \\
Sr-90 & $1.6 \mathrm{E}+02$ & $<0.05$ & $1.9 \mathrm{E}+01$ & $6.1 \mathrm{E}+02$ \\
Ta-182 & $6.2 \mathrm{E}-01$ & $<0.05$ & $3.4 \mathrm{E}-02$ & $3.2 \mathrm{E}+00$ \\
Te-132 & $5.3 \mathrm{E}-03$ & $<0.05$ & $2.9 \mathrm{E}-04$ & $2.7 \mathrm{E}-02$ \\
$\mathrm{U}-234$ & $2.5 \mathrm{E}+00$ & $<0.05$ & $2.4 \mathrm{E}+00$ & $2.7 \mathrm{E}+00$ \\
$\mathrm{U}-235$ & $1.1 \mathrm{E}-01$ & $<0.05$ & $1.0 \mathrm{E}-01$ & $1.1 \mathrm{E}-01$ \\
$\mathrm{U}-238$ & $5.3 \mathrm{E}-01$ & $<0.05$ & $5.0 \mathrm{E}-01$ & $5.6 \mathrm{E}-01$ \\
Y-90 & $1.4 \mathrm{E}+02$ & $<0.05$ & $1.4 \mathrm{E}+01$ & $5.8 \mathrm{E}+02$ \\
Zr-95 & $5.2 \mathrm{E}-01$ & $<0.05$ & $3.0 \mathrm{E}-02$ & $2.6 \mathrm{E}+00$ \\
\hline Total & $1.5 \mathrm{E}+06$ & 100.0 & & \\
\hline
\end{tabular}


Table 3-21a. Inventory of radiological contaminants (listed by quantity) from Argonne National Laboratory-West for the years 1994-2003 (activity at time of disposal).

\begin{tabular}{|c|c|c|c|c|}
\hline Radionuclide & $\begin{array}{c}\text { Best } \\
\text { estimate } \\
\text { (Ci) }\end{array}$ & $\begin{array}{c}\text { Percent } \\
\text { of total } \\
(\%)\end{array}$ & $\begin{array}{l}\text { Lower } \\
\text { bound }\end{array}$ & $\begin{array}{l}\text { Upper } \\
\text { bound }\end{array}$ \\
\hline Co-60 & $6.2 E+05$ & 76.0 & $2.2 \mathrm{E}+05$ & $1.4 \mathrm{E}+06$ \\
\hline Co-58 & $9.7 \mathrm{E}+04$ & 12.0 & $5.3 E+03$ & $4.9 \mathrm{E}+05$ \\
\hline $\mathrm{Mn}-54$ & $6.5 \mathrm{E}+04$ & 8.0 & $3.5 E+03$ & $3.3 \mathrm{E}+05$ \\
\hline $\mathrm{Cr}-51$ & $2.4 \mathrm{E}+04$ & 3.0 & $1.3 E+03$ & $1.2 \mathrm{E}+05$ \\
\hline Fe-59. & $8.1 \mathrm{E}+03$ & 1.0 & $4.4 \mathrm{E}+02$ & $4.1 \mathrm{E}+04$ \\
\hline Cs-137 & $1.1 \mathrm{E}+01$ & $<0.05$ & $3.7 \mathrm{E}+00$ & $2.4 \mathrm{E}+01$ \\
\hline Sr-90 & $9.5 \mathrm{E}+00$ & $<0.05$ & $5.4 \mathrm{E}-01$ & $4.7 \mathrm{E}+01$ \\
\hline Y-90 & $8.8 \mathrm{E}+00$ & $<0.05$ & $5.8 \mathrm{E}-01$ & $4.2 \mathrm{E}+01$ \\
\hline $\mathrm{H}-3$ & $4.0 \mathrm{E}+00$ & $<0.05$ & $5.5 \mathrm{E}-02$ & $2.6 \mathrm{E}+01$ \\
\hline Ce-144 & $1.3 E+00$ & $<0.05$ & $6.6 \mathrm{E}-02$ & $6.7 \mathrm{E}+00$ \\
\hline Eu-155 & $6.7 \mathrm{E}-01$ & $<0.05$ & $1.4 \mathrm{E}-02$ & $4.2 \mathrm{E}+00$ \\
\hline Cs-134 & $4.2 \mathrm{E}-01$ & $<0.05$ & $1.3 \mathrm{E}-02$ & $2.4 \mathrm{E}+00$ \\
\hline Zr-95 & $1.6 \mathrm{E}-01$ & $<0.05$ & $3.0 \mathrm{E}-03$ & $1.0 \mathrm{E}+00$ \\
\hline Co- 57 & $1.2 \mathrm{E}-01$ & $<0.05$ & $4.5 \mathrm{E}-03$ & $6.8 \mathrm{E}-01$ \\
\hline $\mathrm{Na}-22$ & $1.1 \mathrm{E}-01$ & $<0.05$ & $6.1 \mathrm{E}-03$ & 5.5E-01 \\
\hline Ta-182 & $9.9 \mathrm{E}-02$ & $<0.05$ & $7.0 \mathrm{E}-03$ & 4.6E-01 \\
\hline Sn-113 & $6.3 \mathrm{E}-02$ & $<0.05$ & $3.7 \mathrm{E}-03$ & $3.1 \mathrm{E}-01$ \\
\hline In-113m & $5.4 \mathrm{E}-02$ & $<0.05$ & 3.1E-03 & $2.7 \mathrm{E}-01$ \\
\hline Sb-125 & $5.3 \mathrm{E}-02$ & $<0.05$ & $2.2 \mathrm{E}-03$ & $2.9 \mathrm{E}-01$ \\
\hline Eu-154 & $3.6 \mathrm{E}-02$ & $<0.05$ & $1.7 \mathrm{E}-03$ & $1.9 \mathrm{E}-01$ \\
\hline Sn-117m & $3.4 \mathrm{E}-02$ & $<0.05$ & $2.0 \mathrm{E}-03$ & $1.7 \mathrm{E}-01$ \\
\hline $\mathrm{Nb}-95$ & $2.8 \mathrm{E}-02$ & $<0.05$ & $2.4 \mathrm{E}-03$ & $1.2 \mathrm{E}-01$ \\
\hline $\mathrm{I}-131$ & $2.5 \mathrm{E}-02$ & $<0.05$ & $1.4 \mathrm{E}-03$ & $1.2 \mathrm{E}-01$ \\
\hline La-140 & $1.9 \mathrm{E}-02$ & $<0.05$ & $1.3 \mathrm{E}-04$ & $1.4 \mathrm{E}-01$ \\
\hline $\mathrm{Au}-198$ & $1.6 \mathrm{E}-02$ & $<0.05$ & $9.0 \mathrm{E}-04$ & $8.0 \mathrm{E}-02$ \\
\hline Ba-140 & $1.5 \mathrm{E}-02$ & $<0.05$ & $9.6 \mathrm{E}-05$ & $1.1 \mathrm{E}-01$ \\
\hline Ce-141 & $1.3 \mathrm{E}-02$ & $<0.05$ & $7.2 \mathrm{E}-05$ & $9.4 \mathrm{E}-02$ \\
\hline
\end{tabular}


Table 3-21a. (continued).

\begin{tabular}{lcccc}
\hline Radionuclide & $\begin{array}{c}\text { Best } \\
\text { estimate } \\
(\mathrm{Ci})\end{array}$ & $\begin{array}{c}\text { Percent } \\
\text { of total } \\
(\%)\end{array}$ & $\begin{array}{c}\text { Lower } \\
\text { bound }\end{array}$ & $\begin{array}{c}\text { Upper } \\
\text { bound }\end{array}$ \\
\hline Ru-106 & $9.5 \mathrm{E}-03$ & $<0.05$ & $6.2 \mathrm{E}-05$ & $6.8 \mathrm{E}-02$ \\
Pu-239 & $7.9 \mathrm{E}-03$ & $<0.05$ & $1.4 \mathrm{E}-04$ & $5.0 \mathrm{E}-02$ \\
Np-237 & $7.2 \mathrm{E}-03$ & $<0.05$ & $3.6 \mathrm{E}-05$ & $5.2 \mathrm{E}-02$ \\
Te-132 & $2.9 \mathrm{E}-03$ & $<0.05$ & $1.6 \mathrm{E}-04$ & $1.5 \mathrm{E}-02$ \\
U-238 & $2.8 \mathrm{E}-03$ & $<0.05$ & $1.4 \mathrm{E}-03$ & $5.0 \mathrm{E}-03$ \\
Sb-124 & $2.4 \mathrm{E}-03$ & $<0.05$ & $1.3 \mathrm{E}-04$ & $1.2 \mathrm{E}-02$ \\
I-129 & $1.5 \mathrm{E}-03$ & $<0.05$ & $7.5 \mathrm{E}-06$ & $1.1 \mathrm{E}-02$ \\
Ag-110m & $9.7 \mathrm{E}-04$ & $<0.05$ & $5.2 \mathrm{E}-05$ & $4.9 \mathrm{E}-03$ \\
$\mathrm{U}-234$ & $9.4 \mathrm{E}-04$ & $<0.05$ & $1.1 \mathrm{E}-04$ & $3.8 \mathrm{E}-03$ \\
U-235 & $7.3 \mathrm{E}-04$ & $<0.05$ & $4.4 \mathrm{E}-04$ & $1.1 \mathrm{E}-03$ \\
Sr-89 & $5.4 \mathrm{E}-04$ & $<0.05$ & $2.9 \mathrm{E}-05$ & $2.7 \mathrm{E}-03$ \\
Pu-240 & $1.8 \mathrm{E}-05$ & $<0.05$ & $1.0 \mathrm{E}-06$ & $9.4 \mathrm{E}-05$ \\
Am-241 & $1.1 \mathrm{E}-05$ & $<0.05$ & $5.5 \mathrm{E}-08$ & $7.9 \mathrm{E}-05$ \\
Pu-238 & $2.5 \mathrm{E}-06$ & $<0.05$ & $1.3 \mathrm{E}-08$ & $1.8 \mathrm{E}-05$ \\
Total & $8.1 \mathrm{E}+05$ & 100.0 & & \\
\hline
\end{tabular}


Table 3-21b. Inventory of radiological contaminants (listed alphabetically) from Argonne National Laboratory-West for the years 1994-2003 (activity at time of disposal).

\begin{tabular}{|c|c|c|c|c|}
\hline Radionuclide & $\begin{array}{c}\text { Best } \\
\text { estimate } \\
\text { (Ci) }\end{array}$ & $\begin{array}{c}\text { Percent } \\
\text { of total } \\
(\%)\end{array}$ & $\begin{array}{l}\text { Lower } \\
\text { bound }\end{array}$ & $\begin{array}{l}\text { Upper } \\
\text { bound }\end{array}$ \\
\hline $\mathrm{Ag}-110 \mathrm{~m}$ & $9.7 \mathrm{E}-04$ & $<0.05$ & $5.2 \mathrm{E}-05$ & $4.9 \mathrm{E}-03$ \\
\hline Am-241 & $1.1 \mathrm{E}-05$ & $<0.05$ & $5.5 \mathrm{E}-08$ & $7.9 \mathrm{E}-05$ \\
\hline Au-198 & $1.6 \mathrm{E}-02$ & $<0.05$ & $9.0 \mathrm{E}-04$ & $8.0 \mathrm{E}-02$ \\
\hline Ba-140 & $1.5 \mathrm{E}-02$ & $<0.05$ & $9.6 \mathrm{E}-05$ & $1.1 \mathrm{E}-01$ \\
\hline Ce-141 & $1.3 \mathrm{E}-02$ & $<0.05$ & $7.2 \mathrm{E}-05$ & $9.4 \mathrm{E}-02$ \\
\hline Ce-144 & $1.3 E+00$ & $<0.05$ & $6.6 \mathrm{E}-02$ & $6.7 \mathrm{E}+00$ \\
\hline Co-57 & $1.2 \mathrm{E}-01$ & $<0.05$ & $4.5 \mathrm{E}-03$ & $6.8 \mathrm{E}-01$ \\
\hline Co-58 & $9.7 \mathrm{E}+04$ & 12.0 & $5.3 E+03$ & $4.9 \mathrm{E}+05$ \\
\hline Co- 60 & $6.2 \mathrm{E}+05$ & 76.0 & $2.2 \mathrm{E}+05$ & $1.4 \mathrm{E}+06$ \\
\hline $\mathrm{Cr}-51$ & $2.4 \mathrm{E}+04$ & 3.0 & $1.3 \mathrm{E}+03$ & $1.2 \mathrm{E}+05$ \\
\hline Cs-134 & 4.2E-01 & $<0.05$ & $1.3 \mathrm{E}-02$ & $2.4 \mathrm{E}+00$ \\
\hline Cs-137 & $1.1 \mathrm{E}+01$ & $<0.05$ & $3.7 E+00$ & $2.4 \mathrm{E}+01$ \\
\hline Eu-154 & $3.6 \mathrm{E}-02$ & $<0.05$ & $1.7 \mathrm{E}-03$ & $1.9 \mathrm{E}-01$ \\
\hline Eu-155 & $6.7 \mathrm{E}-01$ & $<0.05$ & $1.4 \mathrm{E}-02$ & $4.2 \mathrm{E}+00$ \\
\hline Fe-59 & $8.1 E+03$ & 1.0 & $4.4 \mathrm{E}+02$ & $4.1 E+04$ \\
\hline $\mathrm{H}-3$ & $4.0 \mathrm{E}+00$ & $<0.05$ & $5.5 \mathrm{E}-02$ & $2.6 \mathrm{E}+01$ \\
\hline I-129 & $1.5 \mathrm{E}-03$ & $<0.05$ & $7.5 \mathrm{E}-06$ & $1.1 \mathrm{E}-02$ \\
\hline I-131 & $2.5 \mathrm{E}-02$ & $<0.05$ & $1.4 \mathrm{E}-03$ & $1.2 E-01$ \\
\hline In-113m & $5.4 \mathrm{E}-02$ & $<0.05$ & $3.1 \mathrm{E}-03$ & 2.7E-01 \\
\hline La-140 & $1.9 \mathrm{E}-02$ & $<0.05$ & $1.3 \mathrm{E}-04$ & $1.4 \mathrm{E}-01$ \\
\hline Mn-54 & $6.5 E+04$ & 8.0 & $3.5 E+03$ & $3.3 E+05$ \\
\hline $\mathrm{Na}-22$ & $1.1 \mathrm{E}-01$ & $<0.05$ & $6.1 \mathrm{E}-03$ & $5.5 \mathrm{E}-01$ \\
\hline $\mathrm{Nb}-95$ & $2.8 \mathrm{E}-02$ & $<0.05$ & $2.4 \mathrm{E}-03$ & $1.2 \mathrm{E}-01$ \\
\hline Np-237 & $7.2 \mathrm{E}-03$ & $<0.05$ & $3.6 \mathrm{E}-05$ & $5.2 \mathrm{E}-02$ \\
\hline Pu-238 & $2.5 \mathrm{E}-06$ & $<0.05$ & $1.3 \mathrm{E}-08$ & $1.8 \mathrm{E}-05$ \\
\hline $\mathrm{Pu}-239$ & $7.9 \mathrm{E}-03$ & $<0.05$ & $1.4 \mathrm{E}-04$ & $5.0 \mathrm{E}-02$ \\
\hline $\mathrm{Pu}-240$ & $1.8 \mathrm{E}-05$ & $<0.05$ & $1.0 \mathrm{E}-06$ & $9.4 \mathrm{E}-05$ \\
\hline
\end{tabular}


Table 3-21b. (continued).

\begin{tabular}{|c|c|c|c|c|}
\hline Radionuclide & $\begin{array}{c}\text { Best } \\
\text { estimate } \\
\text { (Ci) }\end{array}$ & $\begin{array}{c}\text { Percent } \\
\text { of total } \\
(\%)\end{array}$ & $\begin{array}{l}\text { Lower } \\
\text { bound }\end{array}$ & $\begin{array}{l}\text { Upper } \\
\text { bound }\end{array}$ \\
\hline Ru-106 & $9.5 \mathrm{E}-03$ & $<0.05$ & $6.2 \mathrm{E}-05$ & $6.8 E-02$ \\
\hline Sb-124 & $2.4 \mathrm{E}-03$ & $<0.05$ & 1.3E-04 & $1.2 \mathrm{E}-02$ \\
\hline Sb-125 & 5.3E-02 & $<0.05$ & 2.2E-03 & 2.9E-01 \\
\hline Sn-113 & $6.3 E-02$ & $<0.05$ & 3.7E-03 & 3.1E-01 \\
\hline Sn-117m & $3.4 \mathrm{E}-02$ & $<0.05$ & $2.0 \mathrm{E}-03$ & $1.7 \mathrm{E}-01$ \\
\hline Sr-89 & $5.4 \mathrm{E}-04$ & $<0.05$ & 2.9E-05 & 2.7E-03 \\
\hline Sr-90 & $9.5 E+00$ & $<0.05$ & $5.4 \mathrm{E}-01$ & 4.7E+01 \\
\hline Ta-182 & $9.9 \mathrm{E}-02$ & $<0.05$ & $7.0 \mathrm{E}-03$ & 4.6E-01 \\
\hline Te-132 & $2.9 \mathrm{E}-03$ & $<0.05$ & $1.6 \mathrm{E}-04$ & $1.5 \mathrm{E}-02$ \\
\hline U-234 & $9.4 \mathrm{E}-04$ & $<0.05$ & $1.1 \mathrm{E}-04$ & $3.8 \mathrm{E}-03$ \\
\hline U-235 & 7.3E-04 & $<0.05$ & 4.4E-04 & $1.1 \mathrm{E}-03$ \\
\hline U-238 & 2.8E-03 & $<0.05$ & $1.4 \mathrm{E}-03$ & $5.0 \mathrm{E}-03$ \\
\hline$Y-90$ & $8.8 \mathrm{E}+00$ & $<0.05$ & 5.8E-01 & $4.2 E+01$ \\
\hline $\mathrm{Zr}-95$ & 1.6E-01 & $<0.05$ & 3.0E-03 & $1.0 \mathrm{E}+00$ \\
\hline Total & $8.1 E+05$ & 100.0 & & \\
\hline
\end{tabular}


Table 3-22a. Inventory of nonradiological contaminants (listed by quantity) from other generators for the years 1984-1993. ${ }^{\mathrm{a}}$

\begin{tabular}{lllll}
\hline $\begin{array}{c}\text { CAS } \\
\text { number }\end{array}$ & \multicolumn{1}{c}{$\begin{array}{c}\text { Best } \\
\text { estimate } \\
(\mathrm{g})\end{array}$} & $\begin{array}{c}\text { Lower } \\
\text { bound }\end{array}$ & $\begin{array}{c}\text { Upper } \\
\text { bound }\end{array}$ \\
\hline $7439-92-1$ & Lead & $2.5 \mathrm{E}+06$ & $2.2 \mathrm{E}+06$ & $2.8 \mathrm{E}+06$ \\
$1332-21-4$ & Asbestos & $7.5 \mathrm{E}+04$ & $5.1 \mathrm{E}+04$ & $9.9 \mathrm{E}+04$ \\
$7440-50-8$ & Copper & $2.3 \mathrm{E}+04$ & $1.1 \mathrm{E}+04$ & $4.5 \mathrm{E}+04$ \\
$7440-47-3$ & Chromium & $2.9 \mathrm{E}+01$ & $1.4 \mathrm{E}+01$ & $4.4 \mathrm{E}+01$ \\
$7439-97-6$ & Mercury & $2.0 \mathrm{E}+00$ & $1.0 \mathrm{E}+00$ & $3.0 \mathrm{E}+00$ \\
$7440-38-2$ & Arsenic & $5.0 \mathrm{E}-01$ & $2.5 \mathrm{E}-01$ & $7.5 \mathrm{E}-01$ \\
$7440-43-9$ & Cadmium & $3.0 \mathrm{E}-02$ & $1.5 \mathrm{E}-02$ & $4.5 \mathrm{E}-02$ \\
\hline & & $\cdot$ & \\
a. "Other" generators include ALE, ARA, CEG, CFA, D\&D, ERP, PBF, WER, and WMC; \\
however, only D\&D and PBF contributed to this waste for 1984-1993. \\
\hline
\end{tabular}

Table 3-22b. Inventory of nonradiological contaminants (listed alphabetically) from other generators for the years 1984-1993. ${ }^{\mathrm{a}}$

\begin{tabular}{lllll}
\hline $\begin{array}{c}\text { CAS } \\
\text { number }\end{array}$ & Chemical & $\begin{array}{c}\text { Best } \\
\text { estimate } \\
(\mathrm{g})\end{array}$ & $\begin{array}{c}\text { Lower } \\
\text { bound }\end{array}$ & $\begin{array}{r}\text { Upper } \\
\text { bound }\end{array}$ \\
\hline $7440-38-2$ & Arsenic & $5.0 \mathrm{E}-01$ & $2.5 \mathrm{E}-01$ & $7.5 \mathrm{E}-01$ \\
$1332-21-4$ & Asbestos & $7.5 \mathrm{E}+04$ & $5.1 \mathrm{E}+04$ & $9.9 \mathrm{E}+04$ \\
$7440-43-9$ & Cadmium & $3.0 \mathrm{E}-02$ & $1.5 \mathrm{E}-02$ & $4.5 \mathrm{E}-02$ \\
$7440-47-3$ & Chromium & $2.9 \mathrm{E}+01$ & $1.4 \mathrm{E}+01$ & $4.4 \mathrm{E}+01$ \\
$7440-50-8$ & Copper & $2.3 \mathrm{E}+04$ & $1.1 \mathrm{E}+04$ & $4.5 \mathrm{E}+04$ \\
$7439-92-1$ & Lead & $2.5 \mathrm{E}+06$ & $2.2 \mathrm{E}+06$ & $2.8 \mathrm{E}+06$ \\
$7439-97-6$ & Mercury & $2.0 \mathrm{E}+00$ & $1.0 \mathrm{E}+00$ & $3.0 \mathrm{E}+00$ \\
\hline & & & \\
a. "Other" generators include ALE, ARA, CEG, CFA, D\&D, ERP, PBF, WER, and WMC; \\
however, only D\&D and PBF contributed to this waste for 1984-1993. \\
\hline
\end{tabular}


Table 3-23a. Inventory of nonradiological contaminants (listed by quantity) from other generators for the years 1994-2003. ${ }^{\mathrm{a}}$

\begin{tabular}{ccccc}
\hline $\begin{array}{c}\text { CAS } \\
\text { number }\end{array}$ & Chemical & $\begin{array}{c}\text { Best } \\
\text { estimate } \\
(\mathrm{g})\end{array}$ & $\begin{array}{c}\text { Lower } \\
\text { bound }\end{array}$ & $\begin{array}{c}\text { Upper } \\
\text { bound }\end{array}$ \\
\hline $1332-21-4$ & Asbestos & $1.0 \mathrm{E}+06$ & $0.0 \mathrm{E}+00$ & $2.0 \mathrm{E}+06$
\end{tabular}

a. "Other" generators include ALE, ARA, CEG, CFA, D\&D, ERP, PBF, WER, and WMC; however, only ARA is expected to contribute to this waste in 1994-2003.

Table 3-23b. Inventory of nonradiological contaminants (listed alphabetically) from other generators for the years 1994-2003. ${ }^{\mathrm{a}}$

\begin{tabular}{|c|c|c|c|c|}
\hline $\begin{array}{c}\text { CAS } \\
\text { number }\end{array}$ & Chemical & $\begin{array}{c}\text { Best } \\
\text { estimate } \\
\text { (g) }\end{array}$ & $\begin{array}{l}\text { Lower } \\
\text { bound }\end{array}$ & $\begin{array}{l}\text { Upper } \\
\text { bound }\end{array}$ \\
\hline $1332-21-4$ & Asbestos & $1.0 E+06$ & $0.0 \mathrm{E}+00$ & $2.0 \mathrm{E}+06$ \\
\hline
\end{tabular}


Table 3-24a. Inventory of radiological contaminants (listed by quantity) from other generators for the years 1984-1993 (activity at time of disposal). ${ }^{\text {a }}$

\begin{tabular}{|c|c|c|c|c|}
\hline Radionuclide & $\begin{array}{l}\text { Best } \\
\text { estimate } \\
\text { (Ci) }\end{array}$ & $\begin{array}{l}\text { Percent } \\
\text { of total } \\
(\%)\end{array}$ & $\begin{array}{l}\text { Lower } \\
\text { bound }\end{array}$ & $\begin{array}{l}\text { Upper } \\
\text { bound }\end{array}$ \\
\hline $\mathrm{H}-3$ & $2.8 \mathrm{E}+03$ & 88.3 & $2.1 E+03$ & $3.7 E+03$ \\
\hline Cs-137 & $2.7 \mathrm{E}+02$ & 8.3 & $6.9 \mathrm{E}+01$ & $7.4 \mathrm{E}+02$ \\
\hline Sr-90 & $4.9 \mathrm{E}+01$ & 1.5 & $3.3 \mathrm{E}-01$ & $3.5 E+02$ \\
\hline Cs-134 & $2.5 E+01$ & 0.8 & $1.4 \mathrm{E}-01$ & $1.8 \mathrm{E}+02$ \\
\hline Co-60 & $1.8 \mathrm{E}+01$ & 0.6 & $8.5 \mathrm{E}+00$ & $3.6 \mathrm{E}+01$ \\
\hline Th-228 & $1.0 \mathrm{E}+01$ & 0.3 & $8.4 \mathrm{E}+00$ & $1.2 \mathrm{E}+01$ \\
\hline U-232 & $2.2 E+00$ & 0.1 & $1.8 \mathrm{E}+00$ & $2.7 \mathrm{E}+00$ \\
\hline $\mathrm{Ra}-226$ & $1.1 E+00$ & $<0.05$ & $8.7 \mathrm{E}-01$ & $1.4 \mathrm{E}+00$ \\
\hline U-234 & 7.1E-01 & $<0.05$ & $5.6 \mathrm{E}-01$ & 8.8E-01 \\
\hline Pu-239 & $6.7 \mathrm{E}-01$ & $<0.05$ & $3.7 \mathrm{E}-02$ & $3.4 \mathrm{E}+00$ \\
\hline Am-241 & $2.8 \mathrm{E}-01$ & $<0.05$ & $1.6 \mathrm{E}-02$ & $1.4 \mathrm{E}+00$ \\
\hline Nb-95 & $2.7 \mathrm{E}-01$ & $<0.05$ & $6.0 \mathrm{E}-03$ & $1.7 \mathrm{E}+00$ \\
\hline La-140 & $2.5 \mathrm{E}-01$ & $<0.05$ & $1.3 \mathrm{E}-03$ & $1.8 \mathrm{E}+00$ \\
\hline $\mathrm{Ba}-140$ & $2.5 E-01$ & $<0.05$ & $1.3 \mathrm{E}-03$ & $1.8 \mathrm{E}+00$ \\
\hline V-48 & $2.0 \mathrm{E}-01$ & $<0.05$ & $4.4 \mathrm{E}-03$ & $1.2 \mathrm{E}+00$ \\
\hline $\mathrm{Pu}-238$ & $2.0 \mathrm{E}-01$ & $<0.05$ & $5.1 \mathrm{E}-03$ & $1.2 \mathrm{E}+00$ \\
\hline Ce-144 & $2.0 \mathrm{E}-01$ & $<0.05$ & $4.3 \mathrm{E}-03$ & $1.2 \mathrm{E}+00$ \\
\hline $\mathrm{Fe}-59$ & $1.8 \mathrm{E}-01$ & $<0.05$ & $5.5 \mathrm{E}-03$ & $1.1 \mathrm{E}+00$ \\
\hline Zr-95 & $1.4 \mathrm{E}-01$ & $<0.05$ & $3.1 \mathrm{E}-03$ & $8.7 \mathrm{E}-01$ \\
\hline Eu-154 & $1.3 \mathrm{E}-01$ & $<0.05$ & $3.6 \mathrm{E}-03$ & 7.7E-01 \\
\hline U-238 & $1.1 \mathrm{E}-01$ & $<0.05$ & $9.4 \mathrm{E}-02$ & $1.3 \mathrm{E}-01$ \\
\hline Eu-152 & $5.0 \mathrm{E}-02$ & $<0.05$ & $1.4 \mathrm{E}-03$ & $3.0 \mathrm{E}-01$ \\
\hline $\mathrm{Pu}-240$ & $4.0 \mathrm{E}-02$ & $<0.05$ & $1.8 \mathrm{E}-03$ & $2.1 \mathrm{E}-01$ \\
\hline U-235 & $3.0 \mathrm{E}-02$ & $<0.05$ & $2.4 \mathrm{E}-02$ & $3.7 \mathrm{E}-02$ \\
\hline $\mathrm{Pu}-241$ & $2.0 \mathrm{E}-02$ & $<0.05$ & $5.1 \mathrm{E}-04$ & $1.2 \mathrm{E}-01$ \\
\hline
\end{tabular}


Table 3-24a. (continued).

\begin{tabular}{|c|c|c|c|c|}
\hline Radionuclide & $\begin{array}{c}\text { Best } \\
\text { estimate } \\
\text { (Ci) }\end{array}$ & $\begin{array}{c}\text { Percent } \\
\text { of total } \\
(\%)\end{array}$ & $\begin{array}{l}\text { Lower } \\
\text { bound }\end{array}$ & $\begin{array}{l}\text { Upper } \\
\text { bound }\end{array}$ \\
\hline C-14 & $1.3 \mathrm{E}-02$ & $<0.05$ & $5.3 \mathrm{E}-04$ & $7.2 \mathrm{E}-02$ \\
\hline $\mathrm{Na}-22$ & $5.0 \mathrm{E}-03$ & $<0.05$ & $1.1 \mathrm{E}-04$ & 3.1E-02 \\
\hline $\mathrm{Mn}-54$ & $5.0 \mathrm{E}-03$ & $<0.05$ & 1.1E-04 & 3.1E-02 \\
\hline Total & $3.2 E+03$ & 99.9 & & \\
\hline
\end{tabular}

a. "Other" generators include ALE, ARA, CEG, CFA, D\&D, ERP, PBF, WER, and WMC; however, ERP did not contribute to the activity for 1984-1993. 
Table 3-24b. Inventory of radiological contaminants (listed alphabetically) from other generators for the years 1984-1993 (activity at time of disposal). ${ }^{\mathrm{a}}$

\begin{tabular}{|c|c|c|c|c|}
\hline Radionuclide & $\begin{array}{c}\text { Best } \\
\text { estimate } \\
\text { (Ci) }\end{array}$ & $\begin{array}{l}\text { Percent } \\
\text { of total } \\
(\%)\end{array}$ & $\begin{array}{l}\text { Lower } \\
\text { bound }\end{array}$ & $\begin{array}{l}\text { Upper } \\
\text { bound }\end{array}$ \\
\hline Am-241 & 2.8E-01 & $<0.05$ & $1.6 \mathrm{E}-02$ & $1.4 \mathrm{E}+00$ \\
\hline $\mathrm{Ba}-140$ & 2.5E-01 & $<0.05$ & $1.3 \mathrm{E}-03$ & $1.8 \mathrm{E}+00$ \\
\hline C-14 & $1.3 \mathrm{E}-02$ & $<0.05$ & 5.3E-04 & $7.2 \mathrm{E}-02$ \\
\hline Ce-144 & 2.0E-01 & $<0.05$ & 4.3E-03 & $1.2 E+00$ \\
\hline Co-60 & $1.8 E+01$ & 0.6 & $8.5 E+00$ & $3.6 \mathrm{E}+01$ \\
\hline Cs-134 & $2.5 E+01$ & 0.8 & $1.4 \mathrm{E}-01$ & $1.8 E+02$ \\
\hline Cs-137 & $2.7 \mathrm{E}+02$ & 8.3 & $6.9 E+01$ & $7.4 \mathrm{E}+02$ \\
\hline Eu-152 & $5.0 \mathrm{E}-02$ & $<0.05$ & $1.4 \mathrm{E}-03$ & $3.0 \mathrm{E}-01$ \\
\hline Eu-154 & $1.3 \mathrm{E}-01$ & $<0.05$ & $3.6 \mathrm{E}-03$ & 7.7E-01 \\
\hline $\mathrm{Fe}-59$ & $1.8 \mathrm{E}-01$ & $<0.05$ & $5.5 E-03$ & $1.1 \mathrm{E}+00$ \\
\hline $\mathrm{H}-3$ & $2.8 E+03$ & 88.3 & $2.1 E+03$ & $3.7 \mathrm{E}+03$ \\
\hline La-140 & $2.5 \mathrm{E}-01$ & $<0.05$ & $1.3 \mathrm{E}-03$ & $1.8 \mathrm{E}+00$ \\
\hline $\mathrm{Mn}-54$ & $5.0 \mathrm{E}-03$ & $<0.05$ & 1.1E-04 & $3.1 \mathrm{E}-02$ \\
\hline $\mathrm{Na}-22$ & $5.0 \mathrm{E}-03$ & $<0.05$ & $1.1 E-04$ & 3.1E-02 \\
\hline $\mathrm{Nb}-95$ & 2.7E-01 & $<0.05$ & $6.0 \mathrm{E}-03$ & $1.7 \mathrm{E}+00$ \\
\hline $\mathrm{Pu}-238$ & $2.0 \mathrm{E}-01$ & $<0.05$ & 5.1E-03 & $1.2 \mathrm{E}+00$ \\
\hline Pu-239 & 6.7E-01 & $<0.05$ & 3.7E-02 & $3.4 \mathrm{E}+00$ \\
\hline $\mathrm{Pu}-240$ & $4.0 \mathrm{E}-02$ & $<0.05$ & $1.8 \mathrm{E}-03$ & 2.1E-01 \\
\hline $\mathrm{Pu}-241$ & $2.0 \mathrm{E}-02$ & $<0.05$ & 5.1E-04 & $1.2 \mathrm{E}-01$ \\
\hline $\mathrm{Ra}-226$ & $1.1 E+00$ & $<0.05$ & 8.7E-01 & $1.4 E+00$ \\
\hline Sr-90 & $4.9 E+01$ & 1.5 & 3.3E-01 & $3.5 E+02$ \\
\hline Th-228 & $1.0 \mathrm{E}+01$ & 0.3 & $8.4 \mathrm{E}+00$ & $1.2 \mathrm{E}+01$ \\
\hline U-232 & $2.2 \mathrm{E}+00$ & 0.1 & $1.8 \mathrm{E}+00$ & 2.7E+00 \\
\hline U-234 & 7.1E-01 & $<0.05$ & $5.6 \mathrm{E}-01$ & 8.8E-01 \\
\hline $\mathrm{U}-235$ & $3.0 \mathrm{E}-02$ & $<0.05$ & $2.4 \mathrm{E}-02$ & 3.7E-02 \\
\hline
\end{tabular}


Table 3-24b. (continued).

\begin{tabular}{|c|c|c|c|c|}
\hline Radionuclide & $\begin{array}{c}\text { Best } \\
\text { estimate } \\
\text { (Ci) }\end{array}$ & $\begin{array}{l}\text { Percent } \\
\text { of total } \\
(\%)\end{array}$ & $\begin{array}{l}\text { Lower } \\
\text { bound }\end{array}$ & $\begin{array}{l}\text { Upper } \\
\text { bound }\end{array}$ \\
\hline U-238 & $1.1 \mathrm{E}-01$ & $<0.05$ & 9.4E-02 & $1.3 \mathrm{E}-01$ \\
\hline V-48 & $2.0 \mathrm{E}-01$ & $<0.05$ & 4.4E-03 & $1.2 \mathrm{E}+00$ \\
\hline Zr-95 & $1.4 \mathrm{E}-01$ & $<0.05$ & $3.1 \mathrm{E}-03$ & $8.7 \mathrm{E}-01$ \\
\hline Total & $3.2 E+03$ & 99.9 & & \\
\hline
\end{tabular}

a. "Other" generators include ALE, ARA, CEG, CFA, D\&D, ERP, PBF, WER, and WMC; however, ERP did not contribute to the activity for 1984-1993. 
Table 3-25a. Inventory of radiological contaminants (listed by quantity) from other generators for the years 1994-2003 (activity at time of disposal). ${ }^{a}$

\begin{tabular}{|c|c|c|c|c|}
\hline Radionuclide & $\begin{array}{l}\text { Best } \\
\text { estimate } \\
\text { (Ci) }\end{array}$ & $\begin{array}{c}\text { Percent } \\
\text { of total } \\
(\%)\end{array}$ & $\begin{array}{l}\text { Lower } \\
\text { bound }\end{array}$ & $\begin{array}{l}\text { Upper } \\
\text { bound }\end{array}$ \\
\hline Co- 60 & $1.9 E+02$ & 37.6 & $8.3 E+01$ & $3.8 \mathrm{E}+02$ \\
\hline $\mathrm{Ni}-63$ & $1.3 \mathrm{E}+02$ & 26.2 & $5.5 \mathrm{E}+01$ & $2.8 \mathrm{E}+02$ \\
\hline Cs-137 & $8.8 \mathrm{E}+01$ & 17.3 & $4.5 \mathrm{E}+01$ & $1.6 \mathrm{E}+02$ \\
\hline $\mathrm{H}-3$ & $2.3 \mathrm{E}+01$ & 4.6 & $1.8 \mathrm{E}+00$ & $1.1 E+02$ \\
\hline $\mathrm{Ce}-144$ & $2.1 E+01$ & 4.2 & $1.6 \mathrm{E}+00$ & $9.9 \mathrm{E}+01$ \\
\hline Sr-90 & $1.6 \mathrm{E}+01$ & 3.2 & $2.5 \mathrm{E}+00$ & $5.8 \mathrm{E}+01$ \\
\hline$Y-90$ & $1.1 \mathrm{E}+01$ & 2.2 & $1.5 \mathrm{E}+00$ & $4.3 E+01$ \\
\hline $\mathrm{Pu}-241$ & $3.9 E+00$ & 0.8 & 2.7E-01 & $1.8 \mathrm{E}+01$ \\
\hline C-14 & $3.9 \mathrm{E}+00$ & 0.8 & $2.7 \mathrm{E}-01$ & $1.8 \mathrm{E}+01$ \\
\hline Sb-125 & $3.6 \mathrm{E}+00$ & 0.7 & $2.7 \mathrm{E}-01$ & $1.7 \mathrm{E}+01$ \\
\hline Eu-155 & $3.2 E+00$ & 0.6 & $2.5 \mathrm{E}-01$ & $1.5 \mathrm{E}+01$ \\
\hline Cs-134 & $1.9 \mathrm{E}+00$ & 0.4 & $2.1 \mathrm{E}-01$ & $7.5 \mathrm{E}+00$ \\
\hline Fe-55 & $1.6 \mathrm{E}+00$ & 0.3 & $7.3 \mathrm{E}-01$ & $3.0 \mathrm{E}+00$ \\
\hline Ir-192 & $1.4 \mathrm{E}+00$ & 0.3 & $1.4 \mathrm{E}-01$ & $5.7 \mathrm{E}+00$ \\
\hline $\mathrm{Ba}-137 \mathrm{~m}$ & $1.1 E+00$ & 0.2 & $5.4 \mathrm{E}-03$ & $7.7 \mathrm{E}+00$ \\
\hline Eu-154 & $8.5 \mathrm{E}-01$ & 0.2 & $5.1 \mathrm{E}-02$ & $4.2 \mathrm{E}+00$ \\
\hline Co-58 & 7.1E-01 & 0.1 & 4.2E-02 & $3.5 \mathrm{E}+00$ \\
\hline $\mathrm{Eu}-152$ & $6.9 \mathrm{E}-01$ & 0.1 & $3.8 \mathrm{E}-02$ & $3.5 \mathrm{E}+00$ \\
\hline Pr-144 & $5.0 \mathrm{E}-01$ & 0.1 & $6.7 \mathrm{E}-02$ & $1.9 \mathrm{E}+00$ \\
\hline $\mathrm{Mn}-54$ & $4.5 \mathrm{E}-01$ & 0.1 & $2.8 \mathrm{E}-02$ & $2.2 \mathrm{E}+00$ \\
\hline Ag-108 & $1.6 \mathrm{E}-01$ & $<0.05$ & $5.2 \mathrm{E}-03$ & $9.4 \mathrm{E}-01$ \\
\hline $\mathrm{Ni}-59$ & $1.5 \mathrm{E}-01$ & $<0.05$ & $1.1 \mathrm{E}-02$ & 7.1E-01 \\
\hline Tc-99 & $8.3 \mathrm{E}-02$ & $<0.05$ & $5.9 \mathrm{E}-03$ & $3.9 \mathrm{E}-01$ \\
\hline Ru-106 & $7.6 \mathrm{E}-02$ & $<0.05$ & $1.1 \mathrm{E}-02$ & $2.8 \mathrm{E}-01$ \\
\hline Rh-106 & $7.6 \mathrm{E}-02$ & $<0.05$ & $1.1 \mathrm{E}-02$ & $2.8 \mathrm{E}-01$ \\
\hline $\mathrm{I}-129$ & $3.9 \mathrm{E}-02$ & $<0.05$ & $3.2 \mathrm{E}-03$ & $1.7 \mathrm{E}-01$ \\
\hline $\mathrm{Cm}-242$ & $2.8 \mathrm{E}-02$ & $<0.05$ & $2.0 \mathrm{E}-03$ & $1.3 \mathrm{E}-01$ \\
\hline
\end{tabular}


Table 3-25a. (continued).

\begin{tabular}{lcccc}
\hline Radionuclide & $\begin{array}{c}\text { Best } \\
\text { estimate } \\
(\mathrm{Ci})\end{array}$ & $\begin{array}{c}\text { Percent } \\
\text { of total } \\
(\%)\end{array}$ & $\begin{array}{c}\text { Lower } \\
\text { bound }\end{array}$ & $\begin{array}{c}\text { Upper } \\
\text { bound }\end{array}$ \\
\hline Pu-239 & $2.6 \mathrm{E}-02$ & $<0.05$ & $1.9 \mathrm{E}-03$ & $1.2 \mathrm{E}-01$ \\
Pu-238 & $2.5 \mathrm{E}-02$ & $<0.05$ & $1.8 \mathrm{E}-03$ & $1.2 \mathrm{E}-01$ \\
$\mathrm{U}-234$ & $2.1 \mathrm{E}-02$ & $<0.05$ & $8.1 \mathrm{E}-03$ & $4.4 \mathrm{E}-02$ \\
$\mathrm{U}-238$ & $1.7 \mathrm{E}-02$ & $<0.05$ & $8.1 \mathrm{E}-03$ & $3.2 \mathrm{E}-02$ \\
Am-241 & $1.4 \mathrm{E}-02$ & $<0.05$ & $1.1 \mathrm{E}-03$ & $6.2 \mathrm{E}-02$ \\
Cm-244 & $1.2 \mathrm{E}-02$ & $<0.05$ & $8.8 \mathrm{E}-04$ & $5.9 \mathrm{E}-02$ \\
Cr-51 & $6.2 \mathrm{E}-03$ & $<0.05$ & $3.4 \mathrm{E}-04$ & $3.2 \mathrm{E}-02$ \\
Pu-240 & $4.4 \mathrm{E}-03$ & $<0.05$ & $3.2 \mathrm{E}-04$ & $2.1 \mathrm{E}-02$ \\
Nb-94 & $5.5 \mathrm{E}-04$ & $<0.05$ & $3.9 \mathrm{E}-05$ & $2.6 \mathrm{E}-03$ \\
Np-237 & $4.0 \mathrm{E}-04$ & $<0.05$ & $2.8 \mathrm{E}-05$ & $1.9 \mathrm{E}-03$ \\
$\mathrm{U}-236$ & $2.6 \mathrm{E}-04$ & $<0.05$ & $1.3 \mathrm{E}-04$ & $4.6 \mathrm{E}-04$ \\
$\mathrm{U}-235$ & $1.4 \mathrm{E}-05$ & $<0.05$ & $7.4 \mathrm{E}-06$ & $2.6 \mathrm{E}-05$ \\
Total & $5.1 \mathrm{E}+02$ & 100.0 & &
\end{tabular}

a. "Other" generators include ALE, ARA, CEG, CFA, D\&D, ERP, PBF, WER, and WMC; however, ALE and CEG are not expected to contribute to the activity for 1994-2003 and PBF's waste is projected to contain miniscule amounts of radioactivity. 
Table 3-25b. Inventory of radiological contaminants (listed alphabetically) from other generators for the years 1994-2003 (activity at time of disposal). ${ }^{a}$

\begin{tabular}{|c|c|c|c|c|}
\hline Radionuclide & $\begin{array}{c}\text { Best } \\
\text { estimate } \\
\text { (Ci) }\end{array}$ & $\begin{array}{c}\text { Percent } \\
\text { of total } \\
(\%)\end{array}$ & $\begin{array}{l}\text { Lower } \\
\text { bound }\end{array}$ & $\begin{array}{l}\text { Upper } \\
\text { bound }\end{array}$ \\
\hline Ag-108 & $1.6 \mathrm{E}-01$ & $<0.05$ & $5.2 \mathrm{E}-03$ & $9.4 \mathrm{E}-01$ \\
\hline Am-241 & $1.4 \mathrm{E}-02$ & $<0.05$ & $1.1 \mathrm{E}-03$ & $6.2 \mathrm{E}-02$ \\
\hline $\mathrm{Ba}-137 \mathrm{~m}$ & $1.1 E+00$ & 0.2 & $5.4 \mathrm{E}-03$ & $7.7 \mathrm{E}+00$ \\
\hline C-14 & $3.9 E+00$ & 0.8 & 2.7E-01 & $1.8 \mathrm{E}+01$ \\
\hline Ce-144 & $2.1 \mathrm{E}+01$ & 4.2 & $1.6 \mathrm{E}+00$ & $9.9 \mathrm{E}+01$ \\
\hline $\mathrm{Cm}-242$ & $2.8 \mathrm{E}-02$ & $<0.05$ & $2.0 \mathrm{E}-03$ & $1.3 \mathrm{E}-01$ \\
\hline $\mathrm{Cm}-244$ & $1.2 \mathrm{E}-02$ & $<0.05$ & 8.8E-04 & $5.9 \mathrm{E}-02$ \\
\hline Co-58 & 7.1E-01 & 0.1 & 4.2E-02 & $3.5 \mathrm{E}+00$ \\
\hline Co- 60 & $1.9 E+02$ & 37.6 & $8.3 E+01$ & $3.8 E+02$ \\
\hline $\mathrm{Cr}-51$ & $6.2 \mathrm{E}-03$ & $<0.05$ & $3.4 \mathrm{E}-04$ & 3.2E-02 \\
\hline Cs-134 & $1.9 E+00$ & 0.4 & 2.1E-01 & $7.5 \mathrm{E}+00$ \\
\hline Cs-137 & $8.8 \mathrm{E}+01$ & 17.3 & $4.5 \mathrm{E}+01$ & $1.6 E+02$ \\
\hline Eu-152 & $6.9 \mathrm{E}-01$ & 0.1 & $3.8 \mathrm{E}-02$ & $3.5 E+00$ \\
\hline Eu-154 & $8.5 \mathrm{E}-01$ & 0.2 & $5.1 E-02$ & $4.2 E+00$ \\
\hline Eu-155 & $3.2 \mathrm{E}+00$ & 0.6 & $2.5 \mathrm{E}-01$ & $1.5 E+01$ \\
\hline $\mathrm{Fe}-55$ & $1.6 \mathrm{E}+00$ & 0.3 & $7.3 \mathrm{E}-01$ & $3.0 \mathrm{E}+00$ \\
\hline $\mathrm{H}-3$ & $2.3 E+01$ & 4.6 & $1.8 \mathrm{E}+00$ & $1.1 \mathrm{E}+02$ \\
\hline $\mathrm{I}-129$ & $3.9 \mathrm{E}-02$ & $<0.05$ & $3.2 \mathrm{E}-03$ & 1.7E-01 \\
\hline Ir -192 & $1.4 \mathrm{E}+00$ & 0.3 & $1.4 \mathrm{E}-01$ & $5.7 E+00$ \\
\hline $\mathrm{Mn}-54$ & 4.5E-01 & 0.1 & $2.8 \mathrm{E}-02$ & $2.2 \mathrm{E}+00$ \\
\hline $\mathrm{Nb}-94$ & $5.5 \mathrm{E}-04$ & $<0.05$ & $3.9 \mathrm{E}-05$ & $2.6 \mathrm{E}-03$ \\
\hline $\mathrm{Ni}-59$ & $1.5 \mathrm{E}-01$ & $<0.05$ & 1.1E-02 & 7.1E-01 \\
\hline $\mathrm{Ni}-63$ & $1.3 \mathrm{E}+02$ & 26.2 & $5.5 \mathrm{E}+01$ & $2.8 E+02$ \\
\hline $\mathrm{Np}-237$ & $4.0 \mathrm{E}-04$ & $<0.05$ & 2.8E-05 & $1.9 E-03$ \\
\hline $\operatorname{Pr}-144$ & 5.0E-01 & 0.1 & 6.7E-02 & $1.9 \mathrm{E}+00$ \\
\hline Pu-238 & $2.5 \mathrm{E}-02$ & $<0.05$ & $1.8 E-03$ & 1.2E-01 \\
\hline $\mathrm{Pu}-239$ & $2.6 \mathrm{E}-02$ & $<0.05$ & $1.9 \mathrm{E}-03$ & $1.2 \mathrm{E}-01$ \\
\hline
\end{tabular}


Table 3-25b. (continued).

\begin{tabular}{lcccc}
\hline Radionuclide & $\begin{array}{c}\text { Best } \\
\text { estimate } \\
(\mathrm{Ci})\end{array}$ & $\begin{array}{c}\text { Percent } \\
\text { of total } \\
(\%)\end{array}$ & $\begin{array}{c}\text { Lower } \\
\text { bound }\end{array}$ & $\begin{array}{c}\text { Upper } \\
\text { bound }\end{array}$ \\
\hline Pu-240 & $\begin{array}{l}\text { 4.4E-03 } \\
\text { Pu-241 }\end{array}$ & $<0.05$ & $3.2 \mathrm{E}-04$ & $2.1 \mathrm{E}-02$ \\
Rh-106 & $3.9 \mathrm{E}+00$ & 0.8 & $2.7 \mathrm{E}-01$ & $1.8 \mathrm{E}+01$ \\
Ru-106 & $7.6 \mathrm{E}-02$ & $<0.05$ & $1.1 \mathrm{E}-02$ & $2.8 \mathrm{E}-01$ \\
Sb-125 & $7.6 \mathrm{E}-02$ & $<0.05$ & $1.1 \mathrm{E}-02$ & $2.8 \mathrm{E}-01$ \\
Sr-90 & $3.6 \mathrm{E}+00$ & 0.7 & $2.7 \mathrm{E}-01$ & $1.7 \mathrm{E}+01$ \\
Tc-99 & $1.6 \mathrm{E}+01$ & 3.2 & $2.5 \mathrm{E}+00$ & $5.8 \mathrm{E}+01$ \\
$\mathrm{U}-234$ & $8.3 \mathrm{E}-02$ & $<0.05$ & $5.9 \mathrm{E}-03$ & $3.9 \mathrm{E}-01$ \\
$\mathrm{U}-235$ & $2.1 \mathrm{E}-02$ & $<0.05$ & $8.1 \mathrm{E}-03$ & $4.4 \mathrm{E}-02$ \\
$\mathrm{U}-236$ & $1.4 \mathrm{E}-05$ & $<0.05$ & $7.4 \mathrm{E}-06$ & $2.6 \mathrm{E}-05$ \\
$\mathrm{U}-238$ & $2.6 \mathrm{E}-04$ & $<0.05$ & $1.3 \mathrm{E}-04$ & $4.6 \mathrm{E}-04$ \\
Y-90 & $1.7 \mathrm{E}-02$ & $<0.05$ & $8.1 \mathrm{E}-03$ & $3.2 \mathrm{E}-02$ \\
\hline Total & $1.1 \mathrm{E}+01$ & 2.2 & $1.5 \mathrm{E}+00$ & $4.3 \mathrm{E}+01$ \\
& $5.1 \mathrm{E}+02$ & 100.0 & &
\end{tabular}

a. "Other" generators include ALE, ARA, CEG, CFA, D\&D, ERP, PBF, WER, and WMC; however, ALE and CEG are not expected to contribute to the activity for 1994-2003 and PBF's waste is projected to contain miniscule amounts of radioactivity. 


\section{References for Section 3}

Bartolomucci, J. A., 1989, letter to J. N. Davis, "Curie Content Estimates for ECF Scrap Casks," NRFE-E-1448, Naval Reactors Facility, February 27, 1989.

Charter, J. L., 1993, "Radioactive Waste Forecasts-Naval Reactors Facility," letter NRFRC-RCE-2247, November 15, 1993.

Clements, T. L., Jr., 1980, Buried Waste Characterization: Nonradiological Hazards Study-Offsite Waste Generators, PR-W-80-027, EG\&G Idaho, Inc., October 1980.

EG\&G Idaho, 1985, Solid Waste Management Information System (SWMIS) SWMIS Users Manual, EG\&G Idaho, Inc., April 1985.

EG\&G Idaho, 1986, Installation Assessment Report for EG\&G Idaho, Inc. Operations at the Idaho National Engineering Laboratory, EGG-WM-6875, EG\&G Idaho, Inc., January 1986.

EG\&G Idaho, 1994, A Comprehensive Inventory of Radiological and Nonradiological Contaminants in Waste Buried in the Subsurface Disposal Area of the INEL RWMC During the Years 1952-1983, EGG-WM-10903, June 1994.

Harker, Y. D., 1995a, Scaling Factors for Waste Activities Measured by G-M Method, EDF-ER-WAG7-57, engineering design file, Lockheed Idaho Technologies Company, February 1995.

Harker, Y. D., 1995b, letter to T. H. Smith, "I-129 Act. in TRA Sections of HDT and RPDT Reports," YDH-2T-95, Lockheed Idaho Technologies Company, April 1995.

Nieslanik, R. W., 1994, "Evaluation of NRF Radiological Waste Streams for Waste Sent to RWMC from NRF (1984-1993)," NRFEM-ER-1223, Naval Reactors Facility, July 11, 1994.

Rich, B. L., S. L. Hinnefeld, C. R. Lagerquist, W. G. Mansfield, L. H. Munson, and E. R. Wagner, 1988, Health Physics Manual of Good Practices for Uranium Facilities, EGG-2530, EG\&G Idaho, Inc., June 1988.

Rodgers, A. D., 1986, letter to distribution, "Elimination of Lead from Low Level Waste," ADR-8-86, EG\&G Idaho, Inc., June 24, 1986.

Rodgers, A. D., 1987, letter to distribution, "Use of Lead in Low-Level Waste Packages Schedule Exception," ADR-46-88, EG\&G Idaho, Inc., December 16, 1987. 


\section{EVALUATION OF INVENTORY ENTRIES FOR CONTAMINANTS WITH "UNKNOWN" QUANTITIES}

For the time period 1984-2003, no contaminant entries were identified for which estimates of the quantities were not possible. This section was retained, however, for two reasons. First, it maintains symmetry between the HDT report (EG\&G Idaho 1994) and this report. Second, this section is reserved for future discussion of unknown quantities, should they be identified at a later date and this report be revised. 


\section{References for Section 4}

EG\&G Idaho, 1994, A Comprehensive Inventory of Radiological and Nonradiological Contaminants in Waste Buried in the Subsurface Disposal Area of the INEL RWMC During the Years 1952-1983, EGG-WM-10903, EG\&G Idaho, Inc., June 1994. 


\section{DATA UNCERTAINTY: SOURCES AND METHODS FOR ESTIMATING}

\subsection{Purpose}

Two primary objectives of this task were to (a) estimate the total quantity of each contaminant disposed of in the SDA during the years 1984-1993 and project the total quantity of each contaminant that will be disposed of in the SDA during the years 1994-2003, and (b) attach uncertainty bounds to these total quantity estimates. The results are reported in Section 3.

This section explains the approach to and results of the uncertainty-estimation process that led to the upper and lower bounds on the contaminant quantities. Data uncertainties that led to corrections in best estimates, due to biases, are also discussed.

Section 5.2 provides a brief, nontechnical summary of the approach. Section 5.3 addresses the applicable requirements. Section 5.4 discusses uncertainties and biases for the recent waste (1984-1993) and how they were addressed. Section 5.5 covers the same for the projected waste (1994-2003).

\subsection{Summary}

Section 5 presents the statistical methods for obtaining best estimates of the contaminant quantities in recent and projected waste and the uncertainties in the best estimates. The equations that are developed allow the construction of upper and lower bounds on the activity of a contaminant in recent waste (1984-1993) and in projected waste (1994-2003).

The analysis of historical documents and data uncovered two significant upwards biases that can occur in the estimation of radioactivities in waste. They are (a) a bias in the G-M counter survey method used to assay much of the waste (recent and projected) and (b) a bias in the forecasting process used by the generators of the waste (projected only). The values of the upward biases are factors of 2 and 4, respectively. Therefore, where appropriate, the best estimates were corrected for these biases. These corrections are presented in the following sections.

In addition to the biases, there are several sources of uncertainty in the best estimate that also must be estimated in order to construct upper and lower bounds on the actual quantity. The major sources identified and estimated include error in the G-M method bias correction, error in the G-M method, error in the generator forecasting bias correction, error in the generator forecasting process for projected waste, error due to the use of scaling factors when estimating radionuclide distributions, and random error. Depending on the situation, only a subset of these uncertainties is applicable.

Section 5.5 presents the four potential cases for projected waste that are combinations of the presence or absence of the two biases. By the use of standard error propagation techniques (NCRPM 1985), the applicable uncertainties are combined to produce an overall uncertainty in the best estimate, thus allowing for construction of upper and lower bounds on the actual activity. 
These two biases do not apply to estimates of the quantities of nonradiological contaminants in recent or projected waste. Bounds on these quantities were established by more straightforward methods, as described later in this section.

\subsection{Requirements Concerning Uncertainty Estimates}

According to the EPA's Supplemental Guidance to RAGS: Calculating the Concentration Term (EPA 1992), one of the most important inputs for a risk assessment is the concentrations of the contaminants. EPA (1992) recommends that an average concentration be used. It also states that, because of the uncertainty associated with estimating the true average concentration at a site, the $95 \%$ upper confidence limit (UCL) of the arithmetic mean should be used. In the absence of data necessary for estimating UCLs, a value other than the 95\% UCL can be used, provided the risk assessor can document that high coverage of the true population mean occurs i.e., the value equals or exceeds the true population mean with high probability. While the guidance deals with contaminant concentrations, it can be applied equally well to contaminant quantities, which is the product of the present task.

Many sources of uncertainty are inherent in the quantification of the contaminant inventory of a waste site as complex as the SDA; some of them are quite large. It is not realistic to think that the total amount of each contaminant can be estimated statistically, especially in the absence of sampling, and that rigorous $95 \%$ confidence limits can be constructed. Therefore, the approach must be based on the second recommendation of EPA (1992). That is, a value other than the $95 \%$ UCL, but analogous to it, will be provided, with reasonable justification that it provides coverage of the true total amount with high probability.

\subsection{How Uncertainties and Biases Were Addressed for the Recent Waste}

\subsubsection{Background}

The waste buried at the SDA during the years 1984-1993 originated from several generators over various time periods and consisted of many different types. The general process from waste generation to disposal is depicted in Figure 5-1. The three boxes within the dashed oval represent the steps in the process that contribute to the uncertainty in the reported contaminant quantities in a shipment.

The step represented by the first box within the oval is the measurement of radioactive waste volumes and radionuclide activities in the shipment. The uncertainty in the estimate is due to many sources of error in this measurement process. The measurement process depends on the type of waste being shipped and the waste generator.

The second box in the uncertainty oval (Figure 5-1) pertains to the nonradioactive contaminants in the waste. Nonradiological contaminants were, at best, identified on shipping records simply as being part of a shipment to the SDA. A formal process for measuring and 


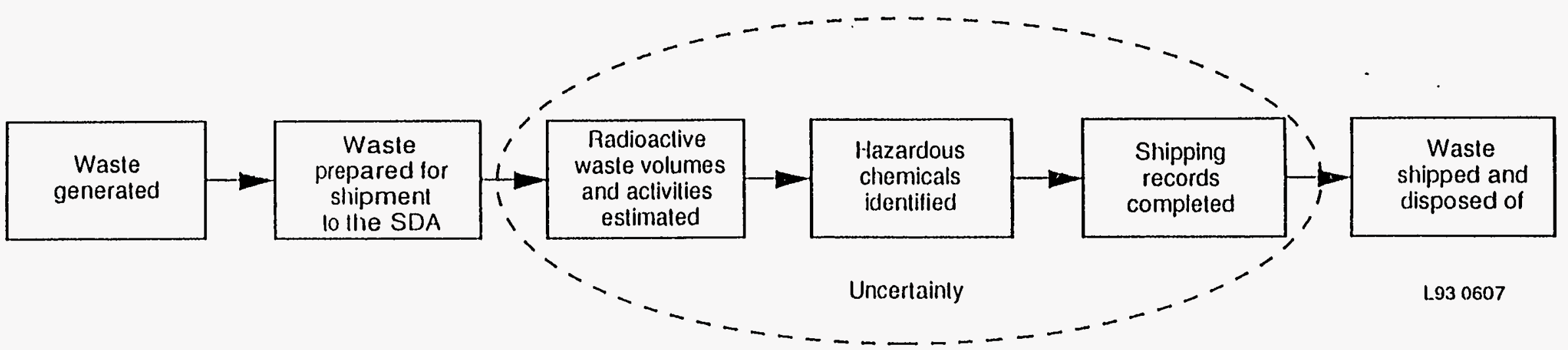

Figure 5-1. The process from waste generation to disposal. 
reporting nonradiological contaminants did not exist at that time, and quantities were generally not reported on shipping records. Therefore, estimation of total quantities and uncertainties for the present task was often based on sources other than the shipping records, e.g., process knowledge and interviews with personnel acquainted with the processes that produced specific waste streams. A major source of uncertainty is the incompleteness of the available information, which tends to cause an underestimation of the total quantities.

The third box of Figure 5-1 addresses the process of recording the measurements on shipping records and transferring that information to the RWMIS database. Errors associated with transcription, summarization, interpretation, radionuclide distributions, and upper-limit reporting result in additional uncertainty in the reported total quantities of contaminants.

As discussed in Section 2, in the present task, a data form was filled out for each waste stream to record the knowledge gained in the information search. An important part of this process was the identification of major sources of uncertainty. As mentioned above, the contaminant-measurement process is dependent on the general type of waste. Furthermore, differences in the process, as well as in the magnitude of uncertainty due to each step in the process, exist among the generators. The following subsections discuss the various uncertainties.

\subsubsection{Biases and Corrections for Radiological Data Originally Obtained by the G-M Counter Survey Method}

For some waste streams or waste shipments, the estimate of radioactivity made at the time of shipment was based on sampling or other methods that are relatively direct in approach, or on nuclear physics calculations. However, for the majority of shipments during this period, an indirect method was used at the time of shipment to estimate the radioactivity in a container of waste. The indirect method is a major source of uncertainty in estimates of radionuclide quantities for these generators. The specific method used since the $1950 \mathrm{~s}$ is referred to here as the G-M counter survey method or, simply, the G-M method. An additional but related source of uncertainty is the lack of specific radionuclide identification in individual waste containers. These two sources of uncertainty are discussed in this section and in Section 5.4.3 in considerable detail because of the large potential effect on the estimated radionuclide inventory.

The G-M method consists of taking radiation readings on each of the five exposed sides of a waste container using a calibrated G-M survey meter, averaging the readings, and multiplying by a constant number to convert the average radiation reading to the estimated radioactivity in curies. Several sources of uncertainty are inherent in this process. These include (a) the geometric position of the radiation source in the container, (b) the type of radiation from the particular radionuclides present in the container, (c) the density of the materials within the container (termed the "fill matrix"), and (d) the error in the survey meter itself.

Three documented studies (Simpson et al. 1982; Hartwell et al. 1987; and Hartwell and Thompson 1988) have explored the adequacy of the G-M method as applied to INEL waste containers. Although the studies involved only low-radiation-level containers, the results are believed to be generally accurate for higher-radiation-level containers, also. 
The position of the source in the container appears to be a particularly large contributor to the uncertainty. According to Simpson et al. (1982), an upward bias of at least 50\% (compared with more rigorous methods, such as gamma-ray spectrometry) was measured when a known MFP test source was located at the center of a mock-up waste box. (The G-M method was derived originally from theoretical considerations for steel waste dumpsters, but was applied to many kinds of waste boxes.) When the source was located away from the center of the box, biases as large as $8,500 \%$ were measured for unusual situations. The conclusion of Simpson et al. (1982) was that the G-M method is highly susceptible to overestimation of the actual curie content because of "hot spots" located near a container side and small detector-to-source distance.

Simpson et al. (1982) also noted that results using the G-M method depended on the radionuclides present in the container, compared with the radionuclides used in developing and calibrating the method. For example, if the radionuclide in the container were Co-60 and if $0.7-\mathrm{MeV}$ gammas had been assigned for conversion of the radiation readings to the estimated radioactivity, the effect could be overestimation by a factor of 2 (USHEW 1970).

Another significant contributor to the uncertainty is the density of the waste container fill matrix. This contributor includes both self-shielding within the source and shielding because of other materials within the container. Hartwell et al. (1987) investigated this effect and concluded that underestimation of the actual curie content occurs even at very slight attenuation. As the fill matrix density increases, the attenuation increases, and the underestimation becomes more severe. The conversion calculation from radiation reading to curies assumes that the container offers very slight attenuation. Thus, this problem is not accounted for in the conversion. Tests conducted on various densities of fill matrix (Hartwell et al. 1987) indicated underestimation by the G-M method ranging from approximately $-90 \%$ to $-50 \%$ (i.e., factors of one-tenth to one-half) of the known actual value. Since the main objective was the safety of the people handling the waste, it is reasonable to assume that the fill matrix density was purposely increased when necessary to provide additional protection. Interviews have confirmed this assumption, which results in further inflation of an already significant negative bias.

Interviews with health physics personnel indicated that, during the early years, the random error in the survey meter itself was $\pm 20 \%$. After approximately 1976 , improvements in the calibration of the meters reduced this error to $\pm 10 \%$.

Because of the highly variable (shipment-dependent) nature of the sources of the above uncertainty estimates, a statistically rigorous propagation to an overall uncertainty was not feasible. However, by combining professional judgment, reasonable assumptions, and standard statistical techniques, defendáble bounds on actual quantities could be determined. These bounds are analogous to $95 \%$ confidence limits and represent "reasonable certainty" that they contain the true value. The following paragraphs describe the rationale used in arriving at estimates of the bias and the random error in the G-M method.

Uncertainty in the G-M method because of source position is a positive bias ranging from $50 \%$ to $8,500 \%$, depending on the position of the source. The closer the source is to a face of the container, the more severe the bias. Typically, the contamination is not concentrated in a small volume of the container, but rather distributed throughout. A reasonable assumption is uniform distribution throughout the container. If we also assume that the bias increases 
(according to the inverse of the source-to-detector distance squared) from $50 \%$ to $8,500 \%$ as the source is moved from the center of the container to a face, the resulting average bias due to source position for a uniformly distributed source is approximately $1,050 \%$, or 11.5 times the true value.

As stated previously, the bias due to density of the fill matrix ranges from $-50 \%$ to $-90 \%$, depending on the density, based on measurements of mock-up containers with known sources and fill materials ranging from air to stacked paper (specific gravity approximately 0.8) (see Hartwell et al. 1987). The majority of the actual waste containers of the time period of interest would be expected to have effective fill densities no more than that of stacked paper. (This observation is based on a review of data for waste generated more recently, and the fact that container packing density has tended to increase over the years.)

The combined bias due to source position and fill density was evaluated as follows. Based on the data described above, the largest value that could be used for the combined bias is $8,500 \%$ (a factor of 86 ) for source location and $-50 \%$ (a factor of 0.5 ) for fill density, yielding a product of $4,200 \%$ (a factor of 43 ). The smallest value that could be used for the combined bias is $50 \%$ (a factor of 1.5 ) for source location and $-90 \%$ (a factor of 0.1 ) for fill density, yielding a product of $-85 \%$ (a factor of 0.15 ). However, these extreme values reflect highly unusual situations, such as a waste container in which a point source of radiation rests against one inner face of the container and nothing else except air is inside the container.

A more realistic set of limits on the bias was developed by assuming a uniformly distributed radiation source within the waste container. As stated above, the average bias due to source position in this case is $1,050 \%$ (a factor of 11.5 ). The same range of fill densities as above was retained. Thus, the largest realistic value that could be used for the combined bias is $1,050 \%$ (a factor of 11.5 ) for source location and $-50 \%$ (a factor of 0.5 ) for fill density, yielding a product of $475 \%$ (a factor of 5.75). The smallest realistic value that could be used for the combined bias is $1,050 \%$ (a factor of 11.5 ) for source location and $-90 \%$ (a factor of 0.1 ) for fill density, yielding a product of $15 \%$ (a factor of 1.15). A midpoint value for the combined bias is $1,050 \%$ (a factor of 11.5 ) for the source location and $-70 \%$ (a factor of 0.3 ) for fill density, yielding a product of $245 \%$ (a factor of 3.45). This is the best estimate for the value of the bias. To be somewhat conservative, however, a combined bias of $100 \%$ (a factor of 2) was used for these two factors. In other words, ignoring variability because of error in the survey meter, the actual radioactivities are expected to be approximately half the value of the reported measurements using this method.

The studies by Hartwell and Thompson (1988) and Simpson et al. (1982) include the measurement of numerous actual waste containers using the more accurate gamma-ray spectrometry method and the G-M method. In all cases, the G-M method resulted in measurements exceeding those of the gamma-ray spectrometry method by percentages ranging from $10 \%$ to $3,500 \%$. This lends some confirmation to the conservative estimate of the positive bias of a factor of 2 and to the range of realistic combined biases derived above.

While the actual energy of the radiation from the radionuclides in a waste container is definitely a contributor to error in the reported activities, it was not included here in the bias correction. This is because a large portion of the inventory is near the assumed energy level of $0.7 \mathrm{MeV}$. Radionuclides of higher energy exist in substantial quantities as well, but their effect on 
the bias is to further overestimate the total quantities. To be conservative, this effect was ignored.

Thus, if the indications are that the radioactivity in a waste stream was originally estimated using the G-M method, the reported estimates of total radionuclide quantities for specitic years were adjusted by dividing by two to correct for these biases and to arrive at a best estimate. This correction is an approximation because of the large numbers and varieties of waste streams and radionuclides involved. However, use of the correction is believed to result in a more accurate inventory than use of the uncorrected G-M counter readings.

The random error due to the G-M survey meter was conservatively taken to be $\pm 10 \%$ for all radioactivity estimates believed to have been developed using the G-M method during the recent time period. The total random error, including the uncertainty in the bias correction itself, is developed in Section 5.4.5.

As stated previously, for certain waste streams, the data gatherers used records of direct measurements, personal knowledge, interviews, and nuclear physics calculations to arrive at a sound judgment on the uncertainty in their reported total quantities. In these cases, the data gatherers' uncertainty estimates were used to determine upper and lower bounds on the total quantities.

There are some exceptions to the approaches described above. These occurred when (a) the data gatherer lacked sufficient information to provide uncertainty estimates in the reported total quantities, and (b) the bias correction for the G-M method was not applicable. The bias correction is not applicable for radionuclides emitting weak gamma rays or no gamma rays.

CIDRA has been programmed such that, if uncertainty information does not exist in the appropriate data fields for the bounds on radionuclide quantities, it automatically calculates upper and lower bounds (see Section 5.4.5) after correcting for the G-M method bias by dividing the reported estimate by two. To ensure that these automatic calculations are not performed erroneously for radionuclides that emit very little or no gamma radiation, each waste stream was checked manually for potential occurrences of this type. Where there was any indication that the G-M method was not used for the radionuclides in question, estimates for the upper and lower bounds were provided to ensure that the G-M method correction was not applied.

Some additional considerations apply in developing the uncertainties for waste from NRF and ANL-W. These considerations are discussed in the following paragraphs.

Because high-energy-emitting Co-60 was the principal radionuclide of interest at NRF, the survey meters were typically calibrated using high-energy radiation. This adds some uncertainty in the measurement when the container holds large quantities of radionuclides emitting low-energy radiation (e.g., Fe-55 and Ni-63). These uncertainties, however, are not considered to be any more significant than other assay uncertainties. Therefore, the bias and uncertainty estimates described in this section were also applied to most of the waste from NRF. The exception was the scrap core structural material shipped from ECF in scrap casks. 
In a letter dated February 27, 1989 (Bartolomucci 1989), the manager of ECF Engineering at NRF informed EG\&G Idaho that ECF's past method for estimating radioactivity, or curie content, for scrap casks was in error. The letter provided revised curie content estimates, and these revised estimates were subsequently incorporated into the RWMIS database. Bartolomucci (1989) did not, however, assign uncertainty limits to the estimates.

Another letter issued by NRF (Nieslanik 1994) applied an accuracy of $+10 \%$ and $-30 \%$ to scrap cask activity calculations, taking into consideration incomplete content data on some cores when received, approximations that deleted radionuclides contributing less than $1 \%$ to the total activity, and assumptions that had to be made regarding radioactive flux and core life.

The method used by NRF to arrive at radioactivity estimates for the scrap cask shipments was based on knowledge of the metal alloys in the reactor core structural materials and of the reactor core radiation history. This information allowed NRF to calculate the extent of expected neutron activation of the core structural material. This activity was then decayed for the length of time from the end of reactor operation until the scrap was shipped from ECF to the SDA.

In summary, NRF's uncertainty estimate of $+10 \%$ and $-30 \%$ for the scrap cask estimates was used in this report, whereas the bias and uncertainty estimates in this section related to the G-M method were applied to all the other waste from NRF.

Radioactivity estimates of ANL-W waste generated after 1970 were made at the time of shipment using a refined G-M counter method. The method factored in the type of waste container and other information. This method is considered more reliable than the typical G-M counter method, which was used by all generators listed previously. Therefore, upon the advice of ANL-W technical personnel, no bias correction was applied to ANL-W waste activity measurements made beginning in 1971. The random error was specified by ANL-W personnel to be $\pm 25 \%$ for such measurements.

For all generators, in the CIDRA database, the radionuclide quantities (including the effects of the G-M correction, if any) are listed as the "best estimates." The uncorrected quantities are also available from CIDRA and are called the "reported estimates."

\subsubsection{Scaling Factor Uncertainties for Radiological Data}

Another significant source of uncertainty is that due to the use of scaling factors for estimating radionuclide distributions. In fact, based on the following analysis, it appears to be the dominant source of uncertainty in estimates of the total activity of a specific radionuclide.

A scaling factor is a fraction or percentage of the activity of another radionuclide or of the total activity of a group of radionuclides. Scaling factors were used to estimate the activities of several difficult-to-measure radionuclides in waste shipments to the SDA. For example, suppose the total activity in a waste shipment is $100 \mathrm{Ci}$ and the scaling factor for Sr-90 (whose activity is difficult to measure outside a laboratory) is $0.15(15 \%)$. Then the estimated activity of Sr-90 in the shipment is $15 \mathrm{Ci}$. 
Development of scaling factors was performed by evaluating the data from analytical laboratories possessing the capabilities to analyze the activities of these difficult-to-measure radionuclides and relate the activities to those of easily analyzed radionuclides or total sample activities.

The uncertainty in the scaling factor must be estimated and incorporated into the overall uncertainty in the radionuclide activity. The following paragraphs provide an overview of the development of the uncertainty estimates for the scaling factors. Einerson and Smith (1995) provides the details. Section 5.4.5 incorporates the scaling factor uncertainty into the overall uncertainty.

Limited INEL data exist on scaling factors for the waste disposed of in the SDA. The most comprehensive data available elsewhere exist in a report prepared for EPRI (EPRI 1987). That report provides the results of an extensive data collection and analysis effort, including activities of several radionuclides from various waste types and reactor types. The data most closely resembling SDA waste came from samples originating in waste from pressurized water reactors of commercial nuclear utilities.

Two basic approaches are possible for estimating the uncertainty due to the use of scaling factors. The first is to identify all of the sources of uncertainty inherent in the process of developing and using scaling factors (e.g. analytical error, error due to the G-M survey method). These uncertainties would then be propagated to obtain an overall uncertainty estimate due to the use of scaling factors. The second method is strictly empirical. This approach would involve the use of a large data set (such as that found in the EPRI report) containing the activities of several radionuclides for several waste streams. Then, by constructing scaling factors and estimating the distributional properties, the uncertainty is empirically developed.

Since a large data set that is somewhat representative of the SDA waste streams exists in the EPRI (1987) report, the empirical approach was used here. The three basic steps were to (a) choose subsets of the EPRI radionuclides thought to best represent the radionuclides present in the SDA waste, (b) estimate the scaling factor mean, standard deviation, and relative standard deviation (RSD, the uncertainty) for each radionuclide in this subset, and (c) apply these uncertainty estimates to appropriate subsets of the radionuclides and waste streams for the SDA waste. A subset of radionuclides from the EPRI data was selected because the analysis of every radionuclide would have added only minimal information.

The subset of radionuclides analyzed from the EPRI data included C-14, Fe-55, Ni-63, Sr-90, Tc-99, I-129, Co-60, and Cs-137. These radionuclides were selected because they are representative of the difficult-to-measure radionuclides present in the SDA waste and the radionuclides to which their activities are compared. Therefore, they should demonstrate the range of scaling factor uncertainties inherent in the radionuclides present in the SDA.

The scaling factor for a radionuclide is the ratio of the activity for the radionuclide to the total activity in the waste. The total activity in a sample is defined here to be the sum of the eight radionuclides given above and is shown in equation (5-1). It is recognized that, in actuality, several more radionuclides may constitute the total set. However, it seems reasonable to assume that the estimate of scaling factor uncertainty will not depend on the number of radionuclides 
used when calculating a "total" activity, as long as the set of radionuclides used is representative and fairly comprehensive.

The total activity in a sample is defined here to be the sum of the eight radionuclides indicated and is shown in equation (5-1):

$\mathrm{t}_{\mathrm{j}}=\Sigma_{\mathrm{i}} \mathrm{a}_{\mathrm{ij}}$

where

$\mathrm{t}_{\mathrm{j}}=$ total activity for sample $\mathrm{j}$, and

$a_{i j}=$ activity of radionuclide $\mathrm{i}$ for sample $\mathrm{j}$.

Then for each sample and each radionuclide used in this analysis, a scaling factor can be written as

$\mathrm{w}_{\mathrm{ij}}=\mathrm{a}_{\mathrm{ij}} / \mathrm{t}_{\mathrm{j}}$

where

$\mathrm{w}_{\mathrm{ij}}=$ scaling factor for radionuclide $\mathrm{i}$ and sample $\mathrm{j}$.

The uncertainty referred to above is in terms of the RSD, which is defined as the standard deviation divided by the mean. Therefore, the next step in the analysis was to estimate the mean, standard deviation, and RSD of the scaling factors for each radionuclide across all samples for waste from pressurized water reactors in EPRI (1987). The results are presented in Table 5-1, along with the number of samples comprising the estimates.

Table 5-1. Scaling factor relative standard deviations for EPRI (1987) data.

\begin{tabular}{ccc}
\hline Ratio & $\begin{array}{c}\text { Number of } \\
\text { samples }\end{array}$ & RSD \\
\hline C-14/total & 273 & 3.4 \\
Fe-55/total & 268 & 0.9 \\
Ni-63/total & 280 & 1.0 \\
Sr-90/total & 234 & 4.8 \\
Tc-99/total & 30 & 4.4 \\
I-129/total & 20 & 3.7 \\
Co-60/total & 333 & 0.7 \\
Cs-137/total & 241 & 1.1 \\
\hline
\end{tabular}


Logical groupings of RSD values are apparent from the results in Table 5-1. The scaling factor RSDs for Fe-55, Ni-63, Co-60, and Cs-137 are 0.9, 1.0, 0.7, and 1.1, respectively. The scaling factor RSDs for C-14, Sr-90, and Tc-99 were 3.4, 4.8, and 4.4, respectively. Based on these results, two scaling factor RSDs, 1 and 5, were chosen for application to the uncertainty estimation for the radionuclides in the SDA waste that involved the use of scaling factors. These values of 1 and 5 were chosen based on simplicity and conservatism. While it would have been possible in theory to estimate a separate RSD for each radionuclide, the effort was not warranted considering the limited additional accuracy obtainable and the limited data available.

As described in Einerson and Smith (1995), the uncertainty in the scaling factors also depends on the particular stream in which the radionuclide exists because the method of estimating the activity of a given radionuclide sometimes varied from stream to stream. Thus, the radionuclides in the SDA waste can be placed into three groups corresponding to the three possibilities of scaling factor uncertainty: RSDs of 0,1 , and 5. An RSD of zero occurs for those radionuclides for which scaling factors were not used in determining their activity.

Table 5-2 presents the scaling factor uncertainty used for each of the radionuclides when incorporating this uncertainty into the overall uncertainty of the total activities. Details of the rules for applying scaling factor uncertainties, as well as some exceptions to Table 5-2 based on the method by which the distribution was estimated for each waste stream, are presented in Einerson and Smith (1995).

Unless excluded by either or both considerations related to an RSD of 0 or an excluded waste stream, the scaling factor uncertainty was added to the other identified uncertainties, whether or not the data gatherer had listed upper and lower bounds for the radioactivity entry on the datasheets.

\subsubsection{Uncertainties for Nonradiological Contaminants}

For nonradiological contaminants, the main source of uncertainty is the lack of information. For some waste streams, the data gatherers obtained good estimates, with associated uncertainties, of the total quantities of particular contaminants. In these instances, the data gatherers' estimates

Table 5-2. Scaling factor relative standard deviations for use in the Recent and Projected Data Task uncertainty estimation. 
were used. These estimates are for a variety of contaminants from several waste streams and can be considered a representative subset of all the nonradiological contaminants identified. In the HDT report, the upper bounds estimated by the data gatherers ranged from 1 to 3.6 times the estimated amount, with the majority being less than a factor of 2 . When lacking uncertainty information, a factor of 2 , based on the data gatherer's professional judgment, was conservatively used to construct an upper bound on the total quantities disposed of. The same assumption was used for the reporting period 1984-1993.

\subsubsection{Best Estimates and Bounds for the Recent Waste}

Each waste stream from each waste generator was identified, and annual quantities of radiological and nonradiological contaminants in the streams were estimated. In addition to these estimates of annual quantities disposed of, bounds on these estimates were calculated. While it was not possible to calculate $95 \%$ confidence limits in the standard way because of the lack of sampling and appropriate data, it was possible to arrive at reasonable and defensible bounds based on the historical information acquired and on knowledge of the sources of uncertainty described in the preceding sections.

When possible, the bounds provided represent the data gatherers' indication that, with reasonable certainty, the true annual quantities buried are contained within them. In some cases, the data gatherers' indications are based on the particular waste stream and the measurement methods used at the time. In other cases, heavier reliance was placed on professional judgment. When professional judgment could not be made, generic error bounds were constructed by propagation of known biases and uncertainties. "Reasonable certainty" can be considered analogous to $95 \%$ confidence; while not statistically rigorous, it represents a legitimate attempt at quantifying a very difficult parameter.

With the assumption that the bounds estimated by the data gatherers (or through propagation) represent $95 \%$ confidence limits, the following discussion presents the method used to propagate the uncertainties so that uncertainty bounds could be constructed on the total amount of a contaminant disposed of at the SDA in all waste streams.

An individual contaminant may occur in a variety of forms and in a variety of waste streams. Therefore, it may or may not be useful to group all occurrences together when estimating contaminant quantities for use in a risk assessment. Groupings of contaminant occurrences will have to be performed based on the particular objectives of the data used in the risk assessment.

Once a risk assessor determines a desired grouping, all occurrences in CIDRA for which the contaminant meets the grouping specification (e.g., a particular physical form of the contaminant) are flagged. An occurrence is a single row of Part C or Part D of the data form (see Appendix A). Each row corresponds to information for one contaminant from a single waste stream for a single year (or a range of years during which the generation rate was assumed constant). A single data form is restricted to describing only a single waste stream.

After the contaminants of interest have been selected, grouped, and flagged in the database, the next step is to estimate the quantities needed by the risk assessor. These include the best 
estimate of the total amount disposed of and its upper bound (analogous to a 95\% UCL) for each uniquely flagged contaminant grouping.

The best estimate for the total amount of a contaminant grouping is simply the sum over all waste streams and all years for that contaminant grouping, as expressed by the following equation:

$T=\Sigma_{\mathrm{i}} \Sigma_{\mathrm{j}} \mathrm{T}_{\mathrm{ij}}$

where

$\mathrm{T}=$ best estimate of the total quantity of a particular contaminant grouping disposed of

$\mathrm{T}_{\mathrm{ij}}=$ best estimate of the quantity of the particular contaminant grouping disposed of from waste stream $\mathrm{i}$ in year $\mathrm{j}$.

To construct an upper bound on $T$ requires $s_{i j}$, the standard deviations of $T_{i j}$. In cases where analysis data or professional judgment have been used to estimate $U_{\mathrm{ij}}$, the upper bound on $T_{i j}$, the standard deviation of $T_{i j}$ can be estimated as given in Equation (5-4).

$s_{i j}=\left(U_{i j}-T_{i j}\right) / 2$, when based on analysis data or professional judgment.

When such information is not available, $s_{\mathrm{ij}}$ is estimated based on the biases and random error involved. For radiological contaminants, the bias was shown earlier to range from a factor of 1.15 to a factor of 5.75 . Thus, a bias correction (division by the bias) would range from 0.87 to 0.17 with a midpoint of 0.5 , which is the correction factor used. It is assumed that this range is an approximate $95 \%$ confidence interval on the true bias. Given this assumption, an estimate of the uncertainty $s_{k}$ (one standard deviation) in the bias correction is shown in Equation (5-5).

$s_{\mathrm{k}}=\frac{\text { range of } 95 \% \text { confidence interval }}{4}=\frac{0.87-0.17}{4}=0.17$

The estimate of the uncertainty $s_{X}$ due to random error in the G-M survey meter is $10 \%$ of the reported quantity, as given in Equation (5-6).

${ }^{\mathrm{s}} \mathrm{X}_{\mathrm{ij}}=0.1 \mathrm{X}_{\mathrm{ij}}$, where $\mathrm{X}_{\mathrm{ij}}$ is the reported quantity of a particular contaminant grouping disposed of from waste stream $i$ in year $j$.

The estimate of the uncertainty due to the scaling factor, in terms of the RSD $s_{w} / w$, depends on the specific radionuclide and waste stream, as mentioned in Section 5.4 .3 and discussed in detail in Einerson and Smith (1995). The three distinct cases are RSDs of 0, 1, and 5.

Combining these uncertainties, using the method of statistical differentials (Kotz and Johnson 1988), leads to a formula for estimating the standard deviation of $T_{\mathrm{ij}}$, as shown in Equations (5-7) and (5-8). 
$\mathrm{T}_{\mathrm{ij}}=\mathrm{kX}_{\mathrm{ij}}$, where $\mathrm{k}$ is the bias correction, whose value is 0.5 .

$$
\begin{aligned}
s_{i j} & =\sqrt{\left(k X_{i j}\right)^{2}\left[\left(\frac{s_{k}}{k}\right)^{2}+\left(\frac{s_{X_{i j}}}{X_{i j}}\right)^{2}+\left(\frac{s_{w}}{w}\right)^{2}\right]} \\
& =T_{i j} \sqrt{0.12+\left(\frac{s_{w}}{w}\right)^{2}} \text {, when analysis data or professional judgement are not available. }
\end{aligned}
$$

For nonradiological contaminants, a conservative estimate of half the reported quantity, based on the discussion in Section 5.4.4, is used for $\mathrm{s}_{\mathrm{ij}}$ when professional judgement cannot be made.

$\mathrm{s}_{\mathrm{ij}}=0.5 \mathrm{~T}_{\mathrm{ij}}$, for nonradiological contaminants when professional judgement cannot be made.

The standard deviation $\mathrm{s}$ of $\mathrm{T}$ can then be calculated as

$s=\left(\Sigma_{\mathrm{i}} \Sigma_{\mathrm{j}} \mathrm{s}_{\mathrm{ij}}^{2}\right)^{1 / 2}$

Data of this type typically follow a lognormal distribution (Gilbert 1987). Therefore, it is reasonable to assume that the total activity $\mathrm{T}$ of a radionuclide (or total quantity of a nonradiological contaminant) is lognormally distributed with mean $\alpha$ and standard deviation $\beta$, where $\alpha$ and $\beta$ are estimated by T and s. Due to the relationship between the normal and lognormal distributions (Blackwood 1992), it follows that the natural logarithm of $\mathrm{T}$ is normally distributed with mean $\mu$ and standard deviation $\sigma$ with

$\alpha=\mathrm{e}^{\mu+\frac{1}{2} \sigma^{2}}$

$$
\beta^{2}=e^{2 \mu+\sigma^{2}}\left(e^{\sigma^{2}}-1\right)
$$

Solving for $\mu$ and $\sigma$ and using $T$ and $s$ as estimates of $\alpha$ and $\beta$ gives:

$$
\begin{aligned}
& \mu=\ln (T)-\frac{1}{2} s^{2} \\
& \sigma^{2}=\ln \left(\frac{T^{2}+s^{2}}{T^{2}}\right) .
\end{aligned}
$$


An upper bound on the total quantity for a particular contaminant grouping $U$ can now be calculated as shown in Equation (5-15).

$U=e^{(\mu+2 \sigma)}$

The construction of a lower bound $L$ on $T$ is analogous to the upper bound and is given in Equation (5-16).

$L=e^{(\mu-2 \sigma)}$.

The above approach cannot be considered statistically rigorous. However, with the combination of professional judgment, reasonable assumptions, and conservative approximations, there is reasonable certainty (i.e., 95\% confidence) that the upper bounds derived with this approach are not exceeded.

\subsection{How Uncertainties and Biases Were Addressed for the Projected Waste}

Except for one factor, the uncertainties and biases for the projected waste were addressed by the same method as for the recent waste discussed in Section 5.4. That factor relates to the uncertainties and biases of the process by which the quantities of contaminants in future waste were estimated. The method for addressing this factor is discussed later in this section.

\subsubsection{Background}

The quantities of radiological contaminants in the projected waste (1994-2003) were estimated based largely on the forecasts of waste generators. (See Section 2.4 for a discussion of the method used to project contaminants in future waste.) The generator forecasts contain biases and uncertainties. To obtain best estimates of any future waste activities that were projected using the generator forecasts, the forecasts must be corrected for the biases. To obtain uncertainties in the best estimates, uncertainties in the bias corrections must be estimated and combined with other sources of error. This section provides the methods and formulae for estimating the biases and uncertainties. Additional details on the error propagation techniques used here can be found in $A$ Handbook of Radioactivity Measurements Procedures

(NCRPM 1985).

As discussed in Section 5.4, it was estimated that there also existed a G-M survey method bias of $100 \%$ (factor of 2 upward) requiring correction by multiplying the reported value by 0.5 . It was also estimated that this bias correction has an uncertainty of 0.17 (one standard deviation). These conclusions are summarized in equations (5-17) and (5-18).

$\mathrm{k}=0.5=\mathrm{G}-\mathrm{M}$ survey method bias correction 
$s_{k}=0.17=$ the standard deviation of the bias correction for the G-M survey method.

The G-M survey method will continue to be used by waste generators for assaying some of the projected waste. Therefore, the same bias correction and uncertainty due to the G-M survey method will be applied where appropriate.

Uncertainty due to the use of scaling factors was also discussed in Section 5.4 and applies to the projected waste as well. The estimated uncertainty due to scaling factors, expressed as RSDs, is 0,1 , or 5 , depending on the radionuclide and how its activity was estimated in a given stream.

\subsubsection{Bias and Uncertainty of Waste Generator Forecasts}

The bias and uncertainty of the generator forecasts were estimated by comparing past forecasted radioactivity against the "actual"a disposed radioactivity reported later in RWMIS. The accuracy of the forecasts has improved slightly from their initial use in 1977 for waste to be generated in 1978. Therefore, only data from the most recent 4 years were used.

Table 5-3 summarizes data comparisons for forecasts made during 1989 for the years 1990 through 1993 (Welch 1990), during 1990 for the years 1991 through 1993 (Welch 1991), during 1991 for the years 1992 and 1993 (Welch 1992), and during 1992 for 1993 (Hutchison 1993).

The data are not $100 \%$ complete. For NRF, only generator forecasts made in 1990 and 1991 are available. For TRA, the disposed value in 1993 is due almost totally to the unanticipated disposal of beryllium reflector blocks containing 293,000 Ci. Since this particular disposal was not part of the forecast (except for the forecast made in 1992), the activity was subtracted from the reported amount before the comparisons were made (except for the reported amount corresponding to the forecast made in 1992).

For each year, the forecasted amounts and actual amounts were summed across facilities. The last three columns of Table 5-3 present these totals, along with the ratio of the forecasted total to the actual total. In every case, this ratio is greater than 1 . This result indicates that a positive bias exists in the forecasting process, i.e., the generator forecasts are higher than the actual amount. Furthermore, the ratios range from 2.27 to 5.80 with a mean of 4.0 and a standard deviation of 1.11. This result indicates an average forecast bias of $300 \%$ (a factor of 4 upward). Therefore, multiplication by 0.25 is required to correct the best estimates of radioactivity in projected waste for this bias in the waste generator forecasts.

In addition to the generator forecasting bias as a source of error, there exists variability in the bias itself, as apparent from the range of ratios, and random error in the forecasting process. These two sources of variability cannot be separately estimated because there are not multiple

a. In the current discussion, the term "actual" disposed radioactivity means the radioactivity reported after the future years have come to pass and the waste has actually been generated and disposed of. The term is not intended to mean that the reported radioactivity is an errorless measurement of the radioactivity disposed of. 
Table 5-3. Comparisons of forecasted and reported actual radioactivity (Ci) in waste disposed of in the Subsurface Disposal Area, for recent years and facilities where data were available. ${ }^{a}$

\begin{tabular}{|c|c|c|c|c|c|c|c|c|c|c|c|c|c|c|c|c|c|c|}
\hline \multirow{2}{*}{$\begin{array}{l}\text { Year } \\
\text { forecast } \\
\text { made }\end{array}$} & \multirow{2}{*}{$\begin{array}{l}\text { Year } \\
\text { forecast } \\
\text { for }\end{array}$} & \multicolumn{2}{|c|}{ ANL } & \multicolumn{2}{|c|}{ ICPP } & \multicolumn{2}{|c|}{$D \& D$} & \multicolumn{2}{|c|}{ TAN } & \multicolumn{2}{|c|}{ TRA } & \multicolumn{2}{|c|}{ WERF } & \multicolumn{2}{|c|}{ NRF } & \multicolumn{3}{|c|}{ Total } \\
\hline & & Forecast & Actual & Forecas & Actual & Forecast & Actual & Forecas & Actual & Forecast & Actual & Forecast & Actual & Forecast & Actual & Forecast & Actual & Ratio \\
\hline 1989 & 1990 & 276,000 & 130,511 & 360 & 211 & 1.05 & $<1$ & 6,630 & 2,658 & 19,926 & 68 & $<1^{b}$ & 6 & $\mathrm{NA}^{c}$ & 74,087 & 302,918 & $133,455^{d}$ & 2.27 \\
\hline 1989 & 1991 & 280,000 & 82,261 & 360 & 24 & $<1$ & $<1$ & $<1$ & $<1$ & 3,766 & 2,430 & $<1$ & 3 & $\mathrm{NA}$ & 102,849 & 284,129 & $84,720^{d}$ & 3.35 \\
\hline 1989 & 1992 & 310,000 & 92,896 & 360 & 2 & $<1$ & $<1$ & $<1$ & 347 & 3,766 & 909 & $<1$ & $\mathrm{NA}^{c}$ & $\mathrm{NA}$ & 49,795 & 314,129 & $94,155^{d}$ & 3.34 \\
\hline 1989 & 1993 & 330,000 & 87,058 & 320 & $<1$ & $<1$ & 2 & $<1$ & 216 & 9,166 & $5,152^{e}$ & $<1$ & $<1$ & NA & 42,259 & 339,489 & $92,430^{d}$ & 3.67 \\
\hline 1990 & 1991 & 360,000 & 82,261 & 360 & 24 & 0 & $<1$ & $<1$ & $<1$ & 23,500 & 2,430 & 1.32 & 3 & 136,000 & 102,849 & 519,862 & 187,569 & 2.77 \\
\hline 1990 & 1992 & 450,000 & 92,896 & 360 & 2 & 0 & $<1$ & $<1$ & 347 & 3,710 & 909 & 1.43 & NA & 153,000 & 49,795 & 607,072 & 143,950 & 4.22 \\
\hline 1990 & 1993 & 520,000 & 87,058 & 320 & $<1$ & 0 & 2 & $<1$ & 216 & 9,100 & $5,152^{e}$ & 1.43 & $<1$ & 161,000 & 42,259 & 690,422 & 134,689 & 5.13 \\
\hline 1991 & 1992 & 560,000 & 92,896 & 360 & 2. & 110 & $<1$ & $<1$ & 347 & 30,700 & 909 & 0 & NA & 123,000 & 49,795 & 714,171 & 143,950 & 4.96 \\
\hline 1991 & 1993 & 448,000 & 87,058 & 320 & $<1$ & 120 & 2 & $<1$ & 216 & 4,620 & $5,152^{e}$ & $<1$ & $<1$ & 144,000 & 42,259 & 597,062 & 134,689 & 4.43 \\
\hline 1992 & 1993 & 767,000 & 87,058 & 160 & $<1$ & 3.76 & 2 & $<1$ & 216 & $1,470,000$ & $298,152 f$ & 20 & $<1$ & $\mathrm{NA}$ & 42,259 & $2,237,184$ & $385,430^{d}$ & 5.80 \\
\hline
\end{tabular}

a. If both forecasted and actual data for at least 1 year at a facility are not available, the facility is not presented here. Also, if all data for a facility are less than 1 curie, the facility is not presented here.

b. The value of 1 was used for " $<1$ " entries when summing for totals.

c. Data were not available.

d. These totals do not include NRF actuals since NRF forecasts were not available.

e. The reported actual had 293,000 curies removed since it was due to the unanticipated disposal of beryllium reflector blocks and therefore not part of the forecast.

f. It was assumed that the beryllium reflector blocks were accounted for in the 1992 forecasting of the 1993 amount and therefore the 293,000 curies were included in the actual. 
forecasts in single years. However, the standard deviation of the ratios of 1.11 given above contains both the bias variability and random error in the forecasting process.

An estimate of the uncertainty in the generator forecast bias correction is derived as follows:

$\overline{\mathrm{r}}=4.0=$ mean of the forecast-to-actual ratios

$\mathrm{a}=\frac{1}{\overline{\mathrm{r}}}=0.25=$ forecast bias correction

$\mathrm{s}_{\mathrm{r}}=1.11=$ the standard deviation of the forecast-to-actual ratios

$s_{\bar{r}}=\left[\frac{s_{r}^{2}}{10}\right]^{\frac{1}{2}}=\left[\frac{(1.11)^{2}}{10}\right]^{\frac{1}{2}}=0.35=$ the standard error of the mean ratio,

where 10 is the number of ratios used to estimate $s_{r}$.

$\left.\mathrm{s}_{\mathrm{a}}=\left[\frac{\mathrm{s}_{\overrightarrow{\mathrm{r}}}}{\mathrm{s}^{4}}\right]^{1}\right]^{\frac{1}{2}}=\left[\frac{(0.35)^{2}}{256}\right]^{\frac{1}{2}}=0.022=$ the standard deviation of the forecast bias correction.

In some cases, the data gatherers did not use the generator forecasts. Some other source of information was used in projecting the activity in future waste. There may be some bias in projections of this type that were made by the data gatherers. However, no projected-versus-actual data are available for this situation. Therefore, no bias was ascribed to such forecasts and no bias correction was applied. This approach is probably conservative due to historic overestimation of curies by generator forecasters.

\subsubsection{Best Estimates and Bounds for the Projected Waste-General}

In an analogous expression to Equation (5-3) for the recent waste, the best estimate for the total activity of a radionuclide in the projected waste is the sum of the best estimates over all waste streams and all years for that radionuclide, as expressed by the following equation:

$\mathrm{T}=\Sigma_{\mathrm{i}} \Sigma_{\mathrm{j}} \mathrm{T}_{\mathrm{ij}}$

where

$\mathrm{T}=$ best estimate of the total activity of a radionuclide

$\mathrm{T}_{\mathrm{ij}}=$ best estimate of the activity of the radionuclide from waste stream $\mathrm{i}$ in year $\mathrm{j}$. 
Upper and lower bounds, analogous to $95 \%$ confidence bounds, for the best estimate were discussed in Section 5.4.5 [Equations (5-11) through (5-16)] and are summarized in the following equations:

$$
\begin{aligned}
& U=e^{(\mu+2 \sigma)} \\
& L=e^{(\mu-2 \sigma)}
\end{aligned}
$$

where

$$
\begin{aligned}
& \mu=\ln (T)-\frac{1}{2} s^{2} \\
& \sigma^{2}=\ln \left(\frac{T^{2}+s^{2}}{T^{2}}\right) .
\end{aligned}
$$

As shown in the above equations, the bounds on $T$ require $s_{\mathrm{ij}}$, an estimate of the standard deviation of $\mathrm{T}_{\mathrm{ij} \text {. }}$ The construction of the best estimates and bounds depends on the sources of uncertainty involved. Four cases need to be considered for the projected waste. The first is the case in which neither the G-M method bias correction nor the generator forecasting bias correction is applicable. The second is when only the G-M method bias correction is applicable. The third is when only the generator forecast bias correction is applicable, and the fourth is when both bias corrections are necessary. The following sections provide the details for obtaining best estimates and associated uncertainties for each of these four cases.

It may not be readily apparent how projections of the radioactivity in future waste can be affected by G-M counter measurements, which can be made only on waste that exists. The reason for the interaction is that many generator forecasts of activity are made by some method of extrapolating past data, with or without adjustments to reflect changes in planned operations. If the past data were obtained using the G-M method and, therefore, are biased, then the extrapolated data for future waste are similarly biased. This bias needs to be corrected to use the forecasts in the current study.

\subsubsection{Best Estimates and Uncertainty for Projected Waste when Bias Corrections are Not Applicable}

In the first case, the estimates of radioactivity in projected waste are based on information about recent waste for which the G-M survey method was not used. For example, laboratory results for the radioactivity in recent waste may have been extrapolated to project the radioactivity in future waste. In such cases, the G-M correction is not applicable. 
Additionally, in this case, the projections are based on information obtained by the data gatherer and not on the generator forecasts. Therefore, it is assumed that the systematic over-estimation in generator forecasts, described in Section 5.5.2, does not apply.

Three sources of uncertainty still exist, however. The first is random error in the measurement method used, $\mathrm{s}_{\mathrm{X}}$. This uncertainty is assumed to be the same as that estimated for the G-M method (i.e. 10\% of the measured value). The second is uncertainty due to the use of scaling factors, expressed as relative standard deviation $\mathrm{s}_{\mathrm{w}} / \mathrm{w}$. This uncertainty is assumed to be the same as the $s_{\mathrm{w}} / \mathrm{w}$ estimated for the recent waste. The third uncertainty is random error in the projections made by the data gatherers. Due to the lack of any data to estimate this error, the standard deviation of the forecast-to-actual ratios, $s_{r}$, will be used. As stated in the preceding section, $\mathrm{s}_{\mathrm{r}}$ contains both variability in the forecast bias and random error in the forecasting process. Thus, it should be somewhat conservative as an estimate of the random error in the data gatherers' predictions. The following equations were used for this first case involving projected waste.

The best estimate of the activity of a radionuclide is given by

$$
T_{i j}=X_{i j}
$$

where

$\mathrm{X}_{\mathrm{ij}}=$ projected activity of a radionuclide for waste stream $\mathrm{i}$ and year $\mathrm{j}$.

The standard deviation of the best estimate is given by

$$
\begin{aligned}
s_{i j} & =\sqrt{T_{i j}^{2}\left[\left(\frac{s_{X_{i j}}}{X_{i j}}\right)^{2}+\left(\frac{s_{w}}{w}\right)^{2}\right]+s_{r}^{2}} \\
& =\sqrt{T_{i j}^{2}\left[0.01+\left(\frac{s_{w}}{w}\right)^{2}\right]+1.23}
\end{aligned}
$$

where

$$
\begin{aligned}
s_{\mathrm{X}_{\mathrm{ij}}}= & 0.10 \mathrm{X}_{\mathrm{ij}}=\text { standard deviation due to random error in the measurement method } \\
& \text { (assumed to equal that for the G-M method) } \\
\mathrm{s}_{\mathrm{r}}= & 1.11=\text { the standard deviation of the forecast-to-actual ratios }
\end{aligned}
$$


$\frac{s_{w}}{w}=$ scaling factor RSD of 0,1 , or 5, depending on the radionuclide and waste stream.

\subsubsection{Best Estimates and Uncertainty for Projected Waste when G-M Method Bias Correction is Applicable but Generator Forecast Bias Correction is Not}

The second case is when the estimates of radioactivity in projected waste are based on data for recent waste that were obtained using the G-M method. However, in this case, the data gatherer did not base the projection on generator forecasts, but rather on some other source of information. It is assumed that the generator forecasting bias discussed earlier does not apply. Therefore, only the G-M method bias correction is necessary. Uncertainties due to the G-M method bias correction, random error in the G-M measurement method, scaling factor uncertainty, and random error in the data gatherers' projection must be considered in estimating the overall uncertainty. As in the preceding section, the standard deviation of the forecast-to-actual ratios, $s_{r}$, will be used as a conservative estimate of the random error in the data gatherers' projections. The following equations were used for this case involving projected waste.

The best estimate of the activity of a radionuclide is given by

$$
\mathrm{T}_{\mathrm{ij}}=\mathrm{kX}_{\mathrm{ij}}=0.5 \mathrm{X}_{\mathrm{ij}}
$$

where

$$
\begin{aligned}
& \mathrm{X}_{\mathrm{ij}}=\text { projected activity of a radionuclide for waste stream } \mathrm{i} \text { and year } \mathrm{j} \\
& \mathrm{k}=0.5=\mathrm{G}-\mathrm{M} \text { method bias correction. }
\end{aligned}
$$

The standard deviation of the best estimate is given by

$$
\begin{aligned}
& s_{i j}=\sqrt{T_{i j}^{2}\left[\left(\frac{s_{X_{i j}}}{x}\right)^{2}+\left(\frac{s_{w}}{w}\right)^{2}\right]+s_{r}^{2}} \\
& =\sqrt{\mathrm{T}_{\mathrm{ij}}^{2}\left[0.01+\left(\frac{\mathrm{s}_{\mathrm{w}}}{\mathrm{w}}\right)^{2}\right]+1.23}
\end{aligned}
$$

where

$$
\mathrm{s}_{\mathrm{X}_{i j}}=0.10 \mathrm{X}_{\mathrm{ij}}=\text { standard deviation due to random error in the } \mathrm{G}-\mathrm{M} \text { method }
$$




$$
\begin{aligned}
& \frac{s_{w}}{w}=\text { scaling factor RSD of } 0,1 \text {, or } 5 \text { depending on the radionuclide and waste stream } \\
& s_{r}=1.11=\text { the standard deviation of the forecast-to-actual ratios. }
\end{aligned}
$$

\subsubsection{Best Estimates and Uncertainty for Projected Waste when G-M Method Bias Correction is Not Applicable but Generator Forecast Bias Correction is}

In the third case, the estimates of radioactivity in projected waste are based on extrapolations of data for recent waste that were obtained without the G-M survey method. Generator forecasts are the basis for the projections and, therefore, the generator forecast bias correction is applicable. Uncertainties due to the generator forecast bias correction, random error in the measurement method, scaling factor uncertainty, and random error in the generator forecasting process must also be factored into the overall uncertainty. The following equations were used for this case involving projected waste.

From Equation (5-20), the best estimate of the activity of a radionuclide is given by

$$
\mathrm{T}_{\mathrm{ij}}=\mathrm{aX} \mathrm{X}_{\mathrm{ij}}=0.25 \mathrm{X}_{\mathrm{ij}}
$$

where

$$
\begin{aligned}
& X_{i j}=\text { forecasted activity of a radionuclide for waste stream } i \text { and year } j \\
& a=0.25=\text { forecast bias correction. }
\end{aligned}
$$

The standard deviation of the best estimate is given by

$$
\begin{aligned}
s_{i j} & =\sqrt{T_{i j}^{2}\left[\left(\frac{s_{a}}{a}\right)^{2}+\left(\frac{s_{x_{i j}}}{X_{i j}}\right)^{2}+\left(\frac{s_{w}}{w}\right)^{2}\right]+s_{r}^{2}} \\
& =\sqrt{T_{i j}^{2}\left[0.018+\left(\frac{s_{w}}{w}\right)^{2}\right]+1.23}
\end{aligned}
$$

where

$$
\begin{aligned}
& \mathrm{s}_{\mathrm{a}}=0.022=\text { standard deviation of forecast bias correction } \\
& \mathrm{s}_{\mathrm{X}}=0.10 \mathrm{X}_{\mathrm{ij}}=\text { standard deviation due to random error in the G-M method }
\end{aligned}
$$


$\frac{\mathrm{s}_{\mathrm{w}}}{\mathrm{w}}=$ scaling factor $\mathrm{RSD}$ of 0,1 , or 5 , depending on the radionuclide and waste stream

$\mathrm{s}_{\mathrm{r}}=1.11=$ the standard deviation of the forecast-to-actual ratios.

\subsubsection{Best Estimates and Uncertainty for Projected Waste when G-M Method Bias Correction and Generator Forecast Bias Correction are Applicable}

In the final case, the estimates of radioactivity in projected waste are based on generator forecasts that used data on recent waste as the basis for the forecasts. Additionally, the G-M survey method was used in measuring the activity given in that recent waste data. For this case, all sources of error described in the preceding sections are applicable when estimating the overall uncertainty. The following equations were used for this case involving projected waste.

The best estimate of the activity of a radionuclide is given by

$$
\mathrm{T}_{\mathrm{ij}}=\mathrm{akX} \mathrm{X}_{\mathrm{ij}}=0.125 \mathrm{X}_{\mathrm{ij}}
$$

where

$$
\begin{aligned}
& \mathrm{X}_{\mathrm{ij}}=\text { forecasted activity of a radionuclide for waste stream } \mathrm{i} \text { and year } \mathrm{j} \\
& \mathrm{a}=0.25=\text { forecast bias correction } \\
& \mathrm{k}=0.5=\text { G-M method bias correction. }
\end{aligned}
$$

The standard deviation of the best estimate is given by

$$
\begin{aligned}
s_{i j} & =\sqrt{T_{i j}^{2}\left[\left(\frac{s_{a}}{a}\right)^{2}+\left(\frac{s_{k}}{k}\right)^{2}+\left(\frac{s_{X_{i j}}}{X_{i j}}\right)^{2}+\left(\frac{s_{w}}{w}\right)^{2}\right]+s_{r}^{2}} \\
& =\sqrt{T_{i j}^{2}\left[0.133+\left(\frac{s_{w}}{w}\right)^{2}\right]+1.23}
\end{aligned}
$$

where

$$
\begin{aligned}
& \mathrm{s}_{\mathrm{a}}=0.022=\text { standard deviation of forecast bias correction } \\
& \mathrm{s}_{\mathrm{k}}=0.17=\text { standard deviation of G-M method bias correction }
\end{aligned}
$$


$\mathrm{s}_{\mathrm{X}_{i j}}=0.10 \mathrm{X}_{\mathrm{ij}}=$ standard deviation due to random error in the G-M method

$$
\begin{aligned}
& \frac{\mathrm{s}_{\mathrm{w}}}{\mathrm{w}}=\text { scaling factor RSD of } 0,1 \text {, or } 5 \text {, depending on the radionuclide and waste stream } \\
& \mathrm{s}_{\mathrm{r}}=1.11=\text { the standard deviation of the forecast-to-actual ratios. }
\end{aligned}
$$

\subsubsection{Uncertainties for Nonradiological Contaminants}

The approach for addressing uncertainties for nonradiological contaminants in the projected waste was identical to that used in the HDT and for the recent waste. The waste generators forecasts did not address nonradiological contaminants, so the bias correction for such forecasts did not apply.

\subsection{Summary of Equations for Standard Deviations}

For convenience, Table 5-4 summarizes the equations used for calculating $\mathrm{s}_{\mathrm{ij}}$ when laboratory analysis data and informed professional judgement are not available for a particular radionuclide entry on a data sheet. If laboratory data or informed professional judgement is available, data from that source are used, instead, for $\mathrm{s}_{\mathrm{ij}}$. 
Table 5-4. Formulae for calculating standard deviation $\mathrm{s}_{\mathrm{ij}}$ for radiological contaminants when laboratory analysis data and informed professional judgement are not available.

\begin{tabular}{lccc}
\hline \multicolumn{1}{c}{ Time period } & Historical & Recent & Projected \\
\hline $\begin{array}{l}\text { No GM correction } \\
\text { No forecast correction }\end{array}$ & $\mathrm{NA}^{\mathrm{a}}$ & $\mathrm{NA}$ & $\mathrm{s}_{\mathrm{ij}}=\sqrt{\mathrm{X}_{\mathrm{ij}}^{2}\left[0.01+\left(\frac{\mathrm{s}_{\mathrm{w}}}{\mathrm{w}}\right)^{2}\right]+1.23}$
\end{tabular}

GM correction

No forecast correction

$$
\mathrm{s}_{\mathrm{ij}}=0.5 \mathrm{X}_{\mathrm{ij}} \sqrt{0.16+\left(\frac{\mathrm{s}_{\mathrm{w}}}{\mathrm{w}}\right)^{2}}
$$$$
\mathrm{s}_{\mathrm{ij}}=0.5 \mathrm{X}_{\mathrm{ij}} \sqrt{0.12+\left(\frac{\mathrm{s}}{\mathrm{w}}\right)^{2}}
$$

NA

No GM correction

Forecast correction

NA

NA

NA

GM correction

Forecast correction $s_{i j}=\sqrt{\left(0.5 X_{i j}\right)^{2}\left[0.01+\left(\frac{s_{w}}{w}\right)^{2}\right]+1.23}$

$s_{i j}=\sqrt{\left(0.25 X_{i j}\right)^{2}\left[0.018+\left(\frac{s_{w}}{w}\right)^{2}\right]+1.23}$

$s_{\mathrm{ij}}=\sqrt{\left(0.125 \mathrm{X}_{\mathrm{ij}}\right)^{2}\left[0.133+\left(\frac{\mathrm{s}_{\mathrm{w}}}{\mathrm{w}}\right)^{2}\right]+1.23}$

Definition: $\mathrm{X}_{\mathrm{ij}}=$ reported quantity.

a. Not applicable.

b. $\frac{s_{w}}{w}=$ scaling factor $\mathrm{RSD}$ of $0,1,5$, depending on radionuclide and waste stream. 


\section{References for Section 5}

Bartolomucci, J. A., 1989, letter to J. N. Davis, "Curie Content Estimates for ECF Scrap Casks," NRFE-E-1448, Naval Reactors Facility, February 27, 1989.

Blackwood, L. G., 1992, "The Lognormal Distribution, Environmental Data, and Radiological Monitoring," Environmental Monitoring and Assessment, 21: 193-210, 1992.

Einerson, J. J., and T. H. Smith, 1995, Estimation and Application of Scaling Factor Uncertainties for the Historical Data Task and the Recent and Projected Data Task, EDF-ER-WAG7-62, April 1995.

EPA, 1992, Supplemental Guidance to RAGS: Calculating the Concentration Term, EPA Publication 928517-081, U. S. Environmental Protection Agency, May 1992.

EPRI, 1987, Updated Scaling Factors in Low-level Radwaste, EPRI NP-5077, Impell Corporation, March 1987.

Gilbert, R. O., 1987, Statistical Methods for Environmental Pollution Monitoring, Van Nostrand Reinhold, New York, 1987.

Hartwell, J. K, and D. N. Thompson, 1988, Investigation of a Gamma-Ray Spectrometric Low-Level Waste Measurement System: FY 1988 Activities, ST-CS-028-88, September 1988.

Hartwell, J. K, D. N. Thompson, S. W. Duce, and A. L. Freeman, 1987, Investigation of a Gamma Spectrometric Low-Level Waste Measurement System, ST-CS-022-87, September 1987.

Hutchison, D. P., 1993, letter to J. T. Case, "1993 and 10-Year Radioactive Waste Forecasts," EG\&G Idaho, Inc., DPH-03-93, January 15, 1993.

Kotz, S., and N. L. Johnson (eds.), 1988, Encyclopedia of Statistical Sciences, Volume 8, John Wiley and Sons, New York, pages 646-647, 1988.

NCRPM, 1985, A Handbook of Radioactivity Measurements Procedures, National Council on Radiation Protection and Measurements, NCRP Report No. 58, Second Edition, February 1, 1985.

Nieslanik, R. W., 1994, letter to T. H. Smith, "NRF Comments to the Radioactive Waste Management Complex (RWMC) Waste Inventory Report," NRFEM-RR-1122, Naval Reactors Facility, March 29, 1994.

Simpson, O. D., L. D. Koeppen, and E. D. Cadwell, 1982, Solid Waste Characterization Study at TRA, RE-P-82-121, EG\&G Idaho, Inc., December 1982. 
USHEW, 1970, Radiological Health Handbook, revised edition, U.S. Department of Health, Education, and Welfare, January 1970.

Welch, J. M., 1990, letter to W. N. Sato, "1990 and 10-Year Radioactive Waste Forecasts," EG\&G Idaho, Inc., JMW-12-90, February 7, 1990.

Welch, J. M., 1991, letter to J. R. Wade, "Revised 1991 and 10-Year Radioactive Waste Forecasts," EG\&G Idaho, Inc., JMW-43-91, March 7, 1991.

Welch, J. M., 1992, letter to S. T. Hinschberger, "1992 and 10-Year Radioactive Waste Forecasts," EG\&G Idaho, Inc., JMW-07-92, January 15, 1992. 


\section{CONFIRMING THE COMPLETENESS OF THE RESULTS}

This section compares the contaminant inventory against estimates given in previous reports and in existing databases, to the extent that such comparisons are possible and meaningful. In some cases, adjustments were necessary to compare values on the same basis. The inventory is also compared against the list of contaminants detected in environmental monitoring conducted at the RWMC. The results of all these comparisons help to confirm the credibility and substantial completeness of the inventory compiled in this task.

Although estimates of waste volume are included in CIDRA, no similar comparisons have been performed to confirm the accuracy of the volume estimates. The BRA will not use the volume estimates from CIDRA, so no special confirmation was considered necessary.

\subsection{Comparison of Inventory with Estimates Given in Earlier Reports}

Many earlier reports (see the references cited in Sections 2 and 3, for example) provide useful information on the inventories of contaminants buried in the SDA. The earlier reports were examined as part of the data gathering in the present task. However, the inventories in the earlier reports either (a) contain estimates for only a portion of the total inventory (e.g., only one disposal unit), (b) provide mostly or solely qualitative information, (c) deal with a somewhat different time period, or (d) were developed for a different purpose and made different assumptions to deal with the lack of definitive data in the original records. Therefore, only limited comparisons were possible between the total inventory developed in the present task and the inventories in previous reports. Nevertheless, even the limited comparisons are useful to help confirm the credibility and substantial completeness of the current results.

\subsubsection{Nonradiological Contaminants}

Background. As discussed in Section 1.2, the acceptance of mixed waste for disposal at the SDA was generally discontinued in April 1984 (Nelson 1984). The number and quantities of nonradiological contaminants in the waste being disposed of decreased dramatically after that time because most (but not all) of those nonradiological contaminants constitute hazardous waste, per RCRA.

The one temporary exception to the termination of mixed waste receipts related to the disposal of lead used as shielding in waste containers. Lead used as shielding continued to be accepted after April 1984. In March 1985, acceptance of radioactive waste containing any lead was suspended until the issue could be evaluated (Rodgers 1985). In June 1986, it was decided (Rodgers 1986) that all lead, regardless of category or use, would be barred from disposal at the SDA on November 30, 1987. On December 16, 1987, a one-time extension of the disposal deadline for lead shielding until December 31, 1987, was announced (Rodgers 1987).

Because of the various announcements just discussed, the quantities of RCRA nonradiological contaminants other than lead in waste disposed of after April 1984 would be expected to be (and were found to be) very small. No appreciable quantity of lead should have 
been disposed of after 1987, and none was identified in the present study. In addition, the quantities of non-RCRA nonradiological contaminants in waste disposed of after April 1984 decreased substantially.

Comparisons. A search of INEL reports and letters identified very few studies on the nonradiological contaminants buried in the SDA during the recent period (1984 through 1993). Two documents, Cerven (1987) and Wells (1986), provided limited information on which to base some comparisons; these are discussed below.

An INEL engineering design file (Cerven 1987) addressed nonradiological contaminants in the waste buried in the SDA. The report reviewed the RWMIS data through October 30, 1987, and also included responses to a request for information on quantities of halogenated solvents disposed of at the SDA. Most of the information in Cerven (1987) relates to the waste disposed of from 1954 through 1981. Very limited information was provided on the waste disposed of from 1982 through October 30,1987, a time period that partially overlaps the time period covered in the present study.

The RWMIS rollups from 1982 to October 30, 1987, in Cerven (1987) provided minimal information on the disposal of some lead and some asbestos. The rollups also showed some used ion-exchange resin that could have contained some unknown hazardous chemicals. The responses to Cerven's request for information revealed that generally no halogenated solvents were disposed of at the SDA after 1983. Minor (residual) amounts of halogenated solvents may have been disposed of in rags used for wiping up small amounts of commercial products such as "WD-40" or "Tap Magic."

The rollups presented by Cerven (1987) covered time periods both before and after the January 1, 1984, start date for the RPDT waste. As a result, no direct comparisons of the Cerven data against CIDRA data could be made in the present document.

A letter by Wells (1986) covers disposals during the period from November 1980 through January 15, 1986. Again, Wells (1986) covers time periods both before and after the start date of January 1, 1984, for coverage in the RPDT. Nevertheless, the letter is useful for comparison purposes.

Wells (1986) includes estimates of the amounts of lead disposed of in 1984, 1985, and early January 1986 (see Table 6-1). Table 6-1 shows that $8.0 \mathrm{E}+07 \mathrm{~g}$ of lead was disposed of in 1984, $9.9 \mathrm{E}+06 \mathrm{~g}$ in 1985 , and $1.2 \mathrm{E}+05 \mathrm{~g}$ in early January 1986.

The quantities in Table 6-1 agree with those in CIDRA for these generators and these time periods. The agreement was to be expected because Wells (1986) was one of the information sources used in the RPDT. CIDRA includes substantial lead disposals in 1986 after January 15 and in 1987; these disposals came after the issuance of the Wells letter. Therefore, the CIDRA total for lead is somewhat larger than that in Wells (1986).

Wells (1986) provides very limited information on zirconium oxide, insufficient for direct comparisons. 
Table 6-1. Lead disposal in the Subsurface Disposal Area from 1984 through January 15, 1986, taken from Wells (1986).

\begin{tabular}{lllll}
\hline \multicolumn{1}{c}{ Description } & Generator & Year & $\begin{array}{c}\text { Number of } \\
\text { shipments }\end{array}$ & $\begin{array}{c}\text { Lead } \\
\text { quantity, } g \\
(\text { lbs })\end{array}$ \\
\hline $\begin{array}{l}\text { HFEF-5 insert with } \\
\text { lead shielding }\end{array}$ & ANL-W & 1984 & 23 & $\begin{array}{l}2.8 \mathrm{E}+06 \\
(6.16 \mathrm{E}+03)\end{array}$ \\
$\begin{array}{l}\text { Fuel charging casks } \\
\text { with lead shielding }\end{array}$ & ICPP & 1984 & 4 & $\begin{array}{l}6.3 \mathrm{E}+07 \\
(1.38 \mathrm{E}+05)\end{array}$ \\
$\begin{array}{l}\text { Wooden boxes with } \\
\text { lead }\end{array}$ & ICPP & 1984 & & $\begin{array}{l}1.4 \mathrm{E}+07 \\
(3.02 \mathrm{E}+04)\end{array}$ \\
$\begin{array}{l}\text { HFEF-5 insert with } \\
\text { lead shielding }\end{array}$ & ANL-W & 1985 & 2 & $\begin{array}{l}2.0 \mathrm{E}+06 \\
(4.29 \mathrm{E}+03)\end{array}$ \\
$\begin{array}{l}\text { Resin cask with lead } \\
\text { shielding }\end{array}$ & TAN & 1985 & 16 & $\begin{array}{l}5.4 \mathrm{E}+06 \\
(1.20 \mathrm{E}+04)\end{array}$ \\
$\begin{array}{l}\text { Concrete resin module } \\
\text { with lead shielding }\end{array}$ & (LOFT) & $(5-31-85)$ & 1 & $\begin{array}{l}2.5 \mathrm{E}+06 \\
(5.60 \mathrm{E}+03)\end{array}$ \\
$\begin{array}{l}\text { HFEF-5 insert with } \\
\text { lead shielding }\end{array}$ & PBF & 1985 & 1 & $\begin{array}{l}1.2 \mathrm{E}+05 \\
(2.68 \mathrm{E}+02)\end{array}$ \\
\hline
\end{tabular}

In conclusion, Wells (1986) and Cerven (1987) provided some useful information for confirming the completeness of the CIDRA quantities of lead in the recent period. They provided very limited information on asbestos and zirconium oxide, insufficient for direct comparisons. No reports were found for comparison with the CIDRA quantities of beryllium, copper, chromium, mercury, cadmium, or arsenic.

No documents provided comprehensive information on nonradiological contaminants in the projected waste, against which to compare the CIDRA results.

\subsubsection{Radiological Contaminants}

A search was made for reports containing radionuclide inventories against which to compare the CIDRA data. For valid comparisons of the CIDRA data with radionuclide inventories in other reports, several aspects of the inventories must match. These aspects include the time period under consideration, the sources of the waste, the type of waste considered, and in which part of the SDA the waste was buried. This study examined all waste buried at the SDA from all generators from 1984-1993 and all waste projected to be buried from 1994-2003. 
6.1.2.1 Recent Period (1984-1993). The report by Plansky and Hoiland (1992) contains data for waste disposed of in the SDA during part of the recent period (1984-1989). The data are nearly identical to those in RWMIS. A detailed comparison was not carried out because a comparison against RWMIS for the years 1984-1993 is made in Section 6.2.

No reports were identified containing radionuclide inventories independent of those in RWMIS. Thus, no comparisons were possible against other reports containing radiological inventories for the SDA for the period 1984-1993.

\subsubsection{Projected Period (1994-2003).}

Comparisons-The waste in the projected time period has not yet been generated. Therefore, the only type of inventory document against which to compare the CIDRA results for the projected time period is the waste generator forecasts. These forecasts were one of the sources of information for CIDRA.

As discussed in Section 2.4.2, the waste forecasts from all generators are compiled in an annual letter (i.e., Randall 1994). The letter gives the total radioactivity by generator and by year, although the specific radionuclides are not indicated. No nonradiological contaminants are included in Randall (1994).

As a completeness check, the CIDRA inventory of radiological contaminants in the projected waste, by generator, was compared against the corresponding inventory based directly on the waste generator forecasts (Randall 1994). The results are given in Table 6-2.

The first column of Table 6-2 lists the six major generators. The next column lists the projected total radioactivity from each major generator, as taken from Randall (1994). The next column provides the CIDRA "reported" estimate of radioactivity (i.e., the estimates before applying the corrections for biases in the generator forecasts and in the G-M method). The last column provides the CIDRA best estimate (i.e., the estimate after applying both bias corrections, where applicable).

Evaluation of Differences for Reported Estimates in CIDRA-The reported estimates in CIDRA are virtually identical to the values from the waste generator forecasts. The totals match exactly, to within the precision of the standard two significant digits. The values for most of the individual generators match exactly or almost exactly. Because, as stated in Section 2.4.4, the generator forecasts were the starting point for evaluating the projected waste in the current study, the close agreement is not surprising.

The differences between the generator forecasts and the CIDRA reported estimates are discussed below.

The small difference of about $3 \mathrm{Ci}$ for waste from TAN is due to including in CIDRA some TAN hot cell and hot shop waste that is not included in the generator forecast. 
Table 6-2. Comparison of CIDRA radionuclide inventory for the projected period (1994-2003) against direct compilation of waste generator forecasts for the same years (Randall 1994).

\begin{tabular}{lccc}
\hline Generator & $\begin{array}{c}\text { Compilation of } \\
\text { waste generator } \\
\text { forecasts } \\
(\mathrm{Ci})\end{array}$ & $\begin{array}{c}\text { CIDRA reported } \\
\text { estimate (no generator } \\
\text { forecast corrections and } \\
\text { no G-M corrections) } \\
(\mathrm{Ci})\end{array}$ & $\begin{array}{c}\text { CIDRA best estimate } \\
\text { (with generator } \\
\text { forecast corrections } \\
\text { and } \mathrm{G}-\mathrm{M} \text { corrections) } \\
(\mathrm{Ci})\end{array}$ \\
\hline TAN & $1.0 \mathrm{E}-01$ & $3.2 \mathrm{E}+00$ & $1.5 \mathrm{E}+00$ \\
TRA & $2.8 \mathrm{E}+06$ & $2.8 \mathrm{E}+06$ & $2.8 \mathrm{E}+06$ \\
ICPP & $1.3 \mathrm{E}+03$ & $1.2 \mathrm{E}+03$ & $1.6 \mathrm{E}+02$ \\
NRF & $5.5 \mathrm{E}+05$ & $5.5 \mathrm{E}+05$ & $1.4 \mathrm{E}+05$ \\
ANL-W & $3.2 \mathrm{E}+06$ & $3.2 \mathrm{E}+06$ & $8.1 \mathrm{E}+05$ \\
Other & $2.6 \mathrm{E}+02$ & $1.5 \mathrm{E}+03$ & $5.1 \mathrm{E}+02$ \\
Total & $6.6 \mathrm{E}+06$ & $6.6 \mathrm{E}+06$ & $3.8 \mathrm{E}+06$ \\
\hline
\end{tabular}

The small difference in projected radioactivity from ICPP is strictly due to rounding. If the calculations are carried out more precisely, both the detailed waste generator forecast letter from ICPP (Hitz and Skinner 1993) and the CIDRA waste datasheet for stream CPP-ALL-1P give a total radioactivity of $1,255 \mathrm{Ci}$.

For the generators termed "other," the reported CIDRA value is considerably higher than that in the generator forecasts: $1,500 \mathrm{Ci}$ versus $260 \mathrm{Ci}$. The difference is attributed to higher estimates for (a) D\&D waste- $890 \mathrm{Ci}$ in CIDRA versus $230 \mathrm{Ci}$ in the generator forecasts, and (b) waste to be treated at WERF and disposed of in the SDA-510 Ci in CIDRA versus $0 \mathrm{Ci}$ in the generator forecasts.

The difference in the radioactivity of waste expected to come from D\&D is explained as follows. The D\&D generator forecast in Randall (1994) shows no radioactivity in the D\&D waste to be produced after 1998, even though increasing volumes of waste are projected after 1998. The reason for this anomaly is that the radioactivity in the D\&D waste to be produced after 1998 is not well known; facility characterizations have not yet been completed. In the present study, the radioactivity in all of the D\&D waste through 2003 was estimated. The method for estimating the radioactivity after 1998 was to (a) assume that the concentration of radioactivity $\left(\mathrm{Ci} / \mathrm{m}^{3}\right)$ in 1999-2003 waste would equal that found in the 1984-1993 waste, then (b) multiply by the projected volume of the $\mathrm{D} \& \mathrm{D}$ waste after 1998 . This approach leads to a larger value of the projected radioactivity in D\&D waste in 1994-2003 than that given in Randall (1994). 
The difference in the radioactivity of waste expected to come from WERF to the SDA for disposal is explained as follows. The generator forecast values in Table 6-2 apply only to waste expected to be shipped directly from the generator to the SDA. At the time when Randall (1994) was prepared, WERF was shut down. WERF personnel were not certain when, if ever, WERF would restart. Therefore, the entries in Randall (1994) showing future treated waste going from WERF to the SDA were all zero for 1994-2003. Randall (1994) also does not include the waste stored at WERF awaiting treatment, since it had already been generated in the past. Randall (1994) does, however, provide separate rollups (not included in the total) for the waste expected to go first to WERF for treatment and then to the SDA. Those separate rollups total $607 \mathrm{Ci}$. CIDRA includes the waste to be treated that is already stored at WERF. CIDRA also reflects the assumption that WERF would restart in 1994; Section 2.5.6 indicates that size reduction and compaction have restarted, and incineration is now expected to restart in 1995 . All of these entries in CIDRA total $510 \mathrm{Ci}$.

Evaluation of Differences for Best Estimates in CIDRA-The best-estimate projections in CIDRA reflect the application of corrections where applicable for (a) the upward bias in waste generator forecasts, which were generally the starting point for the CIDRA projections, and (b) the upward bias in projected values of radioactivity that are based on past measurements of radioactivity using the G-M method. The first bias correction is multiplication by a factor of 0.25 . The second bias correction is multiplication by a factor of 0.5 . The bases for these bias corrections and the explanations of the applicability of each are provided in Section 5.

The last column of Table 6-2 shows that applying the two downward corrections where appropriate reduces the projected radioactivity, as expected. The total radioactivity is reduced by $42 \%$, although the amount of the reduction varies from generator to generator.

In terms of radioactivity, the largest waste generator in this time period is ANL-W, with a reported estimate of 3.2 million $\mathrm{Ci}$. More than $99 \%$ of the ANL-W radioactivity is in stream ANL-785-1P, remote-handled, nonprocessible, subassembly waste. As stated in Section 5, the bias correction for the G-M method does not apply to ANL-W in this time period. The bias correction for the waste generator forecasts does apply, however. Therefore, one would expect the best estimate radioactivity for ANL-W to be approximately one-fourth of the reported radioactivity. In Table $6-2$, the ratio of these two quantities is $8.1 \mathrm{E}+05 / 3.2 \mathrm{E}+06=0.25$, as expected.

The second largest generator is TRA, with a reported estimate of 2.8 million $\mathrm{Ci}$. Approximately $98 \%$ of the TRA radioactivity is in stream TRA-670-1P, beryllium reflectors. No corrections apply to this stream for the following reasons. The G-M method was not used or extrapolated to estimate the radioactivity, which is nearly all $\mathrm{H}-3$ (a pure beta-emitter not detectable by the G-M method). The waste generator forecast correction does not apply because much of the subject radioactivity has already been generated in the reflectors. Disposal of this waste stream is essentially certain to occur, although the exact year of future disposal is uncertain. Therefore, the best estimate value of the projected radioactivity from TRA matches the reported value.

The third largest generator is NRF, with a reported estimate of $550,000 \mathrm{Ci}$. More than $99 \%$ of the NRF radioactivity is in stream NRF-618-8P, structural components removed from Navy 
nuclear fuel modules. For this stream, the G-M correction does not apply because core operating histories and nuclear physics calculations were used, as discussed in Section 5. The bias correction for the waste generator forecasts does apply, however. Therefore, one would expect the bestestimate radioactivity for NRF to be approximately one-fourth of the reported radioactivity. In Table 6-2, the ratio of these two quantities is $1.4 \mathrm{E}+05 / 5.5 \mathrm{E}+05=0.25$, as expected.

The three remaining major generators are projected to generate much smaller activities than the three just evaluated. For each generator, if both corrections applied to all streams, the bestestimate radioactivity would be one-eighth of the reported radioactivity. If neither correction applied to any streams, the two values would be identical. For TAN, ICPP, and other generators, the ratios are $0.47,0.13$, and 0.34 , respectively. These values all fall within the expected range of 0.12 to 1.00 .

Conclusion-For the projected time period, the CIDRA values of radioactivity agree with the waste generator forecasts in the instances where such agreement would be expected. The CIDRA values differ from the generator forecasts in the expected way when the CIDRA bias corrections and other refinements are applied. There is no indication that any substantial radioactivity is missing from the CIDRA data for the projected time period.

\subsection{Comparison of Inventory with Inventories in Existing Databases}

\subsubsection{Introduction}

This section compares the contaminant inventory developed in this task with corresponding inventories in existing databases. One objective was to confirm the substantial completeness and accuracy of the data collection for this task. A second objective was to identify and explain any major differences in inventory values between the databases, and justify the new values that will be used in the BRA.

Only one database was identified against which to compare the complete contaminant inventory: RWMIS. Since RWMIS contains little information on nonradiological contaminants in the waste and no estimates of uncertainties, the comparisons here involved only reported estimates and best estimates of radiological contaminants. Also, because waste in the projected time period has not been generated and the data have not been entered into RWMIS, only the recent period is addressed.

Because of the thousands of data involved in the radionuclide inventory, the comparisons reported here were for the purpose of general checking. The comparisons were not intended to be an exact accounting (which would not be useful, anyway, because of the uncertainties in the data). 


\subsubsection{Comparisons at the Level of Individual Radionuclides, Summed Over All Generators}

6.2.2.1 Approach. The RWMIS shipping record rollups were used for these comparisons against CIDRA. Figure 6-1 illustrates the approach. The strategy was to check for agreement first at the level of the total inventory of each radionuclide (over all waste generators). If, for a given radionuclide, the numbers were not reasonably close at that level, resolution was sought by comparisons at the level of the individual waste generators. Because CIDRA is organized by waste stream and RWMIS is organized by waste shipment, direct comparisons below the generator level were generally not feasible.

As the upper-right portion of Figure 6-1 shows, before the activities could be compared on the same basis, the RWMIS results had to be adjusted to replace the generic terms MAP, MFP, and unidentified beta-gamma with specific estimates by radionuclide. (Approximately 7,000 Ci of the RWMIS radioactivity for 1984-1993 is listed in these generic terms.) The radionuclide distributions used in CIDRA for MAP, MFP, etc., vary by waste generator and sometimes even by waste stream for the same generator. For purposes of this comparison only, approximate breakdowns were developed as follows for each of the generic terms in RWMIS. For each generator, radionuclide distributions were identified that had been used in CIDRA, either for all waste streams or as a rough average (see Appendix E for the detailed distributions). These percentages were then multiplied by the RWMIS value, in curies, for each generic term for each generator. The resulting activities of each radionuclide were then added to the RWMIS values for the specific radionuclides. For example, the Co-60 activities deriving from the MAP value and from the unidentified beta-gamma value were added to the Co-60 activity that was listed separately in RWMTS. This process was performed for each affected radionuclide for each generator.

There is an additional complication. Section 5.4 noted that the radioactivity determinations for most waste containers from most facilities were based on radiation surveys using G-M counters. The bias and random error of that method were discussed. A correction factor-multiplication by 0.5 -was derived. CIDRA applies that correction factor to all bestestimate inventory entries for which uncertainties were not available, except as discussed in Section 5. Unfortunately, applying the correction factor makes it difficult to compare RWMIS and CIDRA as a completeness confirmation for CIDRA. For ease of comparison, the initial comparisons were made without the factor of 0.5 incorporated. The final comparisons reflect the factor of 0.5 where appropriate, as shown at the bottom of Figure 6-1.

6.2.2.2 Inventories as Listed in RWMIS and CIDRA. This section discusses how the inventory information was assembled for the comparisons. The successive columns of Table 6-3 indicate the results at various stages of the comparisons.

The first two columns of Table 6-3 list the total inventory for each radionuclide, as given in the RWMIS shipping record rollups. The radionuclides are listed in order of activity. The activities listed for the generic terms MFP, MAP, etc., are evident. 


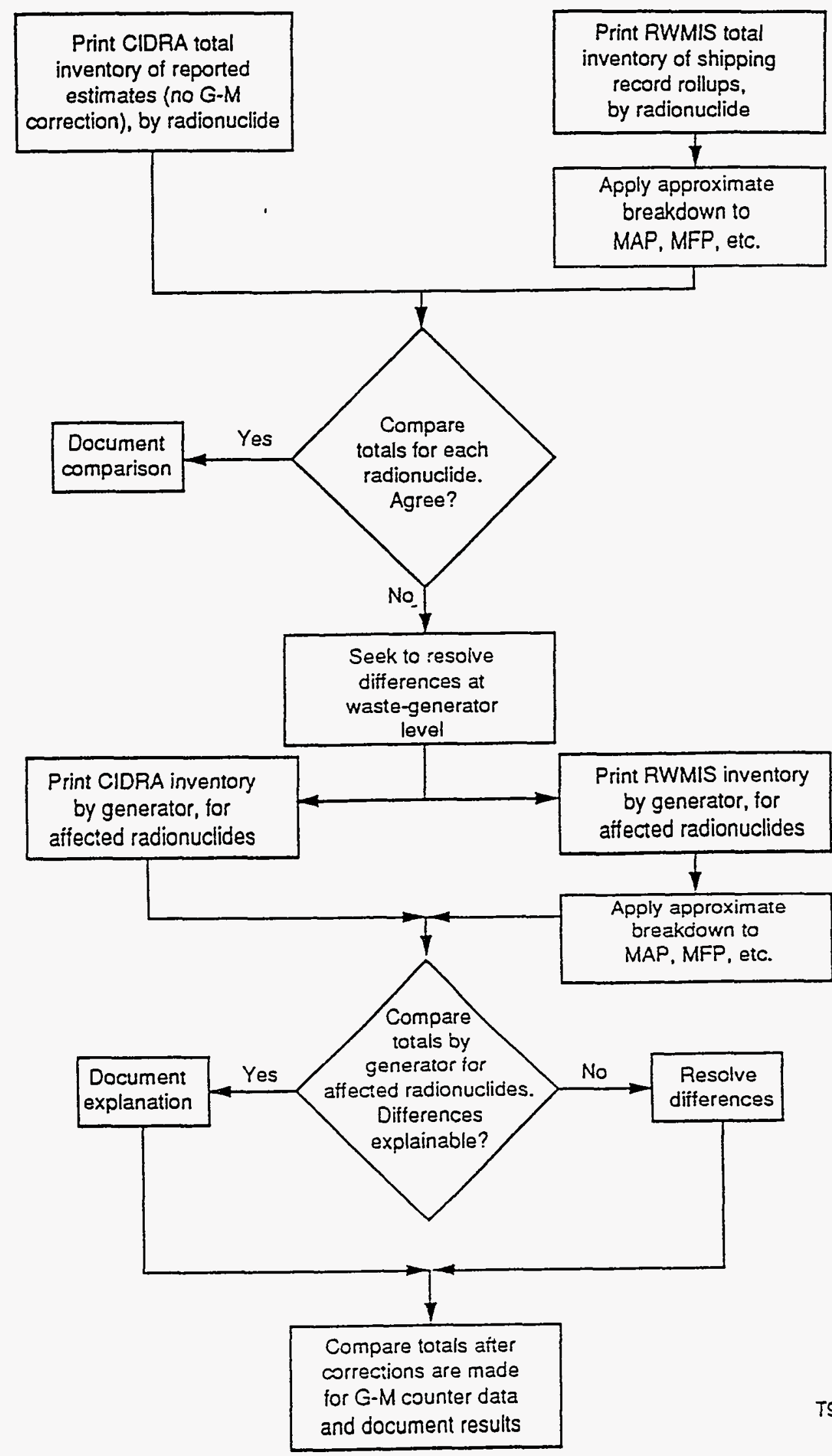

T94 0447

Figure 6-1. Approach for comparing the radionuclide inventory in CWRA with that in the shipping record rollups of the RWMIS. 
Table 6-3. Radionuclide inventories as given by RWMIS shipping record rollups and by CIDRA (with and without Geiger-Müller counter corrections): 1984-1993.

\begin{tabular}{|c|c|c|c|c|}
\hline Radionuclide & $\begin{array}{l}\text { RWMIS } \\
\text { inventory } \\
\text { (Ci) }\end{array}$ & $\begin{array}{l}\text { RWMIS (with } \\
\text { generic entries } \\
\text { distributed) } \\
\text { (Ci) }\end{array}$ & $\begin{array}{l}\text { CIDRA reported } \\
\text { estimates (no } \\
\text { G-M corrections) } \\
\text { (Ci) }\end{array}$ & $\begin{array}{c}\text { CIDRA best } \\
\text { estimate (with } \\
\text { G-M corrections) } \\
\text { (Ci) }\end{array}$ \\
\hline Co-60 & $1.0 E+06$ & $1.0 \mathrm{E}+06$ & $1.4 \mathrm{E}+06$ & $1.4 E+06$ \\
\hline $\mathrm{Ni}-63$ & $4.8 E+05$ & $4.8 E+05$ & $4.8 \mathrm{E}+05$ & $4.8 E+05$ \\
\hline Co-58 & $4.5 \mathrm{E}+05$ & $4.5 E+05$ & $2.0 E+05$ & $2.0 \mathrm{E}+05$ \\
\hline$M n-54$ & $3.2 E+05$ & $3.2 E+05$ & $1.2 \mathrm{E}+05$ & $1.2 E+05$ \\
\hline $\mathrm{H}-3$ & $3.0 \mathrm{E}+05$ & $3.0 \mathrm{E}+05$ & $3.0 \mathrm{E}+05$ & $3.0 \mathrm{E}+05$ \\
\hline $\mathrm{Fe}-55$ & $1.5 E+05$ & $1.5 \mathrm{E}+05$ & $1.6 \mathrm{E}+05$ & $1.6 E+05$ \\
\hline $\mathrm{Cr}-51$ & $3.7 \mathrm{E}+04$ & $3.7 E+04$ & $4.7 \mathrm{E}+04$ & $4.7 E+04$ \\
\hline Ta-182 & $2.0 E+04$ & $2.0 E+04$ & $1.8 E+04$ & $1.8 \mathrm{E}+04$ \\
\hline Sn- $119 m$ & $8.9 E+03$ & $8.9 E+03$ & $8.8 E+03$ & $8.8 E+03$ \\
\hline W-185 & $5.5 E+03$ & $5.5 \mathrm{E}+03$ & $6.4 E+03$ & $6.4 \mathrm{E}+03$ \\
\hline Cs-137 & $4.1 E+03$ & $6.4 \mathrm{E}+03$ & $5.7 E+03$ & $3.1 E+03$ \\
\hline $\mathrm{Nb}-95$ & $4.0 E+03$ & $4.0 E+03$ & $3.8 \mathrm{E}+03$ & $3.8 E+03$ \\
\hline MFP & $3.8 E+03$ & 0 & 0 & 0 \\
\hline Hf-181 & $3.8 E+03$ & $3.8 E+03$ & $3.4 E+03$ & $3.4 E+03$ \\
\hline $\mathrm{Fe}-59$ & $3.8 E+03$ & $3.8 E+03$ & $1.5 E+04$ & $1.5 E+04$ \\
\hline Sb-125 & $2.9 E+03$ & $3.0 E+03$ & $2.9 \mathrm{E}+03$ & $2.9 E+03$ \\
\hline MAP & $2.9 E+03$ & 0 & 0 & 0 \\
\hline Hf-175 & $2.4 \mathrm{E}+03$ & $2.4 \mathrm{E}+03$ & $2.8 E+03$ & $2.8 \mathrm{E}+03$ \\
\hline Zr-95 & $2.2 E+03$ & $2.2 \mathrm{E}+03$ & $2.1 E+03$ & $2.1 E+03$ \\
\hline $\mathrm{Ni}-59$ & $1.4 \mathrm{E}+03$ & $1.4 \mathrm{E}+03$ & $1.4 \mathrm{E}+03$ & $1.4 \mathrm{E}+03$ \\
\hline $\mathrm{Zn}-65$ & $1.0 \mathrm{E}+03$ & $1.0 E+03$ & $1.0 \mathrm{E}+03$ & $1.0 \mathrm{E}+03$ \\
\hline Ce-144 & $9.2 \mathrm{E}+02$ & $1.6 \mathrm{E}+03$ & $3.5 E+02$ & $2.1 E+02$ \\
\hline W-187 & $9.2 E+02$ & $9.2 \mathrm{E}+02$ & 0 & 0 \\
\hline Sr-90 & $4.5 \mathrm{E}+02$ & $9.8 E+02$ & $9.9 E+02$ & $5.8 E+02$ \\
\hline Cs-134 & $2.7 E+02$ & $2.9 E+02$ & $2.1 E+02$ & $1.4 \mathrm{E}+02$ \\
\hline Pr-144 & $2.4 \mathrm{E}+02$ & $2.7 \mathrm{E}+02$ & $2.2 E+02$ & $1.1 E+02$ \\
\hline $\begin{array}{l}\text { Unidentified } \\
\text { beta-gamma }\end{array}$ & $1.4 \mathrm{E}+02$ & 0 & 0 & 0 \\
\hline$Y-90$ & $1.3 E+02$ & $1.4 \mathrm{E}+02$ & $2.6 \mathrm{E}+02$ & $2.0 \mathrm{E}+02$ \\
\hline Ru-106 & $1.2 E+02$ & $1.3 E+02$ & $1.2 E+02$ & $6.4 E+01$ \\
\hline $\mathrm{Rh}-106$ & $1.2 E+02$ & $1.3 E+02$ & $1.2 E+02$ & $6.1 E+01$ \\
\hline Sn-117M & $1.2 \mathrm{E}+02$ & $1.2 \mathrm{E}+02$ & $1.2 \mathrm{E}+02$ & $1.2 \mathrm{E}+02$ \\
\hline Sc-46 & $5.0 \mathrm{E}+01$ & $5.0 \mathrm{E}+01$ & $5.0 \mathrm{E}+01$ & $5.0 \mathrm{E}+01$ \\
\hline $\mathrm{Te}-125 \mathrm{~m}$ & $4.2 \mathrm{E}+01$ & $4.2 E+01$ & $4.2 \mathrm{E}+01$ & $4.2 E+01$ \\
\hline
\end{tabular}


Table 6-3. (continued).

\begin{tabular}{|c|c|c|c|c|}
\hline Radionuclide & $\begin{array}{l}\text { RWMIS } \\
\text { inventory } \\
\text { (Ci) }\end{array}$ & $\begin{array}{l}\text { RWMIS (with } \\
\text { generic entries } \\
\text { distributed) } \\
\text { (Ci) }\end{array}$ & $\begin{array}{l}\text { CIDRA reported } \\
\text { estimates (no } \\
\text { G-M corrections) } \\
\text { (Ci) }\end{array}$ & $\begin{array}{c}\text { CIDRA best } \\
\text { estimate (with } \\
\text { G-M corrections) } \\
\text { (Ci) }\end{array}$ \\
\hline Sr-89 & $3.0 \mathrm{E}+01$ & $3.0 \mathrm{E}+01$ & $3.0 E+00$ & $3.0 \mathrm{E}+00$ \\
\hline Sn-113 & $2.4 \mathrm{E}+01$ & $2.4 \mathrm{E}+01$ & $2.4 \mathrm{E}+01$ & $2.4 \mathrm{E}+01$ \\
\hline Eu-152 & $1.0 E+01$ & $1.0 \mathrm{E}+01$ & $7.3 E+00$ & $4.1 E+00$ \\
\hline Th-228 & $1.0 \mathrm{E}+01$ & $1.0 \mathrm{E}+01$ & $1.0 \mathrm{E}+01$ & $1.0 \mathrm{E}+01$ \\
\hline C-14 & $1.0 \mathrm{E}+01$ & $3.8 \mathrm{E}+01$ & $7.1 \mathrm{E}+01$ & $4.0 E+01$ \\
\hline$E u-154$ & $6.0 \mathrm{E}+00$ & $6.0 \mathrm{E}+00$ & $6.0 \mathrm{E}+00$ & $3.3 E+00$ \\
\hline $\mathrm{Ba}-137 \mathrm{~m}$ & $5.5 E+00$ & $5.5 \mathrm{E}+00$ & $5.2 E+00$ & $4.6 E+00$ \\
\hline Ce-141 & $3.0 \mathrm{E}+00$ & $3.0 \mathrm{E}+00$ & $2.9 E+00$ & $2.9 E+00$ \\
\hline $\mathrm{Na}-24$ & $2.7 E+00$ & $2.7 \mathrm{E}+00$ & $2.7 \mathrm{E}+00$ & $2.7 E+00$ \\
\hline La-140 & $2.6 E+00$ & $3.1 \mathrm{E}+00$ & $3.1 E+00$ & $2.8 E+00$ \\
\hline $\mathrm{Pm}-147$ & $2.4 \mathrm{E}+00$ & $2.4 \mathrm{E}+00$ & $2.4 \mathrm{E}+00$ & $2.4 \mathrm{E}+00$ \\
\hline U-238 & $2.3 E+00$ & $2.3 E+00$ & $1.6 \mathrm{E}+00$ & $1.6 \mathrm{E}+00$ \\
\hline $\mathrm{U}-232$ & $2.2 \mathrm{E}+00$ & $2.2 \mathrm{E}+00$ & $2.2 E+00$ & $2.2 E+00$ \\
\hline $\mathrm{Ba}-140$ & $2.2 E+00$ & $2.7 \mathrm{E}+00$ & 2.7E+00 & $2.4 \mathrm{E}+00$ \\
\hline Eu-155 & $2.1 E+00$ & $8.9 E+01$ & $6.6 \mathrm{E}+01$ & $3.9 \mathrm{E}+01$ \\
\hline $\mathrm{Ag}-110 \mathrm{M}$ & $1.9 E+00$ & $1.9 E+00$ & 3.3E-02 & $1.8 \mathrm{E}-02$ \\
\hline $\mathrm{Mn}-56$ & $1.3 E+00$ & $1.3 E+00$ & $1.3 E+00$ & $1.3 E+00$ \\
\hline Gd-153 & $1.3 E+00$ & $1.3 E+00$ & $1.3 E+00$ & $1.3 E+00$ \\
\hline $\mathrm{Ra}-226$ & $1.2 E+00$ & $1.2 \mathrm{E}+00$ & $1.1 E+00$ & $1.1 E+00$ \\
\hline $\mathrm{I}-132$ & $1.0 E+00$ & $1.0 \mathrm{E}+00$ & $1.0 \mathrm{E}+00$ & $1.0 \mathrm{E}+00$ \\
\hline Ba-La-140 & $1.0 E+00$ & 0 & 0 & 0 \\
\hline Pu-239 & $3.0 \mathrm{E}-01$ & $3.0 \mathrm{E}-01$ & $2.6 \mathrm{E}+00$ & $2.4+00$ \\
\hline $\mathrm{Pu}-241$ & $1.0 \mathrm{E}-01$ & $1.0 \mathrm{E}-01$ & $3.4 \mathrm{E}+01$ & $1.7 \mathrm{E}+01$ \\
\hline Am-241 & $3.9 E-01$ & $3.9 E-01$ & $4.0 E+00$ & $3.7 E+00$ \\
\hline U-234 & $1.5 \mathrm{E}-02$ & $1.5 \mathrm{E}-02$ & $3.5 E+00$ & $3.5 E+00$ \\
\hline Ag-110 & 7.5E-02 & $7.5 \mathrm{E}-02$ & $1.9 E+00$ & $1.9 E+00$ \\
\hline Co-57 & 4.7E-02 & 4.7E-02 & $1.5 \mathrm{E}+00$ & $1.5 E+00$ \\
\hline Тc-99 & $7.6 \mathrm{E}-03$ & $2.5 E+00$ & $1.0 \mathrm{E}+00$ & $5.0 \mathrm{E}-01$ \\
\hline $\mathrm{Nb}-94$ & 4.0E-02 & 4.0E-02 & 2.0E-01 & $2.0 \mathrm{E}-01$ \\
\hline $\mathrm{I}-129$ & $5.4 \mathrm{E}-04$ & $6.8 \mathrm{E}-04$ & 4.2E-03 & 2.1E-03 \\
\hline Total & $2.8 E+06$ & $2.8 E+06$ & $2.8 E+06$ & $2.8 E+06$ \\
\hline
\end{tabular}


Radionuclides were included in the comparison if their activity listed in RWMIS was at least $1 \mathrm{Ci}$. Additional radionuclides were included at the end of the list if their activity in the CIDRA database was at least $1 \mathrm{Ci}$ before correction for the bias in the G-M counter readings. In addition, I-129 and Nb-94 were included because, although their activities were very small, they are very long-lived and relatively mobile when released from confinement.

In order to compare the CIDRA and RWMIS entries on the same basis, the generic terms had to be eliminated from the RWMIS entries. The activity represented by the generic terms was broken down as described in Section 6.2.2.1, leading to the values in the third column of Table 6-3. Also, dual radionuclide entries in $\mathrm{RWMIS}$, such as $\mathrm{Zr}-\mathrm{Nb}-95$, were assigned as described in Appendix E. (Section 3.1.1 discusses the treatment of secular equilibrium in the CIDRA inventory and in the risk assessment.) The third column, therefore, represents the radionuclide inventory if RWMIS is used and the generic terms and dual radionuclide entries are broken down into their constituent radionuclides, as per the general methods used in the current study.

The fourth column gives the CIDRA values for the same radionuclides. The data in this column do not reflect the corrections made for the bias in inventory information based on the G-M counter surveys of waste containers. Thus, the data in this column are not the final CIDRA data, but are a version used only to check for completeness against the RWMIS values.

\subsubsection{Comparisons of Results Before Applying Corrections to Activity Estimates} Derived from G-M Counter Survey Data. The third and fourth columns of Table 6-3 enable comparisons of the results from CIDRA with those from RWMIS, with the generic radionuclide terms in RWMIS distributed using a simplified version of the CIDRA results, but without the effect of the corrections to data originally obtained from the G-M counter surveys. The following paragraphs discuss the results for only the predominant radionuclides. For both databases, data rollups by generator were consulted in evaluating the results, but generally are not presented here for brevity.

The nuclide-by-nuclide comparisons are discussed most easily by grouping the radionuclides according to fission products, activation products, and actinides. (Actinides include actinium and higher-numbered elements on the Periodic Table, such as plutonium, americium, and uranium.) Tritium $(\mathrm{H}-3)$ is a special case and is addressed first.

Tritium ( $\mathrm{H}-3)$-The CIDRA value agrees with the RWMIS entry to within the study precision of two significant figures. Virtually all of the H-3 is in stream TRA-670-1R, beryllium reflectors. Although the $\mathrm{H}-3$ in this stream during the historical period (TRA-670-1H) was not reported in RWMIS, the $\mathrm{H}-3$ in the stream was reported in RWMIS during the recent.period. Hence, the agreement.

Fission Products-For the 8 fission products that constitute nearly all of this type of activity, the CIDRA and RWMIS values are compared below. They are discussed in the same order as their ranking in the CIDRA reported estimates.

The total activities of these 8 principal fission products in CIDRA (reported) and RWMIS (with generic entries distributed) differ by about $20 \%$. The values are approximately $8,000 \mathrm{Ci}$ and 
$10,000 \mathrm{Ci}$, respectively. The difference is less than the total random error for estimating the radioactivity in an individual waste shipment.

The distributions of the fission products in the two inventories also differ slightly. The sizes of the differences and the reasons for the differences are discussed below.

- Cs-137. The CIDRA value is approximately $11 \%$ smaller than the RWMIS value. The difference is less than the total random error for estimating the radioactivity in an individual waste shipment. Most of the Cs-137 is from TAN.

- Sr-90. The CIDRA value is approximately $1 \%$ larger than the RWMIS value. The difference is less than the total random error for estimating the radioactivity in an individual waste shipment. The Sr-90 is distributed fairly evenly over several generators.

- Ce-144. The CIDRA value is approximately one-fifth of the RWMIS value. Most of the Ce-144 is from ANL-W and from TRA in the MFP entries of RWMIS.

- Y-90. The CIDRA value is approximately twice the RWMIS value. As explained in Section 3.1, Y-90 is a short-lived decay product of Sr-90. Secular equilibrium is established quickly between the two radionuclides. Some preparers of waste information include the Y-90; some do not. The lack of full reporting of Y-90 is not important to the BRA; the calculations of radioactive decay performed in conjunction with the BRA will reflect equilibrium and the appropriate activity of Y-90.

- Cs-134. The CIDRA value is about three-fourths of the RWMIS value. CIDRA shows approximately $210 \mathrm{Ci}$, of which $92 \mathrm{Ci}$ is from TAN, $66 \mathrm{Ci}$ is from TRA, and $49 \mathrm{Ci}$ is from PBF. RWMIS shows $290 \mathrm{Ci}$, of which $31 \mathrm{Ci}$ is from TAN, $66 \mathrm{Ci}$ is from TRA, $120 \mathrm{Ci}$ is from ANL-W, $49 \mathrm{Ci}$ is from PBF, and $20 \mathrm{Ci}$ is from distributing generic entries. The difference is due primarily to a change in the distribution of radioactivity in the ANL-W waste.

- Pr-144. The CIDRA value is $18 \%$ smaller than the RWMIS value. The difference is less than the total random error for estimating the radioactivity in an individual waste shipment. Almost all of the Pr-144 is from ICPP.

- Ru-106. The CIDRA value is about $8 \%$ smaller than that of RWMIS. The difference is less than the total random error for estimating the radioactivity in an individual waste shipment. Almost all of the Ru-106 is from ICPP.

- Rh-106. The CIDRA value is about $8 \%$ smaller than that of RWMIS. The difference is less than the total random error for estimating the radioactivity in an individual waste shipment. Almost all of the Rh-106 is from ICPP.

I-129 is not one of the top 8 fission products in CIDRA in terms of activity. However, I-129 is important to the BRA because of its very long half-life (15.7 million years) and its potential for a comparatively high mobility in subsurface transport. The CIDRA value for I-129 is $4.2 \mathrm{E}-03 \mathrm{Ci}$, 
almost entirely from TRA. The activity was estimated by means of the nuclear physics calculations described in Section 2.5.2. The RWMIS value is only 5.4E-04 Ci before distributing the generic entries, and $6.8 \mathrm{E}-04 \mathrm{Ci}$ after. $\mathrm{I}-129$ is seldom reported in waste shipments because it is very difficult to measure (EPRI 1987).

For the principal fission products and for the fission products as a whole, the comparison against the data in RWMIS confirmed that the CIDRA inventory of fission products is substantially complete. The only principal fission products for which the CIDRA values are substantially smaller than the RWMIS values are Cs-134 and Ce-144. These two radionuclides are relatively short-lived. The half-life of Cs-134 is only about 2 yr. The half-life of Ce-144 is less than 1 yr.

Activation Products-For the 18 activation products that constitute nearly all of this type of activity, the CIDRA and RWMIS values are compared below. They are discussed in the same order as their ranking in the reported estimates of CIDRA.

The total activities of these 18 principal activation products in CIDRA and RWMIS differ very slightly ( 2.47 million $\mathrm{Ci}$ and 2.49 million $\mathrm{Ci}$, respectively).

The distributions of the activation products in the two inventories differ somewhat more. The sizes of the differences and the reasons for the differences are discussed below.

- Co-60. The CIDRA value is about $40 \%(400,000 \mathrm{Ci})$ larger than the RWMIS value. The difference arises primarily from the fact that the Co-60 for ANL-W waste is 370,000 Ci larger in CIDRA than in RWMIS. The ANL-W data reflect a more recent estimate of the distribution of activation products in the waste.

- Ni-63. The CIDRA value matches that of RWMIS. Nearly all of the Ni-63 is from NRF.

- Co-58. The CIDRA value is approximately one-half of the RWMIS value, for the same reason as discussed under Co-60. Nearly all of the Co-58 is from ANL-W.

- Fe-55. The CIDRA value is approximately $7 \%$ larger than the RWMIS value. The difference is less than the total random error for estimating the radioactivity in an individual waste shipment. Nearly all of the Fe-55 is from NRF.

- Mn-54. The CIDRA value is approximately one-third of the RWMIS value, for the same reason as discussed under Co-60. Nearly all of the Mn-54 is from ANL-W.

- Cr-51. The CIDRA value is approximately 25\% larger than the RWMIS value, for the same reason as discussed under Co-60. Nearly all of the Cr-51 is from ANL-W.

- Ta-182. The CIDRA value is approximately $10 \%$ smaller than the RWMIS value. The difference is less than the total random error for estimating the radioactivity in an individual waste shipment. Nearly all of the Ta-182 is from NRF. 
- Fe-59. The CIDRA value is approximately four times the RWMIS value. Nearly all of the Fe-59 is from ANL-W. The reason for the difference is discussed under Co-60.

- $\quad$ Sn-119m. The CIDRA value matches that of RWMIS within about $1 \%$. Nearly all of the $\mathrm{Sn}-119 \mathrm{~m}$ is from NRF.

- W-185. The CIDRA value is about $16 \%$ larger than the RWMIS value. The difference is less than the total random error for estimating the radioactivity in an individual waste shipment. All of the W-185 is from NRF.

- $\quad \mathrm{Nb}-95$. The CIDRA value is approximately 5\% smaller than the RWMIS value. The difference is less than the total random error for estimating the radioactivity in an individual waste shipment. Almost all of the Nb-95 is from NRF.

- Hf-181. The CIDRA value is approximately $10 \%$ smaller than the RWMIS value. The difference is less than the total random error for estimating the radioactivity in an individual waste shipment. Almost all of the Hf-181 is from NRF.

- $\quad \mathrm{Sb}-125$. The CIDRA value is $3 \%$ smaller than that of RWMIS. The difference is less than the total random error for estimating the radioactivity in an individual waste shipment. Almost all of the Sb-125 is from NRF.

- Hf-175. The CIDRA value is approximately $17 \%$ larger than the RWMIS value. The difference is less than the total random error for estimating the radioactivity in an individual waste shipment. Almost all of the Hf-175 is from NRF.

- $\quad$ Zr-95. The CIDRA value is approximately $5 \%$ smaller than the RWMIS value. The difference is less than the total random error for estimating the radioactivity in an individual waste shipment. Almost all of the $\mathrm{Zr}-95$ is from NRF.

- Ni-59. The CIDRA value matches that of RWMIS. Nearly all of the Ni-59 is from NRF.

- Zn-65. The CIDRA value matches that of RWMIS. All of the $\mathrm{Zn}-65$ is from TRA.

- W-187. CIDRA shows no W-187 in the waste, whereas RWMIS shows $920 \mathrm{Ci}$, all from NRF. NRF personnel indicate that the W-187 entry in RWMIS is erroneous and should be W-185 instead. Making this correction would increase the RWMIS activity for W-185 such that it matches the CIDRA activity.

C-14, Tc-99, and Nb-94 are not among the top 18 activation products in CIDRA in terms of activity. However, they are important to the BRA because of their very long half-lives $(5,730$ years for $\mathrm{C}-14,213,000$ years for Tc-99, and 20,000 years for $\mathrm{Nb}-94)$ and their potential for comparatively high mobilities in subsurface transport. Their activities are discussed below. 
The CIDRA value for $\mathrm{C}-14$ is $71 \mathrm{Ci}$, of which $61 \mathrm{Ci}$ is from TRA and $10 \mathrm{Ci}$ from NRF. The RWMIS value (before distributing the generic entries) is only $10 \mathrm{Ci}$, consisting almost solely of the $10 \mathrm{Ci}$ from NRF. The NRF value in both CIDRA and RWMIS was developed by means of nuclear physics calculations. The TRA value in CIDRA was developed by means of nuclear physics-based scaling factors. The TRA value in RWMIS is $<1 \mathrm{Ci}$ because C-14 is very difficult to measure in waste shipments; evidently, nuclear physics calculations were not performed to support the TRA data submittal to RWMIS.

The CIDRA value for Tc-99 is $1.0 \mathrm{Ci}$, almost all from TRA. RWMIS shows $<0.01 \mathrm{Ci}$ of Tc-99 (before distributing the generic entries). The explanation for the different inventories of this difficult-to-measure radionuclide is the same as that for C-14.

The CIDRA value for $\mathrm{Nb}-94$ is $0.2 \mathrm{Ci}$, almost all from TRA. RWMIS shows $0.04 \mathrm{Ci}$. The explanation for the different inventories of this difficult-to-measure radionuclide is the same as that for C-14.

Among the principal activation products, the CIDRA inventory is substantially less than that in RWMIS only for Co-58 and Mn-54 (other than the erroneous RWMIS entry for W-187). Both of these radionuclides have half-lives of less than 1 year. Thus, for the principal activation products and for the activation products as a whole, the comparison against the data in RWMIS confirmed that the CIDRA inventory of activation products is substantially complete.

Actinides-The activity of actinides in the inventory for the recent period (1984-1993) is much smaller than that in the inventory for the historical period (1952-1983). The reason is that waste from RFP, which contained large quantities of actinides, was not disposed of at the SDA during the recent period.

For the eight actinides that constitute nearly all of this type of activity, the CIDRA and RWMIS values are compared below. The total activity of these eight principal actinides in CIDRA is much greater than the corresponding total in RWMIS (approximately $59 \mathrm{Ci}$ versus $17 \mathrm{Ci}$ ). These total activities are not particularly large, however.

The sizes of the differences and the reasons for the differences are discussed below.

- Pu-241. The CIDRA value is 340 times the RWMIS value, although neither value is large $(34 \mathrm{Ci}$ versus $0.1 \mathrm{Ci}$ ). Nearly all of the Pu-241 in CIDRA is from TRA. The reason for the difference is that the Pu-241 from TRA was estimated using the nuclear physics calculation methods described in Section 2.5.2. The shipping records seldom report the Pu-241 that may be present in small activities, because of the difficulty in measuring it.

- Th-228. The CIDRA value matches that of RWMIS. Nearly all of the Th-228 is from ANL-E.

- Am-241. The CIDRA value is approximately 10 times the RWMIS value, although neither value is large $(4 \mathrm{Ci}$ versus $0.39 \mathrm{Ci}$ ). Nearly all of the Am-241 is from TRA. The reason for the difference is the same as that discussed under Pu-241. 
- U-234. The CIDRA value is approximately 230 times the RWMIS value, although neither value is large ( $3.5 \mathrm{Ci}$ versus $0.015 \mathrm{Ci}$ ). The U-234 in CIDRA is from several generators. The reason for the difference is that the RPDT data gatherers used nuclear physics calculations to ascribe U-234 to any substantial entries for U-235 and U-238. The amount of attributed U-234 depends on the quantity of uranium and the degree of enrichment, as described in Section 3.1. In the shipping records that provided the data for RWMIS, U-234 was seldom listed for shipments of uranium.

- Pu-239. The CIDRA value is approximately 9 times the RWMIS value, although neither value is large (2.6 Ci versus $0.3 \mathrm{Ci}$ ). Most of the Pu-239 in CIDRA is from ANL-W.

- U-232. The CIDRA value matches that of RWMIS. All of the U-232 is from ANL-E.

- U-238. The CIDRA value of $1.6 \mathrm{Ci}$ is about $70 \%$ of the RWMIS value of $2.3 \mathrm{Ci}$. Both the CIDRA value and the RWMIS value include approximately $1.0 \mathrm{Ci}$ from the SMC facility at TAN, the largest generator of the U-238.

The next largest generator of the U-238 is ANL-E. This is the primary source of the different values for U-238. For ANL-E, RWMIS lists $0.75 \mathrm{Ci}$ of U-238, as well as $0.00073 \mathrm{Ci}$ of U-234 and $0.0048 \mathrm{Ci}$ of U-235, for a total of $0.756 \mathrm{Ci}$ of uranium. For ANL-E, CIDRA lists $0.11 \mathrm{Ci}$ of U-238, as well as $0.71 \mathrm{Ci}$ of U-234 and $0.030 \mathrm{Ci}$ of U-235, for a total of $0.85 \mathrm{Ci}$ of uranium. The RPDT data gatherer for the ANL-E waste reviewed the RWMIS printouts. It was concluded that the distribution of uranium radionuclides in RWMIS was not representative of the enrichment of uranium that would be expected in waste from ANL-E activities. The ratio of U-234 activity to U-238 activity in RWMIS was $0.00073 / 0.75=0.001$ and did not correspond to any possible enrichment of uranium. [The values of the U-234/U-238 activity ratio should range from approximately 0.32 for depleted uranium to 100 or more for the most highly enriched uranium (Rich et al. 1988, EG\&G Idaho 1985)]. The data gatherer determined to adjust the uranium radionuclide distribution. It was assumed that the uranium in the principal ANL-E waste stream resulted from research on the nuclear fuel for EBR-II, the ANL-W-operated reactor for which ANL-E provides technical support. A common enrichment for the uranium in EBR-II fuel is $50 \%$ U-235 by mass. For such an enrichment, the activity breakdown is approximately $95 \% \mathrm{U}-234,4 \%$ U-235, and 1\% U-238 (Rich et al. 1988, EG\&G Idaho 1985). Thus, an appropriate value for the activity ratio of U-234/U -238 would be in the neighborhood of 95 , not 0.001 . The RPDT data gatherer adjusted the relative activities of uranium radionuclides in the principal uranium-bearing stream, ANL-317-2R, in CIDRA, accordingly. The total amount of uranium was maintained essentially constant. (Other ANL-E streams contained smaller quantities of uranium and were not moditied in the described manner, so the final CIDRA activity ratio does not equal 95.) The net result of this improved estimating process was to change much of the U-238 activity reported in RWMIS to U-234 activity, as entered in CIDRA. Thus, although the activity of U-238 from ANL-E in CIDRA is less than that in RWMIS, the activity of U-234 in CIDRA is correspondingly greater than that in RWMIS. (Also, see the discussion under U-234.) 
- Ra-226. The CIDRA value is approximately $8 \%$ less than the RWMIS value. The difference is less than the total random error for estimating the radioactivity in an individual waste shipment. All of the Ra-226 is from ANL-E.

The only principal actinide in the CIDRA inventory whose activity is substantially less than that in RWMIS is U-238. That difference resulted from the improved method for estimating the distribution of the uranium radionuclides. Thus, the comparison against the data in RWMIS confirmed that the CIDRA inventory of actinides is substantially complete.

Total Inventory-The total activity in CIDRA (without the G-M corrections) is 2.8 million $\mathrm{Ci}$; the total inventory in RWMIS is also 2.8 million $\mathrm{Ci}$. The two totals agree to within the precision used in this study (two significant figures).

Conclusion-For the principal, longer-lived radionuclides (i.e., half-lives beyond 1 or 2 years) in each segment of the inventory-fission products, activation products, and actinides-the activity in CIDRA is similar to or larger than that in RWMIS. In addition, the total inventories over all radionuclides agree to within the precision used in this study. Therefore, the results of these comparisons of CIDRA values (without the G-M correction) against RWMIS values (with the generic activity terms distributed) confirm that the current task has not overlooked any substantial radioactivity in the waste.

\subsubsection{Comparisons of Results After Applying CIDRA Corrections for G-M Counter} Survey Data. The third and fifth columns of Table 6-3 enable comparisons of CIDRA and RWMIS results, including the effect of the corrected data from G-M counter surveys. Because of the corrections made to some of the values taken from the records, this comparison is less useful than the preceding one in identifying possible oversights in CIDRA. However, the comparison is useful to show the overall change in contaminant inventory. The following paragraphs discuss the impacts of the corrections, in reference to the comparisons against RWMIS.

The effect of the correction to the data derived from G-M counter surveys is to reduce the activities of certain radionuclides in the CIDRA inventory. This reduction arises in the following way. For individual waste streams, the reduction ranges from no change to a factor of 2 . If the uncertainty in contaminant quantity was specified by the data gatherer, based on consideration of how the estimates or measurements were made originally, the G-M correction is not applied. If no uncertainty was specified (because the standard G-M counter method was believed to have been used), all activities in the waste stream were divided by two.

If all waste streams contributing to the inventory of a given radionuclide were subject to the factor of 2 reduction, then the total inventory of that radionuclide (last column of Table 6-3) reflects a reduction by a factor of 2 , compared with the entry in the preceding column. For example, such is the case for Pr-144. On the other hand, if none of the contributory streams were subject to the correction, then the entries in the last two columns are identical. For example, the H-3 comes almost entirely from TRA waste streams, in which a nuclear physicsbased calculational method was used rather than the G-M counter survey method. The entries for $\mathrm{H}-3$ in the last two columns are, therefore, identical. For some radionuclides, the amount of the correction falls between these two extremes. 
For radionuclides not affected by the G-M counter correction, such as $\mathrm{H}-3$, the discussion in the previous comparison against RWMIS still applies. For radionuclides strongly affected by the correction, the CIDRA quantity is reduced by as much as a factor of 2 , and the comparison against RWMIS is similarly affected. Only a few of the principal radionuclides are so affected.

Applying the G-M counter correction does not reduce the total activity in CIDRA substantially. To the precision of the two significant figures, the total is unchanged at 2.8 million $\mathrm{Ci}$.

\subsubsection{Comparisons at the Level of Individual Generators, Summed Over All Radionuclides}

6.2.3.1 Approach. The RWMIS shipping record rollups were used for the comparisons at the level of individual generators. The methods used were basically the same as those described in Section 6.2.2. The principal difference is that the total radioactivity in the waste from each major generator in 1984-1993 is given.

Again, it is stressed that the comparisons presented here are for the purpose of confirming the general completeness of CIDRA. The comparisons are not intended to drive the totals from CIDRA to match those in RWMIS because CIDRA contains significantly improved information that is not found in RWMIS.

6.2.3.2 Comparisons. Table $6-4$ provides the results of these comparisons. For confirming the completeness of CIDRA and for understanding the nature of the data-gathering process, the column containing the CIDRA reported estimates (no G-M correction) is compared with the RWMIS column to the left of it. The last column is shown only for perspective. The comparisons are discussed in terms of approximate numbers because of rounding all totals to two significant figures.

- TAN. The CIDRA value of $4,400 \mathrm{Ci}$ for the total radioactivity in TAN waste is slightly larger than the RWMIS value of $3,700 \mathrm{Ci}$. The difference is due to (a) including about $300 \mathrm{Ci}$ in waste from LOFT (later termed the Containment Test Facility) with TAN in CIDRA, but separately in RWMIS, and (b) the fact that CIDRA includes about $460 \mathrm{Ci}$ of Sr-90 that was not reported in RWMIS because it is difficult to measure.

- TRA. The CIDRA value of $330,000 \mathrm{Ci}$ for the total radioactivity in TRA waste is slightly larger than the RWMIS value of $320,000 \mathrm{Ci}$. The difference is probably due to the fact that some of the scaling factors used for TRA waste in the RPDT total more than unity (see Section 2.5.2). Such scaling factors include those for radionuclides whose radiation was not detected by the G-M counter.

- ICPP. The CIDRA value of $1,300 \mathrm{Ci}$ is slightly smaller than the RWMIS value of $1,400 \mathrm{Ci}$. The difference of about $7 \%$ is considered to be within the uncertainty of the inventory approaches used. 
Table 6-4. Radioactivity totals by generator as given by RWMIS shipping record rollups, and by CIDRA (with and without Geiger-Müller counter corrections): 1984-1993.

\begin{tabular}{|c|c|c|c|}
\hline $\begin{array}{l}\text { Major } \\
\text { generator }\end{array}$ & $\begin{array}{l}\text { RWMIS } \\
\text { shipping } \\
\text { record rollups } \\
\text { (Ci) }\end{array}$ & $\begin{array}{l}\text { CIDRA reported } \\
\text { estimates (no } \\
\text { G-M corrections) } \\
\text { (Ci) }\end{array}$ & $\begin{array}{c}\text { CIDRA } \\
\text { best estimate } \\
\text { (with } \mathrm{G}-\mathrm{M} \text { corrections) } \\
(\mathrm{Ci})\end{array}$ \\
\hline TAN & $3.7 E+03$ & $4.4 \mathrm{E}+03$ & $2.2 \mathrm{E}+03$ \\
\hline TRA & $3.2 E+05$ & $3.3 E+05$ & $3.2 E+05$ \\
\hline ICPP & $1.4 \mathrm{E}+03$ & $1.3 E+03$ & $6.7 E+02$ \\
\hline NRF & $9.7 \mathrm{E}+05$ & $9.7 E+05$ & $9.7 E+05$ \\
\hline ANL-W & $1.5 E+06$ & $1.5 E+06$ & $1.5 E+06$ \\
\hline Other & $3.9 \mathrm{E}+03$ & $3.6 \mathrm{E}+03$ & $3.2 \mathrm{E}+03$ \\
\hline Total & $2.8 E+06$ & $2.8 E+06$ & $2.8 \mathrm{E}+06$ \\
\hline
\end{tabular}

- NRF. The CIDRA value of $970,000 \mathrm{Ci}$ matches the RWMIS value.

- ANL-W. The CIDRA value of 1.5 million $\mathrm{Ci}$ matches the RWMIS value.

- Other. The CIDRA value of $3,600 \mathrm{Ci}$ for the total radioactivity in waste from the other generators is slightly smaller than the value of $3,900 \mathrm{Ci}$ in RWMIS. The difference is explained by the fact that the RPDT included the approximately $300 \mathrm{Ci}$ in the waste from LOFT with TAN, rather than with the other generators. This fact also helps explain why the CIDRA activity for TAN (including the $300 \mathrm{Ci}$ from LOFT) is higher than that in RWMIS.

In summary, the generator-by-generator comparisons indicate that CIDRA values match the corresponding RWMIS values if the data uncertainties and the particular organization of the data by major generator are considered.

\subsection{Comparison of the Inventory with Contaminants Detected in Environmental Monitoring}

\subsubsection{Purpose}

It is useful to compare the estimated inventory of contaminants in CIDRA with the list of contaminants whose presence is detected at the RWMC by means of environmental monitoring. Potential gaps in the inventory may thereby be identified.

The following sections include (a) the approach used here to analyze contaminant monitoring results; (b) a summary of routine environmental monitoring activities and of special studies not part of the routine monitoring; (c) a brief summary of the monitoring results in terms of contaminants detected, years, and environmental media; and (d) comparisons of contaminants 
detected against the contaminant inventory in CIDRA for the historical and recent periods. (Because the environmental monitoring may detect contaminants disposed of during either the historical or the recent period, the comparison was performed simultaneously for the inventory of both periods.) The documents from which the monitoring summaries were produced are listed in the bibliography in Appendix F.

\subsubsection{Approach}

Pertinent monitoring data for the RWMC were obtained from two primary sources: (a) annual summary reports for routine monitoring and (b) documentation for special environmental studies. Routine monitoring results for the Environmental Monitoring Program have been summarized annually since 1976 . Concentrations are measured for radiological and nonradiological contaminants in air, soil, water, geologic media, and biotic media. These data were examined and summarized for the years 1976 through 1993. Existing databases and documents were consulted to identify special studies conducted on the SDA that resulted in reported environmental concentrations for radiological or nonradiological contaminants. Routine monitoring and special study results were evaluated by contaminant and medium and were summarized. The monitoring results were compared with the list of contaminants in the CIDRA inventory. The results of the comparison were interpreted with respect to the completeness of the list of contaminants in the inventory.

\subsubsection{Environmental Monitoring Program}

A comprehensive monitoring program is conducted at the RWMC and other areas of the INEL. The program provides for routine monitoring and data interpretation of radioactive and nonradioactive contaminants in the environment associated with the RWMC/SDA (Wilhelmsen et al. 1994).

Routine monitoring activities conducted as part of the program for the RWMC/SDA are summarized in Table 6-5. The program includes measurement of the concentrations of radioactive contaminants in air, water, soil, and biota (vegetation and small mammals), as well as monitoring of ambient radiation (Wilhelmsen et al. 1994). Monitoring conducted by RESL and groundwater monitoring activities conducted by the U.S. Geological Survey (USGS) are incorporated into the program and included in the annual summary reports. Nonradiological contaminants-metals and organics in liquid effluents and drinking water-are also assessed.

\subsubsection{Special Studies}

A number of special or one-time environmental studies for radiological and nonradiological contaminants have been performed at the RWMC/SDA. Data collected as part of the RWMC Subsurface Investigations Program, USGS studies, and other contaminant investigative studies were reviewed and summarized. Investigations included subsurface drilling, soil vapor monitoring, and groundwater monitoring. Data from the studies included in this task date back as far as the mid-1970s. 
Table 6-5. Routine environmental monitoring activities performed at the Subsurface Disposal Area (compiled from Wilhelmsen et al. 1994).

\begin{tabular}{|c|c|c|c|c|}
\hline Activity & Facility & Description & Frequency of analysis & Type of analysis \\
\hline \multicolumn{5}{|c|}{ RADIOLOGICAL CONTAMINAN'IS } \\
\hline Ambient air monitoring & SDA & $\begin{array}{l}\text { Eight low-volume air samples operated at } 0.14 \mathrm{~m}^{3} / \mathrm{min} \\
\text { (includes one control and one replicate) }\end{array}$ & $\begin{array}{l}\text { Semimonthly } \\
\text { Semimonthly } \\
\text { Monthly } \\
\text { Quarterly }\end{array}$ & $\begin{array}{l}\text { Gross alpha } \\
\text { Gross beta } \\
\text { Gamma spectrometry } \\
\text { Radiochemistrya }\end{array}$ \\
\hline Soil sampling & $\mathrm{SDA}$ & $\begin{array}{l}\text { Five locations in each of five major areas (plus one } \\
\text { control area) }\end{array}$ & Triennially & $\begin{array}{l}\text { Gamma spectrometry } \\
\text { Radiochemistrya }\end{array}$ \\
\hline $\begin{array}{l}\text { Subsurface water (sampled } \\
\text { by the USGS) }\end{array}$ & SDA & $\begin{array}{l}\text { 2-L samples from each of six wells (five wells to the } \\
\text { aquifer, one well to perched water) }\end{array}$ & $\begin{array}{l}65-\mathrm{m} \text { (perched water) well annually } \\
183-\mathrm{m} \text { (aquifer) wells quarterly } \\
\text { Production well quarterly }\end{array}$ & $\begin{array}{l}\text { Gamma spectroscopy, } \\
\text { chlorides (i.e., Cl-35), } \\
\mathrm{H}-3, \mathrm{Sr}-90, \mathrm{Co}-60, \mathrm{Cs}-137, \\
\mathrm{Pu}-238, \mathrm{Pu}-239 / 240 \text {, and } \\
\mathrm{Am}-241\end{array}$ \\
\hline Surface water sampling & SDA & $\begin{array}{l}\text { 4-L surface runoff samples from SDA and control } \\
\text { location }\end{array}$ & $\begin{array}{l}\text { Quarterly, but depends on } \\
\text { precipitation }\end{array}$ & $\begin{array}{l}\text { Gross alpha } \\
\text { Gross beta } \\
\text { Gamma spectrometry } \\
\text { Radiochemistry,b,c }\end{array}$ \\
\hline \multirow[t]{3}{*}{ Biotic surveillance } & SDA and TSA & $\begin{array}{l}\text { Small mammals-lliree composites in each of five major } \\
\text { areas (plus one control area) }\end{array}$ & $\begin{array}{l}\text { Annually, but species sampled varies } \\
\text { each year depending on availability }\end{array}$ & $\begin{array}{l}\text { Gamma spectrometry } \\
\text { Radiochemistrya }\end{array}$ \\
\hline & & $\begin{array}{l}\text { Vegetation-three composites in each of five major areas } \\
\text { (plus one control area) }\end{array}$ & $\begin{array}{l}\text { Annually, but species sampled varies } \\
\text { each year depending on availability }\end{array}$ & $\begin{array}{l}\text { Gamma spectrometry } \\
\text { Radiochemistry }\end{array}$ \\
\hline & & $\begin{array}{l}\text { Small mammal burrow excavations (soil)-three } \\
\text { composites from each of five major areas }\end{array}$ & Annually & $\begin{array}{l}\text { Gamma spectrometry } \\
\text { Radiochemistrya }\end{array}$ \\
\hline \multicolumn{5}{|c|}{ NONRADIOLOGICAL CONTAMINANIS } \\
\hline $\begin{array}{l}\text { Subsurface water (sampled } \\
\text { by the USGS) }\end{array}$ & & Drinking water & Production well monthly & $\begin{array}{l}\text { Organics } \\
\text { Specific conductance } \\
\text { Chloride, sodium, nitrate }\end{array}$ \\
\hline \multicolumn{5}{|c|}{ a. Analysis for Am-24I, Pu-238, Pu-239/240, U-235, U-238, and Sr-90. } \\
\hline \multicolumn{5}{|c|}{ b. Samples for radiochemical analyses usually taken during second quarter only. } \\
\hline \multicolumn{5}{|c|}{ c. Exact number of samples may vary due to availability. } \\
\hline
\end{tabular}




\subsubsection{Summary of Monitoring Results}

The results of routine monitoring and special studies for radiological and nonradiological contaminants in the SDA are summarized in Appendix F.

\subsubsection{Comparison of Contaminants Detected in Monitoring Activities Against Contaminants Identified in the Waste Inventory}

Table 6-6 compares the results from environmental monitoring against the results of the inventory compilation for the historical and recent periods. The table lists the contaminants detected in routine monitoring or in special studies, the presence or nonpresence of each contaminant in the waste inventory, the media in which the contaminants were detected, the years in which they were detected, and brief conclusions concerning the comparisons (i.e., monitoring reliability and the qualitative amount of the contaminant in historical and recent periods). The table lists radiological contaminants first, followed by nonradiological contaminants.

6.3.6.1 Radiological Contaminants. No radiological contaminants that were reliably detected in the monitoring were missing from the waste inventory.

The following radiological contaminants were detected in reliable data from the monitoring and were identified in the waste inventory: Am-241, Co-60, Cs-134, Cs-137, H-3, Pu-238, $\mathrm{Pu}-239 / 240, \mathrm{Sb}-125, \mathrm{Sr}-90, \mathrm{U}-234, \mathrm{U}-235$, and U-238.

As stated previously, contaminants detected in monitoring at the SDA might not have migrated from the buried waste. This could be the case, for example, with contaminants that are detected only in the aquifer. As another example, U-234, U-235, and U-238 are detected from time to time at the SDA. However, these radionuclides also occur naturally. Only a carefully constructed set of control samples will discriminate as to the likely origin of these three detected radionuclides, between the naturally occurring source and the source within the buried waste. It is beyond the scope of this document to provide definitive determinations on the source of the contaminants detected in the monitoring. The purpose of the present comparison is a simple check to help ensure that the inventory has not omitted any contaminants whose possible presence in the buried waste is manifest by environmental monitoring data.

The following radiological contaminants were detected only in the years before improved routine monitoring began, about 1984 (as discussed in Appendix F, these detections are questionable): Ac-228, Ag-110, Ba-140, Ce-141, Ce-144, Cr-51, Eu-155, Fe-59, Hf-181, Hg-203, I-131, Mn-54, Nb-95, Pb-212, Ru-103, Ru-106, Sb-124, Sc-46, Ta-182, U-237, Y-91, Zn-65, and $\mathrm{Zr}-95$. There are no known, reliable monitoring data suggesting the migration of these contaminants at the SDA. This conclusion is not surprising because many of these contaminants have extremely low mobilities (being trapped in metal matrices), many have very short half-lives, and many are present in relatively small amounts.

The historical inventory contains a large activity of $\mathrm{Pu}-241$, and this radionuclide is not monitored. The reason is that $\mathrm{Pu}-241$, a beta-emitter, is less radiotoxic than the alpha-emitting 
Table 6-6. Comparison of results of environmental monitoring against results of the inventory compilation.

\begin{tabular}{|c|c|c|c|c|c|}
\hline Contaminant & $\begin{array}{l}\text { Contaminant } \\
\text { present in } \\
\text { inventory- } \\
\text { historical period } \\
\text { 1952-1983? }\end{array}$ & $\begin{array}{l}\text { Contaminant } \\
\text { present in } \\
\text { inventory- } \\
\text { recent period } \\
1984-1993 ?\end{array}$ & $\begin{array}{l}\text { Environmental media } \\
\text { in which detected }\end{array}$ & Years detected $b$ & Conclusion $\mathrm{c}, \mathrm{d}$ \\
\hline
\end{tabular}

\section{RADIOLOGICAL}

\begin{tabular}{|c|c|c|c|c|c|}
\hline Ac-228 & No & No & Aquifer & 1979 & $\begin{array}{l}\text { Not identified in waste for either period; monitoring } \\
\text { detections not reliable }\end{array}$ \\
\hline $\mathrm{Ag}-110$ & Yes & Yes & $\begin{array}{l}\text { Air } \\
\text { Surface water } \\
\text { Soil }\end{array}$ & $\begin{array}{l}1980 \\
1977 \\
1979,80\end{array}$ & $\begin{array}{l}\text { Minute quantities identified in waste for both time } \\
\text { periods; monitoring detections not reliable }\end{array}$ \\
\hline Am-241 & Yes & Yes & $\begin{array}{l}\text { Aquifer } \\
\text { Surface water } \\
\text { Subsurface soil } \\
\text { Surficial sediment } \\
\text { Soil } \\
\text { Biota-vegetation } \\
\text { Biota-roil } \\
\text { Biota-tissue } \\
\text { Air. }\end{array}$ & $\begin{array}{l}1976,81,82,84,87 \\
1977,83-85,90-93 \\
1975-77,85-88,89 \\
1989 \\
1977-81,84,86,88,91,92 \\
1984,86,87,90-93 \\
1984-86,90 \\
1987,89 \\
1978-81,84-93\end{array}$ & $\begin{array}{l}\text { Very large and minute quantities identified in waste for } \\
\text { historical period and for recent period, respectively; } \\
\text { detected frequently in monitoring program }\end{array}$ \\
\hline $\mathrm{Ba}-140$ & Yes & Yes & Air & 1980 & $\begin{array}{l}\text { Small and minute quantities identified in waste for } \\
\text { historical period and for recent period, respectively; } \\
\text { monitoring detections not reliable }\end{array}$ \\
\hline Ce-141 & Yes & Yes & $\begin{array}{l}\text { Aquifer } \\
\text { Surface water } \\
\text { Soil } \\
\text { Air }\end{array}$ & $\begin{array}{l}1983 \\
1977,81 \\
1979-81 \\
1978-81,83-84\end{array}$ & $\begin{array}{l}\text { Small and minute quantities identified in waste for } \\
\text { listorical period and for recent period, respectively; } \\
\text { monitoring detections not reliable }\end{array}$ \\
\hline Ce-144 & Yes & Yes & $\begin{array}{l}\text { Aquifer } \\
\text { Subsurface soil } \\
\text { Surface water } \\
\text { Soil } \\
\text { Air }\end{array}$ & $\begin{array}{l}1976,77,79 \\
1975-78 \\
1976,78,79,82 \\
1978-81 \\
1978-81,83-84\end{array}$ & $\begin{array}{l}\text { Very large and moderate quantities identified in waste for } \\
\text { historical period and for recent period, respectively; } \\
\text { monitoring detections not reliable }\end{array}$ \\
\hline
\end{tabular}


Table 6-6. (continued).

\begin{tabular}{|c|c|c|c|c|c|}
\hline Contaminant & $\begin{array}{c}\text { Contaminant } \\
\text { present in } \\
\text { inventory- } \\
\text { historical period } \\
\text { 1952-1983? }\end{array}$ & $\begin{array}{l}\text { Contaminant } \\
\text { present in } \\
\text { inventory- } \\
\text { recent period } \\
1984-1993 ?\end{array}$ & $\begin{array}{l}\text { Environmental media } \\
\text { in which detected }\end{array}$ & Years detected $\mathbf{b}$ & Conclusion $^{\mathrm{c}, \mathrm{d}}$ \\
\hline Co-58 & Yes & Yes & $\begin{array}{l}\text { Soil } \\
\text { Air }\end{array}$ & $\begin{array}{l}1978-81 \\
1978-81,83,85\end{array}$ & $\begin{array}{l}\text { Very large quantities identified in waste for both time } \\
\text { periods; most monitoring detections not reliable }\end{array}$ \\
\hline $\mathrm{Co}-60$ & Yes & Yes & $\begin{array}{l}\text { Aquifer } \\
\text { Perclied water } \\
\text { Subsurface soil } \\
\text { Surface water } \\
\text { Surficial sediment } \\
\text { Soil } \\
\text { Biota-vegetation } \\
\text { Biota-soil } \\
\text { Biota-tissue } \\
\text { Air }\end{array}$ & $\begin{array}{l}1980,87 \\
1976-77 \\
1976-88,89 \\
1977 \\
1989 \\
1977-81,86 \\
1983 \\
1984 \\
1987,91 \\
1978-81,83,86\end{array}$ & $\begin{array}{l}\text { Very large quantities identified in waste for both time } \\
\text { periods; detected frequently in monitoring program }\end{array}$ \\
\hline $\mathrm{Cr}-51$ & Yes & Yes & $\begin{array}{l}\text { Surface water } \\
\text { Soil } \\
\text { Air }\end{array}$ & $\begin{array}{l}1977 \\
1978-81 \\
1978-81,83\end{array}$ & $\begin{array}{l}\text { Very large and large quantities identified in waste for } \\
\text { historical and recent periods, respectively; monitoring } \\
\text { detections not reliable }\end{array}$ \\
\hline Cs-134 & Yes & Yes & $\begin{array}{l}\text { Surface water } \\
\text { Soil } \\
\text { Biota-vegetation } \\
\text { Air }\end{array}$ & $\begin{array}{l}1977,79,81 \\
1978-81 \\
1987 \\
1978-81,85\end{array}$ & $\begin{array}{l}\text { Moderate and small quantities identified in waste for } \\
\text { historical and recent periods, respectively; detected } \\
\text { occasionally in monitoring program }\end{array}$ \\
\hline Cs-137 & Yes & Yes & $\begin{array}{l}\text { Aquifer } \\
\text { Perched water } \\
\text { Subsurface soil } \\
\text { Surface water } \\
\text { Surficial sediment } \\
\text { Soil } \\
\text { Biota-vegetation } \\
\text { Biota-soil } \\
\text { Biota-tissue } \\
\text { Air }\end{array}$ & $\begin{array}{l}1976,77,80,86,87 \\
1976,77,88 \\
1975-88,89 \\
1976,77,79-81,83-86, \\
88,90,93 \\
1989 \\
1977-81,84,88,89,92 \\
1978,83,84,87 \\
1984,86,90 \\
1987,91,92 \\
1978-81,84-85,87,91\end{array}$ & $\begin{array}{l}\text { Very large and moderate quantities identified in waste for } \\
\text { historical and recent periods, respectively; detected } \\
\text { frequently in monitoring program }\end{array}$ \\
\hline
\end{tabular}


Table 6-6. (continued).

\begin{tabular}{|c|c|c|c|c|c|}
\hline Contaminant & $\begin{array}{l}\text { Contaminant } \\
\text { present in } \\
\text { inventory- } \\
\text { historical period } \\
\text { 1952-1983? }\end{array}$ & $\begin{array}{l}\text { Contaminant } \\
\text { present in } \\
\text { inventory- } \\
\text { recent period } \\
1984-1993 ?\end{array}$ & $\begin{array}{l}\text { Environmental media } \\
\text { in which detected }\end{array}$ & Years detected ${ }^{b}$ & Conclusion $\mathrm{c}, \mathrm{d}$ \\
\hline Eu-152 & Yes & Yes & $\begin{array}{l}\text { Surface water } \\
\text { Soil } \\
\text { Biota-tissue } \\
\text { Air }\end{array}$ & $\begin{array}{l}1976,78-79 \\
1978-81 \\
1987 \\
1978-81\end{array}$ & $\begin{array}{l}\text { Small and minute quantities identified in waste for } \\
\text { historical and recent periods, respectively; most } \\
\text { monitoring detections not reliable }\end{array}$ \\
\hline Eu-154 & Yes & Yes & $\begin{array}{l}\text { Subsurface soil } \\
\text { Surface water } \\
\text { Soil } \\
\text { Biota-tissue } \\
\text { Air }\end{array}$ & $\begin{array}{l}1985 \\
1976,79 \\
1978-81,89 \\
1987 \\
1978-81\end{array}$ & $\begin{array}{l}\text { Moderate and minute quantities identified in waste for } \\
\text { historical and recent periods, respectively; most } \\
\text { monitoring detections not reliable }\end{array}$ \\
\hline Eu-155 & Yes & Yes & $\begin{array}{l}\text { Soil } \\
\text { Air }\end{array}$ & $\begin{array}{l}1981 \\
1981\end{array}$ & $\begin{array}{l}\text { Large and minute quantities identified in waste for } \\
\text { historical and recent periods, respectively; monitoring } \\
\text { detections not reliable }\end{array}$ \\
\hline $\mathrm{Fe}-59$ & Yes & Yes & $\begin{array}{l}\text { Aquifer } \\
\text { Soil } \\
\text { Air }\end{array}$ & $\begin{array}{l}1976 \\
1979-81 \\
1978-81\end{array}$ & $\begin{array}{l}\text { Large quantities identified in waste for both time periods; } \\
\text { monitoring detections not reliable }\end{array}$ \\
\hline $\mathrm{H}-3$ & Yes & Yes & $\begin{array}{l}\text { Aquifer } \\
\text { Perched water }\end{array}$ & $\begin{array}{l}1977-93 \\
1976-77,92,93\end{array}$ & $\begin{array}{l}\text { Very large quantities identified in waste for both time } \\
\text { periods; detected frequently in monitoring program }\end{array}$ \\
\hline Hf-181 & Yes & Yes & $\begin{array}{l}\text { Soil } \\
\text { Air }\end{array}$ & $\begin{array}{l}1978-81 \\
1978-81\end{array}$ & $\begin{array}{l}\text { Minute and moderate quantities identified in waste for } \\
\text { historical and recent periods, respectively; monitoring } \\
\text { detections not reliable }\end{array}$ \\
\hline $\mathrm{Hg}-203$ & Yes & No & $\begin{array}{l}\text { Soil } \\
\text { Air }\end{array}$ & $\begin{array}{l}1980-81 \\
1978-81\end{array}$ & $\begin{array}{l}\text { Minute and no quantities identified in waste for historical } \\
\text { period and recent period, respectively; monitoring } \\
\text { detections not reliable }\end{array}$ \\
\hline $\mathrm{I}-131$ & Yes & Yes & Air & 1980 & $\begin{array}{l}\text { Minute quantities identified in waste for botll time } \\
\text { periods; monitoring detections not reliable }\end{array}$ \\
\hline
\end{tabular}


Table 6-6. (continued).

\begin{tabular}{|c|c|c|c|c|c|}
\hline Contaminant & $\begin{array}{l}\text { Contaminant } \\
\text { present in } \\
\text { inventory- } \\
\text { historical period } \\
\text { 1952-1983? }\end{array}$ & $\begin{array}{l}\text { Contaminant } \\
\text { present in } \\
\text { inventory- } \\
\text { recent period } \\
\text { 1984-1993? }\end{array}$ & $\begin{array}{l}\text { Environmental media } \\
\text { in which detected }\end{array}$ & Years detected ${ }^{b}$ & Conclusion $c, d$ \\
\hline $\mathrm{Mn}-54$ & Yes & Yes & $\begin{array}{l}\text { Soil } \\
\text { Air }\end{array}$ & $\begin{array}{l}1979-81 \\
1978-81,83\end{array}$ & $\begin{array}{l}\text { Very large quantities identified in waste for both time } \\
\text { periods; monitoring detections not reliable }\end{array}$ \\
\hline $\mathrm{Nb}-95$ & Yes & Yes & $\begin{array}{l}\text { Surface water } \\
\text { Soil } \\
\text { Air }\end{array}$ & $\begin{array}{l}1977 \\
1978-81 \\
1978-81\end{array}$ & $\begin{array}{l}\text { Moderate quantities identified in waste for both time } \\
\text { periods; monitoring detections not reliable }\end{array}$ \\
\hline $\mathrm{Pb}-212$ & Yes & No & Aquifer & 1978 & $\begin{array}{l}\text { Minute and no quantities identified in waste for historical } \\
\text { period and recent period, respectively; monitoring } \\
\text { detections not reliable }\end{array}$ \\
\hline $\mathrm{Pu}-238$ & Yes & Yes & $\begin{array}{l}\text { Aquifer } \\
\text { Perched water } \\
\text { Subsurface soil } \\
\text { Surface water } \\
\text { Surficial sediment } \\
\text { Soil } \\
\text { Soil water } \\
\text { Biota-vegetation } \\
\text { Biota-tissue } \\
\text { Air }\end{array}$ & $\begin{array}{l}1981,83,87 \\
1976,77,89 \\
1975,89 \\
1983 \\
1989 \\
1979-81,88,89,91,92 \\
1989 \\
1984,86-87,90 \\
1987,89 \\
1980,86-88\end{array}$ & $\begin{array}{l}\text { Large and small quantities identified in waste for } \\
\text { listorical period and recent period, respectively; detected } \\
\text { frequently in monitoring program }\end{array}$ \\
\hline $\mathrm{Pu}-239 / 240$ & Yes & Yes & $\begin{array}{l}\text { Aquifer, perched } \\
\text { Subsurface soil } \\
\text { Surface water } \\
\text { Surficial sediment } \\
\text { Soil } \\
\text { Soil water } \\
\text { Biota-vegetation } \\
\text { Biota-soil } \\
\text { Biota-tissue } \\
\text { Air }\end{array}$ & $\begin{array}{l}1976,85-89 \\
1975-78,85-88,89 \\
1983-85 \\
1989 \\
1976-77,79-81,86,88,89, \\
91-93 \\
1989 \\
1986-87,90 \\
1984,86-90 \\
1987,89 \\
1980,84-88,90-93\end{array}$ & $\begin{array}{l}\text { Very large and small quantities identified in waste for } \\
\text { historical period and recent period, respectively; detected } \\
\text { frequently in monitoring program }\end{array}$ \\
\hline
\end{tabular}


Table 6-6. (continued).

\begin{tabular}{|c|c|c|c|c|c|}
\hline Contaminant & $\begin{array}{l}\text { Contaminant } \\
\text { present in } \\
\text { inventory- } \\
\text { historical period } \\
\text { 1952-1983? }\end{array}$ & $\begin{array}{l}\text { Contaminant } \\
\text { present in } \\
\text { inventory- } \\
\text { recent period } \\
1984-1993 ?\end{array}$ & $\begin{array}{l}\text { Environmental media } \\
\text { in which detected }\end{array}$ & Years detected ${ }^{b}$ & Conclusion $\mathrm{c}, \mathrm{d}$ \\
\hline $\mathrm{Ru}-103$ & Yes & Yes & $\begin{array}{l}\text { Surface water } \\
\text { Soil } \\
\text { Air }\end{array}$ & $\begin{array}{l}1977,81 \\
1978-81 \\
1978-80,83\end{array}$ & $\begin{array}{l}\text { Small and minute quantities identified in waste for the } \\
\text { historical and recent periods, respectively; monitoring } \\
\text { detections not reliable }\end{array}$ \\
\hline Ru-106 & Yes & Yes & $\begin{array}{l}\text { Surface water } \\
\text { Soil } \\
\text { Biota-vegetation } \\
\text { Air }\end{array}$ & $\begin{array}{l}1976-77,79 \\
1979,81 \\
1978 \\
1978-81\end{array}$ & $\begin{array}{l}\text { Moderate and small quantities identified in waste for the } \\
\text { historical and recent periods, respectively; monitoring } \\
\text { detections not reliable }\end{array}$ \\
\hline Sb-124 & Yes & Yes & $\begin{array}{l}\text { Soil } \\
\text { Air }\end{array}$ & $\begin{array}{l}1979-81 \\
1979-81\end{array}$ & $\begin{array}{l}\text { Moderate and minute quantities identified in waste for } \\
\text { the historical and recent periods, respectively; monitoring } \\
\text { detections not reliable }\end{array}$ \\
\hline Sb-125 & Yes & Yes & $\begin{array}{l}\text { Surface water } \\
\text { Soil } \\
\text { Biota-vegetation } \\
\text { Biota-tissue } \\
\text { Air }\end{array}$ & $\begin{array}{l}1978-81 \\
1978-81 \\
1987 \\
1987 \\
1978-81,84\end{array}$ & $\begin{array}{l}\text { Very large and moderate quantities identified in waste for } \\
\text { the historical and recent periods, respectively; detected } \\
\text { occasionally in monitoring program, but early detections } \\
\text { not reliable }\end{array}$ \\
\hline Sc- 46 & Yes & Yes & $\begin{array}{l}\text { Soil } \\
\text { Air }\end{array}$ & $\begin{array}{l}1979-81 \\
1978-81\end{array}$ & $\begin{array}{l}\text { Minute quantities identified in waste for both time } \\
\text { periods; monitoring detections not reliable }\end{array}$ \\
\hline Sr-90 & Yes & Yes & $\begin{array}{l}\text { Aquifer, perched } \\
\text { Subsurface soil } \\
\text { Surface water } \\
\text { Surficial sediment } \\
\text { Soil } \\
\text { Biota-vegetation } \\
\text { Biota-tissue } \\
\text { Biota-soil } \\
\text { Air }\end{array}$ & $\begin{array}{l}1976,78-80,85-88 \\
1975-88,89 \\
1987 \\
1989 \\
1988,91,92 \\
1983,84,86,87,90-93 \\
1987,89 \\
1984 \\
1986-88,93\end{array}$ & $\begin{array}{l}\text { Very large and small quantities identified in waste for the } \\
\text { historical and recent periods, respectively; detected } \\
\text { frequently in monitoring program }\end{array}$ \\
\hline
\end{tabular}


Table 6-6. (continued).

\begin{tabular}{|c|c|c|c|c|c|}
\hline Contaminant & $\begin{array}{l}\text { Contaminant } \\
\text { present in } \\
\text { inventory- } \\
\text { historical period } \\
\text { 1952-1983? }\end{array}$ & $\begin{array}{l}\text { Contaminant } \\
\text { present in } \\
\text { inventory- } \\
\text { recent period } \\
1984-1993 ?\end{array}$ & $\begin{array}{l}\text { Environmental media } \\
\text { in which detected }\end{array}$ & Years detected ${ }^{b}$ & Conclusion $^{c, d}$ \\
\hline Ta-182 & Yes & Yes & $\begin{array}{l}\text { Soil } \\
\text { Air }\end{array}$ & $\begin{array}{l}1979-81 \\
1979-81\end{array}$ & $\begin{array}{l}\text { Minute and large quantities identified in waste for the } \\
\text { historical and recent periods, respectively; monitoring } \\
\text { detections not reliable }\end{array}$ \\
\hline $\mathrm{U}-234$ & Yes & Yes & $\begin{array}{l}\text { Soil } \\
\text { Biota-vegetation } \\
\text { Biota-issue }\end{array}$ & $\begin{array}{l}1986,92 \\
1985,87 \\
1987\end{array}$ & $\begin{array}{l}\text { Small quantities identified in waste for botl time periods; } \\
\text { detected occasionally in monitoring program }\end{array}$ \\
\hline U-235 & Yes & Yes & $\begin{array}{l}\text { Soil } \\
\text { Biota-vegetation } \\
\text { Biota-tissue }\end{array}$ & $\begin{array}{l}1983 \\
1987 \\
1987,89\end{array}$ & $\begin{array}{l}\text { Small quantities identified in waste for both time periods; } \\
\text { detected rarely in monitoring program }\end{array}$ \\
\hline U-237 & No & No & Air & 1980 & $\begin{array}{l}\text { Not identified in waste for either time period; monitoring } \\
\text { detections not reliable }\end{array}$ \\
\hline U.238 & Yes & Yes & $\begin{array}{l}\text { Soil } \\
\text { Biota-vegetation } \\
\text { Biota-tissue }\end{array}$ & $\begin{array}{l}1983-84,92 \\
1987 \\
1987,89\end{array}$ & $\begin{array}{l}\text { Small quantities identified in waste for both time periods; } \\
\text { detected rarely in monitoring program }\end{array}$ \\
\hline$Y-91$ & Yes & No & $\begin{array}{l}\text { Soil } \\
\text { Air }\end{array}$ & $\begin{array}{l}1979-80 \\
1979-80\end{array}$ & $\begin{array}{l}\text { Minute and no quantities identified in waste for historical } \\
\text { period and recent period, respectively; monitoring } \\
\text { detections not reliable }\end{array}$ \\
\hline $\mathrm{Zn}-65$ & Yes & Yes & $\begin{array}{l}\text { Soil } \\
\text { Air }\end{array}$ & $\begin{array}{l}1979-81 \\
1978-81\end{array}$ & $\begin{array}{l}\text { Small and moderate quantities identified in waste for the } \\
\text { historical and recent periods, respectively; monitoring } \\
\text { detections not reliable }\end{array}$ \\
\hline $\mathrm{Zr}-95$ & Yes & Yes & $\begin{array}{l}\text { Soil } \\
\text { Air } \\
\text { Surface water }\end{array}$ & $\begin{array}{l}1979-81 \\
1978-81 \\
1977\end{array}$ & $\begin{array}{l}\text { Large and moderate quantities identified in waste for the } \\
\text { historical and recent periods, respectively; monitoring } \\
\text { detections not reliable }\end{array}$ \\
\hline
\end{tabular}


Table 6-6. (continued).

\begin{tabular}{|c|c|c|c|c|c|}
\hline Contaminant & $\begin{array}{l}\text { Contaminant } \\
\text { present in } \\
\text { inventory- } \\
\text { historical period } \\
\text { 1952-1983? }\end{array}$ & $\begin{array}{l}\text { Contaminant } \\
\text { present in } \\
\text { inventory- } \\
\text { recent period } \\
1984-1993 ?\end{array}$ & $\begin{array}{l}\text { Environmental media } \\
\text { in which detected }\end{array}$ & Years detected & Conclusion $^{\mathrm{c}, \mathrm{d}}$ \\
\hline
\end{tabular}

\section{NONRADIOLOGICAL}

\section{Organics $^{e}$}

\section{1,1,1-triclloroethane}

Yes

Yes

1,1,2-trichloro-

trifluoroethane

离 1,1-dichloroethylene

1,1-dichloroethane

Acetone

Carbon tetrachloride

Chloroform
No

No

Yes

Yes

Yes
No

Aquifer, perched
Soil borehole (vapor)
Soil/soil gas

Soil/soil gas

Air

No

Perched water

Borehole (vapor)

Soil/soil gas

Air

No

Aquifer, perched

Aquifer, perched

Sedimentary interbed

Air

Aquifer, perched

Borehole (vapor)

Soil/soil gas

Air

No
1987-93

1987-93

1987,88

1987

1991, 94

1987-90

$1987-88$

1987

1989

1987-93

1987

1994

1987-93

1987-88

1987, 92

1987,89
Aquifer, perched

Borehole (vapor) 1987-88, 92

Sedimentary interbed 1987

Air

1989, 94
Very large quantity identified in waste for the historical period; detected frequently in monitoring program

Large quantity in waste for the historical period; detected frequently in monitoring program

Not specifically identified in inventory; detected frequently in monitoring program

Not specifically identified in inventory; detected frequently in monitoring program

Large quantity identified in waste for the historical period; detected rarely in monitoring program

Very large quantity identified in waste for the historical period; detected frequently in monitoring program

Probable very large quantity identified in waste for the historical period; detected frequently in monitoring program 
Table 6-6. (continued).

\begin{tabular}{|c|c|c|c|c|c|}
\hline Contaminant & $\begin{array}{l}\text { Contaninant } \\
\text { present in } \\
\text { inventory- } \\
\text { historical period } \\
\text { 1952-1983? }\end{array}$ & $\begin{array}{l}\text { Contaminant } \\
\text { present in } \\
\text { inventory- } \\
\text { recent period } \\
1984-1993 ?\end{array}$ & $\begin{array}{l}\text { Environmental media } \\
\text { in which detected }\end{array}$ & Years detected ${ }^{b}$ & Conclusion $^{\mathrm{c}, \mathrm{d}}$ \\
\hline
\end{tabular}

Organics (continued)

Dicllorodifluoromethane

No

Methylene chloride

Yes

No

Phenol

Tetrachioroethylene

$\stackrel{1}{\omega}$

Toluene

Trichloroethylene

Yes

No

Aquifer, perched

Soil borchole (vapor)

Sedimentary interbed

Yes

No

Percled

Yes

Aquifer, perched

Sedimentary interbed

Perclied water

Aquifer

Aquifer, perched

Boreliole (vapor)

Soil/soil vapor

Ai

Aquifer, perched

Borehole (vapor)

Air

987-93

1994

1987

1993

1991, 94

1991

1987-93

1987,92

1987

1994

1987-93

1987,92

1994

1987,89

1987-93

1987,92

1987

Antimony

Arsenic
No
Aquifer, perched
1988,93

$1987-88,93$
Not specifically identified in inventory; detected frequently in monitoring program

Very large quantity in waste for the historical period; detected rarely in monitoring program

Not specifically identified in inventory; detected rarely in monitoring program

Very large quantity identified in waste for the historical period; detected frequently in monitoring program

Large quantity identified in waste for the historical period; detected frequently in monitoring program

Very large quantity identified in historical waste; detected frequently in monitoring program

Small quantity identified in waste for the historical period; detected rarely in monitoring program

Only minute quantity identified in waste for recent period; detected rarely in monitoring program 
Table 6-6. (continued).

\begin{tabular}{|c|c|c|c|c|c|}
\hline Contaminant & $\begin{array}{l}\text { Contaminant } \\
\text { present in } \\
\text { inventory- } \\
\text { historical period } \\
\text { 1952-1983? }\end{array}$ & $\begin{array}{l}\text { Contaminant } \\
\text { present in } \\
\text { inventory- } \\
\text { recent period } \\
1984-1993 ?\end{array}$ & $\begin{array}{l}\text { Environmental media } \\
\text { in which detected }\end{array}$ & Years delected & Conclusion $\mathrm{c}, \mathrm{d}$ \\
\hline
\end{tabular}

Metals (continued)

\begin{tabular}{|c|c|c|c|c|}
\hline Barium & No & No & $\begin{array}{l}\text { Perched water } \\
\text { Sedimentary interbed }\end{array}$ & $\begin{array}{l}1988,93 \\
1987\end{array}$ \\
\hline Beryllium & Yes & Yes & $\begin{array}{l}\text { Perched water } \\
\text { Subsurface soil } \\
\text { Sedimentary interbed }\end{array}$ & $\begin{array}{l}1988,93 \\
1991 \\
1987\end{array}$ \\
\hline Boron & No & No & Soil & 1982 \\
\hline Cadmium & Yes & Yes & $\begin{array}{l}\text { Perched water } \\
\text { Soil }\end{array}$ & $\begin{array}{l}1988,93 \\
1982\end{array}$ \\
\hline Chromium & Yes & Yes & $\begin{array}{l}\text { Surface water } \\
\text { Aquifer, perched } \\
\text { Soil } \\
\text { Sedimentary interbed }\end{array}$ & $\begin{array}{l}1986 \\
1985-88,93 \\
1982 \\
1987\end{array}$ \\
\hline Cobalt & No & No & Perclied water & 1988,93 \\
\hline Copper & Yes & Yes & $\begin{array}{l}\text { Perched water } \\
\text { Soil } \\
\text { Sedimentary interbed }\end{array}$ & $\begin{array}{l}1988,93 \\
1982 \\
1987\end{array}$ \\
\hline Lead & Yes & Yes & $\begin{array}{l}\text { Perched water } \\
\text { Soil }\end{array}$ & $\begin{array}{l}1988,93 \\
1982\end{array}$ \\
\hline Mercury & Yes & Yes & $\begin{array}{l}\text { Perched water } \\
\text { Subsurface soil } \\
\text { Sedimentary interbed } \\
\text { Soil vapor }\end{array}$ & $\begin{array}{l}1988,93 \\
1991^{\mathrm{f}} \\
1987 \\
1990\end{array}$ \\
\hline
\end{tabular}
Not identified in waste; detected rarely in monitoring
progran

Very large and large quantities in inventory for the historical and recent periods, respectively; detected occasionally

Not identified in inventory; not on lists of hazardous substances; detected rarely

Large and small quantities of waste identified in historical and recent period, respectively; detected rarely

Moderate and small quantities of waste identified in historical and recent period, respectively; detected occasionally

Not identified as a nonradiological contaminant in waste; detected rarely in monitoring program

Small and moderate quantities of waste identified in historical and recent period, respectively; detected occasionally

Very large quantities identified in inventory for both periods; detected rarely

Large and small quantities of waste identified in historical and recent period, respectively; detected occasionally in environmental monitoring; detected in direct sampling of the Acid Pit 
Table 6-6. (continued).

\begin{tabular}{|c|c|c|c|c|c|}
\hline Contaminant & $\begin{array}{l}\text { Contaminant } \\
\text { present in } \\
\text { inventory- } \\
\text { historical period } \\
\text { 1952-1983? }\end{array}$ & $\begin{array}{l}\text { Contaminant } \\
\text { present in } \\
\text { inventory- } \\
\text { recent period } \\
1984-1993 ?\end{array}$ & $\begin{array}{l}\text { Environmental media } \\
\text { in which detected }\end{array}$ & Years detected $b$ & Conclusion $\mathrm{c}, \mathrm{d}$ \\
\hline
\end{tabular}

Metals (continued)

\begin{tabular}{|c|c|c|c|c|}
\hline Nickel & Yes & No & $\begin{array}{l}\text { Perched water } \\
\text { Sedimentary interbed }\end{array}$ & $\begin{array}{l}1988,93 \\
1987\end{array}$ \\
\hline Selenium & No & No & $\begin{array}{l}\text { Sedimentary interbed } \\
\text { Subsurface water, } \\
\text { perched }\end{array}$ & $\begin{array}{l}1987 \\
1987,88 \\
1993\end{array}$ \\
\hline Silver & Yes & No & $\begin{array}{l}\text { Perched water } \\
\text { Sedimentary interbed }\end{array}$ & $\begin{array}{l}1988,93 \\
1987\end{array}$ \\
\hline Thallium & No & No & $\begin{array}{l}\text { Perclsed water } \\
\text { Sedimentary interbed }\end{array}$ & $\begin{array}{l}1988,93 \\
1987\end{array}$ \\
\hline Tin & No & No & $\begin{array}{l}\text { Perched water } \\
\text { Sedimentary interbed }\end{array}$ & $\begin{array}{l}1988 \\
1987\end{array}$ \\
\hline Vanadium & No & No & $\begin{array}{l}\text { Perched water } \\
\text { Sedimentary interbed }\end{array}$ & $\begin{array}{l}1988,93 \\
1987\end{array}$ \\
\hline Zinc & No & No & $\begin{array}{l}\text { Perched water } \\
\text { Soil } \\
\text { Sedimentary interbed }\end{array}$ & $\begin{array}{l}1988,93 \\
1982 \\
1987\end{array}$ \\
\hline
\end{tabular}
Moderate quantity identified in waste for historical
period; detected rarely in monitoring program

Not identified in waste; detected rarely in monitoring program

Moderate quantity identified in waste for historical period; detected rarely in monitoring program

Not identified in waste; detected rarely in monitoring program

Not identified as a nonradiological contaminant in waste; detected rarely in monitoring program

Not identified in waste; detected rarely in monitoring program

Identified in waste inventory only in radioactive form ( $<1$ g mass); detected rarely

Very large quantity identified in waste for historical period; detected frequently in monitoring program

Small quantity identified in waste for historical period; detected rarely in monitoring program 
Table 6-6. (continued).

\begin{tabular}{|c|c|c|c|c|c|}
\hline Contaminant & $\begin{array}{l}\text { Contaminant } \\
\text { present in } \\
\text { inventory- } \\
\text { historical period } \\
\text { 1952-1983? }\end{array}$ & $\begin{array}{l}\text { Contaminant } \\
\text { present in } \\
\text { inventory- } \\
\text { recent period } \\
1984-1993 ?\end{array}$ & $\begin{array}{l}\text { Environmental media } \\
\text { in whicl detected }\end{array}$ & Years detected & Conclusion $^{\mathrm{c}, \mathrm{d}}$ \\
\hline
\end{tabular}

Other (continued)

\begin{tabular}{|c|c|c|c|c|}
\hline Nitrate & Yes & No & $\begin{array}{l}\text { Aquifer, perched } \\
\text { Surface water } \\
\text { Soil }\end{array}$ & $\begin{array}{l}1982-83,85,87,93 \\
1980-82 \\
1980-83\end{array}$ \\
\hline Sodium ion & Yes & No & $\begin{array}{l}\text { Aquifer, perched } \\
\text { Surface water }\end{array}$ & $\begin{array}{l}1979,82-93 \\
1983-86\end{array}$ \\
\hline Sulfate & Yes & No & Perched water & $1985,88,93$ \\
\hline Sulfide & No & No & $\begin{array}{l}\text { Perched water } \\
\text { Sedimentary interbed }\end{array}$ & $\begin{array}{l}1988 \\
1987\end{array}$ \\
\hline
\end{tabular}
Very large quantity identified in waste for historical period; detected frequently in monitoring program
Very large quantity identified in waste for historical period; detected frequently in monitoring program
Very large quantity identified in waste for historical period; detected occasionally in monitoring program
Not identified in waste; detected rarely in monitoring program

a. Subsurface water includes samples from five wells that sample aquifer water and from one well that samples perched water. Separate entries are indicated where possible.

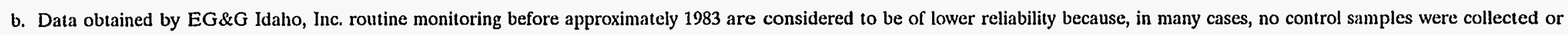

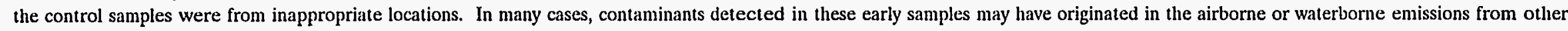
INEL facilities, rather than from the SDA.

c. The following scheme was used to express quantitative inventory values using a set of qualitative terms. The expression $E+03$, for example, covers entries between $E+03$ and $9.9 E+03$.

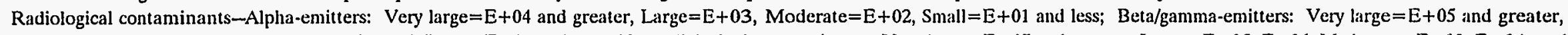

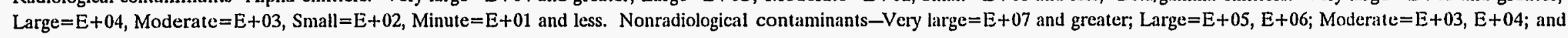
Small $=E+02$ and less.

d. The frequency of detection is expressed in a qualitative hierarchy of terms: frequently, occasionally, rarely. The determination of the appropriate term is based on technical judgment after considering (a) the number of years in which the contaminant was detected, and (b) the number of years in which the contaminant was monitored.

e. During 1984-1993, no organic contaminants were disposed of in the SDA.

f. It is also noted that mercury was sampled for in one SDA trench in 1990 but was not detected. Mercury was sampled for and detected in the Acid Pit. 
plutonium and americium radionuclides that are monitored ( $\mathrm{Pu}-238, \mathrm{Pu}-239 / 240$, and $\mathrm{Am}-241$ ). Pu-241 is more difficult to measure and is also much shorter-lived than the other radionuclides mentioned.

6.3.6.2 Nonradiological Contaminants. Routine monitoring for nonradiological contaminants at the RWMC began in the mid- to late 1980s. All of the data for nonradiological contaminants are considered sufficiently reliable for use in these comparisons.

Ten of the 13 organic contaminants that were detected in the monitoring are listed in the historical inventory. Those not specifically listed in the inventory are 1,1-dichloroethylene, 1,1-dichloroethane, and dichlorodifluoromethane. The detections were in both aquifer water and perched water. The detections were frequent. Any contaminants detected only in the aquifer could have originated at other upgradient INEL facilities. However, any contaminants detected in perched water could have originated in the buried waste.

Several possible explanations exist as to why some of the organic contaminants were detected in the monitoring but not identified specifically in either this inventory or other inventory reports. First, the waste information on which the inventory is based could simply be incomplete. Second, the contaminants could have been secondary species in a waste stream, wherein only the primary species were identified. Third, the contaminants detected in the monitoring could be degradation products originating from a contaminant that is listed in the inventory. These three organics are very similar in molecular structure to organic compounds that have been identified in the inventory in large quantities; 1,1-dichloroethylene is similar to trichloroethylene, 1,1-dichloroethane is similar to 1,1,1-trichloroethane, and dichlorodifluoromethane is similar to 1,1,2-trichloro-1,2,2trifluoroethane. Therefore, there is a strong possibility that these are impurities or degradation products of substances that are listed in the inventory. It is beyond the scope of this comparison to distinguish definitively among these possible explanations for the fact that three organics were detected in the monitoring but not identified specifically in the inventory. The conclusion is that nearly all of the organic contaminants detected in the monitoring were identified in the inventory for the historical period.

Among the metals, only beryllium, chromium, copper, and mercury have been detected more than rarely in the monitoring (i.e., more than once or twice). All of these metals were identified in the inventory, in quantities ranging from small to very large for both the historical and recent periods. Several other metals have been detected once or twice in the monitoring: cadmium, lead, zinc, antimony, arsenic, cobalt, barium, nickel, selenium, silver, thallium, tin, boron, and vanadium.

The measured concentrations approximate natural background levels in many cases. Some of these metals have been identified in the inventory for both the historical and recent periods. The conclusion is that the entire inventory includes all toxic metals that have been detected in the environment on more than rare occasions and at concentrations well above natural background.

The last class of nonradiological contaminants monitored is certain inorganic species. Sodium ion, chlorides, sulfates, and nitrates are detected occasionally to frequently by monitoring; they are listed in the inventory for the historical period in various forms and in very large quantities. Sulfides were detected once in the monitoring, but were not identified in the inventory for either time period. Again, these detected contaminants could have originated from naturally occurring 
sources or from the waste. Cyanide has been detected on two occasions and is identified in the inventory for the historical period in a small quantity.

6.3.6.3 Conclusions. No radiological contaminants that were reliably detected in the monitoring are missing from the waste inventory.

For the nonradiological contaminants, other than rare detections or detections at concentrations near natural background levels, no metals or other inorganics on the list of hazardous substances were detected in the environmental monitoring but not listed in the inventory for one of the two time periods. Ten of the 13 organic contaminants that were detected in the monitoring are listed in the inventory for the historical period. The other three organic contaminants may be degradation products or impurities of contaminants that were identified in the inventory for the historical period, or may have originated from other INEL sources.

\subsection{Contaminant Profile Data* Sheets}

The inventory is also presented in a simple yet informative form, called contaminant profile data sheets, see Appendix G. The data sheets provide a quick reference summary for most of the principal contaminants. Data sheets were prepared for contaminants that were among those present in the largest quantities. Appendix G of this report contains only the data sheet for C-14. All other data sheets are presented in the HDT report (EG\&G Idaho 1994).

Each data sheet briefly lists typical physical and chemical forms and properties of the contaminant, common uses, general presence in the environment, toxicology, and the results of environmental monitoring at the SDA. For radiological contaminants, the radiological properties and radiotoxicity are also included. 


\section{References for Section 6}

Cerven, F., 1987, Estimate of Hazardous Waste Constituents in the RWMC Subsurface Disposal Area, TWT-010-87, engineering design file, EG\&G Idaho, Inc., December 1987.

EG\&G Idaho, 1985, Solid Waste Management Information System (SWIMS) SWIMS Users Manual, EG\&G Idaho, Inc., April 1985.

EG\&G Idaho, 1994, A Comprehensive Inventory of Radiological and Nonradiological Contaminants in Waste Buried in the Subsurface Disposal Area of the INEL RWMC During the Years 1952-1983, EGG-WM-10903, EG\&G Idaho, Inc., June 1994.

EPRI, 1987, Updated Scaling Factors in Low Level Radwaste, EPRI NP-5077, Impell Corporation, March 1987.

Hitz, J. R., and R. L. Skinner, letter to K. A. Taylor, 1993, "Solid Radioactive Waste Forecast," RLS-018-93, Westinghouse Idaho Nuclear Company, Inc., November 15, 1993.

Nelson, J. H., 1984, letter to distribution, "Radioactive Mixed Waste," JHN-52-84, EG\&G Idaho, Inc., April 24, 1984.

Plansky, L. E., and S. A. Hoiland, 1992, Analysis of the Low-Level Waste Radionuclide Inventory of the Radioactive Waste Management Complex Performance Assessment, EGG-WM-9857, Revision 1, EG\&G Idaho, Inc., June 1992.

Randall, V. C., 1994, letter to J. A. Roche, "Transmittal of 1994 and 10-Year Radioactive Waste Forecasts," VCR-03-94, EG\&G Idaho, Inc., January 24, 1994.

Rich, B. L., S. L. Hinnefeld, C. R. Lagerquist, W. G. Mansfield, L. H. Munson, and E. R. Wagner, 1988, Health Physics Manual of Good Practices for Uranium Facilities, EGG-2530, EG\&G Idaho, Inc., June 1988.

Rodgers, A. D., 1985, letter to distribution, "Radioactive Waste Containing Lead," ADR-23-85, EG\&G Idaho, Inc., March 29, 1985.

Rodgers, A. D., 1986, letter to distribution, "Elimination of Lead from Low-Level Waste," ADR-53-86, EG\&G Idaho, Inc., June 24, 1986.

Rodgers, A. D., 1987, letter to distribution, "Use of Lead in Low-Level Waste Packages Schedule Exception," ADR-46-87, EG\&G Idaho, Inc., March 29, 1985.

Wells, J. D., 1986, letter to K. L. Falconer, "Hazardous Materials in the SDA," JDW-02-86, EG\&G Idaho, Inc., January 15, 1986. 
Wilhelmsen, R. N., K. C. Wright, and B. W. McBride, 1993, Environmental Surveilance for EG\&G Idaho Waste Management Facilities at the Idaho National Engineering Laboratory, EGG-2679(93), EG\&G Idaho, Inc., August 1994. 


\section{OBSERVATIONS AND CONCLUSIONS}

The observations and conclusions for the contaminants in the recent (1984-1993) and projected (1994-2003) waste are as follows:

- The combined use of many types of information sources-process knowledge, operating records, nuclear physics calculations, reports, interviews, shipping records, the RWMIS database, waste generator forecasts, and others-was essential to achieve the present degree of completeness of the recent and projected inventories.

- For nonradiological contaminants, the inventory information that could be located or deduced for the 1984-1993 and 1994-2003 periods from information sources and that is compiled in CIDRA is believed to be substantially complete.

- The number and quantities of nonradiological contaminants identified in or projected to be in the waste being disposed of in the SDA decreased dramatically after 1984. For most (but not all) of those nonradiological contaminants, the presence of the contaminant could cause the waste to be designated as hazardous per RCRA. Beginning in 1984, DOE was required to come into compliance with RCRA, so acceptance of mixed waste for disposal at the SDA was discontinued in April 1984. An exception was made for contaminated lead used as radiation shielding, which was allowed for disposal as late as December 31, 1987.

- For the radiological contaminants, the inventory information that could be located or deduced for the 1984-1993 and 1994-2003 periods from information sources and that is compiled in the new CIDRA database is believed to be substantially complete.

- A considerable effort was devoted to estimating the uncertainty in the quantities of nonradiological and radiological contaminants. For the projected waste, this effort included estimating the uncertainty in waste generator forecasts.

- A considerable effort was devoted to breaking down the generic radioactivity terms MAP, MFP, and unidentified beta/gamma-emitters for each generator so that a specific distribution of radionuclides would be available for the risk assessment.

- The predominant (by mass) nonradiological contaminants identified in the waste were as follows: for the 1984-1993 period-lead, beryllium, asbestos, copper, zirconium oxide, and chromium; for the 1994-2003 period-beryllium, asbestos, and chromium.

- The predominant (by radioactivity at the time of disposal) radiological contaminants identified in the waste were as follows: for the 1984-1993 period-Co-60, Ni-63, H-3, Co-58, Fe-55, Mn-54, Cr-51, Ta-182, and Fe-59; for the 1994-2003 period-H-3, Co-60, Co-58, Ni-63, Mn-54, Fe-55, and Cr-51.

- To confirm its substantial completeness, the compiled recent (1984-1993) inventory of radiological contaminants was compared against the corresponding inventory in the RWMIS database. The results of these comparisons confirm that the current task has 
not overlooked any substantial radioactivity in the waste. The total activity in CIDRA (without the G-M correction) agrees with the total inventory in RWMIS to within the accuracy allowed by the use of two significant figures. For all of the principal, longerlived radionuclides, the activity in CIDRA is similar to or larger than that in RWMIS.

- The total activities of the fission products differ between CIDRA and RWMIS by about $20 \%$. This difference is less than the total random error for estimating the radioactivity in an individual waste shipment.

- The CIDRA value agrees with the RWMIS entry for tritium (H-3) to within the study precision of two significant figures. The $\mathrm{H}-3$ is almost entirely in the beryllium reflectors from the TRA waste.

- The total activities of the activation products differ $<1 \%$ between CIDRA and RWMIS.

- The activities of C-14, Tc-99, and I-129 in CIDRA are considerably larger than those in RWMIS. These radionuclides are important because of their very long half-lives and their relatively high mobility if released from the waste form. These radionuclides are very difficult to measure in waste shipments. The values in CIDRA were developed by means of nuclear physics calculations.

- As an additional confirmation of its completeness, the compiled nonradiological inventory for the 1984-1993 period was compared against the information found in previous reports. Very few studies have been performed on the nonradiological contaminants buried in the SDA in the recent period. Therefore, the comparisons were of limited value but identified no evidence that the new inventory was incomplete.

- As an additional confirmation of its completeness, the compiled radiological inventory for the 1984-1993 period was compared against the information found in previous reports. Only one report contained data for the recent period. Because the data were nearly identical to those in the RWMIS database, no detailed comparison was carried out.

- The compiled radiological inventory for the projected period (1994-2003) was compared to the waste generator forecasts. Because the waste generator forecasts . were the starting point for evaluating the projected waste, the close agreement with reported estimates in CIDRA is not surprising. As expected and consistent with the assumptions, the best-estimate CIDRA values (after the bias corrections and other refinements are applied) differ substantially from the generator forecasts.

- As a final confirmation of its substantial completeness, the recent inventory (1984-1993) of contaminants was compared against the list of contaminants detected in environmental monitoring at the RWMC. The historical inventory (1952-1983) was also included in the comparison. No radiological contaminants were reliably detected in the monitoring that had not been identified in either the historical or the recent inventories. The only nonradiological contaminants detected more than rarely in the 
environmental monitoring that were not identified in the inventories were three volatile organic compounds: 1,1-dichloroethylene, 1,1-dichloroethane, and

dichlorodifluoromethane. These three contaminants may be degradation products or impurities associated with closely related contaminants that were identified in the historical inventory. Detected contaminants also could have originated from sources other than the subject waste (e.g., in effluents from other INEL facilities or from other waste at the RWMC).

- A large quantity of information was assembled and entered into CIDRA on the physical and chemical forms of the waste streams and of the contaminants, and on the packaging of the waste streams.

- Even though the information now residing in CIDRA has been through multiple checks and reviews, the possibility exists for oversights and discrepancies. In addition, new information about the waste is identified from time to time in other INEL programs. As new information is discovered, the database will be revised as necessary. 


\section{References for Section 7}

Wells, J. D., 1986, letter to K. L. Falconer, "Hazardous Materials in the SDA," JDW-02-86, EG\&G Idaho, Inc., January 15, 1986. 
Appendix A

\section{Data Collection Forms}


A-2 


\section{Appendix A}

\section{Data Collection Forms}

This appendix presents three items related to collecting the information on the contaminant inventories.

The first item is a blank, five-page data collection form. One data form was completed for each identified waste stream disposed of in the SDA. Continuation pages were added to the form as necessary. The CIDRA database was modeled after this form. Completed forms for all identified waste streams are stored in CIDRA and constitute Appendix B of this report.

The second item is a list of the general physical forms represented in the waste. The list is used in the database compilation of the inventory to facilitate the rollup of all waste streams having a similar physical form, regardless of the generator or building that produced the waste.

The third item is a list of the general container types used for the waste at the SDA. The abbreviations match those used in the RWMIS database. 
DATA INPUT FOR RECENT AND PROJECTED DATA TASK FOR RWMC SUBSURFACE DISPOSAL AREA

\section{PART A - GENERAL INFORMATION}

\section{Preparer}

\section{Generator}

(area or contractor - use code from attached list)

5. Number of the waste stream from this facility

7. Type of radioactive waste (check box)

$\square$ TRU or suspect TRU

$\square$ LLW

$\square$ non-radioactive

8. Actual years disposed of at SDA

Starting year Ending year
2. Date prepared

4. Particular facility

(building number - use code from altached list)

6. Waste stream

9. Waste stream volume

Amount Units

Check box: $\square$ annual or $\square$ total over all years

Check box: $\square$ container volume or $\square$ waste volume

10. Comments (specify number of pertinent question) 


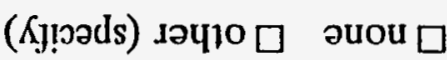

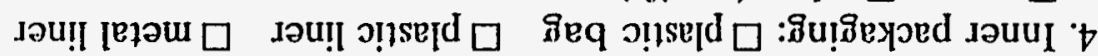

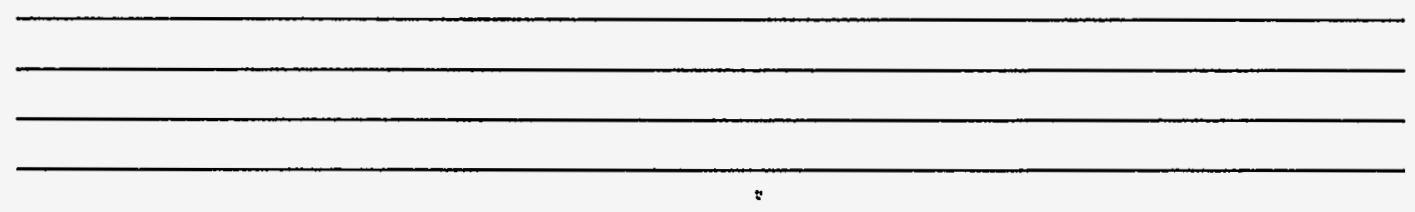

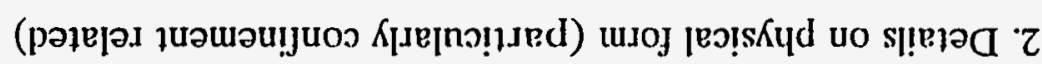

(1s!I pәцวеา วаs) әd

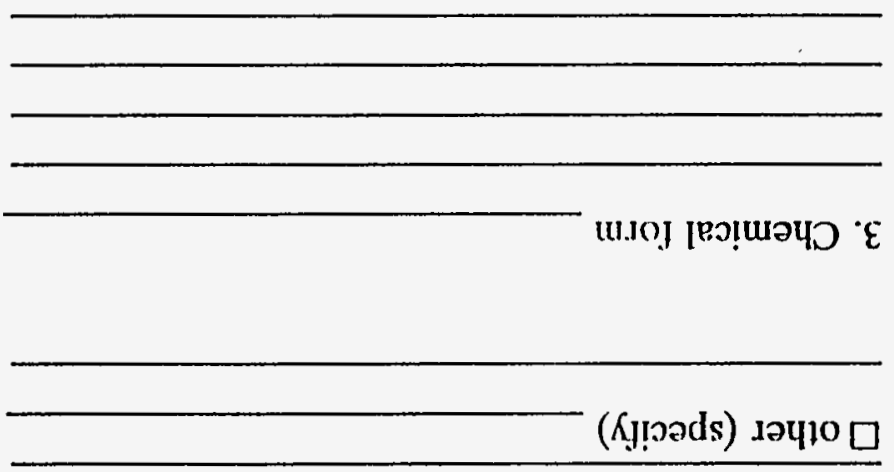

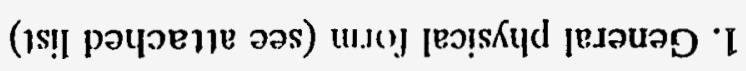




\section{PART C - NONRADIOLOGICAL CONTAMINANTS}

For each contaminant, complete at least one line on the following table. If any eritries for that contaminant vary by year, fill out additional lines as needed to cover the varying entries for different years. For example, if the annual quantity disposed was $\mathrm{x} \mathrm{kg}$ for $1952-56$ and $\mathrm{y} \mathrm{kg}$ for 1957-84, use two lines to handle this situation.

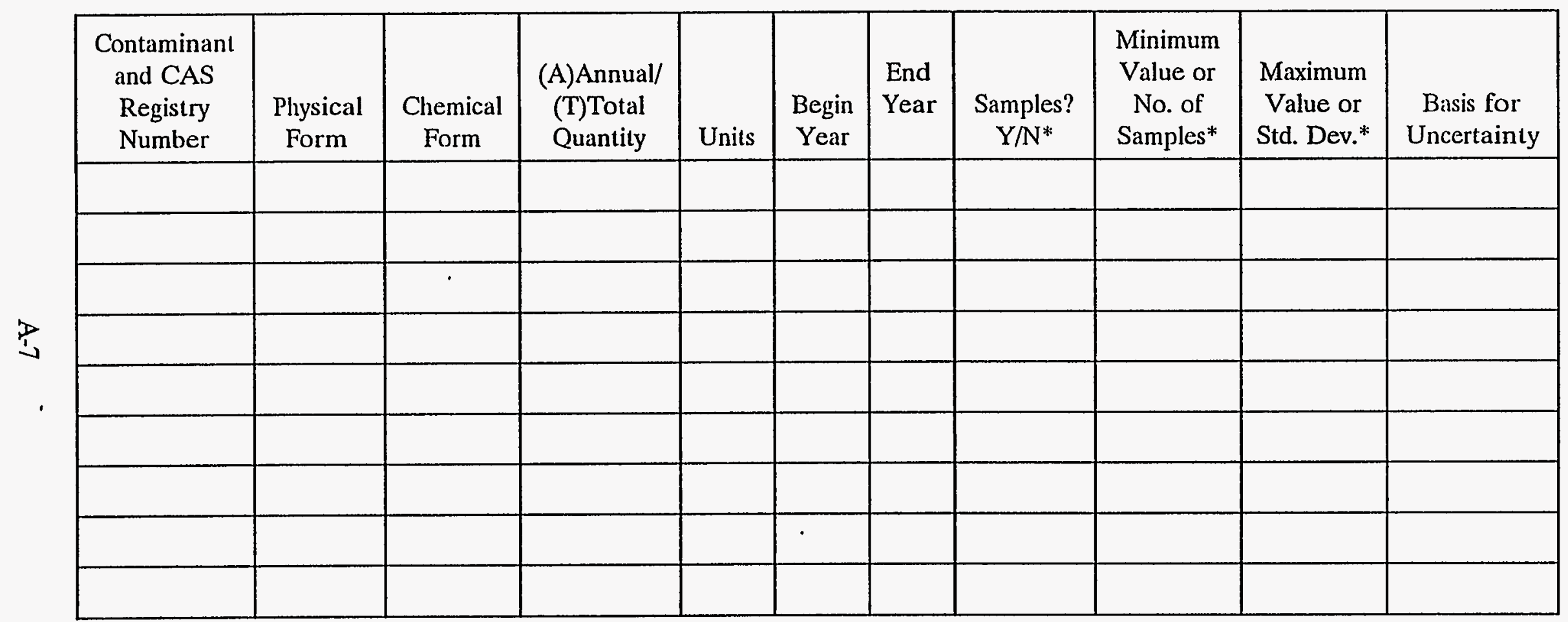

* If sample data are available, mark $\mathrm{Y}$ in the column titled "Samples?" and provide number of samples in the next column and standard deviation in the next column. If not, mark $\mathrm{N}$ and give the minimum value and maximum value.

Additional inlormation or explanations (indicate pertinent contaminant) 
PART D - RADIOLOGICAL CONTAMINANTS

\begin{tabular}{|c|c|c|c|c|c|c|c|c|c|c|c|}
\hline Radionuclide & $\begin{array}{l}\text { Physical } \\
\text { Form }\end{array}$ & $\begin{array}{c}\text { Chemical } \\
\text { Form }\end{array}$ & $\begin{array}{l}\text { (A)Annual/ } \\
\text { (T)Total } \\
\text { Quantity }\end{array}$ & Units & $\begin{array}{l}\text { Begin } \\
\text { Year }\end{array}$ & $\begin{array}{l}\text { End } \\
\text { Year }\end{array}$ & $\begin{array}{c}\text { Waste } \\
\text { Gen. } \\
\text { Fore- } \\
\text { cast } \\
\text { used? } \\
\text { Y/N }{ }^{* *}\end{array}$ & $\begin{array}{c}\text { Samples? } \\
\text { Y/N* }\end{array}$ & $\begin{array}{c}\text { Minimum } \\
\text { Value or } \\
\text { No. of } \\
\text { Samples* }\end{array}$ & $\begin{array}{c}\text { Maximum } \\
\text { Value or } \\
\text { Stc. Dev.* }\end{array}$ & $\begin{array}{l}\text { Basis for } \\
\text { Uncertainty }\end{array}$ \\
\hline & & & & & & & & & & & \\
\hline & & & & & & & & & & & \\
\hline & & & & & & & & & & & \\
\hline & & & & & & & & & & & \\
\hline & & & & & & & & & & & \\
\hline & & & & & & & & & & & \\
\hline & & & & & & & & & & & \\
\hline & & & & & & & & & & & \\
\hline & & & & & & & & & & & \\
\hline
\end{tabular}

* If sample data are available, mark $\mathrm{Y}$ in the column titled "Samples?" and provide number of samples in the next column and standard deviation in the next column. If not, mark $\mathrm{N}$ and give minimum value and maximum value.

** For the projected waste streams, mark $\mathrm{Y}$ if forecast document was used. If not, mark $\mathrm{N}$. This column is not used for the recent waste streams.

Additional information or explanations (indicate pertinent contaminant). 


\section{PART E - SOURCES OF INFORMATION AND UNCERTAINTIES}

1. Type of source of inlormation (check box)

\section{$\square$ RWMIS $\square$ other database}

$\square$ sample analysis data

$\square$ operating records $\square$ interview

$\square$ expert judgment $\square$ reports

$\square$ generator forecasts

$\square$ other (specify)

\section{Do the estimates of contaminant} quantities in Part $C$ and $D$ represent:

(check box)

$\square$ best estimate

$\square$ worst case

$\square$ other (specily)

5. Do the data conllict with RWMIS?

$\square$ no

$\square$ yes

7. Major unknowns in inventories of contaminants
2. Details concerning source [names, report no., dates, etc.]

4. If other than best estimate, explain why

6. If yes, explain why

8. Key assumptions used to deal with the unknowns

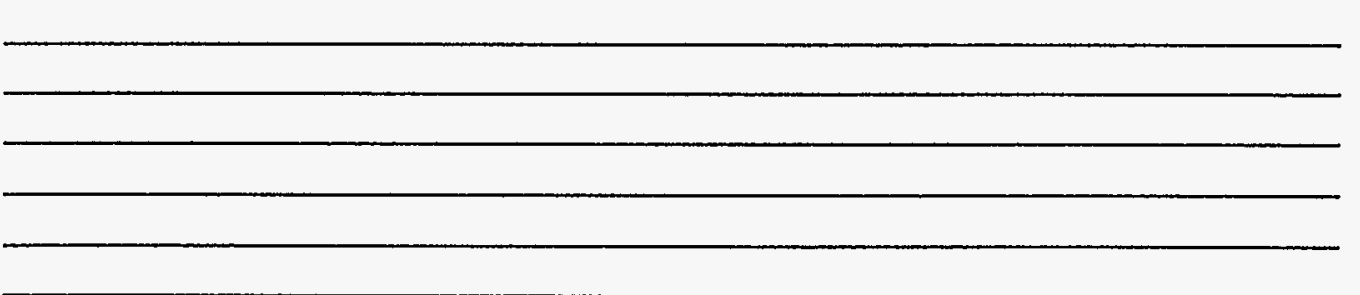




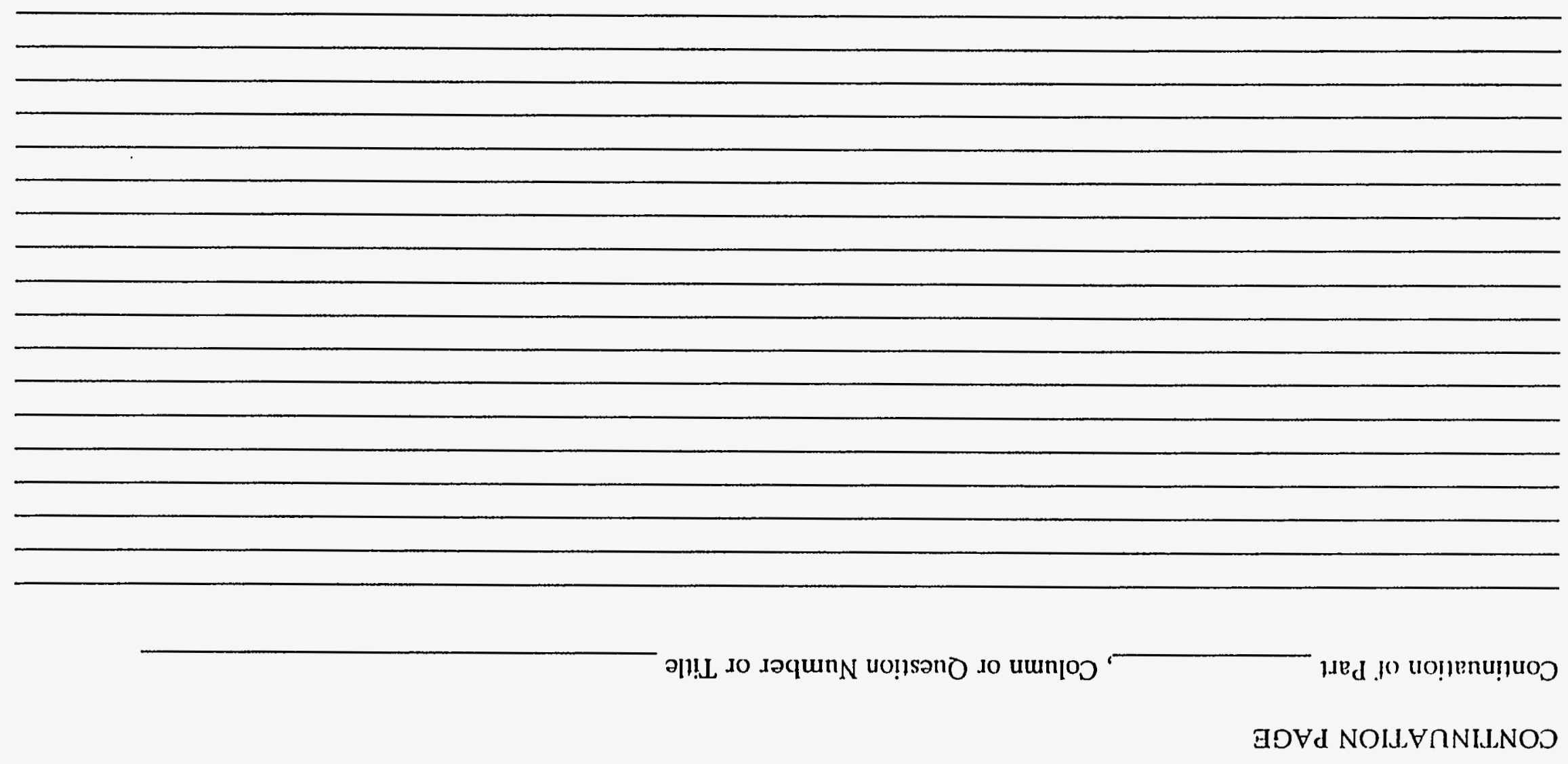




\section{GENERAL PHYSICAL FORMS FOR WASTE BURIED IN THE SUBSURFACE DISPOSAL AREA}

Number

Form

1

2

3

4

5

6

7

8

9

10

11

12

13

14

53
Irradiated fuel rods from experiments

Irradiated fuel from experiments

Unirradiated fuel from experiments

Irradiated end boxes

Other core, reactor vessel, and loop components

Ventilation systems

Lead

Beryllium

Zirconium

Other scrap metals

Sludge

Resin

Vermiculite and other sorbents

Evaporated salts

Other liquid setups

Graphite

Reactive metals

Combustibles (paper, cloth, wood, etc.)

HEPA filters

Other filters

Biological waste

Radiation sources

Concrete, brick, asphalt

Glass

Soil

Plastics

Rubber

Soot, ash

Asbestos

Liquids

Unknown

Other 
These container types/abbreviations were used to describe the physical containment associated with the waste. These terms are standard terminology for the waste data entered into the RWMIS database and are also used in the CIDRA database. The following is a listing of the waste container types and their abbreviations:

BAL Bale (result of NRF compaction)(not valid after 1/87)

BIN Bin (other than WERF ONLY bins)

BXC Cardboard box (to WERF ONLY)

BXW Wooden box

PB2 Wooden box, $64 \mathrm{ft}^{3}, 4 \times 4 \times 4 \mathrm{ft}$

PB3 Wooden box, $64 \mathrm{ft}^{3}, 2 \times 4 \times 8 \mathrm{ft}$

I Insert

O Other

BLX Bale (result of RWMC compaction)

ING Ingot (from WERF only)

MWB Metal waste bin (to or from WERF ONLY)

BXM Metal box

BXS Steel box (from WERF ONLY)

DMP Dumpster (to WERF ONLY)

CAR Cargo container (to WERF ONLY)

BLM Metal barrel, (after $9 / 89$ for barrels other than 55 gal)

RDL Metal barrel, 55 gal, with liner

RD5 Metal barrel, $55 \mathrm{gal}$, without liner

DDB DOT-7A D\&D bin (to WERF ONLY) 


\section{Appendix B}

Complete Printout of the Contaminant Inventory and Other Information from the CIDRA Database 
B-2 


\section{Appendix B}

\section{Complete Printout of the Contaminant Inventory and Other Information from the CIDRA Database}

This appendix contains a complete printout of the CIDRA database covering the time period of 1984-2003. The contaminant inventory and other information is provided in its entirety in Volumes 2 and 3 of this report. The information is organized by generator and by waste stream for a given generator. The database contains completed versions of the five-part blank forms shown in Appendix A for all identified waste streams.

In the main report, the rollup printouts from CIDRA for the time period of 1984-2003 were presented using scientific notation, with two significant digits shown. In the original data forms presented here, conventional notation is used. More than two digits are shown in Parts $\mathrm{C}$ and $\mathrm{D}$ because of the need to express very small activities of certain radionuclides. However, generally speaking, only the first two digits of each entry are considered significant, at best.

NOTE: Because of its size, distribution of Appendix B has been limited. A copy of the volumes containing Appendix B can be provided on request. 


\section{Appendix C}

\section{Untitled}

C-1 
C-2 


\section{Appendix C}

\section{Untitled}

This appendix contains no information for this report covering the RPDT. The appendix exists only for the purpose of maintaining format similarities with the INEL HDT report ${ }^{\mathrm{a}}$, which covers the waste buried at the SDA from 1952 through 1983. In the HDT report, Appendix C discussed the inventory of plutonium, americium, and uranium in waste from the Rocky Flats Plant that was buried at the SDA from 1954 through 1972. However, during the 1984-2003 time period covered in the present report, no waste from the Rocky Flats Plant has been or is expected to be buried at the SDA.

a. EG\&G Idaho, Inc., 1994, A Comprehensive Inventory of Radiological and Nonradiological Contaminants in Waste Buried in the Subsurface Disposal Area of the INEL RWMC During the Years 1952-1983, EGG-WM-10903, June 1994. 
Appendix D

Untitled

D-1 
(... . . . .

D-2 


\section{Appendix D}

\section{Untitled}

This appendix contains no information for this report covering the RPDT. In the HDT report, Appendix D discussed contaminants whose presence in the waste was identified but whose quantities could not be estimated reliably. For the time period 1984-2003, no contaminant entries were identified for which reliable estimates of the quantities were not possible. This appendix was retained, however, for two reasons. First, it maintains symmetry between the HDT report $^{\mathrm{a}}$ and this report. Second, this appendix is reserved for detailed evaluation of future unknown contaminant quantities, should they be identified at a later date and this report be revised.

a. EG\&G Idaho, Inc., 1994, A Comprehensive Inventory of Radiological and Nonradiological Contaminants in Waste Buried in the Subsurface Disposal Area of the INEL RWMC During the Years 1952-1983, EGG-WM-10903, June 1994. 


\section{Appendix E}

Assumed Distributions of Generic Terms and Dual Entries for Radioactivity in the RWMIS Shipping Record Rollups, for Use in the CIDRA Versus RWMIS Comparisons 
E-2 


\section{Appendix E}

\section{Assumed Distributions of Generic Terms and Dual Entries for Radioactivity in the RWMIS Shipping Record Rollups, for Use in the CIDRA Versus RWMIS Comparisons}

The RWMIS shipping records contain some generic entries (MAP, MFP, and unidentified beta-gamma during the recent time period) for some of the radioactivity in the waste. Realistic comparisons of the activities of radionuclides in CIDRA against those in RWMIS require that the generic entries first be replaced conceptually by radionuclide distributions. The distributions used in the comparisons for each major waste generator during the recent time period are provided in this appendix.

For the purpose only of the comparisons, the generic entries in RWMIS were replaced conceptually using the simplified method described below. The conceptual replacement of the generic entries does not replace or affect the detailed distributions used in CIDRA in any way, nor were the generic entries in RWMIS actually replaced.

The method used to conceptually replace the generic entries in RWMIS was based on a simplified application of the radionuclide distributions in CIDRA. For several major waste generators (TAN, TRA, NRF, ANL-W), the distributions in CIDRA generally differ from one waste stream to another because nuclear physics calculations were used to develop the distributions. For these generators, simplified (approximate average) distributions were developed and used in these comparisons to replace the RWMIS generic entries for the given generator.

For ICPP, fixed distributions generally had been used by the data gatherer each time a generic entry was identified in the records (see Section 2.5.3). The same radionuclide distributions were used for the comparisons as were used when the information was entered into CIDRA. Other generators were handled similarly in the comparisons.

RWMIS also contains some dual-radionuclide entries (e.g., Zr-Nb-95). The assumptions made for such entries in the comparisons are also listed in this appendix. 


\section{A. ASSUMED DISTRIBUTIONS OF DUAL-RADIONUCLIDE ENTRIES IN RWMIS}

\begin{tabular}{|c|c|}
\hline RWMIS entry & Assumed distribution \\
\hline $\mathrm{Zr}-\mathrm{Nb}-95$ & $0.5 \mathrm{Zr}-95,0.5 \mathrm{Nb}-95$ \\
\hline Sr-Y-90 & $0.5 \mathrm{Sr}-90,0.5 \mathrm{Y}-90$ \\
\hline Ce-Pr-144 & $0.5 \mathrm{Ce}-144,0.5 \mathrm{Pr}-144$ \\
\hline Ru-Rh-106 & $0.5 \mathrm{Ru}-106,0.5 \mathrm{Rh}-106$ \\
\hline Ba-La-140 & $0.5 \mathrm{Ba}-140,0.5 \mathrm{La}-140$ \\
\hline Sr-89-90 & All Sr-90 \\
\hline Ce-141-144 & All Ce-144 \\
\hline
\end{tabular}

Remarks
Assumed to be in equilibrium
Assumed to be in equilibrium
Assumed to be in equilibrium
Assumed to be in equilibrium
Assumed to be in equilibrium
Conservative assumption
Conservative assumption

B. ASSUMED DISTRIBUTIONS OF GENERIC RADIONUCLIDE TERMS IN RWMIS (Totals may not always add to exact unity because of round-off.)

1. TAN

\begin{tabular}{|c|c|c|c|c|}
\hline & & Assum & hed dis & ibution \\
\hline Term & (Ci) & Nuclide & & Fraction \\
\hline MAP & $1.4 \mathrm{E}+00$ & Co-60 & & 0.622 \\
\hline & & $\mathrm{Mn}-54$ & & 0.266 \\
\hline & & Co-58 & & $\underline{0.112}$ \\
\hline & & & Total & 1.000 \\
\hline MFP & $3.8 E+02$ & Sr-90 & & 0.492 \\
\hline & & Cs-137 & & 0.431 \\
\hline & & Cs-134 & & 0.0657 \\
\hline & & $\mathrm{Ce}-144$ & & 0.0102 \\
\hline & & Ru-106 & & $\underline{0.0011}$ \\
\hline & & & Total & $\overline{1.000}$ \\
\hline
\end{tabular}

2. TRA

\begin{tabular}{|c|c|c|c|}
\hline \multirow[b]{2}{*}{ Term } & \multirow{2}{*}{$\begin{array}{l}\text { RWMIS activity } \\
\text { (Ci) }\end{array}$} & \multicolumn{2}{|c|}{ Assumed distribution } \\
\hline & & Nuclide & Fraction \\
\hline \multirow[t]{5}{*}{ MAP } & $2.7 E+03$ & Co-60 & 0.53 \\
\hline & & $\mathrm{Ni}-63$ & 0.40 \\
\hline & & $\mathrm{H}-3$ & 0.06 \\
\hline & & C-14 & $\underline{0.01}$ \\
\hline & & & $\overline{1.00}$ \\
\hline
\end{tabular}

a. Conservative in terms of half-life and radiotoxicity. 
2. TRA (continued)

\begin{tabular}{|c|c|c|c|c|}
\hline \multirow[b]{2}{*}{ Term } & \multirow{2}{*}{$\begin{array}{l}\text { RWMIS activity } \\
\text { (Ci) }\end{array}$} & \multicolumn{3}{|c|}{ Assumed distribution } \\
\hline & & Nuclide & & Fraction \\
\hline \multirow[t]{8}{*}{ MFP } & $2.7 \mathrm{E}+03$ & Cs-137 & & 0.69 \\
\hline & & $\mathrm{Ce}-144$ & & 0.22 \\
\hline & & $\mathrm{Sb}-125$ & & 0.04 \\
\hline & & Eu-155 & & 0.032 \\
\hline & & Sr-90 & & 0.012 \\
\hline & & Tc-99 & & 0.0009 \\
\hline & & I-129 & & $5 \times 10^{-8}$ \\
\hline & & & Total & 1.00 \\
\hline \multirow{13}{*}{ Unidentified beta-gamma } & $1.4 \mathrm{E}+02$ & Co-60 & & 0.41 \\
\hline & & $\mathrm{Ni}-63$ & & 0.31 \\
\hline & & Cs-137 & & 0.15 \\
\hline & & $\mathrm{H}-3$ & & 0.05 \\
\hline & & Ce-144 & & 0.05 \\
\hline & & C-14 & & 0.009 \\
\hline & & $\mathrm{Sb}-125$ & & 0.008 \\
\hline & & Eu-155 & & 0.007 \\
\hline & & Sr-90 & & 0.003 \\
\hline & & $\mathrm{Ni}-59$ & & 0.0004 \\
\hline & & Tc-99 & & 0.0002 \\
\hline & & $\mathrm{I}-129$ & & $2 \times 10^{-8}$ \\
\hline & & & Total & 1.00 \\
\hline
\end{tabular}

3. ICPP

\begin{tabular}{|c|c|c|c|c|}
\hline \multirow[b]{2}{*}{ Term } & \multirow{2}{*}{$\begin{array}{l}\text { RWMIS activity } \\
\text { (Ci) }\end{array}$} & \multicolumn{3}{|c|}{ Assumed distribution } \\
\hline & & Nuclide & & Fraction \\
\hline \multirow[t]{2}{*}{ MAP } & $8.0 \mathrm{E}-03$ & $\begin{array}{l}\mathrm{Co}-58 \\
\mathrm{Mn}-54\end{array}$ & & $\begin{array}{l}0.500 \\
0.500\end{array}$ \\
\hline & & & Total & 1.000 \\
\hline \multirow[t]{11}{*}{ MFP } & $1.3 E+02$ & Ce-144 & & 0.197 \\
\hline & & Pr-144 & & 0.197 \\
\hline & & Cs -137 & & 0.100 \\
\hline & & Sr-90 & & 0.100 \\
\hline & & Y-90 & & 0.100 \\
\hline & & Ru-106 & & 0.100 \\
\hline & & Rh-106 & & 0.100 \\
\hline & & $\mathrm{Sb}-125$ & & 0.044 \\
\hline & & Zr-95 & & 0.031 \\
\hline & & $\mathrm{Nb}-95$ & & $\underline{0.031}$ \\
\hline & & & Total & $\overline{1.000}$ \\
\hline
\end{tabular}


4. NRF

$\frac{\text { Term }}{\text { MAP }}$

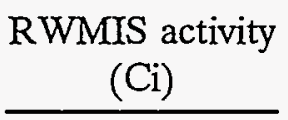

$6.0 \mathrm{E}-02$
Assumed distribution

\begin{tabular}{lll}
\hline \multicolumn{1}{c}{ Nuclide } & & Fraction \\
\cline { 1 - 1 } Ni-63 & & 0.50 \\
Co-60 & & 0.30 \\
Fe-55 & & 0.15 \\
Co-58 & & 0.025 \\
Ta-182 & & $\underline{0.025}$ \\
& Total & 1.00
\end{tabular}

5. ANL-W

$\frac{\text { Term }}{\text { MAP }}$

MFP

Unidentified beta-gamma

\section{RWMIS activity}

(Ci)

1.7E+02

$3.1 \mathrm{E}+02$

$1.2 \mathrm{E}-03$

Nuclide Fraction

Co-60

0.55

Cr-51

$\mathrm{Mn}-54$

Co-58

Sr-90

Cs- 137

Ce-144

0.50

0.30

$\underline{0.20}$

Total $\frac{0.20}{1.00}$

$\begin{array}{lrr}\text { Sr-90 } & & 0.50 \\ \text { Cs-137 } & & 0.30 \\ \text { Ce-144 } & & \underline{0.20} \\ & \text { Total } & 1.00\end{array}$

Assumed distribution

Total $\frac{0.10}{1.00}$

6. OTHER
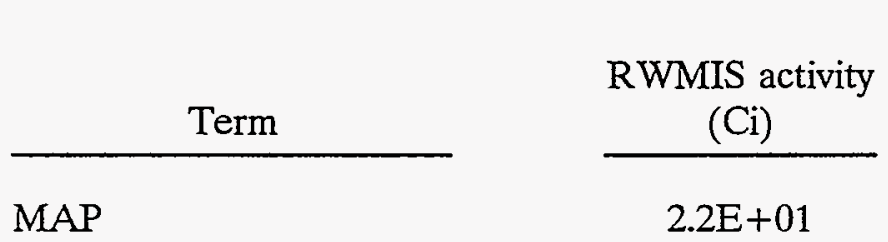

\begin{tabular}{|c|c|}
\hline Nuclide & Fraction \\
\hline \multirow[t]{2}{*}{$\begin{array}{l}\text { Co-60 } \\
\text { Fe-59 }\end{array}$} & $\begin{array}{l}0.75 \\
\underline{0.25}\end{array}$ \\
\hline & $\overline{1.00}$ \\
\hline
\end{tabular}


6. OTHER (continued)

\begin{tabular}{|c|c|c|c|c|}
\hline \multirow[b]{2}{*}{ Term } & \multirow{2}{*}{$\begin{array}{l}\text { RWMIS activity } \\
\text { (Ci) }\end{array}$} & \multicolumn{3}{|c|}{ Assumed distribution } \\
\hline & & Nuclide & & Fraction \\
\hline \multirow[t]{2}{*}{ MFP } & $2.9 E+02$ & $\begin{array}{l}\text { Cs-137 } \\
\text { Sr- } 90\end{array}$ & & $\begin{array}{l}0.50 \\
0.50\end{array}$ \\
\hline & & & Total & 1.00 \\
\hline \multirow[t]{5}{*}{ Unidentified beta-gamma } & 2.5E-01 & Co-60 & & 0.375 \\
\hline & & Cs-137 & & 0.25 \\
\hline & & $\mathrm{Sr}-90$ & & 0.25 \\
\hline & & $\mathrm{Fe}-59$ & & $\underline{0.125}$ \\
\hline & & & Total & 1.000 \\
\hline
\end{tabular}

E-7 


\section{Appendix F}

\section{Summary of Results of Environmental Monitoring at the Subsurface Disposal Area}




\section{Appendix F}

\section{Summary of Results of Environmental Monitoring at the Subsurface Disposal Area}

This appendix provides summary tables of environmental monitoring results at the SDA. The purpose of these summary tables is to provide a broad indication of what contaminants have been detected in the monitoring, for comparison with the data compiled in CIDRA. Separate tables are given for radiological and nonradiological contaminants. Within each table, separate entries are also provided for the results of routine monitoring and special studies because the statistical criteria often varied from one study to another.

The radiological contaminants, which are presented in Table F-1, include those most frequently detected in RWMC environmental samples and others included in routine screening tests. Monitoring data included in this review span 18 years (1976 through 1993); however, only years for which detectable levels were reported appear in Table F-1.

Because Table F-1 is a high-level rollup table for comparison purposes only, the minimum and maximum reported values of concentration were compiled for each medium by combining the results from all of the sampling methods. If only one sample was evaluated, only the single result is listed in the table. Air contaminant concentrations include data from both high- and lowvolume air samplers. Soil concentrations include both surface and near-surface values. Concentrations in subsurface sediments (deeper than near-surface) are reported separately. Contaminant concentrations in samples from all monitoring wells were combined to report a range of concentrations. No distinction between sampling locations within the SDA, monitoring instrumentation, sampling locations, or number of positive samples was considered in this rollup table. Only a gross range in concentration values is presented.

The environmental medium terms for the subsurface (groundwater, subsurface water, perched water, etc.) used in the routine monitoring and special studies reports have not always been defined clearly or used consistently. Since the purpose here is simply to indicate which contaminants have been detected, not the environmental media in which they were detected, no attempt is made to define what is meant by the various terms. The contaminant concentrations are presented with their associated environmental medium term used in the cited report.

Below-measurable concentrations are denoted as BDL (below detection limit). Detection limits for major radiological contaminants monitored at the SDA are included in the annual monitoring reports. Significant concentration results generally reflect a $95 \%$ confidence level, and the uncertainty for analytical results is $\pm 2 \sigma$ for radionuclides. Data reported for biotic vegetation and air sampling are provided by analyses conducted by RESL.

Results of routine monitoring and special studies for nonradiological contaminants are summarized similarly in Table F-2. Monitoring for nonradiological contaminants is smaller in scope than monitoring for radiological contaminants. Organic compounds and metals have been 
monitored regularly at the SDA since 1987. Special studies cover the years listed in Table F-2. Maximum and minimum contaminant concentrations are presented for each medium sampled.

Generally, data reported for nonradiological contaminants reflect an uncertainty of $\pm 1 \sigma$. Below-measurable levels are indicated as PQL (practical quantitation level). PQL values for nonradiological contaminants measured in the SDA are given in the annual monitoring reports.

The detection of contaminants in environmental media at the RWMC does not always imply that the contaminants came from the SDA waste that is inventoried herein. Contaminants detected in the analysis of environmental samples collected at the RWMC could have also resulted from (a) emissions from other INEL facilities, (b) atmospheric fallout from weapons testing, (c) natural occurrence, (d) cross-contamination or erroneous laboratory analysis, or (e) waste located in other parts of the RWMC. Eliminating the other potential sources of contamination requires rigorous design and execution of the sampling and analysis, and careful interpretation of the results. Such evaluations are beyond the scope of these simplified comparisons.

The special studies cited here and the RESL data are believed to be of acceptable reliability for use in these comparisons. The subsurface water sampling and analysis by the USGS is also believed to be of acceptable reliability in this regard. However, in spite of rigorous monitoring activities, contaminants in aquifer samples collected by the USGS at the RWMC could have been the result of waterborne effluents upgradient from other INEL facilities. A case-by-case analysis is required to postulate the source of each detected contaminant.

The data from INEL contractor routine monitoring at the RWMC before about 1983 are considered to be of lower reliability. Quality assurance of the monitoring activities was minimal. In many cases, no control samples were collected or the control samples were from inappropriate locations. In 1983, detailed reviews of the objectives, procedures, and data were completed for the INEL contractor monitoring activities at the RWMC, leading to major improvements in sampling design, laboratory analysis, and data evaluation. Quality assurance was strengthened substantially. The monitoring activity reviews continue to be held on a regular basis. For the INEL contractor routine monitoring, only data obtained in 1984 or later are considered sufficiently reliable for these comparisons. The early data that are affected include contaminant concentrations in air, subsurface and surface water, and subsurface and surface soil. For the present comparisons, the biotic data from all years are considered reliable.

The summary environmental monitoring data are not compared here against background concentrations of the contaminants. Some of the listed detections may simply represent concentrations of contaminants at background levels. 
Table F-1. Summary of results from routine monitoring and special studies for radiological contaminants.

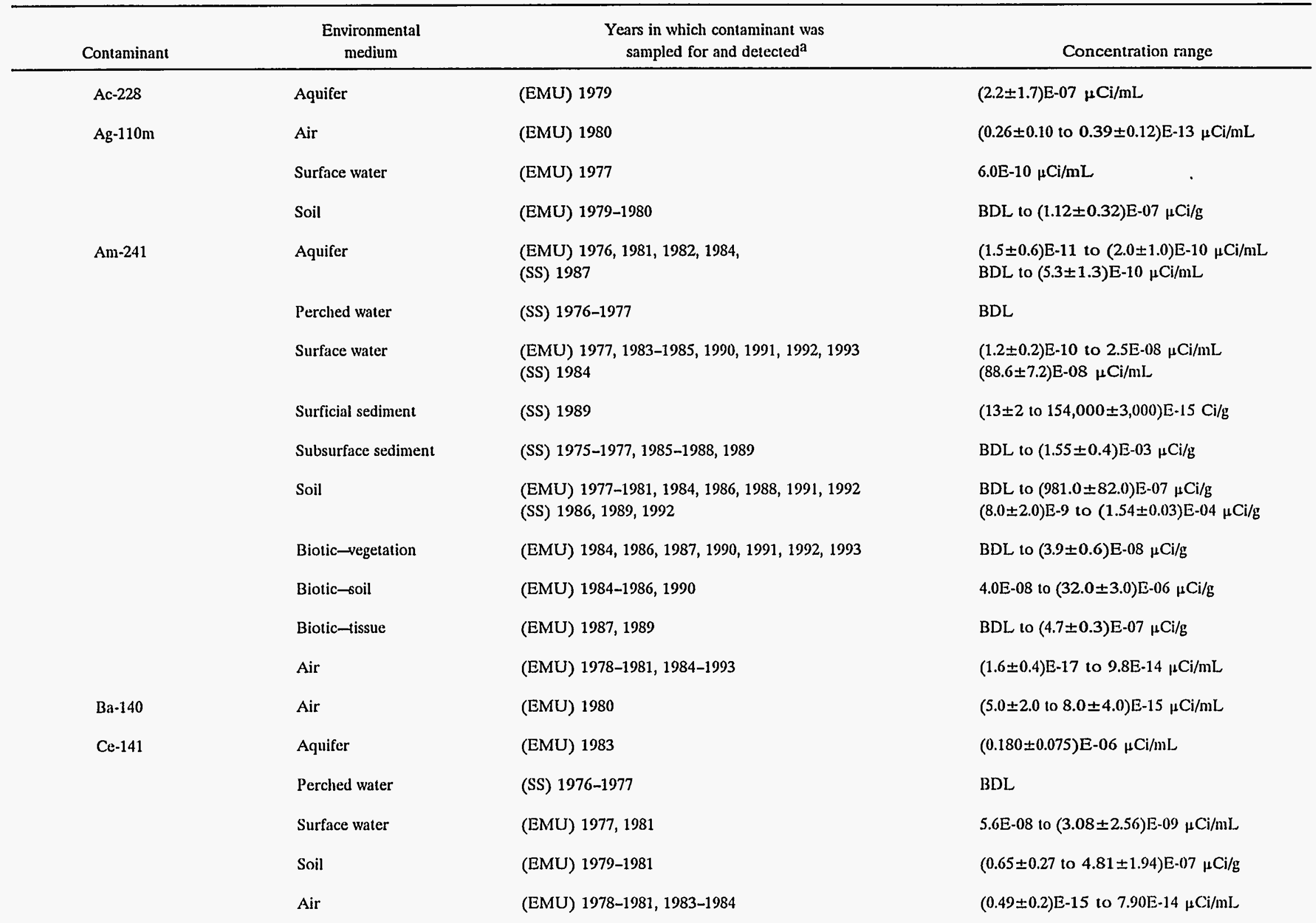


Table F-1. (continued).

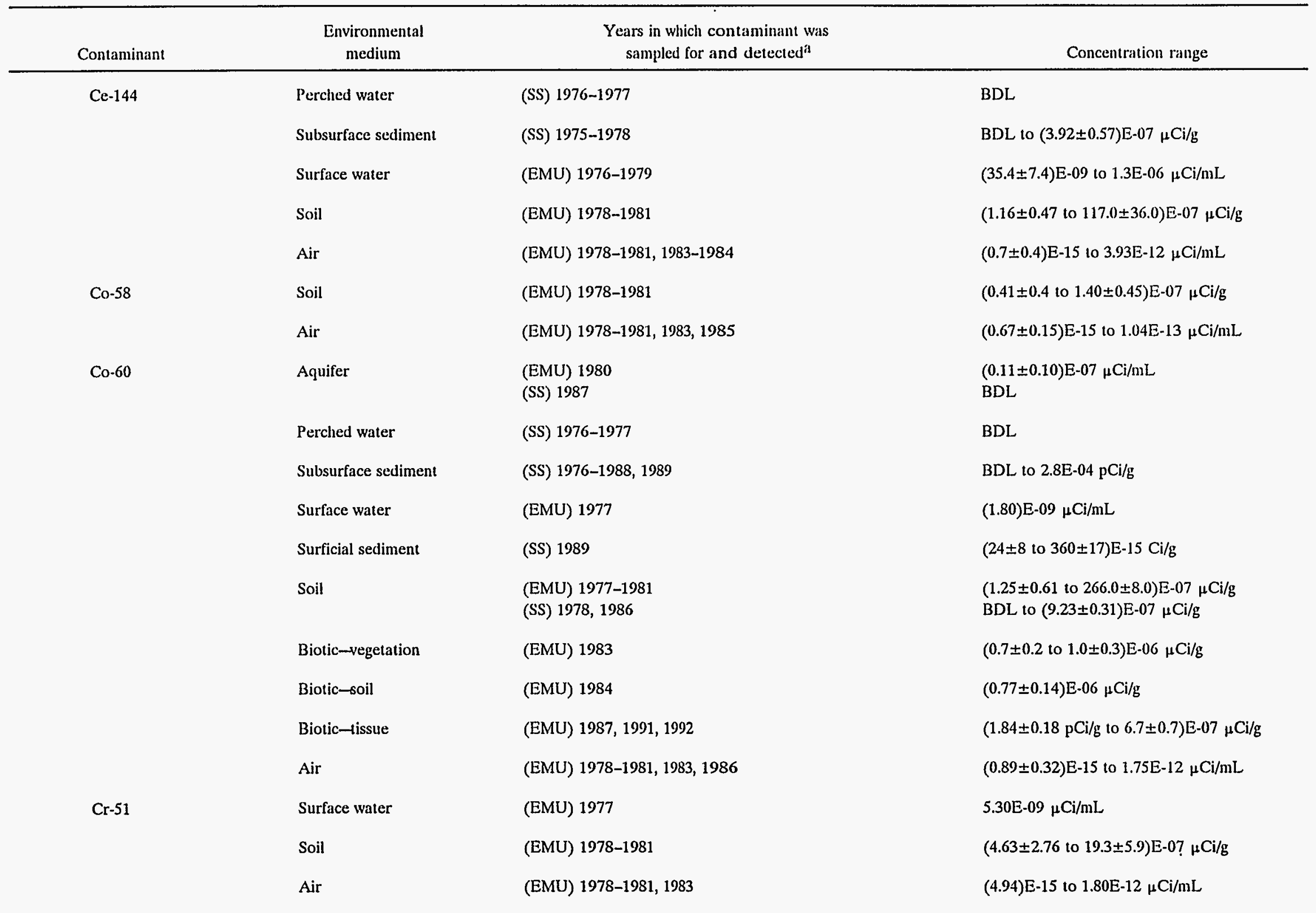


Table F-1. (continued).

\begin{tabular}{|c|c|c|c|}
\hline Contaminant & $\begin{array}{l}\text { Environmental } \\
\text { medium }\end{array}$ & $\begin{array}{l}\text { Years in which contaminant was } \\
\text { sampled for and detected }\end{array}$ & Concentration range \\
\hline \multirow[t]{4}{*}{ Cs-134 } & Surface water & (EMU) 1977, 1979, 1981 & $(0.89 \pm 0.69$ to $8.6 \pm 1.04) \mathrm{E}-09 \mu \mathrm{Ci} / \mathrm{mL}$ \\
\hline & Soil & (EMU) 1978-1981 & $(0.68 \pm 0.33$ to $16.1 \pm 0.57) \mathrm{E}-07 \mu \mathrm{Ci} / \mathrm{g}$ \\
\hline & Biotic-vegetation & (EMU) 1987 & $(1.07 \pm 0.14$ to $1.5 \pm 0.2) \mathrm{E}-07 \mu \mathrm{Ci} / \mathrm{g}$ \\
\hline & Air & (EMU) 1978-1981, 1985 & $(1.11 \pm 0.46) \mathrm{E}-15$ to $1.03 \mathrm{E}-13 \mu \mathrm{Ci} / \mathrm{mL}$ \\
\hline \multirow[t]{10}{*}{ Cs-137 } & Aqquifer & $\begin{array}{l}\text { (EMU) } 1976-1977,1980,1986 \\
\text { (SS) } 1987\end{array}$ & $\begin{array}{l}(1.6 \pm 0.7) \mathrm{E}-08 \text { to }(0.09 \pm 0.03) \mathrm{E}-06 \mu \mathrm{Ci} / \mathrm{mL} \\
\mathrm{BDL}\end{array}$ \\
\hline & Perched water & (SS) $1976-1977$ & BDL \\
\hline & Subsurface sediment & (SS) $1975-1988,1989$ & BDL to $(1,090 \pm 30) \mathrm{E}-05 \mu \mathrm{Ci} / \mathrm{g}$ \\
\hline & Surface water & $\begin{array}{l}\text { (EMU) 1976-1977, 1979-1981, 1983-1986, 1988, } 1990 \text {, } \\
1993\end{array}$ & $(1.4 \pm 0.4) \mathrm{E}-09$ to $(202.4 \pm 0.36) \mathrm{E}-08 \mu \mathrm{Ci} / \mathrm{mL}$ \\
\hline & Surficial sediment & (SS) 1989 & $(27 \pm 8$ to $1,800 \pm 70) \mathrm{E}-15 \mathrm{Ci} / \mathrm{g}$ \\
\hline & Soil & $\begin{array}{l}\text { (EMU) } 1977-1981,1984,1988,1992 \\
\text { (SS) } 1978,1989\end{array}$ & $\begin{array}{l}(1.13 \pm 0.43) E-07 \text { to }(40 \pm 2.0) E-06 \mu \mathrm{Ci} / \mathrm{g} \\
(1.8 \pm 7.0) \mathrm{E}-08 \text { to }(153 \pm 0.05) \mathrm{E}-06 \mu \mathrm{Ci} / \mathrm{g}\end{array}$ \\
\hline & Biotic-vegetation & (EMU) 1983-1984, 1987 & $(0.69 \pm 0.19) \mathrm{E}-07$ to $(2.8 \pm 0.2) \mathrm{E}-04 \mu \mathrm{Ci} / \mathrm{g}$ \\
\hline & Biotic-soil & $(E M U) 1984,1986,1990$ & $(8.0 \mathrm{E}-08$ to $0.94 \pm 0.24) \mathrm{E}-06 \mu \mathrm{Ci} / \mathrm{g}$ \\
\hline & Biotic-lissue & (EMU) 1987, 1991, 1992 & $(4.1 \pm 0.8)$ E- 07 to $(7.32 \pm 0.23) \mathrm{E}-06 \mu \mathrm{Ci} / \mathrm{g}$ \\
\hline & Air & (EMU) 1978-1981, 1984-1985, 1987, 1991 & $(0.5 \pm 0.2) \mathrm{E}-15$ to $(9.08 \pm 0.47) \mathrm{E}-13 \mu \mathrm{Ci} / \mathrm{mL}$ \\
\hline \multirow[t]{5}{*}{ Eu-152 } & Surface water & (EMU) $1976,1978-1979$ & $0.78 \mathrm{E}-09$ to $(1.8 \pm 0.4) \mathrm{E}-08 \mu \mathrm{Ci} / \mathrm{mL}$ \\
\hline & Soil & (EMU) 1978-1981 • & $(1.56 \pm 1.55) \mathrm{E}-07$ to $1.06 \mathrm{E}-06 \mu \mathrm{Ci} / \mathrm{g}$ \\
\hline & & (SS) 1978 & $\mathrm{BDL}$ to $(2.06 \pm 0.36) \mathrm{E}-07 \mu \mathrm{Ci} / \mathrm{g}$ \\
\hline & Air & (EMU) 1978-1981 & $(9.25 \pm 2.39) \mathrm{E}-15$ to $(9.57 \pm 1.37) \mathrm{E}-13 \mu \mathrm{Cj} / \mathrm{mL}$ \\
\hline & Biotic-tissue & (EMU) 1987 & $(14.3 \pm 1.8$ to $52.4 \pm 1.8) \sqrt{2}-07 \mu \mathrm{Ci} / \mathrm{g}$ \\
\hline
\end{tabular}


Table F-1. (continued).

\begin{tabular}{|c|c|c|c|}
\hline Contaminant & $\begin{array}{l}\text { Environmental } \\
\text { medium }\end{array}$ & $\begin{array}{l}\text { Years in which contaminant was } \\
\text { sampled for and detected" }\end{array}$ & Concentration range \\
\hline \multirow[t]{5}{*}{ Eu-154 } & Subsurface sediment & (SS) 1985 & $(29 \pm 9) \mathrm{E}-09 \mu \mathrm{Ci} / \mathrm{g}$ \\
\hline & Surficial sediment & (SS) 1989 & $29 \pm 9 \mathrm{E}-15 \mathrm{Ci} / \mathrm{g}$ \\
\hline & Soil & $\begin{array}{l}\text { (EMU) } 1979-1981 \\
\text { (SS) } 1978,1989\end{array}$ & $\begin{array}{l}(1.82 \pm 0.64 \text { to } 3.20 \pm 1.21) \mathrm{E}-07 \mu \mathrm{Ci} / \mathrm{g} \\
\text { BDL to }(2.74 \pm 0.28) \mathrm{E}-07 \mu \mathrm{Ci} / \mathrm{g}\end{array}$ \\
\hline & Biotic-tissue & (EMU) 1987 & $(7.4 \pm 1.3$ to $39 \pm 3) \mathrm{E}-07 \mu \mathrm{Ci} / \mathrm{g}$ \\
\hline & Air & (EMU) 1978-1981 & $(3.10 \pm 1.50) \mathrm{E}-15$ to $(2.09 \pm 0.82) \mathrm{E}-13 \mu \mathrm{Ci} / \mathrm{mL}$ \\
\hline \multirow[t]{2}{*}{ Eu-155 } & Air & $(E M U) 1981$ & $(5.31 \pm 2.1) \mathrm{E}-15$ to $(1.13 \pm 0.36) \mathrm{E}-13 \mu \mathrm{Ci} / \mathrm{mL}$ \\
\hline & Soil & (EMU) 1981 & $(3.23 \pm 1.46) \mathrm{E}-07 \mu \mathrm{Ci} / \mathrm{g}$ \\
\hline \multirow[t]{2}{*}{$\mathrm{H}-3$} & Aquifer & $\begin{array}{l}\text { (EMU) 1977-1993 } \\
\text { (SS) } 1984-1986,1987\end{array}$ & $\begin{array}{l}(6.0 \pm 4.0) \mathrm{E}-07 \text { to }(2.7 \pm 0.4) \mathrm{E}-06 \mu \mathrm{Ci} / \mathrm{mL} \\
<\text { BDL to }(1.9 \pm 0.4) \mathrm{E}-06 \mu \mathrm{Ci} / \mathrm{mL}\end{array}$ \\
\hline & Perched water & $\begin{array}{l}\text { (SS) } 1976-1977 \\
\text { (EMU) } 1992,1993\end{array}$ & $\begin{array}{l}(5.4 \pm 0.1 \text { to } 18.0 \pm 1.0) \mathrm{E}-06 \mu \mathrm{Ci} / \mathrm{mL} \\
\mathrm{BDL} \text { to }(0.4 \pm 0.2) \mathrm{E}-06{ }_{\mu} \mathrm{Ci} / \mathrm{mL}\end{array}$ \\
\hline \multirow[t]{2}{*}{ Hf-181 } & Soil & (EMU) 1978-1981 & $(0.30 \pm 0.27$ to 4.40$) \mathrm{E}-07 \mu \mathrm{Ki} / \mathrm{g}$ \\
\hline & Air & (EMU) 1978-1981 & $1.21 \mathrm{E}-15$ to $(1.58 \pm 0.77) \mathrm{E}-13 \mu \mathrm{Ci} / \mathrm{mL}$ \\
\hline \multirow[t]{2}{*}{$\mathrm{Hg}-203$} & Soil & (EMU) 1980-1981 & $(0.90 \pm 0.39$ to $2.14 \pm 0.63) \mathrm{E}-07 \mu \mathrm{Ci} / \mathrm{g}$ \\
\hline & Air & $(E M U)$ 1978-1981 & $(0.54 \pm 0.43) \mathrm{E}-15$ to $(0.65 \pm 0.42) \mathrm{E}-13 \mu \mathrm{Ci} / \mathrm{mL}$ \\
\hline
\end{tabular}


Table F-1. (continued).

\begin{tabular}{|c|c|c|c|}
\hline Contaminant & $\begin{array}{l}\text { Environmental } \\
\text { medium }\end{array}$ & $\begin{array}{l}\text { Years in which contaninant was } \\
\text { sampled for and detected }{ }^{\mathrm{a}}\end{array}$ & Concentration range \\
\hline I-131 & Air & $(E M U) 1980$ & BDL to $(0.9 \pm 0.6) \mathrm{E}-15 \mu \mathrm{Ci} / \mathrm{mL}$ \\
\hline \multirow[t]{3}{*}{$\mathrm{Mn}-54$} & Aquifer & (EMU) 1977 & $(1.8 \pm 0.7$ to $1.9 \pm 0.7) \mathrm{E}-08 \mu \mathrm{Ci} / \mathrm{mL}$ \\
\hline & Soil & (EMU) 1979-1981 & $(0.60 \pm 0.44$ to $1.74 \pm 0.59) \mathrm{E}-07 \mu \mathrm{Ci} / \mathrm{g}$ \\
\hline & Air & (EMU) 1978-1981, 1983 & $\mathrm{BDL}$ to $(1.19 \pm 1.03) \mathrm{E}-13 \mu \mathrm{Ci} / \mathrm{mL}$ \\
\hline \multirow[t]{3}{*}{$\mathrm{Nb}-95$} & Surface water & (EMU) 1977 & $5.70 \mathrm{E}-07 \mu \mathrm{Ci} / \mathrm{mL}$ \\
\hline & Soil & (EMU) 1978-1981 & $(0.82 \pm 0.27$ to 4.0$) \mathrm{E}-07 \mu \mathrm{Ci} / \mathrm{g}$ \\
\hline & Air & (EMU) 1978-1981 & $(1.22 \pm 0.18$ to $3.48 \pm 1.5) \mathrm{E}-13 \mu \mathrm{Ci} / \mathrm{mL}$ \\
\hline \multirow{11}{*}{$\begin{array}{l}\mathrm{Pb}-212 \\
\mathrm{Pu}-238\end{array}$} & Aquifer & (EMU) 1978 & $(5.3 \pm 2.6) \mathrm{E}-08 \mu \mathrm{Ci} / \mathrm{mL}$ \\
\hline & Aquifer & $\begin{array}{l}\text { (EMU) } 1981,1983 \\
\text { (SS) } 1987\end{array}$ & $\begin{array}{l}(1.0 \pm 0.8) \text { to }(8.1 \pm 0.8) \mathrm{E}-10 \mu \mathrm{Ci} / \mathrm{mL} \\
\text { Not detected }\end{array}$ \\
\hline & Perched water & (SS) 1976-1977, 1989 & BDL to $(3.22 \pm 0.17) \mathrm{E}-08 \mu \mathrm{Ci} / \mathrm{mL}$ \\
\hline & Surface water & (EMU) 1983 & $(0.015 \pm 0.004) \mathrm{E}-08 \mu \mathrm{Ci} / \mathrm{mL}$ \\
\hline & Surficial sediment & (SS) 1989 & $(5.2 \pm 1.7$ to $6,400 \pm 200) \mathrm{E}-15 \mathrm{Ci} / \mathrm{g}$ \\
\hline & Subsurface sediment & (SS) 1975-1988, 1989 & BDL to $(3.8 \pm 0.4) \mathrm{E} \cdot 07 \mu \mathrm{Ci} / \mathrm{g}$ \\
\hline & Soil & $\begin{array}{l}\text { (EMU) } 1979-1981,1988,1991 \\
\text { (SS) } 1989 \\
\text { (SS) } 1992\end{array}$ & $\begin{array}{l}(0.009 \pm 0.008 \text { to } 0.72 \pm 5.0) \mathrm{E}-06 \mu \mathrm{Ci} / \mathrm{g} \\
(3.8 \pm 0.4) \mathrm{E}-07 \mu \mathrm{Ci} / \mathrm{g} \\
(7.2 \pm 1.5) \mathrm{E}-08 \text { to }(4.0 \pm 0.3) \mathrm{E}-06 \mu \mathrm{Ci} / \mathrm{g}\end{array}$ \\
\hline & Soil water & (SS) 1989 & $(5.3 \pm 1.3) \mathrm{E}-10 \mu \mathrm{Ci} / \mathrm{mL}$ \\
\hline & Biotic-vegetation & (EMU) 1984, 1986-1987, 1990 & BDL to $(0.08 \pm 0.01) \mathrm{E}-06 \mu \mathrm{Ci} / \mathrm{g}$ \\
\hline & Biotic-lissue & (EMU) 1987, 1989 & BDL to $(2.2 \pm 0.2) \mathrm{E}-07 \mu \mathrm{Ci} / \mathrm{g}$ \\
\hline & Air & (EMU) $1980,1986-1988$ & $(4 \pm 1) \mathrm{E}-18$ to $(5.0 \pm 0.08) \mathrm{E}-15 \mu \mathrm{Ci} / \mathrm{mL}$ \\
\hline
\end{tabular}


Table F-t. (continued).

\begin{tabular}{|c|c|c|c|}
\hline Contaminant & $\begin{array}{l}\text { Environmental } \\
\text { medium }\end{array}$ & $\begin{array}{l}\text { Years in which contaminant was } \\
\text { sampled for and detected }\end{array}$ & Concentration range \\
\hline \multirow[t]{11}{*}{$\mathrm{Pu}-239 / 240$} & Aquifer & (SS) $1985-1986,1987$ & BDL \\
\hline & Perched water & $\begin{array}{l}\text { (EMU) } 1976 \\
\text { (SS) } 1989\end{array}$ & $\begin{array}{l}(0.25 \pm 0.09) \mathrm{E}-10 \mu \mathrm{Ci} / \mathrm{mL} \\
(5.8 \pm 0.2) \mathrm{E}-08 \mu \mathrm{Ci} / \mathrm{mL}\end{array}$ \\
\hline & Subsurface sediment & (SS) $1975-1978,1985-1988,1989$ & $B D L$ to $(11 \pm 0.5) E-03 \mu \mathrm{Ci} / \mathrm{g}$ \\
\hline & Surface water & (EMU) 1983-1985 & $(0.016 \pm 0.006$ to $0.15 \pm 0.06) \mathrm{E}-08 \mu \mathrm{Ci} / \mathrm{mL}$ \\
\hline & Surficial sediment & (SS) 1989 & $(5.5 \pm 1.6$ to $33,400 \pm 600) \mathrm{E}-15 \mathrm{Ci} / \mathrm{g}$ \\
\hline & Soil & $\begin{array}{l}\text { (EMU) } 1976-1977,1979-1981,1986,1988,1991, \\
1992,1993 \\
\text { (SS) } 1989 \\
\text { (SS) } 1992\end{array}$ & $\begin{array}{l}\text { BDL to }(0.23 \pm 0.05) \mathrm{E}-07 \mu \mathrm{Ci} / \mathrm{g} \\
(3.34 \pm 0.06) \mathrm{E}-05 \mu \mathrm{Ci} / \mathrm{g} \\
(6.0 \pm 1.5) \mathrm{E}-08 \text { to }(1.16 \pm 0.07) \mathrm{E}-05 \mu \mathrm{Ci} / \mathrm{g}\end{array}$ \\
\hline & Soil water & (SS) 1989 & $(8 \pm 7) \mathrm{E}-11 \mu \mathrm{Ci} / \mathrm{g}$ \\
\hline & Biotic-vegetation & (EMU) $1986,1987,1990$ & $(1.0 \pm 0.2) \mathrm{E}-08$ to $(1.05 \pm 0.08) \mathrm{E}-06 \mu \mathrm{Ci} / \mathrm{g}$ \\
\hline & Biotic-soil & $(E M U) 1984,1986-1990$ & $(4.0 \mathrm{E}-08$ to $16.5 \pm 0.8) \mathrm{E}-06 \mu \mathrm{Ci} / \mathrm{g}$ \\
\hline & Biotic-tissue & (EMU) 1987,1989 & $(2.7 \pm 0.8$ to $30 \pm 2) \mathrm{E}-08 \mu \mathrm{Ci} / \mathrm{g}$ \\
\hline & Air & (EMU) $1980,1984-1988,1990-1993$ & $(2.0 \pm 0.6) \mathrm{E}-18$ to $(1.8 \pm 0.1) \mathrm{E}-15 \mu \mathrm{Ci} / \mathrm{mL}$ \\
\hline \multirow[t]{3}{*}{ Ru-103 } & Surface water & (EMU) 1977,1981 & $(2.78 \pm 0.79) \mathrm{E}-09$ to $1.40 \mathrm{E}-07 \mu \mathrm{Ci} / \mathrm{mL}$ \\
\hline & Soil & (EMU) 1978-1981 & $(0.70 \pm 0.38$ to 3.50$) \mathrm{E}-07 \mu \mathrm{Ci} / \mathrm{g}$ \\
\hline & Air & (EMU) $1978-1980,1983$ & $(1.07 \pm 0.93) \mathrm{E}-15$ to $1.12 \mathrm{E}-13 \mu \mathrm{Ci} / \mathrm{mL}$ \\
\hline \multirow[t]{4}{*}{$\mathrm{Ru}-106$} & Surface water & (EMU) 1976-1977, 1979 & $(30 \pm 11$ to $32.2 \pm 6.2) \mathrm{E}-09 \mu \mathrm{Ci} / \mathrm{g}$ \\
\hline & Soil & $(E M U)$ 1979-1981 & $(4.18 \pm 2.40) \mathrm{E}-07$ to $2.26 \mathrm{E}-06 \mu \mathrm{Ci} / \mathrm{g}$ \\
\hline & Biotic-vegetation & (EMU) 1978 & $2.44 \mathrm{E}-06 \mu \mathrm{Ci} / \mathrm{g}$ \\
\hline & Air & (EMU) 1978-1981 & $(14.0 \pm 3.4) \mathrm{E}-15$ to $(5.88 \pm 1.83) \mathrm{E}-13 \mu \mathrm{Ci} / \mathrm{mL}$ \\
\hline \multirow[t]{2}{*}{ Sb-124 } & Soil & (EMU) 1979-1981 & $(0.53 \pm 0.24$ to $1.13 \pm 0.43) E-07 \mu \mathrm{Ci} / \mathrm{g}$ \\
\hline & Air & (EMU) 1979-1981 & $(1.02 \pm 0.27) \mathrm{E}-15$ to $(0.58 \pm 0.15) \mathrm{E}-13 \mu \mathrm{Ci} / \mathrm{mL}$ \\
\hline
\end{tabular}


Table F-1. (continued).

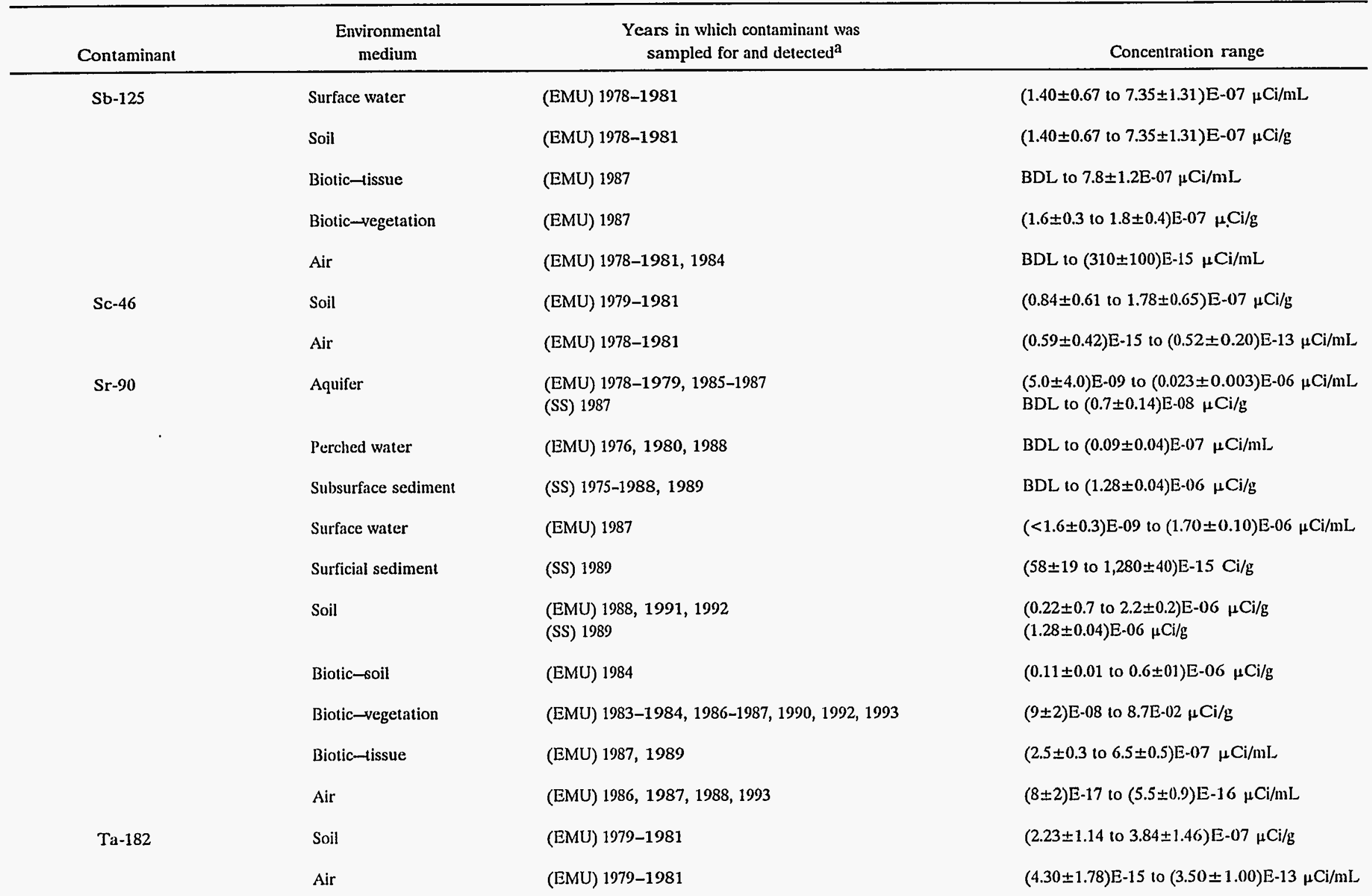


Table F-1. (continued).

\begin{tabular}{|c|c|c|c|}
\hline Contaminant & $\begin{array}{c}\text { Environmental } \\
\text { medium }\end{array}$ & $\begin{array}{l}\text { Years in which contaminant was } \\
\text { sampled for and detected }\end{array}$ & Concentration range \\
\hline \multirow[t]{3}{*}{$\mathrm{U}-234$} & Soil & $\begin{array}{l}\text { (EMU) } 1986 \\
\text { (SS) } 1992\end{array}$ & $\begin{array}{l}4.0 \pm 1.0 \mathrm{E}-07 \mu \mathrm{Ci} / \mathrm{g} \\
(7.9 \pm 1.0) \mathrm{E}-7 \text { to }(1.39 \pm 0.11) \mathrm{E}-06 \mu \mathrm{Ci} / \mathrm{g}\end{array}$ \\
\hline & Biotic-vegetation & $(E M U) 1985,1987$ & $(2.3 \pm 0.3$ to $3.9 \pm 0.5) \mathrm{E}-08 \mu \mathrm{Ci} / \mathrm{g}$ \\
\hline & Biotic-tissue & (EMU) 1987 & $(2.8 \pm 0.4) \mathrm{E}-08$ to $(3.6 \pm 0.4) \mathrm{E}-07 \mu \mathrm{Ci} / \mathrm{g}$ \\
\hline \multirow[t]{3}{*}{ U.235 } & Soil & (SS) 1983 & $(0.34 \pm 0.003$ to $0.06 \pm 0.01) \mathrm{E}-06 \mu \mathrm{Ci} / \mathrm{g}$ \\
\hline & Biotic-vegetation & (EMU) 1987 & $(1.6 \pm 0.5$ to $2.3 \pm 0.6) \mathrm{E}-09 \mu \mathrm{Ci} / \mathrm{g}$ \\
\hline & Biotic-tissue & $(E M U) 1987,1989$ & $\mathrm{BDL}$ to $1.4 \pm 0.2 \mathrm{E}-08 \mu \mathrm{Ci} / \mathrm{g}$ \\
\hline $\mathrm{U}-237$ & Air & (EMU) 1980 & $(1.6 \pm 1.0$ to $8.0 \pm 2.0) \mathrm{E}-15 \mu \mathrm{Ci} / \mathrm{mL}$ \\
\hline \multirow[t]{3}{*}{$\mathrm{U}-238$} & Soil & (SS) 1983-1984, 1992 & $(8.0 \pm 1.0) \mathrm{E}-7$ to $(1.43 \pm 0.1) \mathrm{E}-06 \mu \mathrm{Ci} / \mathrm{g}$ \\
\hline & Biotic-vegetation & (EMU) 1987 & $(2.9 \pm 0.4$ to $4.0 \pm 0.6) \mathrm{E}-08 \mu \mathrm{Ci} / \mathrm{g}$ \\
\hline & Biotic-tissue & (EMU) 1987, 1989 & $(2.5 \pm 0.4) \mathrm{E}-08$ to $(1.2 \pm 0.2) \mathrm{E}-07 \mu \mathrm{Ci} / \mathrm{g}$ \\
\hline \multirow[t]{2}{*}{ Y-91 } & Soil & (EMU) 1979-1980 & BDL to $(934 \pm 538.0) \mathrm{E}-107 \mu \mathrm{Ci} / \mathrm{g}$ \\
\hline & Air & (EMU) 1979-1980 & $(1.46 \pm 1.14) \mathrm{E}-15$ to $(322 \pm 84.0) \mathrm{E}-13 \mu \mathrm{Ci} / \mathrm{mL}$ \\
\hline \multirow[t]{2}{*}{$\mathrm{Zn}-65$} & Soil & (EMU) 1979-1981 & BDL to $(1.93 \pm 0.83) \mathrm{E}-07 \mu \mathrm{Ci} / \mathrm{g}$ \\
\hline & Air & (EMU) 1978-1981 & BDL to $(1.11 \pm 0.90) \mathrm{E}-13 \mu \mathrm{Ci} / \mathrm{mL}$ \\
\hline \multirow[t]{3}{*}{ Zr-95 } & Surface water & (EMU) 1977 & 3.4E-07 $\mu \mathrm{Ci} / \mathrm{mL}$ \\
\hline & Soil & (EMU) 1979-1981 & $(1.55 \pm 0.93$ to 5.00$) \mathrm{E}-07 \mu \mathrm{Ci} / \mathrm{g}$ \\
\hline & Air & (EMU) 1978-1981 & $(1.54 \pm 0.66$ to $168.0 \pm 8.0) \mathrm{E}-15 \mu \mathrm{Ci} / \mathrm{mL}$ \\
\hline
\end{tabular}

a. Years spanned by environmental monitoring results (EMU) presented here are 1976-1993. Results from special studies (SS) span years as shown.

BDL - Below detection limit.

EMU - Data compiled from routine monitoring results published by the Environmental Monitoring Unit.

SS - Special studies. Data compiled from studies other than those that are part of the routine monitoting program. 
Table F-2. Summary of results from routine monitoring and special studies for nonradiological contaminants.

\begin{tabular}{|c|c|c|c|}
\hline Contaminant & Medium & $\begin{array}{l}\text { Years in which contaminant } \\
\text { was detected }\end{array}$ & Concentration \\
\hline \multicolumn{4}{|l|}{ ORGANICS } \\
\hline \multirow[t]{5}{*}{ 1,1,1-trichloroethane } & Aquifer, perched & (EMU) 1987-1993 & $<0.2$ to $0.9 \mu \mathrm{gg} / \mathrm{L}$ \\
\hline & & (SS) 1987-1988, 1993 & $<0.2$ to $15.0 \mu \mathrm{g} / \mathrm{L}$ \\
\hline & Soil/soil gas & (SS) 1987 & $<0.01 \mu \mathrm{g} / \mathrm{L}$ \\
\hline & Borehole vapor & (SS) 1987,1988 & BDL to $120 \mathrm{mg} / \mathrm{m}^{3}$ \\
\hline & Air & (SS) 1991,1994 & $1.4 \mu \mathrm{g} / \mathrm{m}^{3}$ \\
\hline \multirow[t]{5}{*}{ 1,1,2-trichlorotrifluoroethane } & Perched water & (EMU) 1987-1990 & 37 to $250 \mu \mathrm{g} / \mathrm{L}$ \\
\hline & & (SS) 1987-1988 & $<0.2$ to $250 \mu \mathrm{g} / \mathrm{L}$ \\
\hline & Air & (SS) 1989 & $120 \mathrm{mg} / \mathrm{m}^{3}$ \\
\hline & Soil borehole vapor & (SS) 1987 & PQL to $120 \mu \mathrm{g} / \mathrm{L}$ \\
\hline & Soil/soil gas & (SS) 1987 & NR to $310 \mu \mathrm{g} / \mathrm{L}$ \\
\hline \multirow[t]{4}{*}{ 1,1-dichloroethane } & Aquifer & $(E M U)$ 1987-1993 & $<0.2$ to $5.6 \mu \mathrm{g} / \mathrm{L}$ \\
\hline & & (SS) 1987-1988, 1990-1991 & $\begin{array}{l}<0.2 \text { to } 13 \mu \mathrm{g} / \mathrm{L} \\
5.6 \text { to } 22 \mu \mathrm{g} / \mathrm{L}\end{array}$ \\
\hline & Perched water & $(E M U)$ 1987-1990 & 5.6 to $22 \mu \mathrm{g} / \mathrm{L}$ \\
\hline & & (SS) 1987,1993 & 0.3 to $13 \mu \mathrm{g} / \mathrm{L}$ \\
\hline \multirow[t]{4}{*}{ 1,1-dichloroethylene } & Aquifer & $(E M U)$ 1987-1993 & $<0.2$ to $1.0 \mu \mathrm{g} / \mathrm{L}$ \\
\hline & & (SS) 1987-1988, 1990-1991 & $<0.2$ to $3.0 \mu \mathrm{g} / \mathrm{L}$ \\
\hline & Perched water & (EMU) 1987-1990 & 0.8 to $2.6 \mu \mathrm{g} / \mathrm{L}$ \\
\hline & & (SS) 1987 & $<0.8 \mu \mathrm{g} / \mathrm{L}$ \\
\hline 2-butanone & Air & (SS) 1994 & $0.4 \mu \mathrm{g} / \mathrm{m}^{3}$ \\
\hline \multirow[t]{2}{*}{ Acetone } & Sedimentary interbed & (SS) 1987 & $11 \mu \mathrm{g} / \mathrm{kg}$ \\
\hline & Air & (SS) 1994 & $3.0 \mu \mathrm{g} / \mathrm{m}^{3}$ \\
\hline \multirow[t]{8}{*}{ Carbon tetrachloride } & Aquifer & $(E M U)$ 1987-1993 & $<0.2$ to $2.8 \mu \mathrm{g} / \mathrm{L}$ \\
\hline & & (SS) 1987-1991 & $<0.2$ to $6.6 \mu \mathrm{g} / \mathrm{L}$ \\
\hline & Perched water & (EMU) 1987-1990 & 230 to $1,400 \mu \mathrm{g} / \mathrm{L}$ \\
\hline & & (SS) $1987,1988,1993$ & $<0.2$ to $2,100 \mu \mathrm{g} / \mathrm{L}$ \\
\hline & Air & (SS) 1987, 1989 & 17 to $5,800 \mathrm{mg} / \mathrm{m}^{3}$ \\
\hline & Borehole vapor & (EMU) 1987 & 0.1 to $36 \mathrm{mg} / \mathrm{m}^{3}$ \\
\hline & & (SS) 1987-1988 & BDL to $5,800 \mu \mathrm{g} / \mathrm{L}$ \\
\hline & Soil/soil gas & (SS) 1987,1992 & 0.22 to $1,400 \mathrm{ppb}$ \\
\hline
\end{tabular}


Table F-2. (continued).

\begin{tabular}{|c|c|c|c|}
\hline Contaminant & Medium & $\begin{array}{l}\text { Years in which contaminant } \\
\text { was detected }\end{array}$ & Concentration \\
\hline \multirow[t]{7}{*}{ Chloroform } & Aquifer & (EMU) 1987-1993 & $<0.2$ to $1.0 \mu \mathrm{g} / \mathrm{L}$ \\
\hline & & (SS) 1987-1991 & $<0.2$ to $3 \mu \mathrm{g} / \mathrm{L}$ \\
\hline & Perched water & $(\mathrm{EMU}) 1987-1990$ & 300 to $940 \mu \mathrm{g} / \mathrm{L}$ \\
\hline & & $\begin{array}{l}\text { (SS) 1987-1988, 1990-1991, } \\
1993\end{array}$ & $<0.2$ to $1,500 \mu \mathrm{g} / \mathrm{L}$ \\
\hline & Air & (SS) 1989,1994 & 1.7 to $320,000 \mu \mathrm{g} / \mathrm{m}^{3}$ \\
\hline & Soil/borehole vapor & (SS) 1987, 1988, 1992 & BDL to $330 \mu \mathrm{g} / \mathrm{L}$ \\
\hline & Sedimentary interbed & (SS) 1987 & $120 \mu \mathrm{g} / \mathrm{kg}$ \\
\hline \multirow[t]{5}{*}{ Dichlorodifluoromethane } & Aquifer & (EMU) 1987-1993 & $<0.2$ to $<2.6 \mu \mathrm{g} / \mathrm{L}$ \\
\hline & & (SS) 1987-1991 & $<0.2$ to $3.0 \mu \mathrm{g} / \mathrm{L}$ \\
\hline & Air & (SS) 1994 & $0.3 \mu \mathrm{g} / \mathrm{m}^{3}$ \\
\hline & Perched water & (EMU) $1987-1990$ & $\mathrm{BDL}$ to $0.3 \mu \mathrm{g} / \mathrm{L}$ \\
\hline & & (SS) 1987-1988, 1990-1991 & $<0.2$ to $3 \mu \mathrm{g} / \mathrm{L}$ \\
\hline \multirow[t]{3}{*}{ Methylene chloride } & Sedimentary interbed & (SS) 1987 & $42 \mu \mathrm{g} / \mathrm{kg}$ \\
\hline & Perched water & (SS) 1993 & BDL to $<100 \mu \mathrm{g} / \mathrm{L}$ \\
\hline & Air & (SS) 1991,1994 & $0.05 \mu \mathrm{g} / \mathrm{m}^{3}$ \\
\hline Phenol & Aquifer & (SS) 1991 & $0.046 \mathrm{mg} / \mathrm{L}$ \\
\hline \multirow[t]{7}{*}{ Tetrachloroethylene } & Aquifer & (EMU) 1987-1993 & $<0.2$ to $4.5 \mu \mathrm{g} / \mathrm{L}$ \\
\hline & & (SS) $1987,1989-1991$ & $<0.2$ to $3.0 \mu \mathrm{g} / \mathrm{L}$ \\
\hline & Air & (SS) 1994 & $4.2 \mu \mathrm{g} / \mathrm{m}^{3}$ \\
\hline & Perched water & (EMU) 1987-1990 & 4.5 to $1,200 \mu \mathrm{g} / \mathrm{L}$ \\
\hline & & $\begin{array}{l}\text { (SS) 1987, 1988, 1990-1991, } \\
1993\end{array}$ & $<0.2$ to $230 \mu \mathrm{g} / \mathrm{L}$ \\
\hline & Soil/borehole vapor & (SS) 1987,1992 & BDL to $62 \mu \mathrm{g} / \mathrm{L}$ \\
\hline & Soil/soil vapor & (SS) 1987 & 3 to $40 \mu \mathrm{g} / \mathrm{L}$ \\
\hline \multirow[t]{6}{*}{ Toluene } & Aquifer & (EMU) 1987-1993 & $<0.2$ to $<1.0 \mu \mathrm{g} / \mathrm{L}$ \\
\hline & & (SS) 1987, 1988, 1990, 1991 & $<0.2$ to $3.0 \mu \mathrm{g} / \mathrm{L}$ \\
\hline & Air & (SS) 1994 & $0.3 \mu \mathrm{g} / \mathrm{m}^{3}$ \\
\hline & Perched water & (EMU) 1987-1990 & $<0.2$ to $0.3 \mu \mathrm{g} / \mathrm{L}$ \\
\hline & & $\begin{array}{l}\text { (SS) 1987-1988, 1990-1991, } \\
1993\end{array}$ & $<0.2$ to $100 \mu \mathrm{g} / \mathrm{L}$ \\
\hline & Soil/borehole vapor & (SS) 1987,1992 & 0.3 to $191 \mu \mathrm{g} / \mathrm{L}$ \\
\hline
\end{tabular}


Table F-2. (continued).

\begin{tabular}{|c|c|c|c|}
\hline Contaminant & Medium & $\begin{array}{l}\text { Years in which contaminant } \\
\text { was detected }{ }^{a}\end{array}$ & Concentration \\
\hline \multirow[t]{5}{*}{ Trichloroethylene } & Aquifer & $\begin{array}{l}\text { (EMU) } 1987-1993 \\
\text { (SS) } 1987-1988\end{array}$ & $\begin{array}{l}<0.2 \text { to } 1.4 \mu \mathrm{g} / \mathrm{L} \\
<0.2 \text { to } 860 \mu \mathrm{g} / \mathrm{L}\end{array}$ \\
\hline & Perched water & $\begin{array}{l}\text { (EMU) 1987-1990 } \\
\text { (SS) } 1987-1988,1990-1991 \\
1993\end{array}$ & $\begin{array}{l}\text { BDL to } 860 \mu \mathrm{g} / \mathrm{L} \\
<0.2 \text { to } 1,600 \mu \mathrm{g} / \mathrm{L}\end{array}$ \\
\hline & Air & (SS) 1987,1989 & 11 to $380 \mathrm{mg} / \mathrm{m}^{3}$ \\
\hline & Soil/borehole vapor & (SS) 1987,1992 & $\mathrm{BDL}$ to $690 \mu \mathrm{g} / \mathrm{L}$ \\
\hline & Sedimentary interbed & (SS) 1987 & $81 \mu \mathrm{g} / \mathrm{kg}$ \\
\hline Trichlorotrifluoroethane & Air & (SS) 1989 & $24 \mathrm{mg} / \mathrm{m}^{3}$ \\
\hline \multicolumn{4}{|l|}{ METALS } \\
\hline Antimony & Perched water & (SS) 1988,1993 & 2.2 to $70.0 \mu \mathrm{g} / \mathrm{L}$ \\
\hline \multirow[t]{2}{*}{ Arsenic } & Aquifer & (SS) 1987 & 1 to $14.3 \mu \mathrm{g} / \mathrm{L}$ \\
\hline & Perched water & (SS) 1988,1993 & $<2.0$ to $4.2 \mu \mathrm{g} / \mathrm{L}$ \\
\hline \multirow[t]{2}{*}{ Barium } & Sedimentary interbed & (SS) 1987 & $392 \mathrm{mg} / \mathrm{kg}$ \\
\hline & Perched water & (SS) 1988,1993 & 18 to $1,260 \mu \mathrm{g} / \mathrm{L}$ \\
\hline \multirow[t]{3}{*}{ Beryllium } & Perched water & (SS) 1988,1993 & $<0.5$ to $6.4 \mu \mathrm{g} / \mathrm{L}$ \\
\hline & Subsurface soil & (SS) 1991 & 1.9 to $2.7 \mathrm{mg} / \mathrm{kg}$ \\
\hline & Sedimentary interbed & (SS) 1987 & $1.4 \mathrm{mg} / \mathrm{kg}$ \\
\hline Boron & Surface soil & (SS) 1982 & $190 \mathrm{mg} / \mathrm{kg}$ \\
\hline \multirow[t]{2}{*}{ Cadmium } & Perched water & (SS) 1988,1993 & $<1$ to $16.1 \mu \mathrm{g} / \mathrm{L}$ \\
\hline & Surface soil & (SS) 1982 & $0.50 \mathrm{mg} / \mathrm{kg}$ \\
\hline \multirow[t]{5}{*}{ Chromium } & Surface water & (EMU) 1986 & $2.2 \pm 0.1 \mathrm{mg} / \mathrm{L}$ \\
\hline & Aquifer & (SS) $1985-1986,1987$ & 0.05 to $56 \pm 10 \mu \mathrm{g} / \mathrm{L}$ \\
\hline & Perched water & (SS) 1993 & $<6.0$ to $50 \mu \mathrm{g} / \mathrm{L}$ \\
\hline & Sedimentary interbed & (SS) 1987 & $40.0 \mathrm{mg} / \mathrm{kg}$ \\
\hline & Soil & (SS) 1982 & $3.5 \mathrm{mg} / \mathrm{kg}$ \\
\hline Cobalt & Perched water & (SS) 1988,1993 & $<12.0$ to $72.4 \mu \mathrm{g} / \mathrm{L}$ \\
\hline
\end{tabular}


Table F-2. (continued).

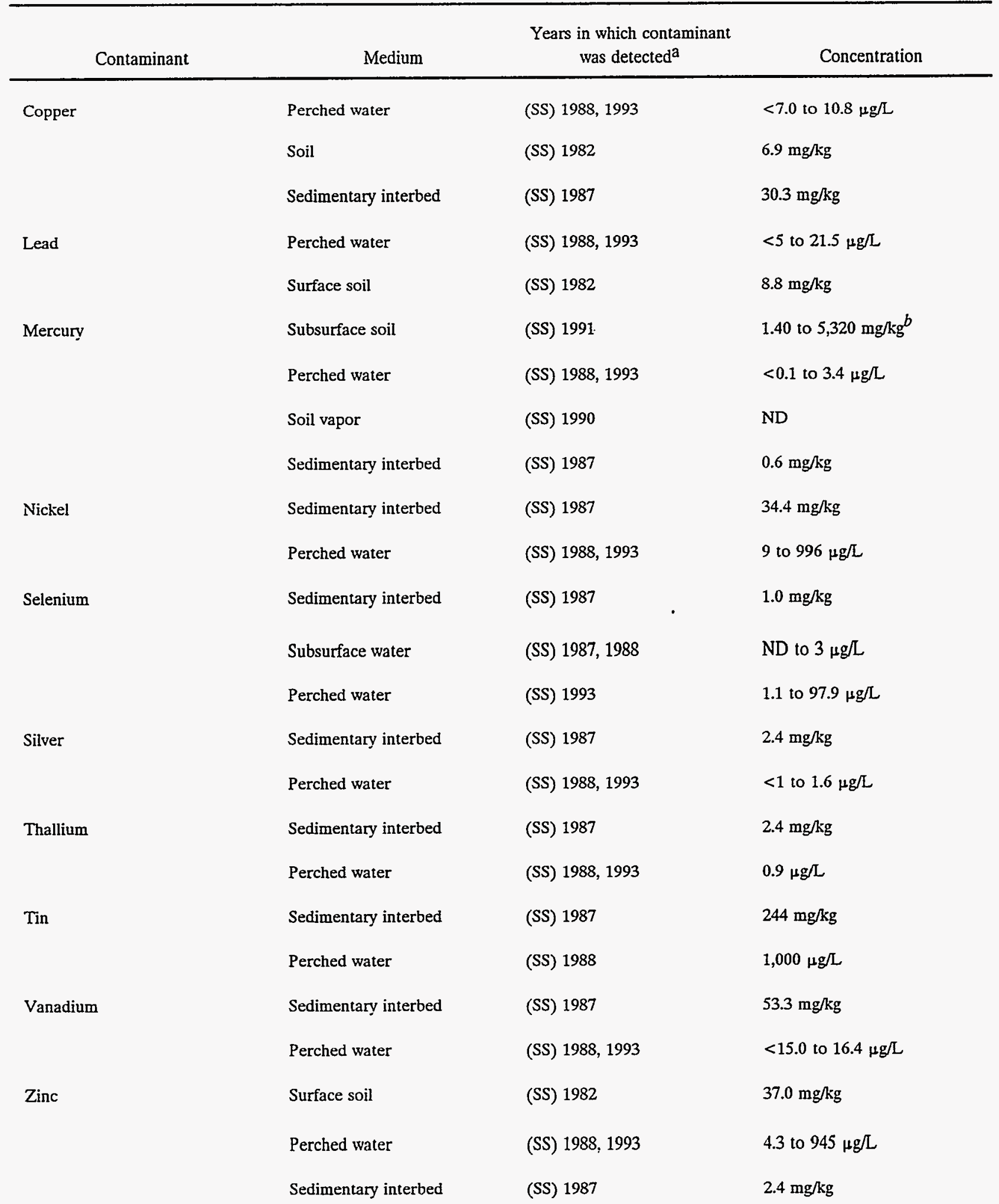


Table F-2. (continued).

\begin{tabular}{|c|c|c|c|c|}
\hline & Contaminant & Medium & $\begin{array}{l}\text { Years in which contamine } \\
\text { was detected }^{\mathrm{a}}\end{array}$ & Concentration \\
\hline \multicolumn{5}{|l|}{ OTHERC } \\
\hline \multirow[t]{4}{*}{ Chloride } & & Aquifer & (EMU) $1979,1982-1993$ & $9 \pm 1$ to $105 \pm 11 \mathrm{ppm}$ \\
\hline & & Perched water & (EMU) 1982-1993 & $62 \pm 6$ to $93 \pm 9 \mathrm{ppm}$ \\
\hline & & & (SS) 1993 & 4,980 to $635,000 \mu \mathrm{g} / \mathrm{L}$ \\
\hline & & Surface soil & (SS) 1982 & $150 \mathrm{mg} / \mathrm{kg}$ \\
\hline \multirow[t]{2}{*}{ Cyanide } & & Perched water & (SS) 1988 & $5 \mu \mathrm{g} / \mathrm{L}$ \\
\hline & & Sedimentary interbed & (SS) 1987 & $1.25 \mathrm{mg} / \mathrm{kg}$ \\
\hline \multirow[t]{5}{*}{ Nitrate } & & Aquifer & (EMU) 1982, 1983, 1987 & 0.5 to $12 \mathrm{mg} / \mathrm{L}$ \\
\hline & & Perched water & (SS) 1993 & 130 to $2,040 \mu \mathrm{g} / \mathrm{L}$ \\
\hline & & Surface water & (EMU) 1980-1982 & 0.08 to $4.7 \mathrm{mg} / \mathrm{L}$ \\
\hline & & Surface soil & (EMU) 1980-1983 & $1-49 \mathrm{ppm}$ \\
\hline & & & (SS) 1982 & $0.28 \mathrm{mg} / \mathrm{kg}$ \\
\hline \multirow{3}{*}{\multicolumn{2}{|c|}{ Sodium ion }} & Surface water & (EMU) 1983-1986 & 6 to $100 \pm 10 \mathrm{mg} / \mathrm{L}$ \\
\hline & & Aquifer & (EMU) 1979, 1982-1993 & $6 \pm 1$ to $52 \pm 5 \mathrm{ppm}$ \\
\hline & & Perched water & (EMU) 1985-1987, 1992 & BDL to $100 \pm 10 \mathrm{ppm}$ \\
\hline \multirow[t]{3}{*}{ Sulfate } & & Perched water & (SS) 1988 & $1 \mu \mathrm{g} / \mathrm{L}$ \\
\hline & & Perched water & (SS) 1993 & 6,290 to $40,800 \mu \mathrm{g} / \mathrm{L}$ \\
\hline & & Perched water & (SS) 1985 & $19.95 \mu \mathrm{g} / \mathrm{L}$ \\
\hline \multicolumn{2}{|l|}{ Sulfide } & Sedimentary interbed & (SS) 1987 & $200 \mathrm{mg} / \mathrm{kg}$ \\
\hline \multicolumn{5}{|c|}{$\begin{array}{l}\text { a. Data included in this table represent data that were actually detected in those years indicated. Occasionally, contaminants were } \\
\text { monitored during a year, but the analyses were not available for inclusion in the annual EMU report. }\end{array}$} \\
\hline \multicolumn{5}{|c|}{ b. Detections involved drilling directly into a disposal unit. } \\
\hline \multicolumn{5}{|c|}{ c. Contaminant monitoring occurred from 1976-1993. } \\
\hline \multicolumn{5}{|c|}{ BDL - Below detection limit. } \\
\hline \multicolumn{5}{|c|}{ EMU - Data compiled from routine monitoring results published by the Environmental Monitoring Unit. } \\
\hline$N D-1$ & Not detected. & & & \\
\hline \multirow{2}{*}{\multicolumn{5}{|c|}{$\begin{array}{l}\text { NR - Minimum measured concentration was not reported in the reference source practical quantitation limit. } \\
\text { PQL - Practical quantitation limit. }\end{array}$}} \\
\hline & & nit. & & \\
\hline$s s-s_{t}$ & $\begin{array}{l}\text { Special studie } \\
\text { the SDA. }\end{array}$ & mpiled from studies oth & nose that are part of the ro & monitoring program at \\
\hline
\end{tabular}




\section{BIBLIOGRAPHY}

Adams, L. E., D. H. Janke, and P. T. Dickman, Annual Report-1978, Environmental Surveillance Report for the INEL Radioactive Waste Management Complex, TREE-1357, June 1979.

Anderson, D. A., letter to D. L. Forsberg, "Validation of Gross Spectrometric Alpha Analysis Data from the Pit-9 Perimeter Soil Samples," DAA-17-92, March 10, 1992.

Anderson, J., Results of the Soil Gas and Shallow Well Screening of the Radioactive Waste Management Complex Subsurface Disposal Area (SDA), ERP-WAG7-09, May 1992.

Bagby, J. C., L. J. White, and R. G. Jensen, Water-Quality Data for Selected Wells On or Near the Idaho National Engineering Laboratory, 1949 through 1982, U.S. Geological Survey OpenFile Report 87-714, DOE/ID-22068, 1985.

Blanchtield, L. A., and L. G. Hoffman, Environmental Surveillance for the INEL Radioactive Waste Management Complex and Other Areas, EGG-2312, August 1984.

Bryan, M. F., Perimeter Monitoring for Airborne Radionuclide Particulates at EG\&G Waste Management Facilities at the Idaho National Engineering Laboratory, ED-SRE-90-002, March 1991.

Burgus, W. H., and S. E. Maestas, The 1975 RWMC Core Drilling Program, IDO-10065, July 1976.

Crockett, A. B., Screening for Hazardous Materials in RWMC Erodible Soils, PG-WM-83-032, October 1983.

Dames and Moore, Compilation and Summarization of the Subsurface Disposal Area Radionuclide Transport Data at the Radioactive Waste Management Complex, EGG-ER-10546, Dames and Moore, November 1992.

Darnell, G. R., T. L. Clements, Jr., and R. R. Wright, Waste Characterization of Rocky Flats Plant Waste Shipped to Idaho National Engineering Laboratory, 1954-1980, WM-F2-81-001, March 1980.

Dickman, P. T., Summary Report of Environmental Studies, PR-W-80-003, February 1980.

Dolenc, M. R., and D. H. Janke, Environmental Surveillance Report for the INEL Radioactive Waste Management Complex Annual Report-1976, TREE-1078, May 1977.

EG\&G Idaho, Remedial Investigation/Feasibility Study Work Plan for the Subsurface Disposal Area, Radioactive Waste Management Complex, draft, EGG-WM-8776, EG\&G Idaho, Inc., December 1989.

Guay, K. P., Inventory Analysis of Stored Transuranic (TRU) Waste at the Radioactive Waste Management Complex (RWMC), WM-PD-90-003, April 1990.

Hedahl, T. G., and D. H. Janke, Environmental Surveillance Report for the INEL Radioactive Waste Management Complex Annual Report-1977, TREE-1251, April 1978. 
Hiaring, C. M., N. E. Josten, D. J. Kuhns, and M. D. McKenzie, Radioactive Waste Management Complex Trench 27 Mercury Investigation, EGG-WM-9730, June 1991.

Hodge, V. E., et al., Draft Final Report: Preliminary Remedial Action Objectives and Remediation Technologies for the Subsurface Disposal Area, EGG-WM-8434, March 1989.

Hoff, D. L., Russell G. M., R. Moore, and R. M. Shaw, The Idaho National Engineering Laboratory Site Environmental Report for Calendar Year 1990, DOE/ID-12082(90), June 1991.

Hubbell, J. M., Perched Groundwater at the Radioactive Waste Management Complex, EGG-ER8779, 1989.

Hubbell, J. M., L. C. Hull, T. G. Humphrey, and B. F. Russell, Annual Progress Report: FY-1987-Subsurface Investigations Program at the Radioactive Waste Management Complex of the INEL, DOE/ID-10153, January 1989.

Hubbell, J. M., Perched Water at the Radioactive Waste Management Complex, ER-VVED-098 Revision 1, December 1993.

Humphrey, T. G., Subsurface Migration of Radionuclides at the Radioactive Waste Management Complex: 1978, EGG-2026, July 1980.

Humphrey, T. G., and F. H. Tingey, The Subsurface Migration of Radionuclides at the Radioactive Waste Management Complex, 1976-77, TREE-1171, October 1978.

Janke, D. H., and T. P. Zahn, Annual Report 1981, Environmental Surveillance for the INEL Radioactive Waste Management Complex, EGG-2209, September 1982.

Janke, D. H., H. W. Reno, and L. E. Wickham, Annual Report-1980, Environmental Surveillance for the INEL Radioactive Waste Management Complex, EGG-2128, December 1981.

Janke, D. H., Environmental Surveillance for the INEL Radioactive Waste Management Complex and Other Areas, EGG-2256, August 1983.

Jorgensen, D. K., Draft WAG-7 Acid Pit Summary Report, EGG-ERD-10242, September 1992.

Knobel, L. L., and L. J. Mann, Radionuclides in Ground Water at the Idaho National Engineering Laboratory, Idaho, DOE/ID-22077, December 1988.

Laney, P. T., S. C. Minkin, R. G. Baca, D. L. McElroy, J. M. Hubbell, L. C. Hull, B. F. Russell, and G. J. Stormberg, Annual Progress Report: FY-1987, Subsurface Investigations Program at the Radioactive Waste Management Complex at the Idaho National Engineering Laboratory, DOE/ID-10183, April 1988.

Litteer, D. L., Radioactive Waste Management Information 1986 Summary and Record-to-Date, DOE/ID-10054(86), June 1987. 
Litteer, D. L., Radioactive Waste Management Information 1984 Summary and Record-to-Date, DOE/ID-10054(84), June 1985.

Liszewski, M. J., and L. J. Mann, Purgeable Organic Compounds in Ground Water at the Idaho National Engineering Laboratory, Idaho, 1990 and 1991, DOE/ID-22104, July 1992.

Lugar, R. M., Evaluation of VOC Emissions and Air Concentrations at the INEL RWMC SDA, EDF ER-WAG7-43, February 1994.

Mann, L. J., Purgeable Organic Compounds in Ground Water at the Idaho National Engineering Laboratory, Idaho-1988 and 1989, DOE/LD-22089, July 1990.

Mann, L. J., and L. L. Knobel, Concentrations of Nine Trace Metals in Ground Water at the Idaho National Engineering Laboratory, Idaho, DOE/ID-22075, May 1988.

Mann, L. J., and L. L. Knobel, Purgeable Organic Compounds in Ground Water at the Idaho National Engineering Laboratory, Idaho, DOE/ID-22074, December 1987.

McElroy, D. L., S. A. Rawson, J. M. Hubbell, S. C. Minkin, R. G. Baca, M. J. Vigil, C. J. Bonzon, J. L. Landon, P. T. Laney, and USGS INEL Project Office, Annual Progress Report: FY1988, Site Characterization Program at the Radioactive Waste Management Complex of the Idaho National Engineering Laboratory, DOE/DD-10233(88), July 1989.

Rawson, S. A., Preliminary Evaluation of Geochemical Controls on Radionuclide Migration at the Radioactive Waste Management Complex (RWMC), FY-1989 summary report, 1989.

Reyes, B. D., M. J. Case, and R. N. Wilhelmsen, Annual Report 1985, Environmental Surveillance for the EG\&G Idaho Radioactive Waste Management Areas at the Idaho National Engineering Laboratory, EGG-2451, August 1986.

Reyes, B. D., J. W. Tkachyk, P. D. Ritter, and R. N. Wilhelmsen, Annual Report-1986, Environmental Surveillance for the EG\&G Idaho Radioactive Waste Management Areas at the Idaho National Engineering Laboratory, EGG-2502, August 1987.

Reyes, B. D., M. J. Case, and T. P. Zahn, Annual Report 1984, Environmental Surveillance for the INEL Radioactive Waste Management Complex and Other Areas, EGG-2386, August 1985.

Ritter, P. D., Monitoring Activities Review of the Radiological Environmental Surveillance Program, EGG-ESQ-10167, March 1992.

Rodgers, A. D, Estimate of Hazardous Waste Constituents in the RWMC Subsurface Disposal Area, EDF-TWT-010-87, December 1987.

Summary of Field Analytical Services Provided to EG\&G Idaho, Contract No. C87-131432, Redmond, Washington, 1987.

Tkachyk, J. W., K. C. Wright, P. D. Ritter, R. N. Wilhelmsen, and W. M. Heileson, Annual Report-1988 Environmental Monitoring for EG\&G Idaho Facilities at the Idaho National Engineering Laboratory, EGG-2564, August 1989. 
Tkachyk, J. W., K. C. Wright, and R. N. Wilhelmsen, Annual Report-1989 Environmental Monitoring for EG\&G Idaho Facilities at the Idaho National Engineering Laboratory, EGG-2612, August 1990.

Tkachyk, J. W., P. D. Ritter, and R. N. Wilhelmsen, Annual Report-1987, Environmental Surveillance for the EG\&G Idaho Radioactive Waste Management Areas at the Idaho National Engineering Laboratory, EGG-2550, August 1988.

Wickham, L. E., and D. H. Janke, Environmental Surveillance for the INEL Radioactive Waste Management Complex, EGG-2042, December 1980.

Wilhelmsen, R. N., K. C. Wright, B. D. Anderson, and L. J. Peterson-Wright, Annual Report-1990 Environmental Monitoring for EG\&G Idaho Facilities at the Idaho National Engineering Laboratory, EGG-2612(90), August 1991.

Wilhelmsen, R. N., and K. C. Wright, Annual Report-1991 Environmental Surveilance for EG\&G Idaho Waste Management Facilities at the Idaho National Engineering Laboratory, EGG-2679(91), August 1992.

Wilhelmsen, R. N., K. C. Wright, and D. W. McBride, Annual Report-1992 Environmental Surveilance for EG\&G Idaho Waste Management Facilities at the Idaho National Engineering Laboratory, EGG-2679(92), August 1993.

Wilhelmsen, R. N., K. C. Wright, and D. W. McBride, Annual Report-1993 Environmental Surveilance for EG\&G Idaho Waste Management Facilities at the Idaho National Engineering Laboratory, EGG-2679(93), August 1994. 
Appendix G

Contaminant Profile Data Sheets 


$$
\text { G-2 }
$$




\section{Appendix G}

\section{Contaminant Profile Data Sheets}

This appendix presents the profile data sheet for carbon-14 (C-14).

The interested reader is referred to the HDT report ${ }^{\mathrm{a}}$, Appendix $\mathrm{G}$, which presents the profile data sheets for the other contaminants that were among those present in large quantities in the SDA waste. EG\&G Idaho (1994) provides profile data sheets for the nonradiological and the radiological contaminants separately.

The profile data sheets provide a quick reference summary for each of the principal contaminants. Each sheet very briefly lists typical physical and chemical forms and properties of the contaminant, common uses, general presence in the environment, toxicology, and the results of environmental monitoring at the SDA.

a. EG\&G Idaho, Inc., 1994, A Comprehensive Inventory of Radiological and Nonradiological Contaminants in Waste Buried in the Subsurface Disposal Area of the INEL RWMC During the Years 1952-1983, EGG-WM-10903, June 1994. 


\section{CARBON (C)-14}

CAS No.: None

\section{Physical Form}

Carbon is most commonly seen as a black elemental solid, but is also found as_diamonds, an 


\section{Appendix G}

\section{Contaminant Profile Data Sheets}

This appendix presents the profile data sheet for carbon-14 (C-14).

The interested reader is referred to the HDT report ${ }^{\mathrm{a}}$, Appendix $\mathrm{G}$, which presents the profile data sheets for the other contaminants that were among those present in large quantities in the SDA waste. EG\&G Idaho (1994) provides profile data sheets for the nonradiological and the radiological contaminants separately.

The profile data sheets provide a quick reference summary for each of the principal contaminants. Each sheet very briefly lists typical physical and chemical forms and properties of the contaminant, common uses, general presence in the environment, toxicology, and the results of environmental monitoring at the SDA.

a. EG\&G Idaho, Inc., 1994, A Comprehensive Inventory of Radiological and Nonradiological Contaminants in Waste Buried in the Subsurface Disposal Area of the INEL RWMC During the Years 1952-1983, EGG-WM-10903, June 1994. 


\section{CARBON (C)-14}

CAS No.: None

\section{Physical Form}

Carbon is most commonly seen as a black elemental solid, but is also found as diamonds, an oxidized gas $\left(\mathrm{CO}\right.$ and $\left.\mathrm{CO}_{2}\right)$, or trapped in a metallic matrix or on the surface of nonmetallic substances.

\section{Chemical Form}

Carbon is found in all organic compounds.

\section{Chemical and Physical Properties}

Carbon, especially when finely divided, readily oxidizes to $\mathrm{CO}$ and $\mathrm{CO}_{2}$.

\section{Radiological Properties}

C-14 is a low-energy beta emitter from natural sources and from nuclear activities. No gamma rays result from $\mathrm{C}-14$ decay. The half-life is 5,730 years.

\section{Common Uses}

The natural presence of $\mathrm{C}-14$ in the environment is used by scientists to age-date archeological artifacts containing carbon. It is also used as a radiation source in thickness gauges and as a tracer in organic chemistry procedures.

\section{General Presence in the Environment}

C-14 occurs naturally in the environment due to the action of cosmic radiation in the upper atmosphere. In addition, the atmospheric testing of nuclear weapons and the nuclear fuel cycle have added to the world-wide inventory of C-14. Very small amounts of C-14 are found in all living things.

\section{Radiotoxicology Highlights}

Due to its low beta energy and the absence of gamma radiation, C-14 is principally an internal hazard. It is readily absorbed into biological systems and tissue. C-14 may preferentially concentrate in one or more parts of the body depending on the nature of the chemical compound into which it has been incorporated, but in general it deposits throughout all parts of the body. 


\section{Environmental Monitoring Results at the SDA}

Since $\mathrm{C}-14$ is ubiquitous in the environment, no effort has been made to monitor $\mathrm{C}-14$ at the SDA. 